\title{
Community pharmacy interventions for health promotion: effects on professional practice and health outcomes (Review)
}

Steed L, Sohanpal R, Todd A, Madurasinghe VW, Rivas C, Edwards EA, Summerbell CD, Taylor SJC, Walton RT

Steed L, Sohanpal R, Todd A, Madurasinghe VW, Rivas C, Edwards EA, Summerbell CD, Taylor SJC, Walton RT. Community pharmacy interventions for health promotion: effects on professional practice and health outcomes. Cochrane Database of Systematic Reviews 2019, Issue 12. Art. No.: CD011207. DOI: 10.1002/14651858.CD011207.pub2.

www.cochranelibrary.com 
TABLE OF CONTENTS

HEADER 1

ABSTRACT

PLAIN LANGUAGE SUMMARY

SUMMARY OF FINDINGS

BACKGROUND

OBJECTIVES

METHODS

Figure 1.

Figure 2.

Figure 3.

RESULTS

Figure 4.

Figure 5.

Figure 6.

DISCUSSION

AUTHORS' CONCLUSIONS

ACKNOWLEDGEMENTS

REFERENCES

CHARACTERISTICS OF STUDIES

DATA AND ANALYSES

Analysis 1.1. Comparison 1 Community pharmacy user health-promotion intervention versus usual treatment, Outcome 1 Health-related behaviour.

Analysis 1.2. Comparison 1 Community pharmacy user health-promotion intervention versus usual treatment, Outcome 2 Intermediate clinical outcomes (final value scores).

Analysis 1.3. Comparison 1 Community pharmacy user health-promotion intervention versus usual treatment, Outcome 3 Intermediate clinical outcome (mean change scores).

Analysis 1.4. Comparison 1 Community pharmacy user health-promotion intervention versus usual treatment, Outcome 4 Quality of life.

ADDITIONAL TABLES

APPENDICES

HISTORY

CONTRIBUTIONS OF AUTHORS

DECLARATIONS OF INTEREST

SOURCES OF SUPPORT

DIFFERENCES BETWEEN PROTOCOL AND REVIEW 
[Intervention Review]

\section{Community pharmacy interventions for health promotion: effects on professional practice and health outcomes}

Liz Steed ${ }^{1}$, Ratna Sohanpal ${ }^{1}$, Adam Todd ${ }^{2}$, Vichithranie W Madurasinghe ${ }^{1}$, Carol Rivas ${ }^{3}$, Elizabeth A Edwards ${ }^{1}$, Carolyn D Summerbell ${ }^{4}$, Stephanie JC Taylor 1,5 , RT Walton 1,5

${ }^{1}$ Centre for Primary Care and Public Health, Barts and The London School of Medicine and Dentistry, Queen Mary University of London, London, UK. ${ }^{2}$ School of Pharmacy, Newcastle University, Newcastle upon Tyne, UK. ${ }^{3}$ Department of Social Science, UCL Institute of Education, University College London, London, UK. ${ }^{4}$ Department of Sport and Exercise Sciences, Durham University, Durham, UK. ${ }^{5}$ Asthma UK Centre for Applied Research, Queen Mary University of London, London, UK

Contact address: Liz Steed, Centre for Primary Care and Public Health, Barts and The London School of Medicine and Dentistry, Queen Mary University of London, Blizard Institute, Yvonne Carter Building, 58 Turner Street, London, E1 2AT, UK. e.a.steed@qmul.ac.uk.

Editorial group: Cochrane Effective Practice and Organisation of Care Group

Publication status and date: New, published in Issue 12, 2019.

Citation: Steed L, Sohanpal R, Todd A, Madurasinghe VW, Rivas C, Edwards EA, Summerbell CD, Taylor SJC, Walton RT. Community pharmacy interventions for health promotion: effects on professional practice and health outcomes. Cochrane Database of Systematic Reviews 2019, Issue 12. Art. No.: CD011207. DOI: 10.1002/14651858.CD011207.pub2.

Copyright ( 2019 The Cochrane Collaboration. Published by John Wiley \& Sons, Ltd.

\section{A B S T R A C T}

\section{Background}

Community pharmacies are an easily accessible and cost-effective platform for delivering health care worldwide, and the range of services provided has undergone rapid expansion in recent years. Thus, in addition to dispensing medication, pharmacy workers within community pharmacies now give advice on a range of health-promoting behaviours that aim to improve health and to optimise the management of long-term conditions. However, it remains uncertain whether these health-promotion interventions can change the professional practice of pharmacy workers, improve health behaviours and outcomes for pharmacy users and have the potential to address health inequalities.

\section{Objectives}

To assess the effectiveness and safety of health-promotion interventions to change community pharmacy workers' professional practice and improve outcomes for users of community pharmacies.

\section{Search methods}

We searched MEDLINE, Embase, CENTRAL, six other databases and two trials registers to 6 February 2018. We also conducted reference checking, citation searches and contacted study authors to identify any additional studies.

\section{Selection criteria}

We included randomised trials of health-promotion interventions in community pharmacies targeted at, or delivered by, pharmacy workers that aimed to improve the health-related behaviour of people attending the pharmacy compared to no treatment, or usual treatment received in the community pharmacy. We excluded interventions where there was no interaction between pharmacy workers and pharmacy users, and those that focused on medication use only.

\section{Data collection and analysis}

We used standard procedures recommended by Cochrane and the Effective Practice and Organisation of Care review group for both data collection and analysis. We compared intervention to no intervention or to usual treatment using standardised mean differences (SMD) and $95 \%$ confidence intervals $(95 \% \mathrm{Cl}$ ) (higher scores represent better outcomes for pharmacy user health-related behaviour and quality 
of life, and lower scores represent better outcomes for clinical outcomes, costs and adverse events). Interpretation of effect sizes (SMD) was in line with Cochrane recommendations.

\section{Main results}

We included 57 randomised trials with 16,220 participants, described in 83 reports. Forty-nine studies were conducted in high-income countries, and eight in middle-income countries. We found no studies that had been conducted in low-income countries. Most interventions were educational, or incorporated skills training. Interventions were directed at pharmacy workers $(n=8)$, pharmacy users $(n=13)$, or both $(n=36)$. The clinical areas most frequently studied were diabetes, hypertension, asthma, and modification of cardiovascular risk. Duration of follow-up of interventions was often unclear. Only five studies gave details about the theoretical basis for the intervention, and studies did not provide sufficient data to comment on health inequalities.

The most common sources of bias were lack of protection against contamination - mainly in individually randomised studies - and inadequate blinding of participants. The certainty of the evidence for all outcomes was moderate. We downgraded the certainty because of the heterogeneity across studies and evidence of potential publication bias.

\section{Professional practice outcomes}

We conducted a narrative analysis for pharmacy worker behaviour due to high heterogeneity in the results. Health-promotion interventions probably improve pharmacy workers' behaviour (2944 participants; 9 studies; moderate-certainty evidence) when compared to no intervention. These studies typically assessed behaviour using a simulated patient (mystery shopper) methodology.

\section{Pharmacy user outcomes}

Health-promotion interventions probably lead to a slight improvement in health-related behaviours of pharmacy users when compared to usual treatment (SMD $0.43,95 \% \mathrm{Cl} 0.14$ to $0.72 ; I^{2}=89 \% ; 10$ trials; 2138 participants; moderate-certainty evidence). These interventions probably also lead to a slight improvement in intermediate clinical outcomes, such as levels of cholesterol or glycated haemoglobin, for pharmacy users (SMD $-0.43,95 \% \mathrm{Cl}-0.65$ to $-0.21 ; 1^{2}=90 \% ; 20$ trials; 3971 participants; moderate-certainty evidence).

We identified no studies that evaluated the impact of health-promotion interventions on event-based clinical outcomes, such as stroke or myocardial infarction, or the psychological well-being of pharmacy users.

Health-promotion interventions probably lead to a slight improvement in quality of life for pharmacy users (SMD $0.29,95 \%$ CI 0.08 to 0.50 ; $\mathrm{I}=82 \%$; 10 trials, 2687 participants; moderate-certainty evidence).

\section{Adverse events}

No studies reported adverse events for either pharmacy workers or pharmacy users.

\section{Costs}

We found that health-promotion interventions are likely to be cost-effective, based on moderate-certainty evidence from five of seven studies that reported an economic evaluation.

\section{Authors' conclusions}

Health-promotion interventions in the community pharmacy context probably improve pharmacy workers' behaviour and probably have a slight beneficial effect on health-related behaviour, intermediate clinical outcomes, and quality of life for pharmacy users.

Such interventions are likely to be cost-effective and the effects are seen across a range of clinical conditions and health-related behaviours. Nevertheless the magnitude of the effects varies between conditions, and more effective interventions might be developed if greater consideration were given to the theoretical basis of the intervention and mechanisms for effecting behaviour change.

\section{PLAIN LANGUAGE SUMMARY}

\section{Can community pharmacy interventions help improve pharmacy workers' skills and pharmacy users' health outcomes through health promotion?}

\section{What is the aim of this review?}

We aimed to find out whether interventions that support people to change health behaviours, and are delivered in community pharmacies, can change the way that pharmacy workers interact with pharmacy users and can improve health outcomes for those users.

\section{Key messages}


Community pharmacies and their workers may have an important part to play in health promotion, and probably improve the health outcomes of pharmacy users slightly, at an acceptable cost and with no evidence of harm (adverse events may or may not have occurred, this is unclear as no adverse effects were reported by the studies).

\section{What was studied in the review?}

Community pharmacies are an easy place for many people to access healthcare advice. In the past this advice was limited to how best to take medicines, but, increasingly, community pharmacy workers are carrying out other activities, such as giving advice on healthy eating and management of long-term conditions. While some community pharmacy workers may offer the sale of products without a strong evidence-base, the professional guidance issued to pharmacists has attempted to reduce these transactions, and has placed more emphasis on developing evidence-based public health services. Many people find health-related lifestyle and self-management behaviours difficult. Pharmacies may be convenient for people to use, but it is important to understand whether health-promoting activities delivered in pharmacies are worthwhile and effective, so that those responsible for commissioning health care can decide whether it is worth spending resources to support them.

\section{What are the main results of the review?}

We identified 57 studies with a total of 16,220 participants that investigated the effects of health-promotion activities compared to normal treatment or no treatment. These were conducted across the world, 49 of them in high-income countries and eight in middle-income countries. Most studies (36/57) targeted both pharmacy workers and pharmacy users; eight were directed at pharmacy workers only, and 13 at pharmacy users only. The health areas most frequently studied were diabetes, hypertension, asthma and reduction of cardiovascular risk. The studies varied in quality. Some studies did not take enough precautions to stop the participants who should have received either no treatment or usual treatment (i.e. the control group) receiving parts of the intervention.

We found that pharmacy workers may be able to change their behaviour, for example improve their communication skills, to help people to manage their health conditions more effectively.

Overall these studies probably show a slight beneficial effect on pharmacy users' health-related behaviour, intermediate clinical outcomes (e.g. levels of cholesterol or glycated haemoglobin) and quality of life. No studies reported measuring pharmacy users' clinical events such as heart attacks or stroke. There was also no evidence of harm reported in any of the studies, but no studies reported measuring adverse events. Five out of seven studies that measured costs showed that health promotion delivered by pharmacy workers was cost effective.

These findings suggest that community pharmacy workers can probably slightly improve pharmacy users' health outcomes at a reasonable cost. The variety of studies includes different countries, conditions, interventions and outcomes, and suggests there is great interest in using the community pharmacy setting for workers to promote health-related behaviours. However, in order to make future studies easier to compare, there is a need for greater use of thorough, systematic approaches in the description of these interventions, use of a standardised set of outcomes, and for new studies to build on prior work.

\section{How up to date is this review?}

We searched for studies that had been published up to February 2018. 


\section{SUMMARY OF FINDINGS}

\section{Summary of findings for the main comparison. Health-promotion interventions within community pharmacy compared to usual treatment: effects on professional practice and health outcomes}

Do health-promotion interventions improve professional practice of community pharmacy workers and improve health outcomes for community pharmacy users?

Patient or population: community pharmacy workers (examples pharmacists, counter assistants etc), community pharmacy users Setting: community pharmacy - the majority of community pharmacies were in urban settings in high-income countries Intervention: a health-promotion intervention delivered to pharmacy workers or users within community pharmacy commonly consisting of education and skills training

Comparison: no treatment or usual treatment received within the community pharmacy

\begin{tabular}{|c|c|c|c|c|}
\hline Outcomes & $\begin{array}{l}\text { Effect of intervention } \\
(95 \% \mathrm{Cl})\end{array}$ & $\begin{array}{l}\text { № of par- } \\
\text { ticipants } \\
\text { (studies) }\end{array}$ & $\begin{array}{l}\text { Certainty } \\
\text { of the ev- } \\
\text { idence } \\
\text { (GRADE) }\end{array}$ & Comments \\
\hline Pharmacy worker behaviour 1 & $\begin{array}{l}\text { Six of nine studies reported im- } \\
\text { provement in pharmacy worker } \\
\text { behaviour, one study found no } \\
\text { benefit, while two had mixed re- } \\
\text { sults }\end{array}$ & $\begin{array}{l}2944 \text { (9 } \\
\text { RTs) }\end{array}$ & $\begin{array}{l}\oplus \oplus \oplus \odot \\
\text { MODER- } \\
\text { ATE2 }^{2}\end{array}$ & \\
\hline $\begin{array}{l}\text { Pharmacy user health-related } \\
\text { behaviour } \\
\text { (Higher scores indicate a bet- } \\
\text { ter outcome) }\end{array}$ & $\begin{array}{l}\text { The mean score in the interven- } \\
\text { tion group was } 0.43 \text { SD higher } \\
\text { ( } 0.14 \text { higher to } 0.72 \text { higher) }\end{array}$ & $\begin{array}{l}2138 \\
\text { (10 RTs) }\end{array}$ & $\begin{array}{l}\oplus \oplus \oplus \odot \\
\text { MODER- } \\
\text { ATE2,4 }\end{array}$ & $\begin{array}{l}\text { A SMD of } 0.43 \text { represents a small } \\
\text { improvement in pharmacy user } \\
\text { health-related behaviour, accord- } \\
\text { ing to Cohen's rule of thumb (Hig- } \\
\text { gins 2011b). }\end{array}$ \\
\hline $\begin{array}{l}\text { Pharmacy user intermediate } \\
\text { clinical outcomes e.g. choles- } \\
\text { terol, glycated haemoglobin } 5 \\
\text { (Lower scores indicate a better } \\
\text { outcome) }\end{array}$ & $\begin{array}{l}\text { The mean score in the interven- } \\
\text { tion group was } 0.43 \mathrm{SD} \text { lower } \\
\text { ( } 0.65 \text { lower to } 0.21 \text { lower) }\end{array}$ & $\begin{array}{l}3971 \\
\text { (20 RTs) }\end{array}$ & $\begin{array}{l}\oplus \oplus \oplus \odot \\
\text { MODER- } \\
\text { ATE2,4 }\end{array}$ & $\begin{array}{l}\text { A SMD of } 0.43 \text { represents a small } \\
\text { difference between groups with } \\
\text { greater benefit in the intervention } \\
\text { group, according to Cohen's rule of } \\
\text { thumb Higgins } 2011 \text { b }\end{array}$ \\
\hline $\begin{array}{l}\text { Pharmacy user event-based } \\
\text { clinical outcomes e.g. stroke, } \\
\text { myocardial infarction }\end{array}$ & $\begin{array}{l}\text { No studies reported this out- } \\
\text { come. }\end{array}$ & (0 studies) & - & \\
\hline $\begin{array}{l}\text { Pharmacy user quality of life } 6 \\
\text { (Higher scores indicate better } \\
\text { quality of life) }\end{array}$ & $\begin{array}{l}\text { The mean score in the interven- } \\
\text { tion group was } 0.29 \text { SD higher } \\
\text { ( } 0.08 \text { higher to } 0.5 \text { higher) }\end{array}$ & $\begin{array}{l}2687 \\
\text { (10 RTs) }\end{array}$ & $\begin{array}{l}\oplus \oplus \oplus \odot \\
\text { MODER- } \\
\text { ATE2,4 }\end{array}$ & $\begin{array}{l}\text { A SMD of } 0.29 \text { higher represents a } \\
\text { small difference between groups } \\
\text { with greater benefit in the in- } \\
\text { tervention group according to } \\
\text { Cohen's rule of thumb (Higgins } \\
\text { 2011b). }\end{array}$ \\
\hline Adverse events & No studies reported this outcome & (0 studies) & - & \\
\hline Costs & $\begin{array}{l}\text { Five of seven studies found the } \\
\text { intervention to be cost-effective. }\end{array}$ & (7 RTs) & $\begin{array}{l}\oplus \oplus \oplus \ominus \\
\text { MODER- } \\
\text { ATE2 }^{2}\end{array}$ & \\
\hline
\end{tabular}

CI: confidence interval; RT: randomised trial; SD: standard deviation; SMD: standardised mean difference

GRADE Working Group grades of evidence

High certainty: We are very confident that the true effect lies close to that of the estimate of the effect 
Moderate certainty: We are moderately confident in the effect estimate: The true effect is likely to be close to the estimate of the effect, but there is a possibility that it is substantially different

Low certainty: Our confidence in the effect estimate is limited: The true effect may be substantially different from the estimate of the effect

Very low certainty: We have very little confidence in the effect estimate: The true effect is likely to be substantially different from the estimate of effect

1.ncludes communication/consultation skills, referral to smoking quit line, demonstration of inhaler technique.

2Downgraded by one level for inconsistency (due to substantial heterogeneity in studies).

3Includes medication adherence $(n=3)$; inhaler technique $(n=4)$, alcohol consumption $(n=1)$, diabetes self-management $(n=1)$, activity impairment $(n=1)$.

${ }^{4}$ Asymmetric funnel plots - considered insufficient to require further downgrading.

5 Includes asthma control $(n=8)$, blood glucose $(n=5)$, systolic blood pressure $(n=5)$, low-density lipoprotein $(n=2)$.

6 Includes generic quality of life $(n=5)$, asthma quality of life $(n=5)$, diabetes quality of life $(n=1)$. 


\section{B A C K G R O U N D}

\section{Description of the condition}

Pharmacists are the third largest regulated healthcare professional group in the world (Chan 2006), with community pharmacy the most common discipline represented. Community pharmacies are an easily accessible platform for delivering healthcare worldwide (DOH 2005; WHO 1998). For example, in England there are over 11,500 community pharmacies, with approximately $89 \%$ of the population able to access one within a 20 -minutes walk (Todd 2014). In Australia, over $90 \%$ of the population visit a pharmacist during the course of a year (Benrimoj 2004). Pharmacies are more densely distributed in areas of high deprivation - a so-called 'positive pharmacy care law' - where better access to pharmacy care is available to those with greatest deprivation (Todd 2014). In lowand middle-income countries, but also increasingly in high-income countries, pharmacies are often seen as the first place to call for advice on symptoms and for early diagnosis of illness (Smith 2009).

The role of the pharmacist has undergone rapid expansion in recent years (Blouin 2017; Mossialos 2015; WHO 2006). For example, in addition to dispensing and medication-linked services, pharmacy workers are now required to give advice on public-health priorities, including modification of health behaviour to minimise risk of disease and to promote a healthy lifestyle in pharmacy users ( $\mathrm{DOH}$ 2005;Public Health England 2017). Smoking cessation was one of the first behaviour-change roles to be delivered in community pharmacies (Anderson 2007), and now others, such as promotion of general healthy lifestyle behaviours, increasing uptake of screening and giving sexual health advice, have been added (Blouin 2017; NICE 2018; RSPH 2016). To address the needs of this changing role and to maintain high professional standards, international guidance for good pharmacy practice has been published which outlines health promotion as one of six components that contribute to the health improvement of the individuals who access community pharmacy services (WHO 2011).

The evidence base that underpins these wider health-promotion responsibilities has not yet been collated to determine effective methods of changing professional practice, or evaluation of the health gains that could result from these changes. Research evidence suggests that whilst pharmacy workers and their users hold positive attitudes to pharmacist involvement in public-health activities, pharmacist confidence in delivering the services is currently low, and additional training needs are perceived (Eades 2011; Lindsey 2017; Weir 2019).

Systematic reviews examining behaviour-change interventions delivered in community pharmacies have begun to emerge by clinical topic (Brown 2016; Garcia-Cardenas 2013; Sabater 2016; Soprovich 2019); but do not provide a comprehensive overview of the role of community pharmacy in health promotion. In addition, some reviews have included small numbers of poor quality studies (Gordon 2011; Sinclair 2004; Watson 2006), which limits conclusions regarding the effectiveness of these services (RSPH 2016). Thus a broad overview of studies of health-promotion interventions in community pharmacies is needed to inform current pharmacy practice and to identify areas for future research.

\section{Description of the intervention}

The World Health Organization (WHO) defines health promotion as "the process of enabling people to increase control over, and to improve, their health". The idea of health promotion has expanded beyond a focus on individual behaviour towards a wide range of social and environmental interventions (WHO 2009). Interventions that target a specific aspect of lifestyle - such as smoking - or that address wider aspects of clinical management - such as obesity or type 2 diabetes mellitus - therefore fall within this definition.

Interventions to support these broad health-promotion and behaviour-change tasks may be directed at pharmacy workers, pharmacy users (who may or may not be patients), or at both groups. The types of intervention vary from educational programmes (Sarayani 2012), to specific training that is targeted at behaviour change, such as motivational interviewing (Brackett 2015). Other interventions target management of medical conditions, for example blood pressure monitoring (Fikri-Benbrahim 2012), or managing asthma (Armour 2007). These types of interventions go beyond the traditional remit of community pharmacy workers, which has conventionally focused on the preparation, dispensing and management of medicines.

Previous Cochrane Reviews have examined non-dispensing services in pharmacies (De Barra 2018; Nkansah 2010; Pande 2013), however, these have still had a strong focus on medications, including medication reviews or stopping medications, and did not focus solely on community pharmacy. To avoid overlap with this previous work, we have excluded any purely medication-related interventions in this review, including those focused primarily at promoting medication adherence.

\section{How the intervention might work}

The way in which health-promotion and behaviour-change interventions work within the community pharmacy setting is likely to be dependent on the theoretical basis for the intervention (Michie 2010), and the behaviour-change techniques used (Michie 2008). For example, interventions may aim to increase self-efficacy (perceived confidence) in performing a behaviour that promotes health, or examine ways of overcoming barriers to performing that behaviour. The behavioural theory underpinning interventions and the mechanisms by which community pharmacy interventions might work have not previously been studied in detail. However, an understanding of the mechanisms by which healthbehaviour change is achieved in successful community pharmacy interventions, and the behaviour-change theories used, is important for designing more effective interventions, both for existing clinical areas and to support the expansion of the future role of the community pharmacy.

This review sought to identify which underpinning theories and theoretical constructs are most effective in achieving health-behaviour change when interventions are delivered in a community pharmacy setting. We aimed to identify generic approaches that could be used to inform development of any health-promotion intervention delivered in a community pharmacy setting.

Many interventions involve training community pharmacists or pharmacy workers, however, evidence is sparse regarding the best methods of training to achieve health-behaviour change. Even if pharmacists and pharmacy workers can be trained effectively and 
can deliver the intervention with fidelity, there still remains the question of whether pharmacy users follow the advice given and whether this results in meaningful improvements in health and well-being. There are no previous comprehensive reviews of the effectiveness of community pharmacy workers as agents for healthbehaviour change (Anderson 2003). It is important, therefore, to consider the complete pathway from intervention to effects on health outcomes. Hence we examined study outcomes related to both the professional behaviour of pharmacy workers and to health-related behaviour and outcomes in their users.

\section{Why it is important to do this review}

This review is important because community pharmacists and their teams are increasingly taking on health-promotion activities as part of their rapidly expanding role in the delivery of health care and public-health services (Blouin 2017; Mossialos 2013). Much of this change has been driven by need for cost efficiencies in the health system, and the need to reduce health inequalities (Crombie 2005), which is predicted to continue in many countries.

\section{OB JECTIVES}

To assess the effectiveness and safety of health-promotion interventions to change community pharmacy workers' professional practice and improve outcomes for users of community pharmacies.

\section{METHODS}

\section{Criteria for considering studies for this review}

\section{Types of studies}

We included randomised trials (RTs) and cluster-randomised trials (cluster-RTs) (EPOC 2017a). Cluster-RTs were only eligible if there were at least two intervention sites and two control sites. Publication status of study (full text, unpublished data) was not a bar to inclusion, unless there was insufficient data, for example, regarding intervention content. For this reason, we excluded abstracts that were not supported with further information (Chandler 2013).

\section{Types of participants}

Participants in the review were pharmacy workers and users of community pharmacies (defined as regulated pharmacy outlets outside secondary healthcare), under the direction of a pharmacist. We included interventions directed at any worker within the community pharmacy, including pharmacists and other workers such as pharmacy technicians and assistants. We excluded studies where participants were seen in a hospital or non-community-based pharmacy, e.g. an outpatient clinic. We included studies that had mixed settings only if the majority of participants took part in the community pharmacy setting, or if the community pharmacy subset was analysed independently. Similarly, where the intervention was multidisciplinary we included studies only if the majority of the intervention was delivered in community pharmacy, or the community pharmacy aspect of the intervention was evaluated separately, for example, change in community pharmacists' behaviour.

\section{Types of interventions}

We included any health-promotion intervention targeted at, or delivered by, community pharmacy workers (including pharmacists, counter assistants etc.) which aimed to improve health behaviours of individuals attending the community pharmacy.

We excluded studies where the intervention was solely focused on medication. This included those interventions that were concerned only with prescription of medication, medication review, or those that focused on promoting adherence to medication. We included interventions where medication management was a single component of an intervention and other behavioural aspects (e.g. diet or exercise) were also targeted.

We excluded studies in which interventions did not involve active interaction between pharmacy workers and their users (e.g. displays of leaflets/posters on lifestyle in the pharmacy).

We have described interventions in terms of:

- mode of delivery (e.g. video/DVD, one-to-one or group-based or web-based sessions);

- agent delivering the intervention (e.g. pharmacist, pharmacy assistant);

- setting (e.g. on site in pharmacy); duration (including length and number of sessions and period over which the intervention was delivered);

- content (e.g. smoking cessation, lifestyle recommendations, condition management).

We also documented the intervention fidelity (i.e. the degree to which the intervention was delivered as intended), where this was assessed. Where necessary, we contacted authors of studies to obtain additional details of interventions and training of pharmacy workers.

\section{Types of outcome measures}

We present the results that were assessed closest to the end of the intervention but only after the intervention was finished.

\section{Primary outcomes}

To assess the effects of community pharmacy interventions on health promotion delivered by pharmacy workers, we looked at three categories of outcomes:

- Professional practice outcomes were primarily behavioural and included:

* uptake of intervention by pharmacy worker, adherence to the intervention (e.g. number of pharmacy users asked about smoking status);

* pharmacy worker behaviour (e.g. correct demonstration of inhaler technique).

- Pharmacy user outcomes included assessment of:

* health-related behaviour (e.g. smoking, exercise, inhaler technique);

* health status including:

$\square$ intermediate clinical outcomes (e.g. cholesterol, glycated haemoglobin);

event-based clinical outcomes (e.g. stroke, myocardial infarction);

$\square$ psychological well-being (e.g. anxiety and depression); and

quality of life. 
- Adverse events included any effect defined as adverse by the included studies, either at the professional or user level.

In line with Cochrane Effective Practice and Organisation of Care Group (EPOC) recommendations (EPOC 2017a), we included only those studies where at least one outcome was assessed using an objective or validated tool, such as a validated questionnaire. For assessment of pharmacy workers, we considered simulated patients (mystery shoppers) to be an objective measurement tool, and trials using them to be eligible for inclusion (Watson 2006; Xu 2012).

\section{Secondary outcomes}

We included costs, as reported by the studies, as a secondary outcome. This included direct and indirect healthcare costs, including scheduled and unscheduled visits to other healthcare providers (healthcare utilisation) and cost-effectiveness.

\section{Search methods for identification of studies}

\section{Electronic searches}

The EPOC Cochrane Information Specialist wrote the search strategies in consultation with the review authors. We searched the Cochrane Database of Systematic Reviews and the Database of Abstracts of Reviews of Effects (DARE) for related systematic reviews, and searched the following databases for primary studies on 6 February 2018:

- Cochrane Central Register of Controlled Trials (CENTRAL; 2018, Issue 1) in the Cochrane Library;

- Health Technology Assessment Database (DARE; 2016; Issue 4) in the Cochrane Library;

- NHS Economic Evaluation Database (NHSEED; 2015, Issue 2) in the Cochrane Library;

- MEDLINE Ovid (including Epub Ahead of Print, In-Process \& Other Non-Indexed Citations and Versions) (1946 to 31 January 2018);

- EMBASE Ovid (1974 to 5 February 2018);

- PsycINFO Ovid (1967 to January Week 5 2018).

The finalised search strategies are provided in Appendix 1. We tested the MEDLINE strategy by screening selected citations for relevance, and validated it using a selection of exemplar papers on the topic of this review. We modified the MEDLINE strategy for other databases using appropriate syntax and vocabulary for those databases. We applied no limits regarding date or language.

\section{Searching other resources}

We searched the grey literature to identify studies that were not indexed in the databases listed above. We searched the following sources on 6 February 2018:

- Open Grey (www.opengrey.eu);

- ProQuest Dissertations \& Theses Global (including COS Conference Papers Index);

- ProQuest Dissertations \& Theses: UK \& Ireland.

\section{Trial Registries}

We searched the following trial registries on 6 February 2018:

- International Clinical Trials Registry Platform (ICTRP), Word Health Organization (WHO) (www.who.int/ictrp/en);

- ClinicalTrials.gov, US National Institutes of Health (NIH) (clinicaltrials.gov).

We also:

- reviewed reference lists of all included studies, relevant systematic reviews, primary studies and other publications;

- contacted authors of relevant studies or reviews to clarify reported information and to seek unpublished results and data;

- conducted cited reference searches for all included studies in citations indexes.

\section{Data collection and analysis}

\section{Selection of studies}

We imported results of each search into a reference management software package (Endnote 2013). One review author removed duplicates and screened titles and abstracts for obvious irrelevance to the review (e.g. not an intervention study). A second review author completed sequential $10 \%$ checks of titles and abstracts until we achieved an inter-rater reliability of 0.75 or greater (excellent agreement) (Orwin 1994). The emphasis was on over-inclusion at this stage. We then retrieved potentially relevant papers and two review authors independently screened all of these against the inclusion criteria. We resolved any disagreements through discussion, referring where necessary to a third review author for arbitration. Where such arbitration was necessary and a study was excluded, we added it to the Characteristics of excluded studies table, and gave reasons for its exclusion. We collated multiple reports for the same study, so that each study - rather than each report - was the unit of interest.

We have documented the full screening process in a PRISMA flowchart Figure 1. 
Figure 1. Study flow diagram.

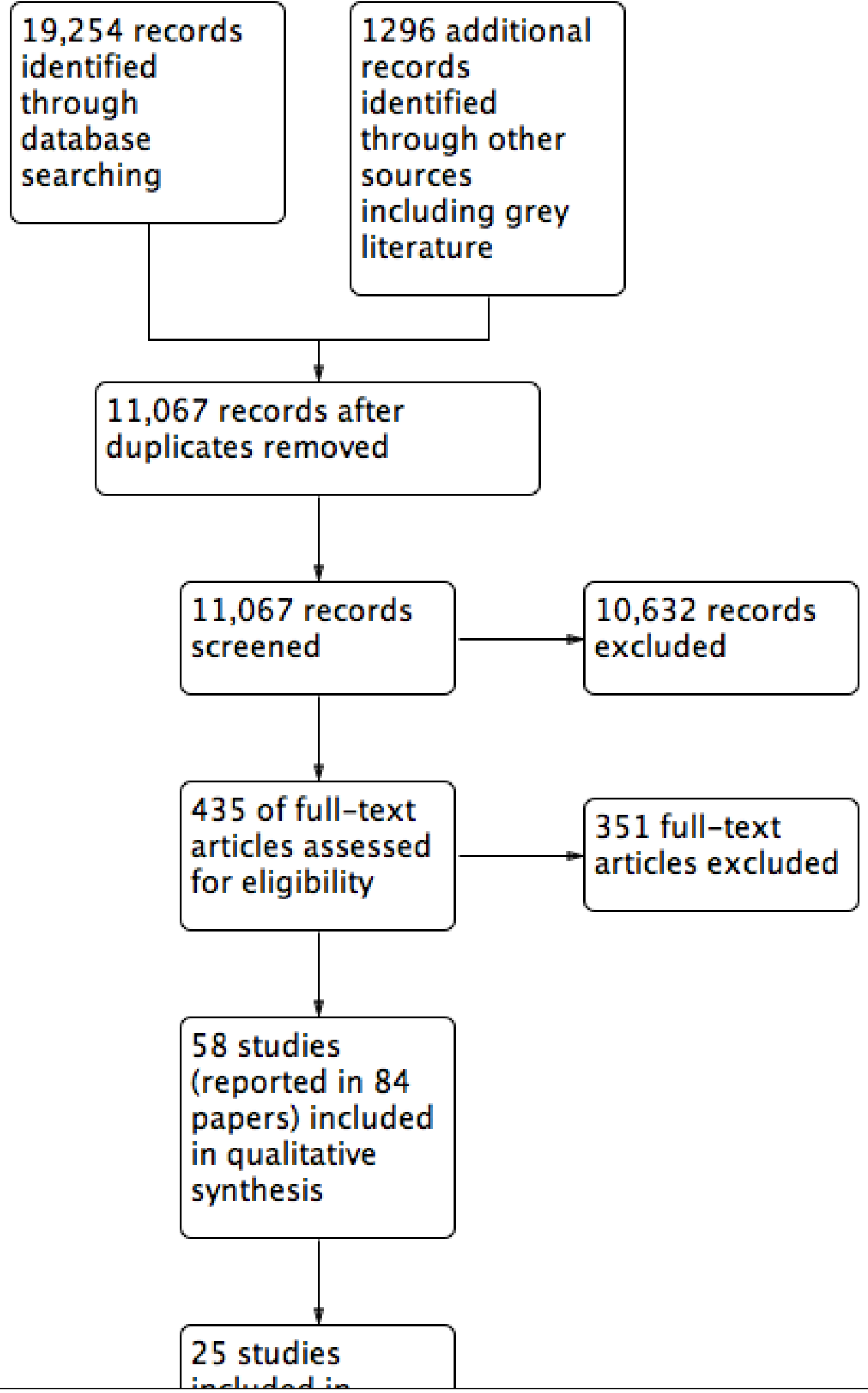

Community pharmacy interventions for health promotion: effects on professional practice and health outcomes (Review) 


\section{Data extraction and management}

We extracted data from eligible studies using a tailored extraction form based on the generic EPOC data collection checklist (EPOC 2017b), and included the following data.

- Study details: author; year; research question; country where research was carried out; inclusion and exclusion criteria; study design (randomised trial (RT), cluster randomised trial (cluster-RT); recruitment method (e.g. self-referral, advertisement); description of usual care.

- Intervention details: intervention target (pharmacy workers, or pharmacy users, or both); behavioural target (smoking, diet, exercise, etc.); health condition targeted; intervention description (mode of delivery; theoretical basis as reported by study authors; and theoretical constructs targeted, as coded by mapping interventions to the Theoretical Domains Framework (TDF) (Cane 2012).

- Pharmacy worker details: number; age; socioeconomic status; ethnicity; gender; time since qualification.

- Pharmacy user details: number; age; socioeconomic status; ethnicity; gender; time since diagnosis (where applicable).

- Quality criteria (in line with EPOC recommendations) (EPOC 2017c).

- Results of primary and secondary outcomes.

Two review authors independently extracted all key information (inclusion criteria, e.g. design, participants, interventions and outcomes, quality criteria and results) from each included paper. As mentioned previously, we resolved any errors or disagreements through discussion, with recourse to a third review author for arbitration (RW), and discussion among the full author group where necessary. EK entered data into Review Manager 5.3 software
(RevMan 2014), while a second review author checked the data entry (LS, CR).

\section{Assessment of risk of bias in included studies}

We assessed the risk of bias of the studies using Cochrane's 'Risk of bias' assessment tool (Higgins 2011a), and following the EPOC 'suggested risk of bias criteria for EPOC reviews' (EPOC 2017c). There are nine standard criteria for all RTs:

- Was the allocation sequence adequately generated?

- Was the allocation adequately concealed?

- Were baseline outcome measurements similar?

- Were baseline characteristics similar?

- Was the study adequately protected against contamination?

- Were incomplete outcome data adequately addressed?

- Was knowledge of the allocated interventions adequately prevented during the study?

- Was the study free from selective outcome reporting?

- Was the study free from other risks of bias?

We scored each study as being at low, high or unclear (if not specified in the paper) risk of bias. For some studies it may not have been possible to blind participants to the intervention, e.g. an exercise intervention, but we still recorded this aspect in the quality assessment. Two review authors assessed each study's risk of bias, compared results, and resolved discrepancies by discussion and by recourse to a third review author when necessary. We measured inter-rater agreement using Cohen's kappa coefficient (Uebersax 1987). We have presented results in both a 'Risk of bias' table Figure 2 , and graphically Figure 3. The authors of the current review were also authors of one included study (Madurasinghe 2017). AT was not an author of the study, and, therefore, screened it for inclusion, and extracted and checked all its data. 
Figure 2. Risk of bias summary: review authors' judgements about each risk of bias item for each included study.

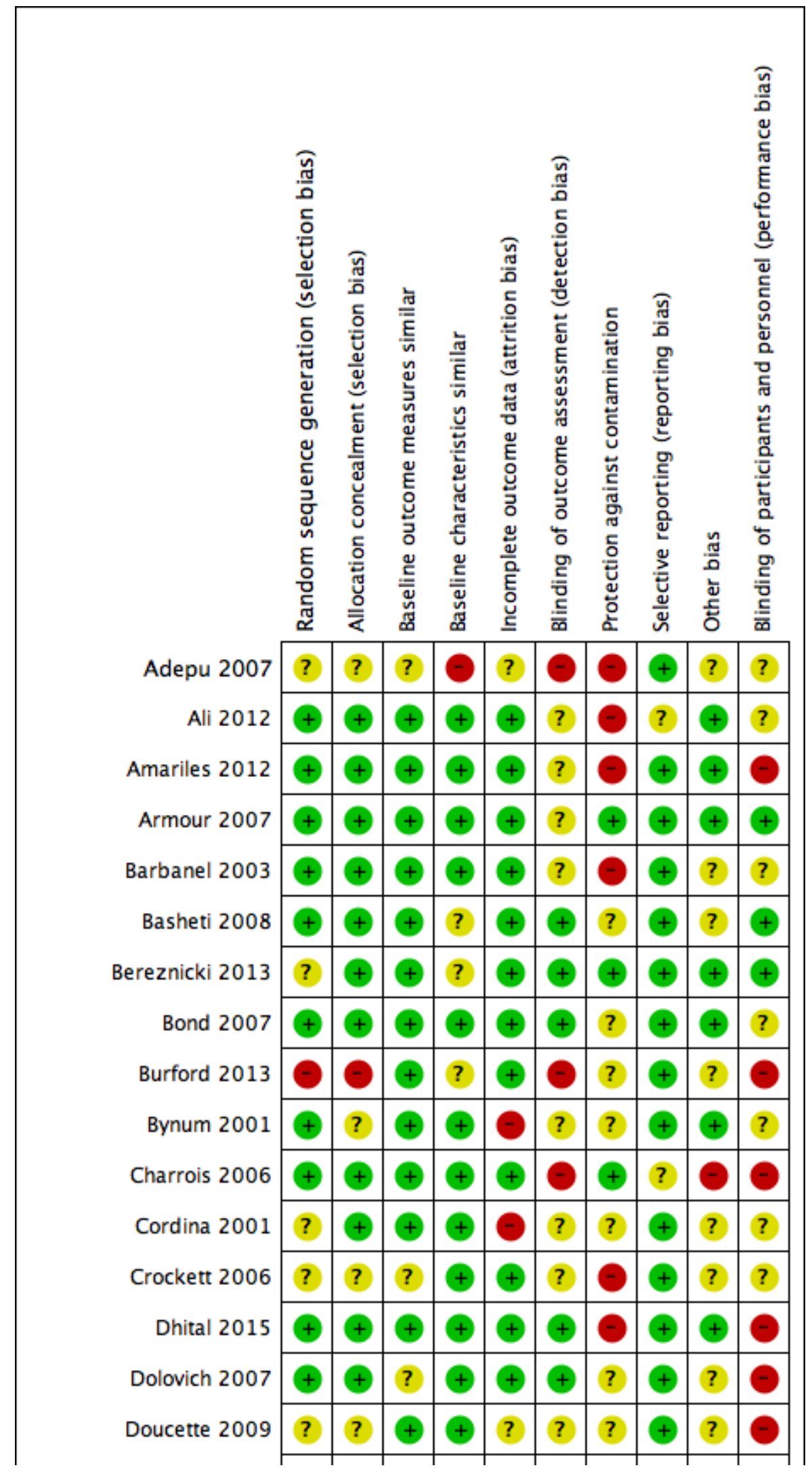


Figure 2. (Continued)

\begin{tabular}{|c|c|c|c|c|c|c|c|c|c|c|}
\hline Dolovich 2007 & + & + & $?$ & 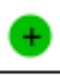 & 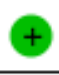 & 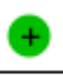 & $?$ & 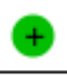 & $?$ & \\
\hline Doucette 2009 & $?$ & $?$ & 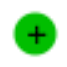 & 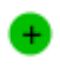 & $?$ & $?$ & $?$ & 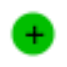 & $?$ & \\
\hline Fuller 2016 & 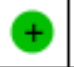 & $\odot$ & $\odot$ & $\hookrightarrow$ & $\odot$ & $\odot$ & + & 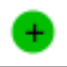 & $\odot$ & \\
\hline Garcia 1998 & $?$ & + & $?$ & $?$ & $?$ & 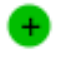 & + & 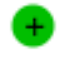 & $?$ & \\
\hline Garcia 2003 & $\odot$ & 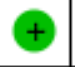 & $?$ & $?$ & $\odot$ & 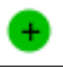 & + & $?$ & 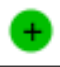 & + \\
\hline Garcia 2012 & 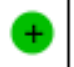 & $\odot$ & $\uparrow$ & $\odot$ & $\uparrow$ & 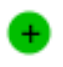 & 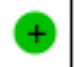 & 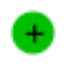 & $\odot$ & \\
\hline Sarcia-Cardenas 2013 & $\odot$ & $\odot$ & $\hookrightarrow$ & $\hookrightarrow$ & $?$ & $?$ & $\odot$ & $\hookrightarrow$ & $\odot$ & \\
\hline Jaffray 2014 & $?$ & $?$ & $\odot$ & $\hookrightarrow$ & $?$ & $\odot$ & $\odot$ & $\hookrightarrow$ & $?$ & + \\
\hline Kraemer 2012 & $?$ & $?$ & $\odot$ & 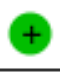 & $?$ & $?$ & - & $\hookrightarrow$ & 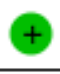 & \\
\hline Krass 2007 & + & + & $\odot$ & 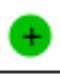 & $?$ & 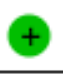 & + & $\hookrightarrow$ & 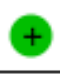 & $?$ \\
\hline Liambila 2010 & $?$ & $?$ & 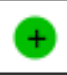 & $?$ & $?$ & $?$ & + & $?$ & $\odot$ & \\
\hline Liekens 2014 & + & + & $?$ & $?$ & 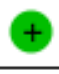 & 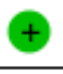 & $?$ & $\hookrightarrow$ & $?$ & 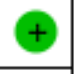 \\
\hline Madurasinghe 2017 & + & + & $?$ & $\odot$ & 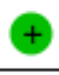 & $?$ & + & $\hookrightarrow$ & - & \\
\hline Maguire 2001 & 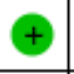 & + & $\odot$ & $?$ & 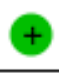 & 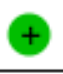 & $\odot$ & $\hookrightarrow$ & 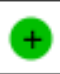 & \\
\hline Mansell 2016 & $\odot$ & $\odot$ & $\odot$ & $\odot$ & 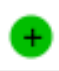 & 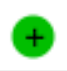 & + & 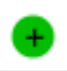 & 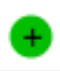 & $?$ \\
\hline Mayer 1998 & $?$ & $?$ & $\odot$ & 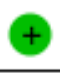 & $?$ & $\odot$ & + & $?$ & $\odot$ & \\
\hline McDonough 2005 & $?$ & $?$ & $\odot$ & $\odot$ & $?$ & $?$ & 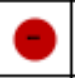 & 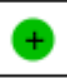 & 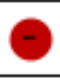 & 1 \\
\hline McLean 2003 & + & + & $?$ & $?$ & $?$ & $?$ & - & $\hookrightarrow$ & $?$ & \\
\hline McLean 2008 & + & + & 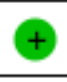 & 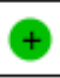 & + & + & + & $?$ & + & \\
\hline Mehuys 2008 & + & + & + & 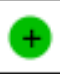 & + & 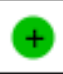 & - & 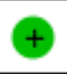 & $?$ & \\
\hline Mehuys 2011 & $\oplus$ & + & $\odot$ & $\oplus$ & 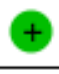 & $\odot$ & 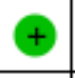 & $\hookrightarrow$ & $?$ & 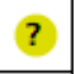 \\
\hline Nishita 2013 & + & + & $\odot$ & 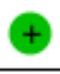 & 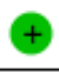 & $\odot$ & 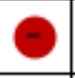 & 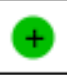 & 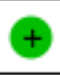 & \\
\hline Nola 2000 & $\odot$ & + & $\odot$ & 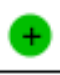 & $?$ & $\odot$ & $\odot$ & 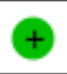 & $?$ & \\
\hline Okada 2018 & + & + & $\odot$ & 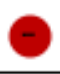 & 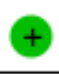 & 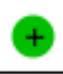 & + & 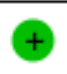 & - & \\
\hline Park 1996 & ? & $\odot$ & $\odot$ & 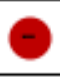 & $?$ & $\odot$ & $\odot$ & $\odot$ & $?$ & \\
\hline Patwardhan 2012 & + & + & + & 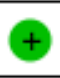 & 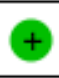 & $?$ & + & 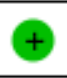 & $?$ & $\uparrow$ \\
\hline Paulos 2005 & $?$ & $?$ & $?$ & $?$ & $?$ & + & $\odot$ & 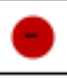 & $?$ & \\
\hline Petkova 2008 & $?$ & $?$ & 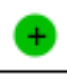 & $\odot$ & 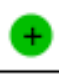 & $?$ & 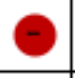 & 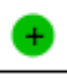 & 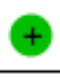 & $?$ \\
\hline Petkova 2009 & $\odot$ & $?$ & & & $\odot$ & $?$ & - & 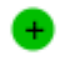 & 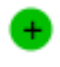 & \\
\hline
\end{tabular}


Figure 2. (Continued)

\begin{tabular}{|c|c|c|c|c|c|c|c|c|c|c|}
\hline Petkova 2008 & $?$ & $?$ & $\odot$ & - & + & $?$ & 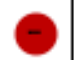 & + & $\odot$ & $?$ \\
\hline Petkova 2009 & + & $?$ & - & - & 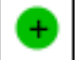 & $?$ & - & + & $\odot$ & - \\
\hline Planas 2012 & + & $?$ & 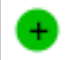 & - & $?$ & + & $?$ & $\oplus$ & $?$ & $?$ \\
\hline Schmiedel 2015 & $?$ & $?$ & $\odot$ & $\odot$ & $\odot$ & $?$ & $\odot$ & $\odot$ & $\odot$ & \\
\hline Skowron 2011 & $\odot$ & $\odot$ & $?$ & $\odot$ & - & $\odot$ & $\odot$ & 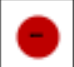 & $\theta$ & \\
\hline Slater 2013 & $\odot$ & 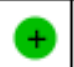 & $\odot$ & + & + & + & + & + & $?$ & 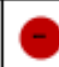 \\
\hline Smith 2011 & $?$ & $?$ & $\odot$ & + & $?$ & $?$ & + & + & $?$ & \\
\hline Svarstad 2013 & + & + & $\odot$ & - & $?$ & + & $?$ & + & + & \\
\hline Tommelein 2014 & + & + & $\odot$ & + & + & - & $?$ & + & + & 1 \\
\hline Tsuyuki 2002 & + & + & + & + & + & - & 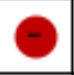 & + & $?$ & - \\
\hline Tsuyuki 2016 - RXACT & + & + & $\odot$ & + & + & + & P & + & + & - \\
\hline Tsuyuki 2016 - RxEACH & + & + & 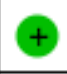 & + & + & + & $\rightarrow$ & + & + & C \\
\hline Venkatesan 2012 & $?$ & $?$ & $?$ & $?$ & + & + & 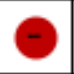 & + & $?$ & $?$ \\
\hline Villeneuve 2010 & + & + & 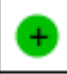 & + & + & $?$ & + & $?$ & $?$ & $?$ \\
\hline Weinberger 2002 & + & + & 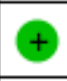 & + & - & + & + & + & O & \\
\hline Yuksel 2010 & + & + & + & + & + & + & - & + & + & - \\
\hline
\end{tabular}


Figure 3. Risk of bias graph: review authors' judgements about each risk of bias item presented as percentages across all included studies.

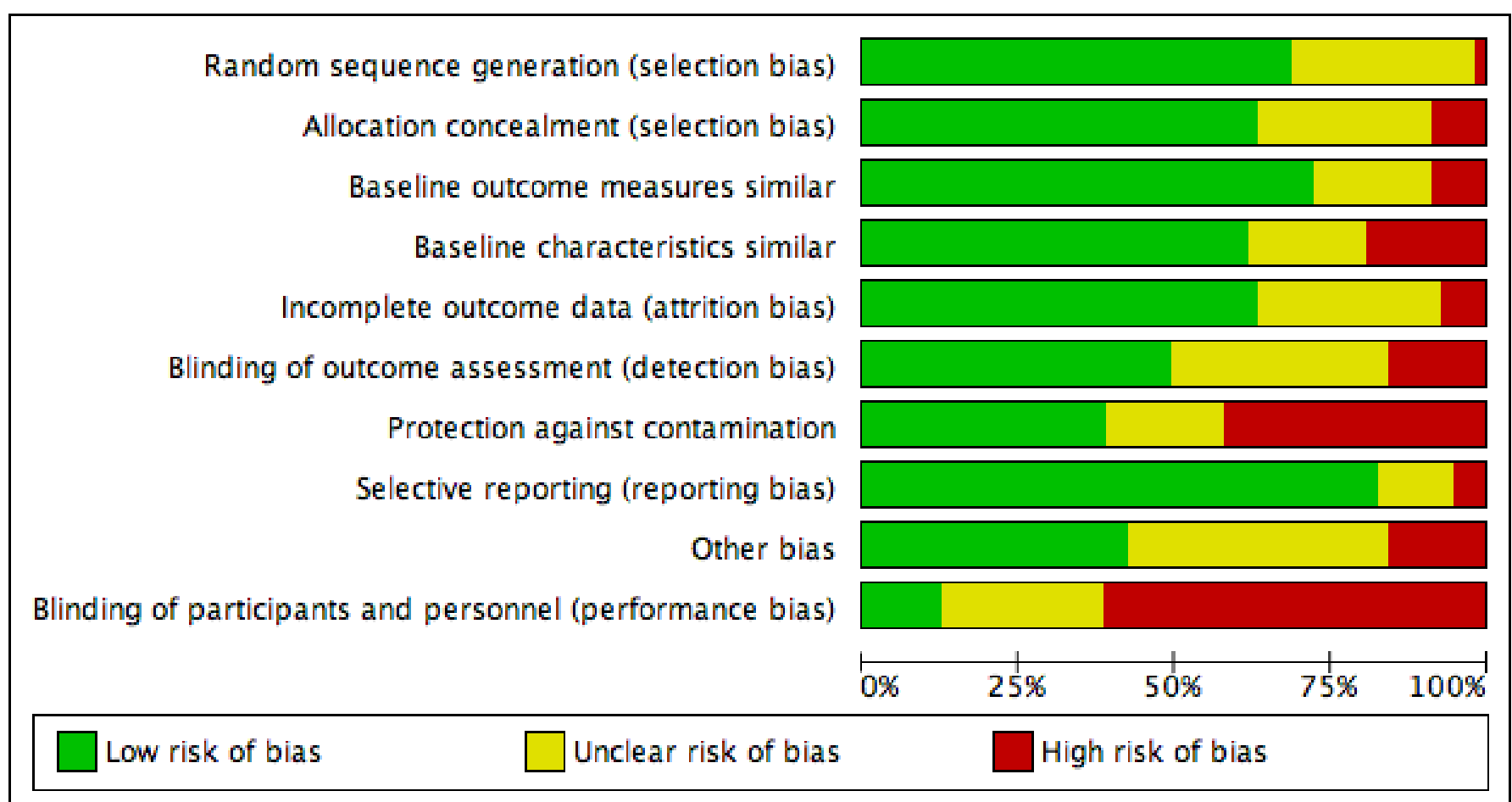

\section{Measures of treatment effect}

For continuous data we estimated treatment effect sizes as standardised mean differences (SMDs) for each outcome, or weighted mean differences where studies had a common outcome measure. We treated the available data as continuous unless there was a defensible cut-point available, in which case we considered the data to be dichotomous. We gave preference to final value scores over change scores where both were presented, although analysis with both results is presented where there were sufficient studies for both analyses.

\section{Unit of analysis issues}

Where cluster-RTs were included, we considered whether any unit of analysis errors had been made in the original analysis. Where we identified such errors, we performed a re-analysis using information on the size or number of clusters and the value of the intra-cluster correlation coefficient (ICC) where the information was available, or we excluded the study from analysis if necessary.

\section{Dealing with missing data}

When a study was missing data, we contacted the study authors and requested the additional data. After this, if data were still missing, we calculated standard deviations for changes, where possible. When there was insufficient information available to calculate the standard deviations, we imputed missing standard deviations for changes from baseline using other available information (e.g. correlation coefficients) (Higgins 2011b). If it was not possible to impute data, we did not include the study in the analysis and we noted its absence.

For dichotomous data, where possible we derived missing treatment estimates and standard errors from the number of partici- pants included or randomised, and from the numbers of individuals with and without the outcomes of interest. We used confidence intervals $(\mathrm{Cl})$ to derive missing standard error estimates.

\section{Assessment of heterogeneity}

Given the diverse nature of behavioural interventions, we anticipated some heterogeneity between studies. We assessed this both qualitatively (e.g. examining intervention characteristics, study populations, context, etc.) and quantitatively. We inspected forest plots visually for poorly overlapping $\mathrm{Cls}$ for the results of individual studies. We also discussed possible reasons for heterogeneity and considered this in interpretation of results.

We assessed the extent of statistical heterogeneity formally using the Cochran $\mathrm{Q}$ statistic and corresponding $\mathrm{Chi}^{2}$ and $\mathrm{I}^{2}$ statistics. This latter statistic describes the percentage of the variability in effect estimates that is due to heterogeneity rather than sampling error (chance) (Higgins 2003); the significance threshold is set at $\mathrm{P}<0.05$.

\section{Assessment of reporting biases}

To test for publication bias we drew funnel plots, if more than 10 studies were identified, and where standard errors and a unitary measure of effect were available (Higgins 2011a). For any given outcome we inspected funnel plots visually for asymmetry.

\section{Data synthesis}

We have provided details of all included studies in a Characteristics of included studies table, irrespective of whether the measured outcome data were reported in a useable way. 
For the main analysis, we split outcomes into those that examined the effect on pharmacy workers and those that examined the effect on pharmacy users.

Firstly, we considered the suitability of studies for meta-analysis. If there was considerable evidence of heterogeneity, such that metaanalysis might be misleading, we reported a narrative synthesis of studies, and presented descriptive and summary data of interventions.

Where meta-analysis was deemed appropriate, given the likely heterogeneity in terms of intervention, setting, and population, we adopted the more conservative random-effects model. If an outcome was measured at different times in the same study, we selected the first value after the end of the intervention period. When there were related outcomes from the same study, we used the outcome most consistent across studies (e.g. SF-36 above condition-specific measures) or the most clinically rigorous measure (for asthma this was: severity or asthma control as measured by (for example) the asthma control questionnaire, followed by forced expiratory volume in one second, followed by peak expiratory flow; for diabetes this was: HbAlc followed by plasma blood glucose; for hypertension this was: systolic blood pressure followed by diastolic blood pressure; for lipids this was: low density lipoproteins followed by cholesterol). In this way we pooled only a single effect size for each study. We used Review Manager 5.3 software to collate data and perform calculations.

\section{Subgroup analysis and investigation of heterogeneity}

We conducted subgroup analyses in RevMan 5 for different patient behaviours, clinical conditions, and generic versus specific quality of life measures, where there were sufficient studies for this to be meaningful.

We also planned to consider whether there were different effects from studies conducted within low- and middle-income countries (LMICS) compared with high-income countries (HMICs) as classified by the (World Bank Group 2009). We also planned to examine whether people from particular ethnic groups and those at extremes of adverse health behaviour (e.g. heavy smokers) were more likely to respond to pharmacy-based interventions. If there were sufficient studies we also planned to explore whether theory-based interventions were more effective than those not based on theory, and whether a financial incentive influences effectiveness. Unfortunately there were insufficient studies for these planned sub-group analyses to be conducted.

\section{Meta regression}

We planned to perform a meta-regression where there was an adequate amount of data, using Stata 12.1. This was to consider which features of interventions were more likely to be successful, and to examine effects of intervention delivery (e.g. single brief consultation, several brief consultations plus follow-up telephone contact etc.).

\section{Sensitivity analysis}

We conducted sensitivity analyses by excluding studies that we assessed as being at high risk of bias. This involved undertaking the meta-analysis twice, with and without the studies in question.

\section{Summary of findings}

We prepared Summary of findings for the main comparison for health-promotion interventions delivered within the community pharmacy compared to no intervention or usual care. We used the Grading of Recommendations and Assessment Development and Evaluation (GRADE) approach to evaluate our confidence in the findings (GRADE 2013). Summary of findings for the main comparison includes the seven most important outcomes for both community pharmacy workers and community pharmacy users. LS and RW assessed all outcomes for importance in line with EPOC recommendations (EPOC 2017d), and were in agreement. They assessed the certainty of the evidence independently, using standard procedures and resolving discrepancies by consultation with ST. We selected pharmacy workers' behaviour and pharmacy users' healthrelated behaviours, intermediate clinical outcomes (e.g. cholesterol, glycated haemoglobin), event-based clinical outcomes, quality of life, adverse events and costs for inclusion in Summary of findings for the main comparison.

\section{RE S U L T S}

\section{Description of studies}

Studies are described in the Characteristics of included studies, Characteristics of excluded studies, and Characteristics of ongoing studies tables.

\section{Results of the search}

The search is summarised in Figure 1 and yielded 20,550 citations, including 1296 from the grey literature. Following removal of duplicates, we screened 11,067 studies and assessed 435 full text papers. We excluded 352 papers, as they did not meet inclusion criteria. We did not categorise papers by individual reasons for exclusion, as many papers had multiple reasons for exclusion, and any categorisation would have misrepresented the situation. We included a total of 57 studies, which were reported in 83 papers. We identified five further studies as ongoing (Davis 2016; Ekers 2017; Michiels 2017; Porteous 2013; Spadaro 2010).

\section{Included studies}

\section{Location}

Although the included studies were conducted worldwide, none were undertaken in low-income countries (as defined by the World Bank) (World Bank Group 2009). Three studies were conducted in low-middle income countries, including India (Adepu 2007; Venkatesan 2012), and Kenya (Liambila 2010); five were conducted in high-middle income countries, specifically Peru (Garcia 1998; Garcia 2003; Garcia 2012), and Bulgaria (Petkova 2008; Petkova 2009). The remaining 49 studies were conducted in high-income countries, including Australia (9 studies), Belgium (4 studies), Germany (1 study), Malta (1 study), Poland (1 study), Spain ( 2 studies), Chile ( 1 study), Japan ( 1 study), the UK ( 7 studies), the USA ( 11 studies), and Canada (11 studies). Twenty nine studies were conducted in urban settings; thirteen studies did not report the type of setting i.e. rural or urban. It was not possible to determine whether interventions reached lower-socioeconomic status populations, as this was poorly described. 


\section{Participants}

Overall, the studies involved a total of 16,220 participants. Twenty-seven studies were cluster-RTs, while all the others were simple randomised trials. We excluded four of the cluster-RTs from entry into meta-analysis, as their analysis did not adequately account for clustering effects (Krass 2007; Mehuys 2011; Skowron 2011; Smith 2011). The majority of studies compared intervention to usual treatment, although eight studies compared the intervention to no treatment. These eight studies all had interventions which primarily targeted the community pharmacy worker (Dolovich 2007; Garcia 1998; Garcia 2003; Garcia 2012; Liambila 2010; Liekens 2014; Mayer 1998; Patwardhan 2012).

\section{Conditions}

Most studies (47 of 57) were directed towards secondary prevention of conditions, including allergic rhinitis (Smith 2011), arthritis (Petkova 2009), asthma (13 studies), chronic obstructive pulmonary disease (Tommelein 2014), cardiovascular disease (Bond 2007), depression (Crockett 2006; Liekens 2014), type 2 diabetes (10 studies), dyslipidaemia (Nola 2000; Paulos 2005; Tsuyuki 2016 - RxACT; Villeneuve 2010), hypertension (Okada 2018; Park 1996; Skowron 2011; Svarstad 2013), low back pain (Slater 2013), osteoporosis (McDonough 2005); skin cancer (Mayer 1998), and insomnia (Fuller 2016). In approximately half of these conditions the intervention was described as being focused on the pharmacy user, whilst the other half mentioned some degree of training for the community pharmacy workers.

Six studies focused specifically on prevention of either diabetes (Schmiedel 2015), osteoporosis (Yuksel 2010), or cardiovascular risk factors (Amariles 2012; McLean 2008; Tsuyuki 2002; Tsuyuki 2016 - RxEACH). A further nine studies targeted lifestyle behaviours including smoking (Burford 2013; Maguire 2001; Patwardhan 2012; Madurasinghe 2017), illicit drug use (Jaffray 2014), family planning (Liambila 2010), and sexually transmitted infection prevention (Garcia 1998; Garcia 2003; Garcia 2012). All of these lifestyle interventions, with the exception of Burford 2013, targeted behaviour change through intervening at the pharmacy worker level, for example by improving knowledge or skills.

\section{Interventions}

Most interventions were educational or incorporated skills training, for example asthma interventions typically trained pharmacy users in inhaler technique. Interventions directed at the community pharmacy workers typically consisted of group workshops supported by written materials for self-directed learning. Training ranged from a single session to sessions held over several weeks (Mayer 1998). In a number of instances the training involved interactive exercises, such as role-play, which are important for the development of skills (Bond 2007; Garcia 1998; Garcia-Cardenas 2013; Krass 2007; Liekens 2014; Madurasinghe 2017; Petkova 2009; Svarstad 2013). Typically training was face to face, although other methods were used occasionally, for example video-conferencing (Crockett 2006), videotape-based training (Mayer 1998), or online training (Tsuyuki 2016 - RxEACH). Face-to-face delivery was also most common for user-directed interventions. Usually, this involved direct face-to-face communication with the community pharmacy worker.

The duration of follow-up was often unclear. Several studies reported assessment at what appeared to be a long-term follow-up (e.g.
12 months), however, this was often the length of the delivery period of the intervention. For this reason, we present the first set of results after the end of the intervention.

\section{Funding}

The majority of studies (34 of 57) were funded by grants from national funding bodies, charities, or institutional funds. Five studies were funded by industry and a further five by a combination of public and industry funding. Eight studies did not report their funding source.

\section{Theory in interventions}

Only five studies reported whether the intervention was based on a specific theoretical approach. Svarstad 2013 based intervention development on Svarstad and Bultman's Health Collaboration Model and Roger's Diffusion of Innovation Model (Rogers 2003; Svarsted 2000). Jaffray 2014 and Nishita 2013 trained pharmacy workers in motivational interviewing. Although motivational interviewing is not underpinned by any specific theory, it is a recognised approach to behaviour change (Miller 2012). Smith 2011 reported a 'goal setting self-management study' which, although not specified, appeared to draw on Social Cognitive Theory (Bandura 1986). A summary of how many interventions addressed each theoretical domain, as coded using the theoretical domains framework (Cane 2012), is reported with the Characteristics of included studies. Most commonly community pharmacy workers were trained to increase knowledge and skills, and frequently the intervention added some form of object to the environment, which could be as simple as having information leaflets to distribute. Pharmacy users were typically provided with information, and, particularly in interventions for asthma, were taught skills such as inhaler technique. Behavioural regulation approaches, such as self-monitoring, were used in 19 interventions. Of note, few interventions addressed the theoretical domains of beliefs about capabilities and consequences, or intentions and emotions.

\section{Excluded studies}

In total, we excluded 352 studies. Studies where consensus was not immediate were discussed amongst the team and are presented in the Characteristics of excluded studies table. We excluded studies for four reasons, namely:

1. not being conducted in a community pharmacy setting;

2. inappropriate design;

3. an intervention that did not fit our inclusion criteria;

4. no validated or appropriate outcome.

Often, there were multiple reasons for the exclusion of a study, however, in the table we report only the first reason of the four given above to optimise efficiency in screening. When we excluded studies on the basis of intervention, it was usually because they targeted medication adherence without a wider behavioural focus. There was some debate as to whether disease management interventions - particularly those related to cardiovascular risk (i.e. hypertension, dyslipidaemia) - should be included or excluded, as many of these were medication focused but also mentioned lifestyle-behaviour change. The extent to which lifestyle advice drew on behaviour-change principles was difficult to determine fully from descriptions; we included these studies, but evaluated them with this point in mind. 


\section{Risk of bias in included studies}

We assessed risk of bias, and provide a summary table and graph of risk of bias in Figure 2 and Figure 3, respectively. The most common sources of bias were lack of protection against contamination, mainly in individually randomised studies, and inadequate blinding of pharmacy users and pharmacy workers.

\section{Allocation}

We included 27 cluster-RTs, which used the community pharmacy as the unit of randomisation. The remaining 30 studies used the pharmacy user as the unit of randomisation. Most individual-level RT studies conducted randomisation in a robust way and conserved allocation concealment. In cluster-RTs, allocation concealment at the pharmacy level was frequently conserved, but for individuals it was typically more complex (Eldridge 2012), and frequently was not clear.

\section{Blinding}

Due to the nature of the interventions, it was often not possible to blind providers (pharmacy workers) and recipients (pharmacy users). This is a common difficulty for interventions of a behavioural nature (Friedberg 2010), although risk can be minimised by the use of independent blinded assessors, which was done in some of the more robust studies (e.g. Amariles 2012; Bereznicki 2013; Liekens 2014; Svarstad 2013). Additionally, the use of objective outcomes for example those used for intermediate clinical outcomes, such as $\mathrm{HbA1c}$, or blood pressure - can help to minimise detection bias.

\section{Incomplete outcome data}

Some level of attrition was common in many studies, most commonly amongst pharmacy users, but also at the pharmacy level in some cases. While a number of studies reported how missing data were managed, this was unclear or not described in approximately half the studies. Therefore, attrition bias is a potential threat to the generalisability of the findings of this review.

\section{Selective reporting}

Examination of funnel plots for the main outcomes suggested possible publication bias for pharmacy users' intermediate clinical outcomes and quality of life (Figure 4; Figure 5; Figure 6).

Figure 4. Funnel plot of comparison: 1 Usual treatment versus Health-promotion intervention, outcome: 1.1 Pharmacy user health-related behaviour.

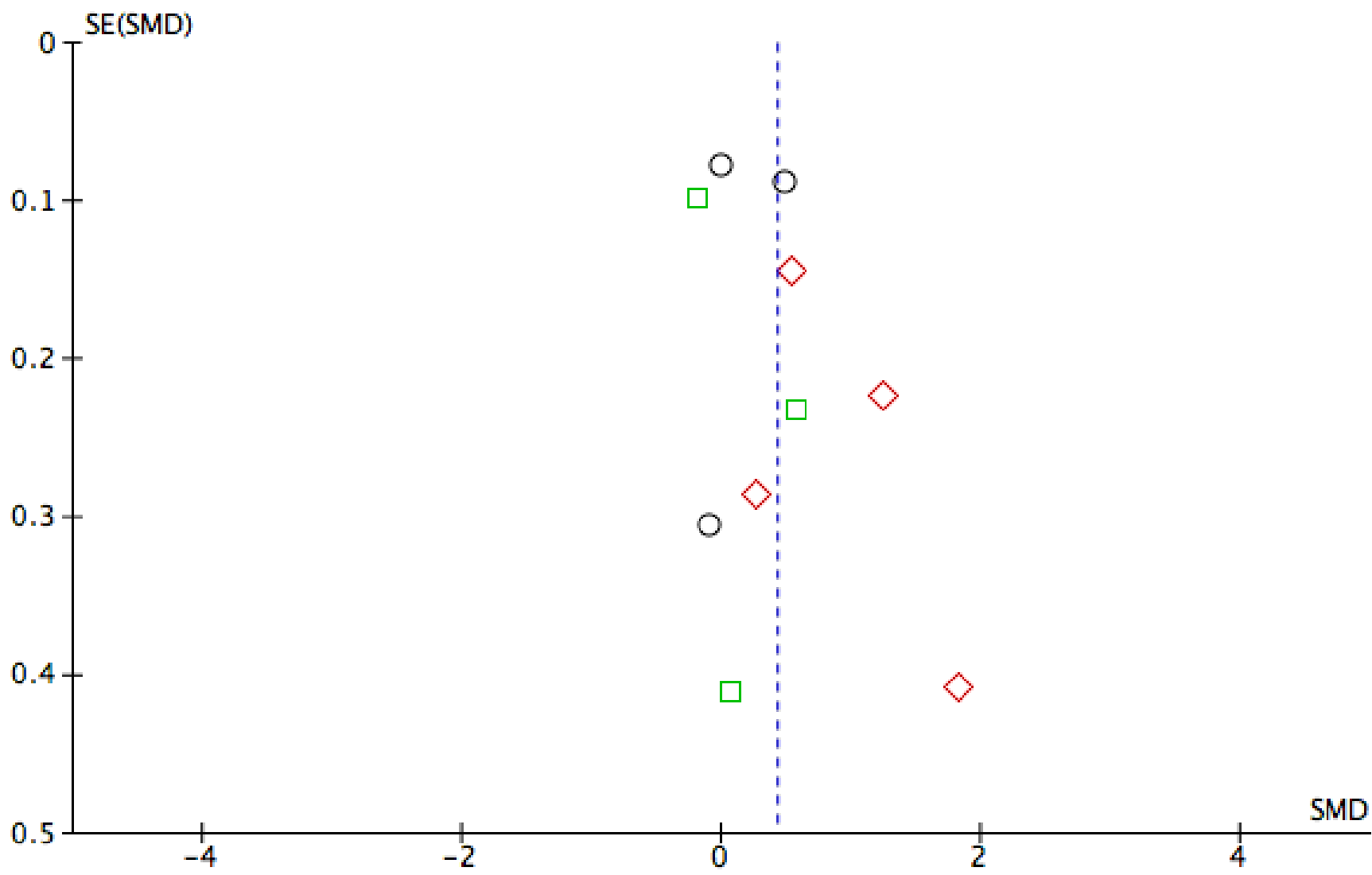

Subgroups

Medication adherence

Inhaler technique

Other - alcohol consumption, diabetes self-care and activity impairment 
Figure 5. Funnel plot of comparison: 1. Health-promotion intervention versus Usual treatment outcome: Analysis 1.2 Pharmacy user intermediate clinical outcomes (final value scores)

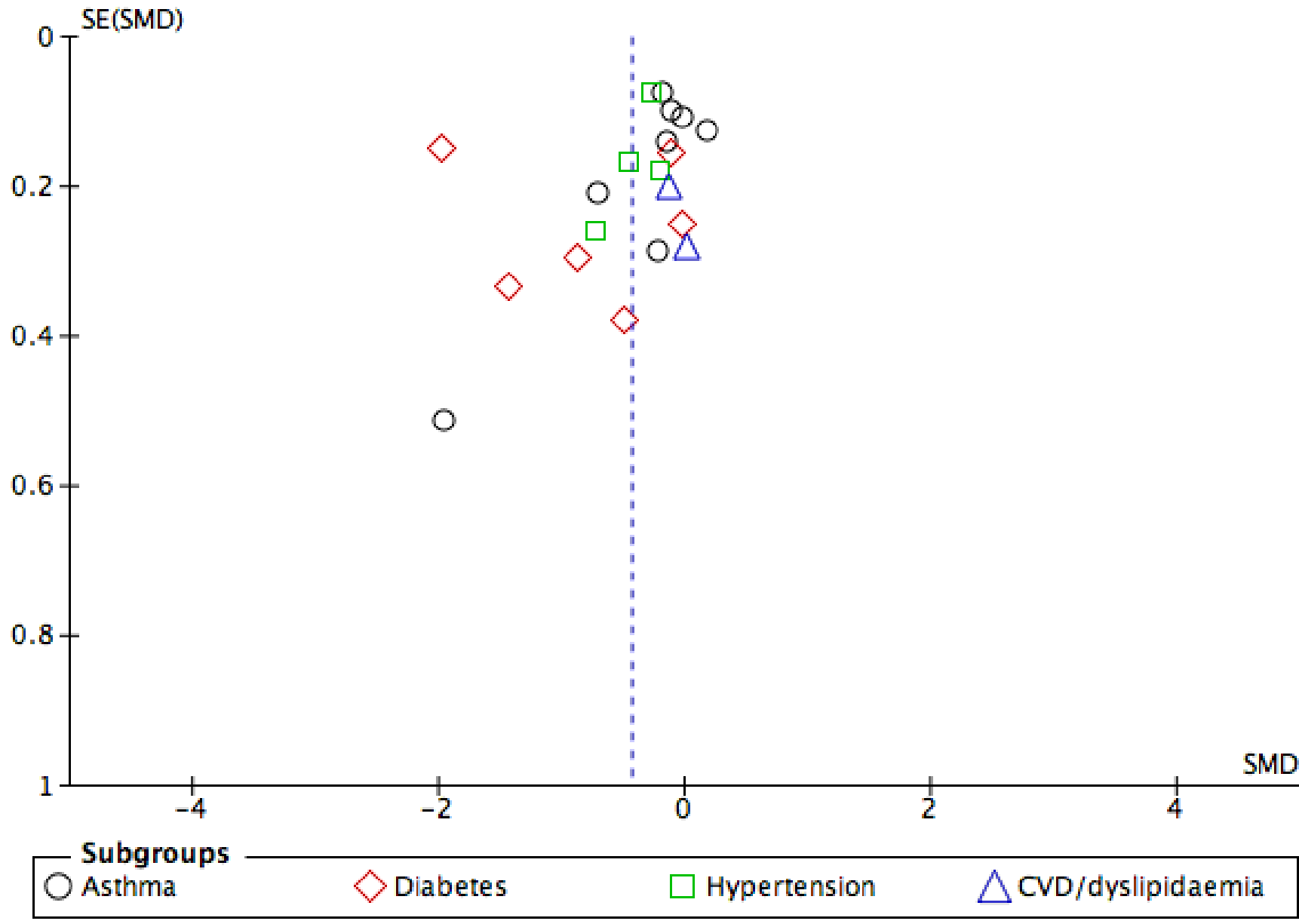


Figure 6. Funnel plot of comparison: 1. Usual treatment versus Health-promotion intervention outcome: Analysis 1.4 Pharmacy user quality of life

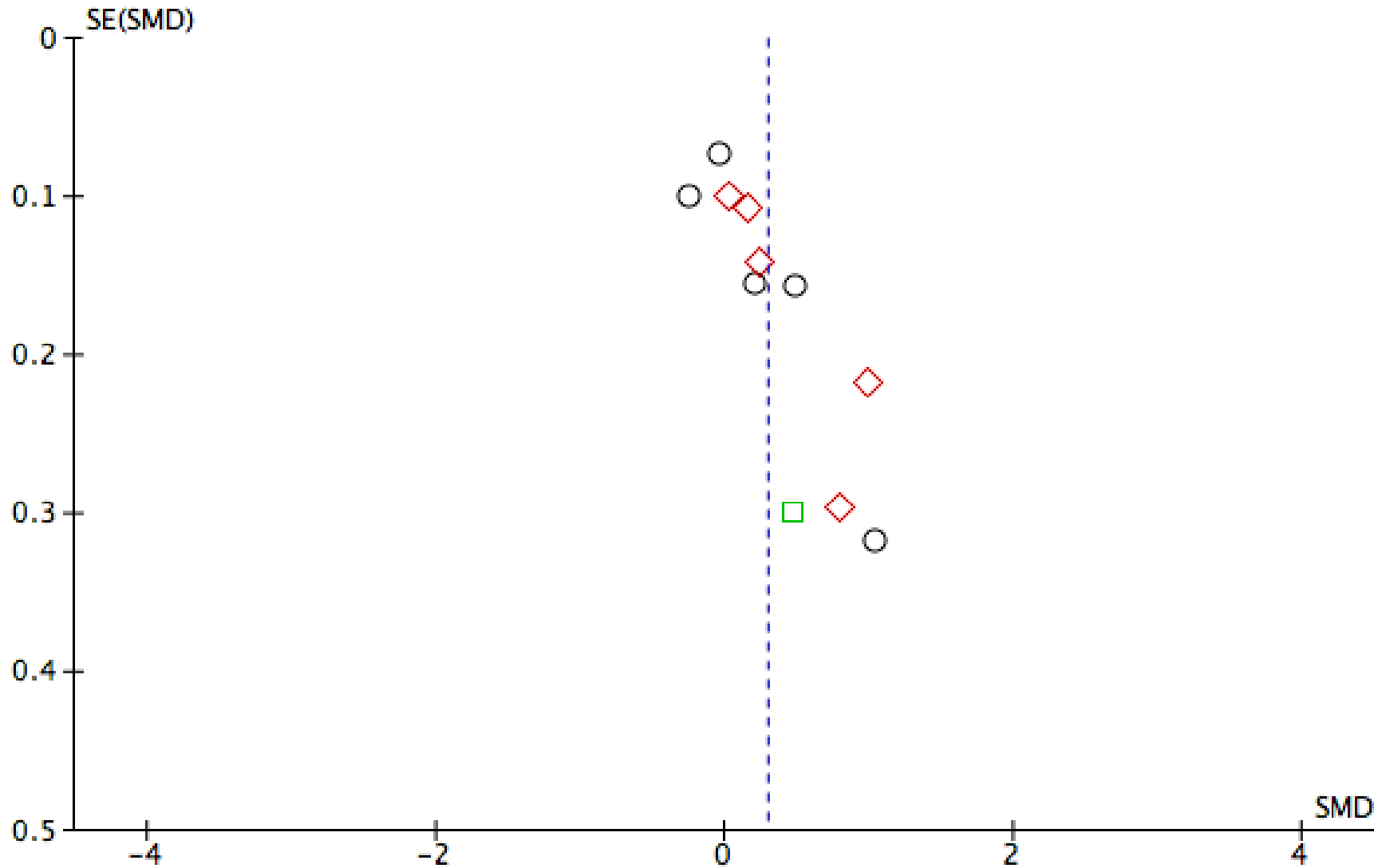

\section{Subgroups}

\section{Other potential sources of bias}

An important potential bias in the included studies was the possibility of contamination between intervention and control groups (see Figure 2). We judged this to be at high risk where randomisation occurred at the level of pharmacy user within the pharmacy, because it can be difficult for a pharmacy worker not to implement skills that have been learned, which risks contamination of the control participants.

\section{Effects of interventions}

See: Summary of findings for the main comparison Health-promotion interventions within community pharmacy compared to usual treatment: effects on professional practice and health outcomes

Summary of findings for the main comparison presents an overview of the effectiveness of interventions; we have used GRADE to indicate the certainty of the evidence. For all outcomes GRADE scores were downgraded to moderate, primarily due to the high heterogeneity present within the studies and evidence of potential publication bias.

\section{Primary outcomes}

\section{Professional practice outcomes}

Fourteen of the 57 studies reported the proportion of pharmacies or pharmacy workers participating in the study. Some studies were conducted in just one or two pharmacies, and others selected pharmacies with specific characteristics. Those studies that reported the proportion of pharmacy workers who consented to take part in the study compared to those invited to participate, reported relatively low figures, for example, $26 \%$ in the Basheti 2008 study, and $33 \%$ in the Armour 2007 study.

Nine studies assessed pharmacy worker outcomes and compared these to no intervention controls. All nine studies assessed the outcome of pharmacy worker behaviour. Eight of the studies were set in urban pharmacies. Seven studies assessed behaviour using a simulated patient model (Dolovich 2007; Garcia 1998; Garcia 2003; Garcia 2012; Liambila 2010; Liekens 2014; Mayer 1998). The behaviours measured by simulated patients ranged from communication skills - using validated measures such as the Roter Interaction Analysis (Dolovich 2007; Liekens 2014) - to noting behaviours such as recommending use of condoms (Garcia 2012). Patwardhan 2012 used an objective measure of behaviour, namely referrals to a smoking quit line following smoking cessation training. 
The Basheti 2008 study assessed maintenance of pharmacy workers' ability to demonstrate asthma inhaler technique two years post training. Two further studies, Jaffray 2014 and Nishita 2013, assessed behaviour as an assessment of fidelity to training but only in the intervention group, not in the control group, so these data were not included in our analysis.

Six of the studies reported improvement in community pharmacy worker behaviour (Basheti 2008; Dolovich 2007; Garcia 2003; Garcia 2012; Mayer 1998; Patwardhan 2012), while one showed no benefits (Liambila 2010), and two had mixed results (Garcia 1998; Liekens 2014). The Dolovich 2007 study indicated a positive effect on both verbal and non verbal communication skills. The Liekens 2014 study showed improved pharmacy worker counselling for depression, and the intervention used in Mayer 1998 improved counselling to avoid ultra-violet radiation (i.e. sunlight). Sexual health counselling was improved in the Garcia 2003 and Garcia 2012 studies at six- and 12-month follow-up, respectively. The Patwardhan 2012 study showed significant improvement in demonstration of inhaler behaviour post-intervention, and the Basheti 2008 study showed maintenance of pharmacy workers' ability to demonstrate correct asthma inhaler technique two years after training. In contrast, interventions in the Liambila 2010 and Garcia 1998 studies produced mixed results for sexual health management.

Due to the heterogeneity of the behaviours measured and the methods used in the studies, we did not consider meta-analysis to be appropriate. We downgraded the certainty of evidence one level, to moderate, because of the high heterogeneity of studies (GRADE 2013).

\section{Pharmacy user outcomes}

\subsection{Pharmacy user health-related behaviour e.g. smoking, exercise,} inhaler technique

Health-related behaviour of pharmacy users was measured in 28 studies (summarised in Table 1). Twelve studies measured medication adherence (please note that this was not the primary target of the intervention, or the trial would have been excluded). Adherence was measured through prescription data, or validated adherence measures such as the medication adherence rating scale (MARS) (Thompson 2000). Seven studies measured inhaler technique within the asthma population specifically. Lifestyle behaviours that were assessed included smoking (Burford 2013; Maguire 2001; Madurasinghe 2017), alcohol consumption (Dhital 2015), diabetes self-care (Doucette 2009; Mansell 2016), physical activity (Okada 2018; Schmiedel 2015), and activity impairment (Slater 2013).

Ten studies provided suitable data for meta-analysis of overall health-related behaviour of pharmacy users (Analysis 1.1). Overall meta-analysis of health-related behaviour of community pharmacy users suggested a probable slight improvement relative to control (SMD $0.43,95 \% \mathrm{Cl} 0.14$ to $0.72 ; 1^{2}=89 \% ; 10$ trials, 2138 participants; moderate-certainty evidence). Inhaler technique was probably improved (SMD 0.92, 95\% Cl 0.35 to $1.48 ;\left.\right|^{2}=82 \%$; 4 trials; 384 participants; moderate-certainty evidence), but interventions showed little or no effect on medication adherence (SMD 0.17, 95\% Cl -0.23 to $0.57 ; 1^{2}=89 \%$; 3 trials, 1245 participants; moderate-certainty evidence), or other behaviours (SMD $0.14,95 \% \mathrm{Cl} 0 .-41$ to 0.68 ; $12=$ $78 \%$; 3 trials, 509 participants; moderate-certainty evidence). We downgraded the certainty of evidence one level to moderate to take into account the high heterogeneity of studies as indicated by high $1^{2}$ values.

\subsubsection{Intermediate clinical outcomes, e.g. cholesterol, HbA1c}

Most studies (35 of 57) included some level of intermediate clinical outcome. The ones measured most consistently were in asthma (9 studies), diabetes (10 studies) and cardiovascular risk (hypertension (8 studies) and dyslipidaemia (4 studies)). We prioritised measures of glycaemic control (e.g. HbA1c) and asthma control (e.g. asthma control test) as the most clinically appropriate for diabetes and asthma, respectively. See Table 2 for an overview of studies. For blood pressure control, most studies presented results for both systolic and diastolic blood pressure. Since we could enter only one value per study into the meta-analysis, we prioritised systolic blood pressure, as recommended by Strandberg 2003. Similarly, the dyslipidaemia studies reported a range of measures, including total cholesterol, high density lipoproteins (HDL) and low-density lipoproteins (LDL). On the basis of the recognised clinical importance of these measures (Silverman 2016), we decided to include LDL values in the meta-analysis.

Meta-analyses for intermediate clinical outcomes, including subgroup analysis by condition are shown in Analysis 1.2. Health-promotion interventions probably improve intermediate clinical outcomes slightly in pharmacy users (SMD $-0.43,95 \% \mathrm{Cl}-0.65$ to -0.21 ; $\mathrm{I}^{2}=90 \%$; 20 trials, 3971 participants; moderate-certainty evidence). These findings were also replicated when mean change rather than final scores were used (SMD $-0.27,95 \% \mathrm{Cl}-0.38$ to $-0.17 ; \mathrm{I}^{2}=0 \% ; 7$ trials, 1413 participants; moderate-certainty evidence; Analysis 1.3).

Sub-group analyses separated by condition suggested that interventions probably improve blood pressure in hypertension (SMD $-0.34,95 \% \mathrm{Cl}-0.49$ to $-0.18 ; \mathrm{I}^{2}=18 \% ; 4$ trials; 1050 participants; moderate-certainty evidence; Analysis 1.2). Interventions probably improve blood glucose levels in diabetes (SMD $-0.81,95 \% \mathrm{Cl}-1.60$ to $-0.02 ; 1^{2}=96 \% ; 6$ trials; 651 participants; moderate-certainty evidence; Analysis 1.2), though the high level of heterogeneity is important here. Interventions probably made little or no difference for asthma control (SMD $-0.20,95 \% \mathrm{Cl}-0.40$ to $-0.00 ; \mathrm{I}^{2}=75 \% ; 8$ trials, 2220 participants; moderate-certainty evidence; Analysis 1.2) or for cardiovascular risk (SMD $-0.08,95 \% \mathrm{Cl}-0.40$ to $0.24 ; \mathrm{I}^{2}=0 \% ; 2$ trials, 150 participants; moderate-certainty evidence; Analysis 1.2). $1^{2}$ values were higher for diabetes and asthma than hypertension or cardiovascular risk. This is likely to reflect the greater similarity in outcome measurement and intervention which was more medication focused in the hypertension and cardiovascular risk than asthma and diabetes.

We assessed the certainty of evidence as moderate after downgrading to take into account the high heterogeneity of studies and unclear distribution (possible publication bias) in funnel plots (GRADE 2013).

\subsubsection{Event-based clinical outcomes, e.g. stroke, myocardial infarction} (MI)

No study measured event-based clinical outcomes such as mortality, stroke or MI.

\subsubsection{Psychological well-being, e.g. anxiety and depression}

Two studies; Crockett 2006 and Fuller 2016, measured psychological well-being. Crockett 2006 employed an intervention targeted 
at depression and measured distress using the K10 (Kessler 2003), but did not report benefits. Fuller 2016 used the DASS-21 to measure depression, anxiety, and stress (Norton 2007), and reported improvement in the intervention group compared to controls on some but not all scales. Given the different ways of combining and calculating psychological well-being in each of these studies it was not considered appropriate to conduct meta-analysis, however, overall it appears that psychological well-being was neither improved nor negatively affected by such interventions.

\subsubsection{Quality of life}

Quality of life was measured in 28 studies as reported Table 3. Fourteen studies used a generic measure, most commonly the SF-36 (Ware 1992), or EQ-5D (Herdman 2011). One study used both a generic and an illness-specific quality of life measure, and 14 studies used an illness-specific measure only. We meta-analysed 10 studies Analysis 1.4. As participants should only be included once in the meta-analysis the diabetes specific quality of life scores from Ali 2012 were not included in the overall analysis. Overall, interventions probably improve quality of life slightly (SMD 0.29, 95\% Cl 0.08 to $0.50 ; 1^{2}=84 \%$; 10 trials, 2687 participants; moderate-certainty evidence). For quality of life measured by a generic tool the interventions may make little or no difference (SMD $0.21,95 \% \mathrm{Cl}-0.10$ to 0.52; $\left.\right|^{2}=86 \%$; 5 trials, 1567 participants; low-certainty evidence). Importantly, however, several studies using a generic quality of life measure were not included in the meta-analysis as data were reported on multiple sub-scales (e.g. Bond 2007, Cordina 2001). For illness specific quality of life there is probably a slight improvement in favour of the intervention groups (SMD $0.38,95 \% \mathrm{Cl} 0.11$ to 0.66 ; $\mathrm{I}^{2}=77 \%$; 6 trials; 1166 participants; moderate-certainty evidence).

\section{Adverse events}

No adverse events were reported in any of the studies.

\section{Secondary outcomes}

\section{Costs}

Seven studies conducted a costs analysis (Armour 2007; Bond 2007; Burford 2013, Garcia 1998; McLean 2003; Svarstad 2013; Tsuyuki 2002). Five of these found the intervention to be cost-effective relative to usual care, even when accounting for costs of intervention. We did not include these in a meta-analysis because of the heterogeneity of methods used, but the consistency of finding is important. Further studies measured healthcare utilisation, most commonly general practitioner visits or hospitalisation (Ali 2012; Charrois 2006; Cordina 2001; Mehuys 2008; Petkova 2008; Petkova 2009; Tommelein 2014; Villeneuve 2010; Weinberger 2002), however, these presented mixed findings about whether the intervention group showed improvement relative to controls.

We were not able to conduct the planned sub-group meta-analysis of low- and middle-income countries versus high-income countries, as there was not sufficient homogeneity of outcomes or consistency in reporting across these groups. From visual assessment it does appear that, in general, studies from lower- to middle-income countries had a higher risk of bias than those in high-income countries. We could not analyse groups at the extremes of health behaviour or cultural/ethnic groups as these data were not reported adequately.

\section{Sensitivity analyses}

We repeated meta-analysis for pharmacy user health-related behaviour, intermediate clinical outcomes and quality of life while omitting outliers or any trial with a high risk of bias (e.g. Park 1996 ), however, this did not significantly change the outcomes of analyses.

\section{Publication bias}

Examination of funnel plots suggested that there was potential publication bias in the community pharmacy user outcomes of quality of life and intermediate clinical outcomes. For these outcomes, fewer smaller non-significant studies were published than small positive studies, however, this effect was not seen for larger studies which contributed greater weight to meta-analysis.

\section{DISCUSSION}

\section{Summary of main results}

The findings of this review suggest that the community pharmacy is potentially a helpful setting in which to offer behavioural and health-promotion interventions. There is evidence to suggest that such interventions probably slightly improve pharmacy user health-related behaviour, intermediate clinical outcomes - particularly for diabetes and hypertension - and quality of life. Importantly, there is also some indication that these interventions may be cost effective. Although these findings were consistent across conditions and outcomes, it is important to note that there was considerable heterogeneity, as indicated by high 12 between studies in terms of intervention content and delivery, outcomes measured, and follow-up periods, so we do not have complete certainty in our findings. Nonetheless, the evidence from this review agrees with the current drive in healthcare provision, both within the UK (NICE 2018), and internationally (Blouin 2017), to extend the role of the community pharmacy.

In addition to the probable slight effects on pharmacy user outcomes, there is evidence that the professional practice of pharmacy workers is probably influenced positively by the interventions. It is of note, however, that only a minority of studies evaluated pharmacy worker behaviour. Descriptions of the pharmacy worker interventions were often reported more briefly than those of the pharmacy user interventions. Many studies were poor at reporting use of theory. This has important implications for replicability of studies, and also the maximisation of benefits and refinement of interventions. We did not find any studies that measured harms from these interventions. Although adverse effects on pharmacy worker and pharmacy user health-related behaviour, intermediate clinical, quality of life, and cost outcomes were not indicated, more subtle harms - such as disruption to traditional pharmacological services due to a misdirection in the pharmacy workers' time - is possible, and should be investigated in future studies.

\section{Overall completeness and applicability of evidence}

This review used stringent inclusion criteria to ensure that only studies of robust quality were included. This led to the exclusion of a significant number of studies from the review, particularly with respect to certain outcomes - for example, lifestyle interventions such as smoking cessation. Smoking cessation interventions are a common health-promotion service for community pharmacies to offer, but trials exploring the effectiveness of these interventions 
were included less frequently in this review than we anticipated because of our requirement for an objective, clinically verified outcome measure, for example, cotinine levels. The requirement for an objective outcome measure was less of a problem for intermediate clinical outcomes, which typically were objective measurements (e.g. HbA1c). The overall finding of effectiveness for this outcome has more weight for generalisability given the number of studies across different countries and different conditions that contributed to it. This must, however, be balanced against the considerable heterogeneity of trials that makes it difficult to conclude whether specific types, or content, of interventions are more beneficial. It is also important to consider that standardized mean difference (SMD) scores were used in Analysis 1.1 and Analysis 1.2 where the constructs of pharmacy user behaviour and pharmacy user intermediate clinical outcomes were measured across different conditions and different sub-groups e.g. of behaviour. As a result findings may be driven by difference in one sub-group (for example inhaler technique Analysis 1.1) but not in others. In addition it is not clear to what extent these findings persist after the intervention period since we used the first measurement after intervention completion.

There were insufficient data to conduct a number of our planned subgroup analysis, including whether outcomes varied according to cultural or ethnic group, and the level of health behaviour or theory used, and these remain important questions to answer. Additionally, it was uncommon for studies to report socio-economic status of participants, so the extent to which these interventions reached into populations that are more difficult to access could not be ascertained.

Our original intention was to categorise interventions according to the behaviour-change techniques used, but this was not possible due to the insufficiency of intervention descriptions. In addition, the way in which pharmacy workers were trained to deliver the intervention was poorly reported. We did conduct a higher level coding of interventions according to the theoretical domains framework (see Characteristics of included studies), which suggested that although studies did frequently involve knowledge and some basic behavioural regulation approaches, they commonly did not explore the more complex elements needed for behaviour change, such as addressing beliefs and emotions. The studies rarely reported being driven by a theoretical model; this is now recommended for development of complex interventions (Craig 2008), and should apply to the development of future community pharmacy healthpromotion interventions.

One issue that is important to consider is the extent to which the studies included in this review were representative of the general community pharmacy population. Studies rarely reported their organisational structure or issues, such as the culture within the practice, which would have aided interpretation of results. In addition, many studies conducted trials in a relatively low number of community pharmacies, which were often close to the research base. When a larger number of pharmacy sites were recruited, there was variable uptake, often with considerable dropout (e.g. $26 \%$ of pharmacists in Skowron 2011), although this was not always the case (e.g. 0\% dropout in Slater 2013). The importance of this issue was highlighted in Garcia 2012, which reported that over a three-year study period $29 \%$ of enrolled pharmacies closed, and the turnover of staff was remarkably high, with $81 \%$ of the staff base changing jobs during the study period. This is an important issue to consider when training staff, and suggests that, if interventions are to be supported in the long term, regular and ongoing pharmacy worker training events should be organised.

\section{Certainty of evidence}

GRADE assessment suggested that there was moderate certainty for the outcomes evaluated, and, therefore, that the research presented is a good indication of the probable effect. We downgraded the certainty from high to moderate because of the considerable heterogeneity in the studies, and the indication of a level of publication bias. Although our methodology excluded very poor quality designs by virtue of only including randomised trials, there was still a wide range in the quality of the studies included. The inclusion of cluster-randomised trials in this review minimised selection bias and protected against contamination (Gums 2016), and so was a strength, as was the overall total number of participants included $(16,315)$.

Where participants were individually randomised within pharmacies, this led to a high risk of contamination bias and was a weakness of such studies. Study quality was also threatened in a number of studies due to poor blinding regarding study group. This blinding is particularly difficult to achieve for behavioural interventions, where it is clear there is a change in practice, however, it can be managed by a choice of objective outcomes or by having outcome assessors who are blinded to study group.

Poor reporting of outcomes, or the use of non validated tools, occurred and led to a number of studies being excluded from the meta-analysis (see Table 2, Table 1, Table 3), which suggests that the results might need to be treated with some caution. Additionally, poor descriptions of some interventions was a significant limitation of many of the studies. The difficulty of reporting behavioural interventions in sufficient detail is a well recognised problem that reporting frameworks, including TiDieR (Hoffmann 2014), and Wider (Albrecht 2013), have aimed to address. These frameworks were not readily reported for any of the trials included in this review, but should be included in future trials (Steed 2017). This will become more feasible with the increase of online supplementary data and open access journals. A final limiting factor concerning the trials was the minimal assessment of fidelity of interventions, which was reported explicitly only by Svarstad 2013, and Nishita 2013. According to Borrelli 2011, this should be assessed at five levels (i.e. study design, training, delivery, receipt, and enactment), but even the most common aspect of fidelity (delivery) that has been measured in other reviews was poorly measured or reported in these trials (Walton 2017).

\section{Potential biases in the review process}

We minimised biases in the review processes by having duplicate screening for full text and extraction, and ensuring reliability of title and abstract screening by using duplicate screening until an excellent level of accuracy was achieved. For several studies, however, we had difficulty in deciding whether to included them or not, usually because the intervention content had not been reported clearly enough. To ensure consistency and minimise bias, two review authors reviewed all studies and, where there was disagreement, sought discussion with a third author. The study team also met to agree issues such as structure of analysis; and to classify which studies focused on pharmacy workers, pharmacy users or both; and whether the intervention could be considered to be behavioural, was purely medication focused, or involved interaction. 
One area of deliberation concerned interventions that were primarily managing disease through altering or promoting medication adherence, but also included some lifestyle advice; this was particularly common in hypertension and dyslipidaemia trials. Typically the extent of lifestyle advice was not well categorised, and this may have caused bias through inclusion of studies that were primarily medication focused. However, we conducted meta-analysis using subgroups with different conditions, and our findings were generally consistent across these subgroups.

The study searches were conducted in February 2018, this may mean some studies have been published since the last search date which could impact on the reliability of the findings.

\section{Agreements and disagreements with other studies or reviews}

The findings of this review largely agree with other recent systematic reviews that have looked at the community pharmacy as a context for the delivery of non-pharmacological interventions. Buss 2018 examined a range of clinical services in community pharmacy and concluded that these led to "improved asthma control, detection of diabetes and cardiovascular risk factors, reduction in smoking rates and weight, and identification of drug-related problems". Brown 2016, which evaluated community pharmacy interventions focused on lifestyle behaviours that included smoking cessation, weight management or alcohol use, concluded that smoking cessation services delivered in this context were both effective and costeffective. Weight management interventions also appeared feasible, but there were insufficient data to permit conclusions to be drawn regarding their effectiveness.

Several reviews have examined community pharmacy-led management of long-term conditions. Their role in control of blood pressure was reported in a review by Cheema 2014, which concluded that community pharmacy-led interventions can significantly reduce both systolic and diastolic blood pressure. Similarly positive effects for diabetes care have been reported in two other reviews that focused on foot care for individuals with type 2 diabetes (Deters 2018; Soprovich 2019). The Garcia-Cardenas 2016 review reported potential benefit for asthma.

However, the Cochrane Review, De Barra 2018, found less clear results, stating it was unclear whether pharmacist services reduced the percentage of patients with glycated haemoglobin levels outside the target range, although it suggested that such services may reduce the percentage of patients whose blood pressure lies outside the target range. The authors concluded there was probably little or no difference in hospital attendance or admissions, adverse drug effects, and mortality, although there was a possibility of improvement in physical functioning. It is worth noting that the De Barra 2018 review was not specific to community pharmacies as it included pharmacists working in hospital outpatient departments, and those attached to primary care practices. The interventions also included those targeted at improving health through use or stopping of medication and excluded health-promotion interventions. These are important differences that may account for the differences in results between this review and the others previously mentioned, including our review.

A further point of similarity encountered by our review and other reviews is the difficulties surrounding the level of description of in- terventions and how to code for theory and behaviour-change techniques. Scott 2016 similarly called for a higher level of detail to be provided for descriptions of interventions. Finally, a review of reviews in the community pharmacy context concluded that there were insufficient data to assess the impact of public health interventions in this context on health inequalities (Thomson 2019).

\section{AUTHORS' CONCLUSIONS}

\section{Implications for practice}

Community pharmacy interventions probably slightly improve pharmacy users' intermediate clinical, behavioural, and quality of life outcomes, and are also cost-effective, so community pharmacies may be considered as another option for patients in terms of accessing public health services and health promotion. Additionally the potential 'reach' of the community pharmacy network - especially in deprived communities (Todd 2014) - means that they could offer a platform to people who might not be able to access other public health services. Community pharmacy staff are often more accessible than other healthcare professionals such as General Practitioners (Todd 2014b), and so may have the opportunity to reduce health inequalities.

\section{Implications for research}

This review supports further study of the development of community pharmacy health and health-promotion services. To date there is insufficient evidence to be clear about the reach of these interventions and whether they are moderated by socio-economic status; this is an area that would benefit from clarification through future research, as these interventions have the potential to be an effective means of reducing health inequalities. Additional high-quality studies across countries with different income levels, in different settings - such as rural and urban - or in different populations (for example people who do not speak English), would also be helpful.

Additionally many of the interventions investigated to date are complex in nature and require targeting the pharmacy team and pharmacy environment as a whole (Steed 2017), as well as pharmacy users. Interventions would benefit from being based upon appropriate theory and using recent approaches to intervention development (O'Cathain 2019). Interventions would also benefit from being described more clearly, as this would improve both examination and replicability (Scott 2016). Description of both pharmacy-worker and user-level interventions should follow the guidelines for description of complex behavioural interventions (Albrecht 2013; Hoffmann 2014). There is also a requirement for greater assessment of fidelity at both the intervention delivery and receipt level.

\section{ACK N O WLEDGEMENTS}

We thank Michelle Fiander for development of the search strategy and conduct of the original search and Paul Miller for the updated search in 2018. A team of several researchers were involved in data extraction including Val Khan and Andrea Takeda, and Emma Konstantiou (EK) contributed significantly to data input. Katrina Kassavou had a significant role at the early stages of the project including design of the data extraction sheet, and Glenn Poon provided considerable administrative support. We are grateful to the whole team for their input and support and referees and reviewers for their recommendations. 


\section{R E F E R E N C E S}

\section{References to studies included in this review}

Adepu 2007 \{published data only\}

Adepu R, Rasheed A, Nagavi B. Effect of patient counseling on quality of life in type-2 diabetes mellitus patients in two selected South Indian community pharmacies: a study. Indian Journal of Pharmaceutical Sciences 2007;69:519-24.

\section{Ali 2012 \{published data only\}}

Ali M, Schifano F, Robinson P, Phillips G, Doherty L, Melnick P, et al. Impact of community pharmacy diabetes monitoring and education programme on diabetes management: a randomized controlled study. Diabetic Medicine 2012;29(9):e326-e33.

\section{Amariles 2012 \{published data only\}}

Amariles P, Sabater-Hernandez D, Garcia-Jimenez E, RodriguezChamorro MA, Prats-Mas R, Marin-Magan F, et al. Effectiveness of Dader method for pharmaceutical care on control of blood pressure and total cholesterol in outpatients with cardiovascular disease or cardiovascular risk: EMDADER-CV randomized controlled trial. Journal of Managed Care Pharmacy 2012;18(4):311-23.

Pharmaceutical Care Research Group. Pharmacotherapy followup: the Dader method (3rd revision: 2005). Pharmacy Practice 2006;4(1):44-53.

\section{Armour 2007 \{published data only\}}

* Armour C, Bosnic-Anticevich S, Brillant M, Burton D, Emmerton L, Krass I, et al. Pharmacy Asthma Care Program (PACP) improves outcomes for patients in the community. Thorax 2007;62(6):496-502.

Gordois A, Armour C, Brillant M, Bosni-Anticevich S, Burton D, Emmerton L, et al. Cost-effectiveness analysis of a pharmacy asthma care program in Australia. Disease Management Health Oucomes 2007;15(6):387-96.

Saini B, Krass I, Armour C. Development, implementation, and evaluation of a community pharmacy-based asthma care model. Annals of Pharmacotherapy 2004;38(11):1854-60.

Barbanel 2003 \{published data only\}

Barbanel D, Eldridge S, Griffiths C. Can a self-management programme delivered by a community pharmacist improve asthma control? A randomised trial. Thorax 2003;58(10):851-4.

\section{Basheti 2008 \{published data only\}}

* Basheti IA, Armour CL, Bosnic-Anticevich SZ, Reddel HK. Evaluation of a novel educational strategy including inhalerbased reminder labels, to improve asthma inhaler technique. Patient Education and Counseling 2008;72:26-33.

Basheti IA, Armour CL, Reddel HK, Bosnic-Anticevich SZ. Long-term maintenance of pharmacists' inhaler technique demonstration skills. American Journal of Pharmaceutical Education 2009;73(2):32.

Basheti IA, Reddel H, Armour CL, Bosnic-Antichevich S. Improved asthma outcomes with a simple inhaler technique intervention by community pharmacists. Journal of Allergy and Clinical Immunology 2007;119(6):1537-8.

\section{Bereznicki 2013 \{published data only\}}

* Bereznicki BJ, Peterson G, Jackson S, Walters EH, George J, Stewart K, et al. Uptake and effectiveness of a community pharmacy intervention programme to improve asthma management. Journal of Clinical Pharmacy \& Therapeutics 2013;38(3):212-8.

Bereznicki BJ, Peterson GM, Jackson SL, Walters EH, Gee PR. The sustainability of a community pharmacy intervention to improve the quality use of asthma medication. Journal of Clinical Pharmaceutical Therapy 2011;36:144-51.

Bereznicki BJ, Peterson GM, Jacson SL, Walters EH, Fitzmaurice KD, Gee PR. Data-mining of medication records to improve asthma management. Medical Journal of Australia 2008;189:21-5.

\section{Bond 2007 \{published data only\}}

* Bond C, on behalf of The Community Pharmacy Medicines Management Project Evaluation Team. The MEDMAN study: a randomized controlled trial of community pharmacy-led medicines management for patients with coronary heart disease. Family Practice 2007;24(2):189-200.

Jaffray M, Krska A, Lee AJ, Bond CM. The MEDMAN project: evaluation of the medicines management training for community pharmacists. Pharmacy Education 2007;7(3):207-14.

Scott A, Tinelli M, Bond C. Costs of a community pharmacist-led medicines management service for patients with coronary heart disease in England: healthcare system and patient perspectives. Pharmacoeconomics 2007;25(5):3970411.

\section{Burford 2013 \{published data only\}}

Burford O, Jiwa M, Carter O, Parsons R, Hendrie D. Internetbased photoaging within Australian pharmacies to promote smoking cessation: randomized controlled trial. Journal of Medical Internet Research 2013;15(3):e64. [DOI: 10.2196/ jmir.2337]

\section{Bynum 2001 \{published data only\}}

Bynum A, Hopkins D, Thomas A, Copeland N, Irwin C. The effect of telepharmacy counseling on metered-dose inhaler technique among adolescents with asthma in rural Arkansas. Telemedicine Journal and E-health 2001;7(3):207-17.

\section{Charrois 2006 \{published data only\}}

Charrois T, Newman S, Sin D, Senthilselvan A, Tsuyuki RT. Improving asthma symptom control in rural communities: the design of the Better Respiratory Education and Asthma Treatment in Hinton and Edson study. Controlled Clinical Trials 2004;25:502-14.

${ }^{*}$ Charrois TL, Newman SC, Senthilselvan A, Tsuyuki RT. Improving asthma control in the rural setting: the BREATHE (Better Respiratory Education and Asthma Treatment in 
Hinton and Edson) study. Canadian Pharmacists Journal 2006;139(4):44-50.

\section{Cordina 2001 \{published data only\}}

Cordina M, McElnay JC, Hughes CM. Assessment of a community pharmacy-based program for patients with asthma. Pharmacotherapy 2001;21(10):1196-203.

\section{Crockett 2006 \{published data only\}}

Crockett J, Taylor S, Grabham A, Stanford P. Patient outcomes following an intervention involving community pharmacists in the management of depression. Australian Journal of Rural Health 2006;14(6):263-9.

\section{Dhital 2015 \{published data only\}}

Dhital R, Norman I, Whittlesea C, Murrells T, McCambridge J. Effectiveness of alcohol brief intervention delivered by community pharmacists: study protocol of a two-arm randomised controlled trial. BMC Public Health 2013;13:152.

* Dhital R, Norman I, Whittlesea C, Murrells T, McCambridge J. The effectiveness of brief alcohol interventions delivered by community pharmacists: randomized controlled trial. Addiction 2015;110:1586-94.

Quirk A, MacNeil V, Dhital R, Whittlesea C, Norman I, McCambridge J. Qualitative process study of community pharmacist brief alcohol intervention effectiveness trial: can research participation effects explain a null finding?. Drug \& Alcohol Dependence 2016;161:36-41.

\section{Dolovich 2007 \{published data only\}}

Dolovich L, Sabharwal M, Agro K, Foster G, Lee A, McCarthy L, et al. The effect of pharmacist education on asthma treatment plans for simulated patients. Pharmacy World \& Science 2007;29(3):228-39.

\section{Doucette 2009 \{published data only\}}

Doucette WR, Witry MJ, Farris KB, McDonough RP. Community pharmacist-provided extended diabetes care. Annals of Pharmacotherapy 2009;43(5):882-9.

\section{Fuller 2016 \{published data only\}}

Fuller JM, Wong KK, Hoyos C, Krass I, Saini B. Dispensing good sleep health behaviours not pills - a cluster-randomized controlled trial to test the feasibility and efficacy of pharmacistprovided brief behavioural treatment for insomnia. Journal of Sleep Research 2016;25:104-15.

\section{Garcia 1998 \{published data only\}}

Garcia PJ, Gotuzzo E, Hughes JP, Holmes KK. Syndromic management of STDs in pharmacies: evaluation and randomised intervention trial. Sexually Transmitted Infections 1998;74 Suppl 1:S153-8.

\section{Garcia 2003 \{published data only\}}

Garcia P, Hughes J, Carcamo C, Holmes KK. Training pharmacy workers in recognition, management, and prevention of STDs: district-randomized controlled trial. Bulletin of the World Health Organization 2003;81(11):806-14.

\section{Garcia 2012 \{published data only\}}

* Garcia JP, Holmes KK, Carcamo CP, Garnett GP, Hughes JP, Campos PE, et al. Prevention of sexually transmitted infections in urban communities (Peru PREVEN): a multicomponent community-randomised controlled trial. Lancet 2012;379:1120-8.

Garcia PJ, Carcamo CP, Garnett GP, Campos PE, Holmes KK. Improved STD syndrome management by a network of clinicians and pharmacy workers in Peru: the PREVEN Network. PLOS ONE 2012;7(10):e47750.

\section{Garcia-Cardenas 2013 \{published data only\}}

Garcia-Caredenas V, Sabater-Hernandez D, Kenny P, MartínezMartínez F, Faus MJ, Benrimoj SI. Effect of a pharmacist intervention on asthma control. A cluster randomised trial. Respiratory Medicine 2013;107(9):1346-55.

\section{Jaffray 2014 \{published data only\}}

Jaffray M, Matheson C, Bond C, Lee AJ, McLernon DJ, Johnstone A, et al. Does training in motivational interviewing for community pharmacists improve outcomes for methadone patients? A cluster randomised controlled trial.. International Journal of Pharmacy Practice 2014;22(1):4-12.

\section{Kraemer 2012 \{published data only\}}

Kraemer DF, Kradjan WA, Bianco TM, Low JA. A randomized study to assess the impact of pharmacist counseling of employer-based health plan beneficiaries with diabetes: the EMPOWER study. Journal of Pharmacy Practice 2012;25(2):169-79.

\section{Krass 2007 \{published data only\}}

Krass I, Armour CL, Mitchell B, Brillant M, Dienaar R, Hughes J, et al. The Pharmacy Diabetes Care Program: assessment of a community pharmacy diabetes service model in Australia. Diabetic Medicine 2007;24(6):677-83.

\section{Liambila 2010 \{published data only\}}

Liambila W, Obare F, Keesbury J. Can private pharmacy providers offer comprehensive reproductive health services to users of emergency contraceptives? Evidence from Nairobi, Kenya. Patient Education and Counseling 2010;81(3):368-73.

\section{Liekens 2014 \{published data only\}}

Liekens S, Vandael E, Roter D, Larson S, Smits T, Laekeman G, et al. Impact of training on pharmacists' counseling of patients starting antidepressant therapy. Patient Education and Counseling 2014;94(1):110-5.

\section{Madurasinghe 2017 \{published data only\}}

* Madurasinghe VW, Sohanpal R, James W, Steed L, Eldridge S, Taylor S, et al. Smoking treatment optimisation in pharmacies (STOP): a cluster randomised pilot trial of a training intervention. Pilot \& Feasibility Studies 2017;3:1.

Steed L, Sohanpal R, James WY, Rivas C, Jumbe S, Chater A, et al. Equipping community pharmacy workers as agents for health behaviour change: developing and testing a theory-based smoking cessation intervention. BMJ Open 2017;7(8):e015637. 
Maguire 2001 \{published data only\}

Maguire T. Pharmaceutical care - a realistic pharmaceutical service. Pharmacy Today 1996;7:20-4.

* Maguire TA, McElnay JC, Drummond A. A randomized controlled trial of a smoking cessation intervention based in community pharmacies. Addiction 2001;96(2):325-31.

\section{Mansell 2016 \{published data only\}}

Mansell K, Evans C, Tran D, Sevany S. The association between self-monitoring of blood glucose, hemoglobin $\mathrm{A} 1 \mathrm{C}$ and testing patterns in community pharmacies: results of a pilot study. Canadian Pharmacists Journal 2016;149:28-37.

\section{Mayer 1998 \{published data only\}}

Mayer JA, Eckhardt L, Stepanski BM, Sallis JF, Elder JP, Slymen DJ, et al. Promoting skin cancer prevention counseling by pharmacists. American Journal of Public Health 1998;88(7):1096-9.

* Mayer JA, Slymen DJ, Eckhardt L, Rosenberg C, Stepanski BM, Creech L, et al. Skin cancer prevention counseling by pharmacists: specific outcomes of an intervention trial. Cancer Detection \& Prevention 1998;22(4):367-75.

\section{McDonough 2005 \{published data only\}}

McDonough RP, Doucette WR, Kumbera P, Klepser DG. An evaluation of managing and educating patients on the risk of glucocorticoid-induced osteoporosis. Value in Health 2005;8(1):24-31.

\section{McLean 2003 \{published data only\}}

McLean W, Gillis J, Waller R. The BC Community Pharmacy Asthma Study: A study of clinical, economic and holistic outcomes influenced by an asthma care protocol provided by specially trained community pharmacists in British Columbia. Canadian Respiratory Journal 2003;10(4):195-202.

\section{McLean 2008 \{published data only\}}

Houle SK, Chuck AW, McAlister FA, Tsuyuki RT. Effect of a pharmacist-managed hypertension program on health system costs: an evaluation of the Study of Cardiovascular Risk Intervention by Pharmacists-Hypertension (SCRIP-HTN). Pharmacotherapy 2012;32(6):527-37.

${ }^{*}$ McLean D, McAlistair F, Johnson J. A randomized trial of the effect of community pharmacist and nurse care on improving blood pressure management in patients with diabetes mellitus: study of cardiovascular risk intervention by pharmacistshypertension (SCRIP-HTN). Archives of Internal Medicine 2008;168(21):2355-61.

McLean DL, McAlister FA, Johnson JA, King DM, Jones CA, Tsuyuki RT. Improving blood pressure management in patients with diabetes: the design of the SCRIP-HTN study. Canadian Pharmaceutical Journal 2006;139(4):36-9.

\section{Mehuys 2008 \{published data only\}}

Mehuys E, Van Bortel L, De Bolle L, Van Tongelen I, Annemans L, Remon JP, et al. Effectiveness of pharmacist intervention for asthma control improvement. European Respiratory Journal 2008;31(4):790-9.

\section{Mehuys 2011 \{published data only\}}

Mehuys E, Van Bortel L, De Bolle L, Van Tongelen I, Annemans L, Remon JP, et al. Effectiveness of a community pharmacist intervention in diabetes care: a randomized controlled trial. Journal of Clinical Pharmacy \& Therapeutics 2011;36(5):602-13.

Nishita 2013 \{published data only\}

Nishita C, Cardazone G, Uehara DL, Tom T. Empowered diabetes management: life coaching and pharmacist counseling for employed adults with diabetes. Health Education \& Behavior 2013;40(5):581-91.

\section{Nola 2000 \{published data only\}}

Nola KM, Gourley DR, Portner TS, Gourley GK, Solomon DK, Elam M, et al. Clinical and humanistic outcomes of a lipid management program in the community pharmacy setting. Journal of the American Pharmaceutical Association 2000;40(2):166-73.

\section{Okada 2018 \{published data only\}}

Okada H, Onda M, Shoji M, Sakane N, Nakagawa Y, Sozu T, et al. Effects of lifestyle advice provided by pharmacists on blood pressure: the COMmunity Pharmacists ASSist for Blood Pressure (COMPASS-BP) randomized trial. Bioscience Trends 2018;11:632-9.

\section{Park 1996 \{published data only\}}

Park JJ, Kelly P, Carter BL, Burgess PP. Comprehensive pharmaceutical care in the chain setting: drug therapy monitoring and counseling by pharmacists contributed to improved blood pressure control in study patients. Journal of the American Pharmaceutical Association 1996;NS36(7):443-51.

\section{Patwardhan 2012 \{published data only\}}

Patwardhan PD, Chewning BA. Ask, advise and refer: hypothesis generation to promote a brief tobacco-cessation intervention in community pharmacies. International Journal of Pharmacy Practice 2009;17(4):221-9.

* Patwardhan PD, Chewning BA. Effectiveness of intervention to implement tobacco cessation counseling in community chain pharmacies. Journal of the American Pharmacists Association : JAPhA 2012;52(4):507-14.

Patwardhan PD, Chewning BA. Tobacco users' perceptions of a brief tobacco cessation intervention in community pharmacies. Journal of the American Pharmacists Association: JAPhA 2010;50(5):568-74.

\section{Paulos 2005 \{published data only\}}

Paulós CP, Nygren CE, Celedón C, Cárcamo CA. Impact of a pharmaceutical care program in a community pharmacy on patients with dyslipidemia. Annals of Pharmacotherapy 2005;39(5):939-43.

\section{Petkova 2008 \{published data only\}}

Petkova VB. Pharmaceutical care for asthma patients: a community pharmacy based pilot project. Allergy and Asthma Proceedings 2008;29(1):55-61. 
Petkova 2009 \{published data only\}

Petkova VB. Education for arthritis patient: a community pharmacy based pilot project. Pharmacy Practice (Granada) 2009; 7(2):88-93.

\section{Planas 2012 \{published data only\}}

Planas LG, Crosby KM, Farmer KC, Harrison DL. Evaluation of a diabetes management program using selected HEDIS measures. Journal of the American Pharmaceutical Association 2012;52(6):e130-8.

\section{Schmiedel 2015 \{published data only\}}

Schmiedel K, Mayr A, Fiesler C, Schlager H, Friedland K. Effects of the lifestyle intervention program GLICEMIA in people at risk for type 2 diabetes: a cluster-randomized controlled trial. Diabetes Care 2015;38:937-9.

\section{Skowron 2011 \{published data only\}}

Skowron A, Polak S, Brandys J. The impact of pharmaceutical care on patients with hypertension and their pharmacists. Pharmacy Practice (Granada) 2011;9(2):110-5.

\section{Slater 2013 \{published data only\}}

Slater H, Briggs AM, Watkins K, Chua J, Smith AJ. Translating evidence for low back pain management into a consumerfocused resource for use in community pharmacies: a clusterrandomised controlled trial.. PLOS One 2013;8(8):e71918.

\section{Smith 2011 \{published data only\}}

Smith L, Nguyen T, Seeto C, Saini B, Brown L. The role of nonclinicians in a goal setting model for the management of allergic rhinitis in community pharmacy settings. Patient Education and Counseling 2011;85(2):26-32.

\section{Svarstad 2013 \{published data only\}}

Shireman TI, Svarstad BL. Cost-effectiveness of Wisconsin TEAM model for improving adherence and hypertension control in black patients. Journal of the American Pharmacists Association: JAPhA 2016;56(4):389-96.

* Svarstad BL, Kotchen JM, Shireman TI, Brown RL, Crawford SY, Mount JK, et al. Improving refill adherence and hypertension control in black patients: Wisconsin TEAM trial. Journal of the American Pharmacists Association : JAPhA 2013;53(5):520-9.

Svarsted BL, Morley Kotchen J, Shireman TI, Crawford SY, Palmer PA, Vivian EM, et al. The Team Education and Adherence Monitoring (TEAM) trial: pharmacy interventions to improve hypertensive control in blacks. Circulation. Cardiovascular Quality and Outcomes 2009;2(3):264-71.

\section{Tommelein 2014 \{published data only\}}

Tommelein E, Mehuys E, Van Hees T, Adriaens E, Van Bortel L, Christiaens T, et al. Effectiveness of pharmaceutical care for patients with chronic obstructive pulmonary disease (PHARMACOP): a randomized controlled trial. British Journal of Clinical Pharmacology 2014;77:756-66.

\section{Tsuyuki 2002 \{published data only\}}

Simpson SH, Johnson JA, Biggs RS, Tsuyuki RT, Scrip I. Greater effect of enhanced pharmacist care on cholesterol management in patients with diabetes mellitus: a planned subgroup analysis of the Study of Cardiovascular Risk Intervention by Pharmacists (SCRIP).. Pharmacotherapy 2004;24(3):389-94.

Simpson SH, Johnson JA, Tsuyuki RT. Economic impact of community pharmacist intervention in cholesterol risk management: an evaluation of the study of cardiovascular risk intervention by pharmacists. Pharmacotherapy 2001;21(5):627-35.

* Tsuyuki RT, Johnson JA, Teo KK, Simpson SH, Ackman ML, Biggs RS, et al. A randomized trial of the effect of community pharmacist intervention on cholesterol risk management: the Study of Cardiovascular Risk Intervention by Pharmacists (SCRIP). Archives of Internal Medicine 2002;27(162):1149-55.

Tsuyuki RT, Olson KL, Dubyk AM, Schindel TJ, Johnson JA. Effect of community pharmacist intervention on cholesterol levels in patients at high risk of cardiovascular events: the Second Study of Cardiovascular Risk Intervention by Pharmacists (SCRIPplus). American Journal of Medicine 2004;116(2):130-3.

Tsuyuki RT1, Johnson JA, Teo KK, Ackman ML, Biggs RS, Cave A, Chang WC, Dzavik V, Farris KB, Galvin D, Semchuk W, Simpson SH, Taylor JG. Study of Cardiovascular Risk Intervention by Pharmacists (SCRIP) a randomized trial design of the effect of a community pharmacist intervention program on serum cholesterol risk.. Ann Pharmacother 1999;33(9):909-910.

\section{Tsuyuki 2016 - RXACT \{published data only\}}

Tsuyuki RT, Rosenthal M, Pearson GJ. A randomized trial of a community-based approach to dyslipidemia management: pharmacist prescribing to achieve cholesterol targets (RxACT Study). Canadian Pharmacists Journal 2016;149:283-92.

* Tsuyuki RT, Rosenthal M, Pearson GJ. Improving dyslipidemia management in the community: a randomized trial of pharmacist prescribing, the RXACT study. Canadian Journal of Cardiology 2014;30(10 Suppl 1):S118-9.

\section{Tsuyuki 2016 - RxEACH \{published data only\}}

Al Hamarneh YN, Hemmelgarn BR, Hassan I, Jones CA, Tsuyuki RT. The effectiveness of pharmacist interventions on cardiovascular risk in adult patients with type 2 diabetes: the multicentre randomized controlled RxEACH trial. Canadian Journal of Diabetes 2017;41(6):580-6.

Al Hamarneh YN, Tsuyuki RT, Jones CA, Manns B, Tonelli M, Scott-Douglass N, et al. Effectiveness of pharmacist interventions on cardiovascular risk in patients with CKD: a subgroup analysis of the randomized controlled RxEACH trial. American Journal of Kidney Diseases 2018;71(1):42-51.

* Tsuyuki RT, Al Hamarneh YN, Jones CA, Hemmelgarn BR. The effectiveness of pharmacist interventions on cardiovascular risk: the multicenter randomized controlled RxEACH trial. Journal of the American College of Cardiology 2016;67:2846-54.

Venkatesan 2012 \{published data only\}

Venkatesan R, Devi AS, Parasuraman S, Sriram S. Role of community pharmacists in improving knowledge and glycemic 
control of type 2 diabetes. Perspectives in Clinical Research 2012;3(1):26-31.

\section{Villeneuve 2010 \{published data only\}}

* Villeneuve J, Genest J, Blais L, Vanier MC, Lamarre D, Fredette M, et al. A cluster randomized controlled Trial to Evaluate an Ambulatory primary care Management program for patients with dyslipidemia: the TEAM study. Canadian Medical Association Journal 2010;182(5):447-55.

Villeneuve J, Lamarre D, Lussier MT. Physician-pharmacist collaborative care for dyslipidemia patients: knowledge and skills of community pharmacists. Journal of Continuing Education in the Health Professions 2009;29:201-8.

Villeneuve J, Lamarre D, Vanier MC. How to help patients manage their dyslipidemia: a primary care physicianpharmacist team intervention. Canadian Pharmaceutical Journal 2007;140:300-5.

\section{Weinberger 2002 \{published data only\}}

Weinberger M, Murray MD, Marrero DG, Brewer N, Lykens M, Harris LE, Tierney WM. Pharmaceutical care program for patients with reactive airways disease.. Am J Health Syst Pharm. 2001;58(9):791-6.

* Weinberger M, Murray MD, Marrero DG, Brewer N, Lykens M, Harris LE, et al. Effectiveness of pharmacist care for patients with reactive airways disease: a randomized controlled trial. JAMA 2002;288(13):1594-602.

\section{Yuksel 2010 \{published data only\}}

* Yuksel N, Majumdar SR, Biggs C, Tsuyuki RT. Community pharmacist-initiated screening program for osteoporosis: randomized controlled trial. Osteoporosis International 2010;21(3):391-8.

Yuksel N, Majumdar SR, Biggs C, Tsuyuki RT. Design of a randomized trial of a community pharmacist initiated screening and intervention program for osteoporosis. Canadian Pharmaceutical Journal 2006;139(2):50-1.

\section{References to studies excluded from this review}

\section{Ahrens 2003 \{published data only\}}

Ahrens RA, Hower M, Best AM. Effects of Weight Reduction Interventions by Community Pharmacists. J Am Pharm Assoc 2003;43:583-9.

\section{Aleo 2014 \{published data only\}}

Aleo CL, Murchison AP, Dai Y, Hark LA, Mayro EL, Collymore B, et al. Improving eye care follow-up adherence in diabetic patients with ocular abnormalities: the effectiveness of patient contracts in a free, pharmacy-based eye screening. Public Health 2015;129:996-9.

* Aleo CL, Murchison AP, Hark LA, Dai Y, Mayro E, Leiby B, et al. Improving eye care follow-up adherence in patients with diabetes: the effectiveness of patient contracts in a communitybased eye screening. Investigative Ophthalmology and Visual Science 2014;55 (13):6094.

\section{Ammari 2013 \{published data only\}}

Ammari WG, Chrystyn H. Optimizing the inhalation flow and technique through metered dose inhalers of asthmatic adults and children attending a community pharmacy. Journal of Asthma 2013;50(5):505-13.

\section{Anderson 1995 \{published data only\}}

Anderson C. A controlled study of the effect of a health promotion training scheme on pharmacists' advice about smoking cessation. Journal of Social and Administrative Pharmacy 1995;12(3):115-24.

\section{Anderson 2003 \{published data only\}}

Anderson C. Pharmacists' role in asthma. Pharmacy in practice 2003;16:300.

\section{Armour 2004 \{published data only\}}

Armour CL, Taylor SJ, Hourihan F, Smith C, Krass I. Implementation and evaluation of Australian pharmacists' diabetes care services. Journal of the American Pharmacists Association: JAPhA 2004;44(4):455-66.

\section{Armour 2013 \{published data only\}}

Armour CL, Reddel HK, LeMay KS, Saini B, Smith LD, BosnicAnticevich SZ, et al. Feasibility and effectiveness of an evidencebased asthma service in Australian community pharmacies: a pragmatic cluster randomized trial. Journal of Asthma 2013;50(3):302-9.

Basheti 2005 \{published data only\}

Basheti IA, Reddel HK, Armour CL, Bosnic-Anticevich SZ. Counseling about turbuhaler technique: needs assessment and effective strategies for community pharmacists. Respiratory Care 2005;50(5):617-23.

Bauld 2009 \{published data only\}

Bauld L, Chesterman J, Ferguson J, Judge K. A comparison of the effectiveness of group-based and pharmacy-led smoking cessation treatment in Glasgow. Addiction 2009;104(2):308-16.

\section{Bernsten 2001 \{published data only\}}

Bernsten C, Bjorkman I, Caramona M, Crealey G, Frokjaer F, Grundberger $\mathrm{E}$, et al. Improving the well-being of elderly patients via community pharmacy-based provision of pharmaceutical care: a multi-centre study in seven European countries. Drugs and Aging 2001;18(1):63-77.

\section{Bock 2010 \{published data only\}}

Bock BC, Hudmon KS, Christian J, Graham AL, Bock FR. A tailored intervention to support pharmacy-based counseling for smoking cessation. Nicotine \& Tobacco Research 2010;12(3):217-25

\section{Butt 2016 \{published data only\}}

Butt M, Mhd Ali A, Bakry MM, Mustafa N. Impact of a pharmacist led diabetes mellitus intervention on $\mathrm{HbAlc}$, medication adherence and quality of life: a randomised controlled study. Saudi Pharmaceutical Journal 2016;24:40-8. 
Chabot 2003 \{published data only\}

Chabot I, Moisan J, Gregoire JP, Milot A. Pharmacist intervention program for control of hypertension. Annals of Pharmacotherapy 2003;37(9):1186-93.

\section{Chalker 2002 \{published data only\}}

${ }^{*}$ Chalker J, Chuc NT, Falkenberg T, Tomson G. Private pharmacies in Hanoi, Vietnam: a randomized trial of a 2-year multi-component intervention on knowledge and stated practice regarding ARI, STD and antibiotic/steroid requests. Tropical Medicine \& International Health 2002;7(9):803-10.

Chuc NT, Larsson M, Do NT, Diwan VK, Tomson GB, Falkenberg T. Improving private pharmacy practice: a multi-intervention experiment in Hanoi, Vietnam. Journal of Clinical Epidemiology 2002;55:1148-55.

\section{Cody 1998 \{published data only\}}

Cody M, McCombs JS, Parker JP. The Kaiser Permanente/USC Patient Consultation Study: change in quality of life. American Journal of Health-system Pharmacy 1998;55:2615-20.

\section{Correr 2009 \{published data only\}}

Correr CJ, Pontarolo R, Wiens A, Rossignoli P, Melchiors AC, Radominski R, et al. Economic evaluation of pharmacotherapeutic follow-up in type 2 diabetes mellitus patients in community pharmacies. Arquivos Brasileiros de Endocrinologia e Metabologia 2009;53(7):825-33.

\section{Crawford 2013 \{published data only\}}

Crawford ND, Amesty S, Rivera AV, Harripersaud K, Turner A, Fuller CM. Community impact of pharmacy-randomized intervention to improve access to syringes and services for injection drug users. Health Education \& Behavior 2014;41:397-405.

* Crawford ND, Amesty S, Rivera AV, Harripersaud K, Turner A, Fuller CM. Randomized, community-based pharmacy intervention to expand services beyond sale of sterile syringes to injection drug users in pharmacies in New York City. American Journal of Public Health 2013;103(9):1579-82.

\section{Denig 2003 \{published data only\}}

Denig P, Onnes B, Haaijer-Ruskamp FM. Improvement remains forthcoming. Effect of a peer review programme about the treatment of asthma on quality of life in patients [Verbetering Blijft nog uit. Effect vam eem FTO-programma over asthma op kwaliteit van leven bij patienten]. Pharmceutisch Weekblad 2003;138:1276-81.

\section{DeRemer 2008 \{published data only\}}

DeRemer CE, VanLandingham J, Carswell J, Killough D. Pharmacy outreach education program in local community. American Journal of Pharmaceutical Education 2008;72(4):94

\section{De Vera 2014 \{published data only\}}

De Vera MA, Sadatsafavi M, Tsao NW, Lynd LD, Lester R, Gastonguay $L$, et al. Empowering pharmacists in asthma management through interactive SMS (EmPhAsIS): study protocol for a randomized controlled trial. Trials 2014;15:488.

\section{de Vries 2010 \{published data only\}}

de Vries TW, van den Berg PB, Duiverman EJ, de Jong-van den Berg LT. Effect of a minimal pharmacy intervention on improvement of adherence to asthma guidelines. Archives of Disease in Childhood 2010;95(4):302-4.

DiDonato 2013 \{published data only\}

DiDonato KL, May JR, Lindsey CC. Impact of wellness coaching and monitoring services provided in a community pharmacy. Journal of the American Pharmacists Association: JAPhA 2013;53(1):14-21.

\section{Ditusa 2001 \{published data only\}}

Ditusa L, Luzier AB, Brady PG, Reinhardt RM, Snyder BD. A pharmacy-based approach to cholesterol management. American Journal of Managed Care 2001;7(10):973-9.

Ekedahl 2008 \{published data only\}

Ekedahl A, Oskarsson V, Sundberg B, Gustafsson V, Lundberg T, Gullberg B. Impact of postal and telephone reminders on pick-up rates of unclaimed e-prescriptions. Pharmacy World \& Science 2008;30(5):503-8.

\section{Fera 2008 \{published data only\}}

Fera T, Bluml BM, Ellis WM. Diabetes Ten City Challenge: final economic and clinical results. Journal of the American Pharmacists Association : JAPhA 2009;49(3):383-91.

* Fera T, Bluml BM, Ellis WM, Schaller CW, Garrett DG. The Diabetes Ten City Challenge: interim clinical and humanistic outcomes of a multi-site community pharmacy diabetes care program. Journal of the American Pharmacists Association: JAPhA 2008;48(2):181-90.

\section{Fikri-Benbrahim 2012 \{published data only\}}

Fikri-Benbrahim N, Faus MJ, Martinez-Martinez F, Alsina DG, Sabater-Hernandez D. Effect of a pharmacist intervention in Spanish community pharmacies on blood pressure control in hypertensive patients. American Journal of Health-System Pharmacy 2012;69(15):1311-8.

Fornos 2006 \{published data only\}

Fornos JA, Andres NF, Andres JC, Guerra MM, Egea B. A pharmacotherapy follow-up program in patients with type-2 diabetes in community pharmacies in Spain. Pharmacy World \& Science 2006;28(2):65-72.

Fuller 2007 \{published data only\}

Fuller CM, Galea S, Caceres W, Blaney S, Sisco S, Vlahov D. Multilevel community-based intervention to increase access to sterile syringes among injection drug users through pharmacy sales in New York City. American Journal of Public Health 2007;97(1):117-24

\section{Garcao 2002 \{published data only\}}

Garcao JA, Cabrita J. Evaluation of a pharmaceutical care program for hypertensive patients in rural Portugal. Journal of the American Pharmaceutical Association 2002;42(6):858-64. 


\section{Goeree 2013 \{published data only\}}

Goeree R, von Keyserlingk C, Burke N, He J, Kaczorowski J, Chambers L, et al. Economic appraisal of a community-wide cardiovascular health awareness program. Value in Health 2013;16(1):39-45.

\section{Gorgas 2012 \{published data only\}}

Gorgas Torner MQ, Paez VF, Camos RJ, de Puig CE, Jolonch SP, Homs $P E$, et al. Integrated pharmaceutical care programme in patients with chronic diseases. Farmacia Hospitalaria 2012;36(4):229-39.

\section{Grainger-Rousseau 1997 \{published data only\}}

Grainger-Rousseau TJ, Miralles MA, Hepler CD, Segal R, Doty RE, Ben-Joseph R. Therapeutic outcomes monitoring: application of pharmaceutical care guidelines to community pharmacy. Journal of the American Pharmaceutical Association 1997;NS37(6):647-61.

\section{Green 2008 \{published data only\}}

Green BB, Anderson ML, Ralston JD, Catz S, Fishman PA, Cook AJ. Patient ability and willingness to participate in a webbased intervention to improve hypertension control. Journal of Medical Internet Research 2011;13(1):e1.

Green BB, Anderson ML, Ralston JD, Catz SL, Cook AJ. Blood pressure 1 year after completion of web-based pharmacist care. JAMA Internal Medicine 2013;173(13):1250-2.

* Green BB, Cook AJ, Ralston JD, Fishman PA, Catz SL, Carlson J, et al. Effectiveness of home blood pressure monitoring, web communication, and pharmacist care on hypertension control: a randomized controlled trial. JAMA 2008;299(24):2857-67.

\section{Haga 2017 \{published data only\}}

Haga SB, Moaddeb J, Mills R, Voora D. Assessing feasibility of delivering pharmacogenetic testing in a community pharmacy setting. Pharmacogenomics 2017;18:327-35.

\section{Herborg 2001 \{published data only\}}

* Herborg H, Soendergaard B, Froekjaer B, Fonnesbaek L, Jorgensen T, Hepler CD, et al. Improving drug therapy for patients with asthma - part 1: patient outcomes. Journal of the American Pharmaceutical Association 2001;41(4):539-50.

Herborg H, Soendergaard B, Jorgensen T, Fonnesbaek L, Hepler CD, Holst $\mathrm{H}$, et al. Improving drug therapy for patients with asthma - part 2: use of antiasthma medications. Journal of the American Pharmaceutical Association 2001;41(4):551-9.

\section{Kaczorowski 2008 \{published data only\}}

Kaczorowski J, Chambers LW, Dolovich L, Paterson JM, Karwalajtys T, Gierman T, et al. Improving cardiovascular health at population level: 39 community cluster randomised trial of Cardiovascular Health Awareness Program (CHAP). BMJ 2011;342:442.

* Kaczorowski J, Chambers LW, Karwalajtys T, Dolovich L, Farrell B, McDonough B, et al. Cardiovascular Health Awareness Program (CHAP): a community cluster-randomised trial among elderly Canadians. Preventive Medicine 2008;46(6):537-44.

\section{Karwalajtys 2009 \{published data only\}}

Karwalajtys T, Kaczorowski J, Hutchison B, Myers MG, Sullivan SM, Chambers LW, et al. Blood pressure variability and prevalence of hypertension using automated readings from multiple visits to a pharmacy-based community-wide programme. Journal of Human Hypertension 2009;23(9):585-9.

Kradjan 1999 \{published data only\}

Kradjan WA, Schulz R, Christensen DB, Stergachis A, Sullivan S, Fullerton DS, et al. Patients' perceived benefit from and satisfaction with asthma-related pharmacy services. Journal of the American Pharmaceutical Association (Washington,D.C. : 1996) 1999;39(5):658-66

\section{Krass 2011 \{published data only\}}

Krass I. Optimising pharmacy support in type 2 diabetes. Australian Journal of Pharmacy 2010;91(1086):39-40.

* Krass I, Mitchell B, Song YJ, Stewart K, Peterson G, Hughes J, et al. Diabetes medication assistance service stage 1 : impact and sustainability of glycaemic and lipids control in patients with type 2 diabetes. Diabetic Medicine 2011;28(8):987-93.

\section{Kritikos 2007 \{published data only\}}

Kritikos V, Armour CL, Bosnic-Anticevich SZ. Interactive smallgroup asthma education in the community pharmacy setting: a pilot study. Journal of Asthma 2007;44(1):57-64.

\section{Kumar, 2009 \{published data only\}}

Kumar A, Adepu R, Parthasarathi G, Mahesh PA. Impact of community pharmacist provided patient education in asthma patients on treatment outcomes - a study. Indian Journal of Pharmaceutical Education and Research 2009;43:125-33.

\section{Lalonde 2008 - PRoFIL \{published data only\}}

Beaunoyer S, Dupuis S, Dumoulin-Charette A, Mouchbahani M, Daigneault AM, Lord A, et al. The impact of ProFiL program on the progression of chronic kidney disease (CKD) and its risk factors: an interim analysis. Journal of Population Therapeutics and Clinical Pharmacology 2014;21(1):e126-7.

Lalonde L, Letendre S, Clement V, Lord A, Bell R, Mouchbahani M. ProFiL, a training-and-communication network program in nephrology for community pharmacists: Impact on knowledge, clinical competences, quality of medication use and clinical variables. International Journal of Clinical Pharmacy 2015;37:423-4.

* Lalonde L, Normandeau M, Lamarre D, Lord A, Berbiche D, Corneille $L$, et al. Evaluation of a training and communicationnetwork nephrology program for community pharmacists. Pharmacy World \& Science 2008;30(6):924-33.

Lalonde L, Quintana-Barcena P, Lord A, Bell R, Clement V, Daigneault AM, et al. Community pharmacist training-andcommunication network and drug-related problems in patients with CKD: a multicenter, cluster-randomized, controlled trial. American Journal of Kidney Diseases 2017;70:386-96.

\section{Lugo de Ortellado 2007 \{published data only\}}

Lugo de Ortellado G, Bittner MR, Chavez H, Perez S. Implementation of a pharmaceutical care program for the 
detection of hypertension and drug therapy to be followed up in community pharmacies [Implementacion de un programa de atencion farmaceutica en farmacias comunitarias pas la deteccion de la hipertension arterial y su seguimiento farmacoterpeutico]. Latin American Journal of Pharmacy 2007;26:590-5

\section{Manfrin 2015 \{published data only\}}

* Manfrin A, Thomas T, Krska J. Randomised evaluation of the Italian medicines use review provided by community pharmacists using asthma as a model (RE I-MUR). BMC Health Services Research 2015;15:171.

Manfrin A, Thomas T, Krska J. Symptom control and adherence are major issues for asthmatic patients: can they be improved and are they linked?. Pharmacoepidemiology and Drug Safety 2016;25(S2):18-9.

Manfrin A, Tinelli M, Thomas T, Krska J. A cluster randomised control trial to evaluate the effectiveness and cost-effectiveness of the Italian medicines use review (I-MUR) for asthma patients. BMC Health Services Research 2017;17:300.

\section{Mangiapane 2005 \{published data only\}}

Mangiapane S, Schulz M, Muhlig S, Ihle P, Schubert I, Waldmann HC. Community pharmacy-based pharmaceutical care for asthma patients. Annals of Pharmacotherapy 2005;39(11):1817-22.

\section{Marra 2012 \{published data only\}}

Marra CA, Cibere J, Grubisic M, Grindrod KA, Gastonguay L, Thomas JM, et al. Pharmacist-initiated intervention trial in osteoarthritis: a multidisciplinary intervention for knee osteoarthritis. Arthritis Care \& Research 2012;64(12):1837-45.

\section{Marrero 2006 \{published data only\}}

Marrero W, Hernandez L, Garcia R, Gutirrez L. Immunization program against influenza for adults 65 years or older at a community pharmacy in Puerto Rico [Programa de Immunizacion contra la Influenza para adultos de 65 anos o mas en una farmacia de comunidad en Puerto Rico]. Puerto Rico Health Sciences Journal 2006;25(1):35-42.

\section{Meijer 2005 \{published data only\}}

Meijer WM, de Smit DJ, Jurgens RA, de Jon-van den Berg LT. Improved periconceptional use of folic acid after patient education in pharmacies: promising results of a pilot study in the Netherlands. International Journal of Pharmacy Practice 2005;13:47-51.

\section{Michie 2014 \{published data only\}}

Michie L, Cameron S T, Glasier A, Larke N, Muir A, Lorimer A. Pharmacy-based interventions for initiating effective contraception following the use of emergency contraception: a pilot study. Contraception 2014;90:447-53.

\section{Michiels 2017a \{published data only\}}

Michiels Y, Tilleul P, Mechin H, Hammes F. Impact of a community pharmacy-based information protocol on multiple sclerosis patients' adherence to treatment with dimethyl fumarate: TECPHIE, a randomized study vs usual practice. Multiple Sclerosis Journal 2017;23(3 Suppl 1):922.
Noor 2016 \{published data only\}

* Noor ZM, Smith AJ, Smith SS, Nissen LM. A feasibility study: use of actigraph to monitor and follow-up sleep/wake patterns in individuals attending community pharmacy with sleeping disorders. Journal of pharmacy \& bioallied sciences 2016;8:173-80.

Noor ZM, Smith AJ, Smith SS, Nissen LM. A study protocol: a community pharmacy-based intervention for improving the management of sleep disorders in the community settings. $B M C$ Health Services Research 2014;14:74.

\section{O'Dwyer 2016 \{published data only\}}

O'Dwyer SM, MacHale E, Sulaiman I, Holmes M, Hughes C, D'Arcy S, et al. The effect of providing feedback on inhaler technique and adherence from an electronic audio recording device, INCA, in a community pharmacy setting: study protocol for a randomised controlled trial. Trials 2016;17:226.

\section{Obarcanin 2015 \{published data only\}}

Obarcanin E, Kruger M, Muller P, Nemitz V, Schwender H, Hasanbegovic $S$, et al. Pharmaceutical care of adolescents with diabetes mellitus type 1: the DIADEMA study, a randomized controlled trial. International Journal of Clinical Pharmacy 2015;37:790-8.

\section{Olivera 2016 \{published data only\}}

Olivera CM, Vianna EO, Bonizio RC, de Menezes MB, Ferraz E, Cetlin AA, et al. Asthma self-management model: randomized controlled trial. Health Education Research 2016;31:639-52.

\section{Phimarn 2017 \{published data only\}}

* Phimarn W, Paktipat P, Pansiri K, Klabklang P, Duangjanchot P, Tongkul A. Effect of weight control counselling in overweight and obese young adults. Indian Journal of Pharmaceutical Sciences 2017;79:35-41.

Phimarn W, Pianchana P, Limpikanchakovit P, Suranart K, Supapanichsakul S, Narkgoen A, et al. Thai community pharmacist involvement in weight management in primary care to improve patient's outcomes. International Journal of Clinical Pharmacy 2013;35(6):1208-17.

\section{Podhipak 1993 \{published data only\}}

Podhipak A, Varavithya W, Punyaratabandhu P, Vathanophas K, Sangchai R. Impact of an educational program on the treatment practices of diarrheal diseases among pharmacists and drugsellers. Southeast Asian Journal of Tropical Medicine and Public Health 1993;24(1):32-9.

\section{Prokhorov 2010 \{published data only\}}

Prokhorov AV, Humon KS, Marani S, Foxhall L, Ford KH, Luca NS, et al. Engaging physicians and pharmacists in providing smoking cessation counseling. Archives of Internal Medicine 2010;170(18):1640-6.

\section{Ratanajamit 2002 \{published data only\}}

Ratanajamit C, Chongsuvivatwong V, Geater AF. A randomized controlled educational intervention on emergency contraception among drugstore personnel in southern 
Thailand. Journal of the American Medical Womens Association 2002;57(4):196-9.

\section{Rickles 2006 \{published data only\}}

Rickles NM, Svarstad BL, Statz-Paynter JL, Taylor LV, Kobak KA. Improving patient feedback about and outcomes with antidepressant treatment: a study in eight community pharmacies. Journal of the American Pharmacists Association: JAPhA 2006;46(1):25-32.

\section{Rouleau 2007 \{published data only\}}

Rouleau R, Beauchesne MF, Laurier C. Impact of a continuing education program on community pharmacists' interventions and asthma medication use: a pilot study. Annals of Pharmacotherapy 2007;41(4):574-80.

\section{Rubio-Valera 2009 \{published data only\}}

Rubio-Valera M, March PM, Fernandez A, Penarrubia-Maria MT, Trave P, Lopez Del HY, et al. Evaluation of a pharmacist intervention on patients initiating pharmacological treatment for depression: a randomized controlled superiority trial. European Neuropsychopharmacology 2013;23(9):1057-66.

* Rubio-Valera M, Serrano-Blanco A, Trave P, PenarrubiaMaria MT, Ruiz M, Pujol MM. Community pharmacist intervention in depressed primary care patients (PRODEFAR study): randomized controlled trial protocol. BMC Public Health 2009;9:284

\section{Saini 2008 \{published data only\}}

* Saini B, Filipovska J, Bosnic-Anticevich S, Taylor S, Krass I, Armour C. An evaluation of a community pharmacy-based rural asthma management service. Australian Journal of Rural Health 2008;16(2):100-8.

Saini B, Krass I, Armour C. Development, implementation, and evaluation of a community pharmacy-based asthma care model. Annals of Pharmacotherapy 2004;38(11):1954-60.

\section{Saji 2012 \{published data only\}}

Saji M, Jiju AJ, Sundaran S. Study on the impact of patient counseling on the quality of life and pulmonary function of asthmatic patients. International Journal of Pharmacy and Pharmaceutical Sciences 2012;4:300-4.

\section{Santos 2010 \{published data only\}}

Santos DO, Martins MC, Cipriano SL, Pinto RM, Cukier A, Stelmach R. Pharmaceutical care for patients with persistent asthma: assessment of treatment compliance and use of inhaled medications. Jornal Brasileiro De Pneumologia: Publicacao Oficial Da Sociedade Brasileira De Pneumologia E Tisilogia 2010;36(1):14-22.

\section{Sarayani 2012 \{published data only\}}

Sarayani A, Rashidian A, Gholami K, Torkamandi H, Javadi M. Efficacy of continuing education in improving pharmacists' competencies for providing weight management service: three-arm randomized controlled trial. Journal of Continuing Education in the Health Professions 2012;32(3):163-73.

\section{Sarkadi 2004 \{published data only\}}

* Sarkadi A, Rosenqvist U. Experience-based group education in type 2 diabetes: a randomised controlled trial. Patient Education \& Counseling 2004;53(3):291-8.

Sarkadi A, Veg A, Rosenqvist U. The influence of participant's self-perceived role on metabolic outcomes in a diabetes group education program. Patient Education \& Counseling 2005;58(2):137-45.

\section{Sinclair 1998 \{published data only\}}

Sinclair HK, Bond CM, Lennox AS, Silcock J, Winfield AJ, Donnan PT. Training pharmacists and pharmacy assistants in the stage-of-change model of smoking cessation: a randomised controlled trial in Scotland. Tobacco Control 1998;7(3):253-61.

\section{Sperandio 2012 \{published data only\}}

Sperandio da Silva GM, Chambela MC, Sousa AS, Sangenis LH, Xavier SS, Costa AR, et al. Impact of pharmaceutical care on the quality of life of patients with Chagas disease and heart failure: randomized clinical trial. Trials 2012;13:244.

\section{Stergachis 2002 \{published data only\}}

Stergachis A, Gardner JS, Anderson MT, Sullivan SD. Improving pediatric asthma outcomes in the community setting: does pharmaceutical care make a difference?. Journal of the American Pharmaceutical Association 2002;42(5):743-52.

\section{Suppapitiporn 2005 \{published data only\}}

Suppapitiporn S, Chindavijak B, Onsanit S. Effect of diabetes drug counseling by pharmacist, diabetic disease booklet and special medication containers on glycemic control of type 2 diabetes mellitus: a randomized controlled trial. Journal of the Medical Association of Thailand 2005;88 Suppl 4:S134-41.

Taskila 2012 \{published data only\}

Taskila T, Macaskill S, Coleman T, Etter JF, Patel M, Clarke S, Bridson R, Aveyard P. A randomised trial of nicotine assisted reduction to stop in pharmacies - the RedPharm study. BMC Public Health 2012;12(12):182.

Thavorn 2008 \{published data only\}

Thavorn K, Chaiyakunapruk N. A cost-effectiveness analysis of a community pharmacist-based smoking cessation programme in Thailand. Tobacco Control 2008;17(3):177-82.

\section{Tobari 2010 \{published data only\}}

Tobari H, Arimoto T, Shimojo N, Yhara K, Noda H, Yamagishi K, et al. Physician-pharmacist cooperation program for blood pressure control in patients with hypertension: a randomized-controlled trial. American Journal of Hypertension 2010;10:1144-52.

\section{Tsuyuki 2015 \{published data only\}}

Tsuyuki RT, Houle SK, Charrois TL, Kolber MR, Rosenthal MM, Lewanczuk R, et al. Randomized trial of the effect of pharmacist prescribing on improving blood pressure in the community: the Alberta clinical trial in optimizing hypertension (RXACTION). Circulation 2015;132:93-100. 
Tumwikirize 2004 \{published data only\}

Tumwikirize WA, Ekwaru PJ, Mohammed K, Ogwal-Okeng JW, Aupont $\mathrm{O}$. Impact of a face-to-face educational intervention on improving the management of acute respiratory infections in private pharmacies and drug shops in Uganda. East African Medical Journal 2004;Suppl:S25-32.

\section{Usami 2009 \{published data only\}}

Usami T, Hashiguchi M, Kouhara T, Ishii A, Nagata T, Mochizuki M. Impact of community pharmacists advocating immunization on influenza vaccination rates among the elderly. Yakugaku Zasshi - Journal of the Pharmaceutical Society of Japan 2009;129(9):1063-8.

\section{Van de Steeg-van 2011 \{published data only\}}

Van de Steeg-van Gompel CH, Wensing M, De Smet PA. Implementation of a pharmacist-led intervention to enhance statin prescribing for secondary prevention in primary care: a cluster randomized trial. European Journal of Preventive Cardiology 2012;19(2):169-76.

* Van de Steeg-van Gompel CH, Wensing M, De Smet PA. Implementation of patient education at first and second dispensing of statins in Dutch community pharmacies: the sequel of a cluster randomized trial. BMC Health Services Research 2011;11:313, 2011.

Van de Steeg-van Gompel CH, Wensing M, De Smet PA. Implementation of patient education at first and second dispensing of statins in Dutch community pharmacies: the sequel of a cluster randomized trial. Pharmaceutisch Weekblad 2012;147:115-21.

\section{Viens 2007 \{published data only\}}

Viens C, Leclerc G, Moisan S, Lebeau A. Assess the impact of the health education program prescription drugs: yes...no....maybe [Efficacite d'un programme d'eduction des aines a la sante]. Canadian Journal of Public Health 2007;98(4):301-5.

\section{Wang 2013 \{published data only\}}

Wang J, Ford LJ, Wingate L, Uroza SF, Jaber N, Smith CT, et al. Effect of pharmacist intervention on herpes zoster vaccination in community pharmacies. Journal of the American Pharmacists Association: JAPhA 2013;53(1):46-53.

\section{Watson 2002 \{published data only\}}

Watson MC, Bond CM, Grimshaw JM, Mollison J, Ludbrook A, Walker AE. Educational strategies to promote evidence-based community pharmacy practice: a cluster randomized controlled trial (RCT). Family Practice 2002;19(5):529-36.

\section{Westrick 2016 \{published data only\}}

Westrick SC, Owen J, Hagel H, Owensby JK, Lertpichitkul T. Impact of the RxVaccinate program for pharmacy-based pneumococcal immunization: a cluster-randomized controlled trial. Journal of the American Pharmacists Association: JAPhA 2016;56:29-36.e1.

\section{Wilson 2004 \{published data only\}}

Wilson SJ, MacLellan E, Cox JL, Meek W, Monette K, Morash T, et al. A pilot study evaluating the feasibility of monitoring oral anticoagulant therapy with point of care testing in a community pharmacy. Canadian Journal of Hospital Pharmacy 2004;57:158-64.

\section{Young 2012 \{published data only\}}

Young HN, Havican SN, Griesbach S, Thorpe JM, Chewning BA, Sorkness CA. Patient and phaRmacist telephonic encounters (PARTE) in an underserved rural patient population with asthma: results of a pilot study. Telemedicine Journal and Ehealth 2012;18(6):427-33.

\section{References to ongoing studies}

Davis 2016 \{published data only\}

Davis E, Marra C, Gamble JM, Farrell J, Lockyer J, FitzGerald JM, et al. Effectiveness of a pharmacist-driven intervention in COPD (EPIC): study protocol for a randomized controlled trial. Trials 2016;17:502.

\section{Ekers 2017 \{published data only\}}

Ekers D, Littlewood L. Community pharmacies mood intervention study (CHEMIST). www.isrctn.com/ ISRCTN11290592. [DOI: 10.1186/ISRCTN11290592]

\section{Michiels 2017 \{published data only\}}

* Michiels Y, Bugnon O, Chicoye A, Verges B, Moisan C, Mechin H, et al. Impact of a community pharmacy-based information program on type 2 diabetic patients' adherence to their oral treatment: IPhODia, a cluster randomized study vs usual practice. International Journal of Clinical Pharmacy 2016;38(5):1342.

Michiels Y, Bugnon O, Chicoye A, Verges B, Moisan C, Mechin H, et al. Impact of a community pharmacy-based information program on type 2 diabetic patients' adherence to their oral treatment: IPhODia, a cluster randomized study vs usual practice. Value in Health 2016;19(7):A675-6.

\section{Porteous 2013 \{published data only\}}

Porteous T, Wyke S, Smith S, Bond C, Francis J, Lee AJ, et al. 'Help for Hay Fever', a goal-focused intervention for people with intermittent allergic rhinitis, delivered in Scottish community pharmacies: study protocol for a pilot cluster randomized controlled trial. Trials 2013;14:217.

\section{Spadaro 2010 \{published data only\}}

Spadaro F, Falzone R, De Bastiani E, Ferri M, Roni R, et al. Towards an involvement of pharmacies in the integrated management of patients with heart failure. The protocol of the GIFT project. Giornale Italiano di Farmacia Clinica 2010;24(2):88-98.

\section{Additional references}

\section{Albrecht 2013}

Albrecht L, Archibald M, Arseneau D, Scott SD. Development of a checklist to assess the quality of reporting of knowledge translation interventions using the Workgroup for Intervention Development and Evaluation Research (WIDER) recommendations. Implementation Science 2013;8(52):1748-52. 


\section{Anderson 2007}

Anderson S. Community pharmacy and public health in Great Britain, 1936 to 2006: how a phoenix rose from the ashes. Journal of Epidemiology and Community Health 2007;61:844-8.

\section{Bandura 1986}

Bandura A. Social Foundations of Thought and Action: A Social Cognitive Theory. Prentice-Hall, 1986.

\section{Benrimoj 2004}

Benrimoj SI, Frommer MS. Community pharmacy in Australia. Australian Health Review 2004;28(2):238-46.

\section{Blouin 2017}

Blouin RA, Adams ML. The role of the pharmacist in health care: expanding and evolving. North Carolina Medical Journal 2017;78:165-7.

\section{Borrelli 2011}

Borrelli B. The assessment, monitoring, and enhancement of treatment fidelity in public health clinical trials. Journal of Public Health Dentistry 2011;71:S51-72.

\section{Brackett 2015}

Brackett A, Butler M, Chapman L. Using motivational interviewing in the community pharmacy to increase adult immunization readiness: a pilot evaluation. Journal of the American Pharmacists Association 2015;55(2):182-6.

\section{Brown 2016}

Brown TJ, Todd A, O'Malley C, Moore HJ, Husband AK, Bambra C, et al. Community pharmacy-delivered interventions for public health priorities: a systematic review of interventions for alcohol reduction, smoking cessation and weight management, including meta-analysis for smoking cessation. BMJ Open 2016;6:e009828. [10.1136/bmjopen-2015- 009828]

\section{Buss 2018}

Buss V, Shield A, Kosari S, Naunton M. The impact of clinical services provided by community pharmacies on the Australian healthcare system: a review of the literature. Journal of Pharmaceutical Policy and Practice 2018;11:22.

\section{Cane 2012}

Cane J, O'Connor D, Michie S. Validation of the theoretical domains framework for use in behaviour change and implementation. Implementation Science 2012;7:37.

\section{Chan 2006}

Chan XH, Wuliji T. Global pharmacy workforces and migration report: a call to action. Available at www.fip.org/files/fip/ publications/PharmacyWorkforceMigration.pdf 2006.

\section{Chandler 2013}

Chandler J, Churchill R, Higgins J, Lasserson T, Tovey D. Methodological standards for the conduct of new Cochrane intervention reviews. www.editorial-unit.cochrane.org/ sites/editorial-unit.cochrane.org/files/uploads/ MECIR_conduct_standards\%202.3\%2002122013.pdf (accessed 5 March 2014); Vol. version 2.3 .

\section{Cheema 2014}

Cheema E, Sutliffe P, Singer DR. The impact of interventions by pharmacists in community pharmacies on control of hypertension: a systematic review and meta-analysis of randomized controlled trials. British Journal of Clinical Pharmacology 2014;78(6):1238-47.

\section{Craig 2008}

Craig P, Dieppe P, Macintyre S, Michie S, Nazareth I, Petticrew M. Developing and evaluating complex interventions: the new Medical Research Council guidance. BMJ 2008;337:1665.

\section{Crombie 2005}

Crombie I, Irvine L, Elliott L, Wallace H. Closing the health inequalities gap: an international perspective. World Health Organisation Europe 2005.

\section{De Barra 2018}

de Barra M, Scott CL, Scott NW, Johnston M, de Bruin M, Nkansah N, et al. Pharmacist services for non-hospitalised patients. Cochrane Database of Systematic Reviews 2018, Issue 9. [DOI: 10.1002/14651858.CD013102]

\section{Deters 2018}

Deters MA, Laven A, Castejon A, Doucette WR, Ev LS, Krass I, et al. Effective interventions for diabetes patients by community pharmacists: a meta-analysis of pharmaceutical care components. Annals of Pharmacotherapy 2018;52(2):198-211.

\section{DOH 2005}

Department of Health. Implementing the new Community Pharmacy Contractual Framework (draft). webarchive.nationalarchives.gov.uk/20130123204454/. London, 2005.

\section{Eades 2011}

Eades CE, Ferguson JS, O'Carroll RE. Public health in community pharmacy: a systematic review of pharmacist and consumer views. BMC Public Health 2011;11:582-94.

\section{Eldridge 2012}

Eldridge S, Kerry S. A Practical Guide to Cluster Randomized Trials in Health Services Research. Chichester: Wiley, 2013.

\section{Endnote 2013 [Computer program]}

Endnote. EndNote Collect, Collaborate, Create from Anywhere x6. Thomson Reuters, 2013.

\section{EPOC 2017a}

Cochrane Effective Practice and Organisation of Care Review Group (EPOC). What study designs should be included in an EPOC review and what should they be called? available at epoc.cochrane.org/sites/epoc.cochrane.org/files/public/ uploads/Resources-forauthors accessed 2 December 2017.

\section{EPOC 2017b}

Cochrane Effective Practice and Organisation of Care Review Group (EPOC). Good practice data extraction form. available at epoc.cochrane.org/resources/epoc-resources-reviewauthors\#conducting accessed 2 December 2017. 


\section{EPOC 2017c}

Cochrane Effective Practice, Organisation of Care (EPOC). Suggested risk of bias criteria for EPOC reviews. EPOC Resources for review authors 2017: epoc.cochrane.org/sites/ epoc.cochrane.org/files/public/uploads/Resources-for-authors (accessed 17 May 2019).

\section{EPOC 2017d}

Cochrane Effective Practice, Organisation of Care (EPOC). EPOC worksheets for preparing a Summary of Findings (SoF) table using GRADE. EPOC Resources for review authors 2017: epoc.cochrane.org/resources/epoc-resources-review-authors (accessed 29 September 2018).

\section{Friedberg 2010}

Friedberg JP, Lipsitz SR, Natarajan S. Challenges and recommendations for blinding in behavioral interventions illustrated using a case study of a behavioral intervention to lower blood pressure. Patient Education and Counselling 2010;78:5-11.

\section{Garcia-Cardenas 2016}

Garcia-Cardenas V, Armour C, Benrimoj SI, Martinez-Martinez F, Rotta I, Fernandez-Llimos F. Pharmacists' interventions on clinical asthma outcomes: a systematic review. European Respiratory Journal 2016;47(4):1134-43.

\section{Gordon 2011}

Gordon J, Watson M, Avenell A. Lightening the load? A systematic review of community based weight management interventions. Obesity Reviews 2011;12(11):897-911.

\section{GRADE 2013}

Schünemann H, Brożek J, Guyatt G, Oxman A. Handbook for grading the quality of evidence and the strength of recommendations using the GRADE approach (updated October 2013). GRADE Working Group, 2013. Available from gdt.guidelinedevelopment.org/app/handbook/handbook.html. Cochrane.

\section{Gums 2016}

Gums T, Carter B, Foster E. Cluster randomized trials for pharmacy practice research. International Journal of Clinical Pharmacy 2016;38(3):607-14.

\section{Herdman 2011}

Herdman M, Gudex C, Lloyd A, Janssen M, Kind P, Parkin D, et al. Development and preliminary testing of the new fivelevel version of EQ-5D (EQ-5D-5L). Quality of Life Research 2011;20(10):1727-36.

\section{Higgins 2003}

Higgins JP, Thompson SG, Deeks JJ, Altman DG. Measuring inconsistency in meta-analyses. BMJ 2003;327(7414):557-60.

\section{Higgins 2011a}

Higgins JP, Altman DG, Gotzsche PC, Juni P, Moher D, Oxman AD, et al. The Cochrane Collaboration's tool for assessing risk of bias in randomised trials. BMJ 2011;343(9):d5928.

\section{Higgins 2011b}

Higgins JP, Deeks JJ, Altman DG (editors). Chapter 16: Special topics in statistics. In: Higgins JP, Green S, editor(s). Cochrane Handbook for Systematic Reviews of Interventions Version 5.1.0 (updated March 2011). The Cochrane Collaboration, 2011. Available from handbook.cochrane.org. The Cochrane Collaboration.

\section{Hoffmann 2014}

Hoffmann, TC, Gasziou PP, Milne R, Moher D, Barbour V, Johnston M, et al. Better reporting of interventions: template for intervention description and replication (TIDieR) checklist and guide. BMJ 2014;348:1687.

\section{Kessler 2003}

Kessler RC, Barker PR, Colpe LJ, Epstein JF, Gfroerer JC, Hiripi $\mathrm{E}$, et al. Screening for serious mental illness in the general population. Archives of General Psychiatry 2003;60(2):184-9.

\section{Lindsey 2017}

Lindsey L, Husband A, Steed L, Todd A. Helpful advice and hidden expertize: pharmacy users' experiences of community pharmacy accessibility. Journal of Public Health (Oxford, England) 2017;39(3):609-15.

\section{Michie 2008}

Michie S. What works and how? Designing more effective interventions needs answers to both questions. Addiction 2008;103(6):886-7.

\section{Michie 2010}

Michie S, Prestwich A. Are interventions theory-based? Development of a theory coding scheme. Health Psychology 2010;29(1):1-8.

\section{Miller 2012}

Miller WR, Rollnick S. Motivational Interviewing: Helping People Change. 3rd Edition. New York (NY): Guildford Press, 2012.

\section{Mossialos 2013}

Mossialos E, Naci H, Courtin E. Expanding the role of community pharmacists: policymaking in the absence of policy-relevant evidence?. Health Policy 2013;111(2):135-48.

\section{Mossialos 2015}

Mossialos E, Courtin E, Naci H, Benrimoj S, Bouvy M, Farris K, et al. From "retailers" to health care providers: transforming the role of community pharmacists in chronic disease management.. Health Policy 2015;119(5):628-39.

\section{NICE 2018}

National Institute for Health and Care Excellence. Community pharmacies: promoting health and well-being [NICE guideline (NG102)]. Available at www.nice.org.uk/guidance/ indevelopment/gid-ng10008 2018.

\section{Nkansah 2010}

Nkansah N, Mostovetsky O, Yu C, Chheng T, Beney J, Bond CM, et al. Effect of outpatient pharmacists' non-dispensing roles on patient outcomes and prescribing patterns. 
Cochrane Database of Systematic Reviews 2010, Issue 7. [DOI: 10.1002/14651858.CD000336.pub2]

\section{Norton 2007}

Norton PJ. Depression Anxiety and Stress Scales (DASS-21): psychometric analysis across four racial groups. Anxiety Stress Coping 2007;20(3):253-65.

\section{O'Cathain 2019}

O'Cathain A, Croot L, Sworn K, Duncan E, Rousseau N, Turner K, et al. Taxonomy of approaches to developing interventions to improve health: a systematic methods overview. Pilot and Feasibility Studies 2019;5:41.

\section{Orwin 1994}

Orwin RG. Evaluating coding decisions. In: Cooper H, Hedges LV editor(s). The Handbook of Research Synthesis. New York: Russel Sage Foundation, 1994:177-203.

\section{Pande 2013}

Pande S, Hiller JE, Nkansah N, Bero L. The effect of pharmacistprovided non-dispensing services on patient outcomes, health service utilisation and costs in low- and middle-income countries. Cochrane Database of Systematic Reviews 2013, Issue 2. [DOI: 10.1002/14651858.CD010398]

\section{Public Health England 2017}

Public Health England. Pharmacy: A Way Forward For Public Health. Opportunities For Action Through Pharmacy For Public Health. Available at assets.publishing.service.gov.uk/ government/uploads/system/uploads/attachment_data/ file/643520/Pharmacy_a_way_forward_for_public_health.pdf 2017.

\section{RevMan 2014 [Computer program]}

The Nordic Cochrane Centre, The Cochrane Collaboration. Review Manager 5 (RevMan 5). Version 5.3. Copenhagen: The Nordic Cochrane Centre, The Cochrane Collaboration, 2014.

\section{Rogers 2003}

Rogers E. Diffusion of Innovation. Diffusion of Innovation. 5th Edition. New York (NY): Simon and Schuster, 2003.

\section{RSPH 2016}

Royal Society Public Health. Building Capacity: realising the potential of community pharmacy assets for improving the public's health. Public Health England 2016.

\section{Sabater 2016}

Sabater-Hernández D, Sabater-Galindo M, Fernandez-Llimos F, Rotta I, Hossain LN, Durks D, et al. A systematic review of evidence-based community pharmacy services aimed at the prevention of cardiovascular disease. Journal of Managed Care \& Specialty Pharmacy 2016;22(6):699-713.

\section{Scott 2016}

Scott C, De Barra M, Johnston M, De Bruin M, Scott N, Bond C, et al. Changing patient behaviour in pharmacy interventions: what are the active ingredients?. International Journal of Pharmacy Practice 2016;24(S2):25-6.

\section{Silverman 2016}

Silverman MG, Ference BA, Im K, Wiviott SD, Giugliano RP, Grundy SM, et al. Association between lowering LDL-C and cardiovascular risk reduction among different therapeutic interventions: a systematic review and meta-analysis. JAMA 2016;12:1289-97.

\section{Sinclair 2004}

Sinclair HK, Bond CM, Stead LF. Community pharmacy personnel interventions for smoking cessation. Cochrane Database of Systematic Reviews 200, Issue 1. [DOI: 10.1002/14651858.CD003698.pub2]

\section{Smith 2009}

Smith $\mathrm{F}$. The quality of private pharmacy services in low and middle-income countries: a systematic review. Pharmacy World \& Science 2009;31(3):351-61.

\section{Soprovich 2019}

Soprovich AL, Sharma V, Tjosvold L, Eurich DT, Johnson JA. Systematic review of community pharmacy-based and pharmacist-led foot care interventions for adults with type 2 diabetes. Canadian Pharmaceutical Journal 2019;152(2):109-16.

\section{Steed 2017}

Steed L, Sohanpal R, James WY, Rivas C, Jumbe S, Chater A, et al. Equipping community pharmacy workers as agents for health behaviour change: developing and testing a theory-based smoking cessation intervention. BMJ Open 2017;7(8):e015637.

\section{Strandberg 2003}

Strandberg TE, Pitkala K. What is the most important component of blood pressure: systolic, diastolic or pulse pressure?. Current Opinion In Internal Medicine 2003;2:312-6.

\section{Svarsted 2000}

Svarstad BL, Bultman DC. The patient: behavioral determinants. In: Gennaro AR editor(s). Remington: The Science and Practice of Pharmacy. 20th Edition. Baltimore (MD): Lippincott Williams \& Wilkins, 2000:1948-56.

\section{Thompson 2000}

Thompson K, Kulkarni J, Sergejew AA. Reliabitility and validity of a new Medication Adherence Rating Scale (MARS) for the psychoses. Schizophrenia Research 2000;42(3):241-7.

\section{Thomson 2019}

Thomson K, Hillier-Brown F, Walton N, Bilaj M, Bambra C, Todd $A$. The effects of community pharmacy delivered public health interventions on population health and health inequalities: a review of reviews. Preventative Medicine 2019;19(39):127.

\section{Todd 2014}

Todd A, Copeland A, Husband A, Kasim A, Bambra C. The positive pharmacy care law: an area-level analysis of the relationship between community pharmacy distribution, urbanity and social deprivation in England. BMJ Open 2014;4(8):e005764. 


\section{Todd 2014b}

Todd A, Copeland A, Husband A, Kasim A, Bambra C. Access all areas? An area-level analysis of accessibility to general practice and community pharmacy services in England by urbanity and social deprivation. BMJ Open 2014;5(5):e007328.

\section{Uebersax 1987}

Uebersax JS. Diversity of decision-making models and the measurement of interrater agreement. Psychological Bulletin 1987;101(1):140-6.

\section{Walton 2017}

Walton $\mathrm{H}$, Spector A, Tombor I, Michie S. Measures of fidelity of delivery of, and engagement with, complex, face-to-face health behaviour change interventions: a systematic review of measure quality. British Journal of Health Psychology 2017;22(4):872-903.

\section{Ware 1992}

Ware JE, Sherbourne CD. The MOS 36-item short-form health survey (SF-36). I. Conceptual framework and item selection. Medical Care 1992;30(6):473-83.

\section{Watson 2006}

Watson MC, Blenkinsopp A. The feasibility of providing community pharmacy based services for alcohol misuse: a literature review. International Journal of Pharmacy Practice 2009;17(4):199-205.

\section{Weir 2019}

Weir NM, Newham R, Dunlop E, Bennie M. Factors influencing national implementation of innovations within community pharmacy: a systematic review applying the Consolidated Framework for Implementation Research. Implementation Science 2019;14:21.

\section{CHARACTERISTICS OF STUDIES}

Characteristics of included studies [ordered by study ID]

\section{WHO 1998}

World Health Organization. The role of the pharmacist in self-care and self-medication. Available at apps.who.int/ medicinedocs/en/d/Jwhozip32e/ 1998.

\section{WHO 2006}

World Health Organization. New tool to enhance role of pharmacists in health care. Available at www.who.int/ mediacentre/news/new/2006/nw05/en/ 2006.

\section{WHO 2009}

World Health Organization. Milestones in Health Promotion: Statements from Global Conferences. Available at www.who.int/ healthpromotion/Milestones_Health_Promotion_05022010.pdf 2009.

\section{WHO 2011}

World Health Organization. Joint FIP/WHO Guidelines on Good Pharmacy Practice: Standards for Quality of Pharmacy Services [WHO Technical Report Series, No. 961, 2011]. Available at www.who.int/ medicines/areas/quality_safety/quality_assurance/ FIPWHOGuidelinesGoodPharmacyPracticeTRS961Annex8.pdf (accessed 2nd March 2014) 2011.

\section{World Bank Group 2009}

World Bank Group. Country and Lending Groups. Available at datahelpdesk.worldbank.org/knowledgebase/articles/906519world-bank-country-and-lending-groups (accessed 18 July 2018).

\section{Xu 2012}

Xu T, De Almedia Neto AC, Moles RJ. A systematic review of simulated-patient methods in community pharmacy to assess the provision of non-prescription medicines. International Journal of Pharmacy Practice 2012;20(5):307-19.

* Indicates the major publication for the study

Adepu 2007

$\begin{array}{ll}\text { Methods } & \text { Design: RT } \\ & \text { Groups: intervention group (pharmacist counselling); control group (waiting list control) }\end{array}$

Participants

Pharmacies: 2

Pharmacy workers: not reported

Pharmacy users: 70 people with type 2 diabetes

- mean age: intervention $51.45 \pm 12.27$ years; control $53.77 \pm 10.35$ years

- \% female: intervention 25.7\%; control 37.1\%

Setting: urban 
Adepu 2007 (Continued)

$$
\text { Country: India }
$$

Interventions Pharmacy worker-directed intervention: not reported

Pharmacy worker control: it was unclear whether one pharmacy site acted as a control and the other as the intervention, or whether pharmacists across both sites delivered both counselling to patients receiving the intervention and no treatment to controls

Pharmacy user-directed intervention: patients received counselling and an information leaflet about their disease, diet and lifestyle modifications.

- Delivered by: pharmacists

- Type: behaviour change and education

- Mode of delivery: face-to-face; written materials

- TDF: knowledge

- Duration: not reported

- Follow-up: collected at the final follow-up visit (end of intervention). The duration of intervention delivery was unclear, although the study period was stated as being 6 months.

Pharmacy user control: waiting list

\section{Outcomes}

Pharmacy worker: not assessed

\section{Pharmacy user:}

- Clinical: random capillary blood glucose levels

- Psychological health: not assessed

- Behavioural: not assessed

- Quality of life: Audit of Diabetes-Dependent Quality of Life (ADDQOL-18) questionnaire

- Process: disease awareness and management using Knowledge, Attitude and Practices (KAP) questionnaire

- Costs/health-care utilisation: not assessed

$\begin{array}{ll}\text { Notes } & \text { Study/intervention name: none given } \\ & \text { Funding source: JS Mahavidyapeetha, Mysore }\end{array}$

\section{Risk of bias}

\begin{tabular}{lll}
\hline Bias & Authors' judgement & Support for judgement \\
\hline $\begin{array}{l}\text { Random sequence genera- } \\
\text { tion (selection bias) }\end{array}$ & Unclear risk & Not reported \\
\hline $\begin{array}{l}\text { Allocation concealment } \\
\text { (selection bias) }\end{array}$ & Unclear risk & Not reported \\
\hline $\begin{array}{l}\text { Baseline outcome mea- } \\
\text { sures similar }\end{array}$ & Unclear risk & Not reported \\
\hline $\begin{array}{l}\text { Baseline characteristics } \\
\text { similar }\end{array}$ & High risk & $\begin{array}{l}\text { In the intervention group a higher \% of men had a greater range of duration of } \\
\text { illness }\end{array}$ \\
\hline
\end{tabular}


Adepu 2007 (Continued)

Incomplete outcome data Unclear risk Attrition was reported, but it was unclear whether this was accounted for in (attrition bias) the analysis. Quote: "Out of 70 patients, two expired, four were hospitalized All outcomes and four did not respond."

\begin{tabular}{lll}
$\begin{array}{l}\text { Blinding of outcome as- } \\
\text { sessment (detection bias) } \\
\text { All outcomes }\end{array}$ & High risk & Not reported \\
\hline $\begin{array}{l}\text { Protection against conta- } \\
\text { mination }\end{array}$ & High risk & Patients randomised within pharmacy
\end{tabular}

mination

Selective reporting (re- Low risk All 3 outcomes mentioned in the Methods were reported.
porting bias)

\begin{tabular}{lll}
\hline $\begin{array}{l}\text { Other bias } \\
\text { Unclear risk }\end{array}$ & $\begin{array}{l}\text { Not clear whether the 2 participating pharmacies were representative of this } \\
\text { area. }\end{array}$ \\
\hline $\begin{array}{l}\text { Blinding of participants } \\
\text { and personnel (perfor- } \\
\text { mance bias) }\end{array}$ & Unclear risk & Not reported \\
All outcomes & \\
\hline
\end{tabular}

Ali 2012

$\begin{array}{ll}\text { Methods } & \text { Design: RT } \\ \text { Groups: intervention (diabetes education); control (usual care) }\end{array}$

Participants $\quad$ Pharmacies: 2
Pharmacy workers: pharmacists 3

Pharrmacy users: 48 people with type 2 diabetes

- mean age: control $66.8 \pm 10.2$ years; intervention $66.4 \pm 12.7$ years

- \% female: control $43.5 \%$; intervention $56.5 \%$

Setting: unsure

Country: UK

Interventions

Pharmacy worker-directed intervention: 8-hour training programme involving workshop sessions with a consultant diabetologist and diabetes specialist nurse

TDF: knowledge

Pharmacy worker control: it appears the same pharmacists delivered both control and intervention treatments

Pharmacy user-directed intervention: patients received a programme of education about diabetes, its treatment and associated cardiovascular risk factors.

- Delivered by: pharmacists

- Type: self-management, behaviour change, education materials

- Mode of delivery: individual face-to-face 
Ali 2012 (Continued)

- TDF: knowledge

- Duration: 6 sessions over 12 months (every month for the first 2 months, and then every 3 months until month 12; a total of six appointments)

- Follow up: 12 months (i.e. end of intervention)

Pharmacy user control: usual care

Outcomes

Pharmacy worker: not assessed

\section{Pharmacy user:}

- Clinical: BMI, SBP/DBP, blood glucose, HbA1c, LDL, HDL, triglycerides, total cholesterol

- Psychological health: not assessed

- Behavioural: not assessed

- Quality of life: Diabetes Quality of Life Brief Clinical Inventory (DQOL), Health Status (Short Form-36)

- Process: Satisfaction with Information received about Medicines (SIMS); Patients' concerns and necessities about their medicines (Beliefs about Medication Questionnaire (BMQ); Diabetes Knowledge Test (DKT))

- Costs/resources: emergency hospital visits or admissions (diary)

Notes Study/intervention name: none reported

Funding source: Department of Health, UK; Merck Sharp, Dohme Ltd

\section{Risk of bias}

\begin{tabular}{|c|c|c|}
\hline Bias & Authors' judgement & Support for judgement \\
\hline $\begin{array}{l}\text { Random sequence genera- } \\
\text { tion (selection bias) }\end{array}$ & Low risk & Randomisation conducted by a computer-generated randomised list. \\
\hline $\begin{array}{l}\text { Allocation concealment } \\
\text { (selection bias) }\end{array}$ & Low risk & $\begin{array}{l}\text { List held by the researcher at the School of Pharmacy, eliminating the poten- } \\
\text { tial influence of pharmacists on the randomisation. }\end{array}$ \\
\hline $\begin{array}{l}\text { Baseline outcome mea- } \\
\text { sures similar }\end{array}$ & Low risk & $\begin{array}{l}\text { No difference in primary outcomes, some secondary outcomes not used in } \\
\text { current analysis were significantly different }\end{array}$ \\
\hline $\begin{array}{l}\text { Baseline characteristics } \\
\text { similar }\end{array}$ & Low risk & No differences \\
\hline $\begin{array}{l}\text { Incomplete outcome data } \\
\text { (attrition bias) } \\
\text { All outcomes }\end{array}$ & Low risk & No incomplete data \\
\hline $\begin{array}{l}\text { Blinding of outcome as- } \\
\text { sessment (detection bias) } \\
\text { All outcomes }\end{array}$ & Unclear risk & Not reported \\
\hline $\begin{array}{l}\text { Protection against conta- } \\
\text { mination }\end{array}$ & High risk & Control and intervention participants randomised within same pharmacy \\
\hline $\begin{array}{l}\text { Selective reporting (re- } \\
\text { porting bias) }\end{array}$ & Unclear risk & $\begin{array}{l}\text { Some selective reporting; assessed questionnaires at } 5 \text { months but did not re- } \\
\text { port, data on medication use not included, but no significant differences re- } \\
\text { ported. }\end{array}$ \\
\hline Other bias & Low risk & Not reported \\
\hline
\end{tabular}


Ali 2012 (Continued)

Blinding of participants Unclear risk Not reported
and personnel (perfor-
mance bias)
All outcomes

Amariles 2012

$\begin{array}{ll}\text { Methods } & \text { Design: RT } \\ & \text { Groups: intervention (pharmaceutical care for CVD); control (usual care) }\end{array}$

Participants

Pharmacies: not reported

Pharmacy workers: 60 community pharmacists invited 40 (66.7\%) of whom participated

Pharmacy users: 714 patients with a prescription for at least 1 drug indicated for CVD or CV risk factors

- mean age: control 62.6 (SD 8.0) years, intervention 63.0 (SD 8.3) years

- female: control $46.1 \%$, intervention $49.4 \%$

Setting: urban

Country: Spain

Interventions

Pharmacy worker-directed intervention: 8-hour training-lectures on CVD, CV risk factors, cardiovascular prevention and intervention

TDF: knowledge, environment context and resources

Pharmacy worker control: it appears the same pharmacists delivered both control and intervention treatments

Pharmacy user-directed intervention: the Dader method - patients received verbal and written information regarding CV prevention

- Delivered by: pharmacists

- Type: behaviour change, education materials

- Mode of delivery: individual face-to-face

- TDF: knowledge, environment context and resources

- Duration: 5 sessions over 32 weeks

- Follow up: 8 months (end of intervention)

Pharmacy user control: usual treatment and written information on CV risk

Pharmacy workers: not assessed.

\section{Pharmacy users:}

- Clinical: SBP/DBP, TC, BP/TC

- Psychological health: not assessed

- Behavioural: not targeted

- Quality of life: not targeted

- Process: not targeted 
Amariles 2012 (Continued)

- Costs: not assessed

Notes Study/intervention name: Effectiveness of Dader method for pharmaceutical care on control of blood pressure and total cholesterol in outpatients with cardiovascular disease or cardiovascular risk (EMDADER-CV ) study

Funding source: Roche Diagnostics and Stada Laboratory (Spain)

\section{Risk of bias}

\begin{tabular}{|c|c|c|}
\hline Bias & Authors' judgement & Support for judgement \\
\hline $\begin{array}{l}\text { Random sequence genera- } \\
\text { tion (selection bias) }\end{array}$ & Low risk & Computer-generated randomisation \\
\hline $\begin{array}{l}\text { Allocation concealment } \\
\text { (selection bias) }\end{array}$ & Low risk & Blinded \\
\hline $\begin{array}{l}\text { Baseline outcome mea- } \\
\text { sures similar }\end{array}$ & Low risk & No significant differences \\
\hline $\begin{array}{l}\text { Baseline characteristics } \\
\text { similar }\end{array}$ & Low risk & No significant differences \\
\hline $\begin{array}{l}\text { Incomplete outcome data } \\
\text { (attrition bias) } \\
\text { All outcomes }\end{array}$ & Low risk & Accounted for \\
\hline $\begin{array}{l}\text { Blinding of outcome as- } \\
\text { sessment (detection bias) } \\
\text { All outcomes }\end{array}$ & Unclear risk & $\begin{array}{l}\text { Not reported in paper EMDADER-CV (Efecto del Método Dáder de Seguimiento } \\
\text { Farmacoterapéutico en el riesgo cardiovascular de pacientes con factores de } \\
\text { riesgo o enfermedad cardiovascular [Effectiveness of Dader Method for Phar- } \\
\text { maceutical Care on Control of Blood Pressure and Total Cholesterol in Outpa- } \\
\text { tients with Cardiovascular Disease or Cardiovascular Risk) }\end{array}$ \\
\hline $\begin{array}{l}\text { Protection against conta- } \\
\text { mination }\end{array}$ & High risk & Intervention and controls in same pharmacy \\
\hline $\begin{array}{l}\text { Selective reporting (re- } \\
\text { porting bias) }\end{array}$ & Low risk & Not noted \\
\hline Other bias & Low risk & Not noted \\
\hline $\begin{array}{l}\text { Blinding of participants } \\
\text { and personnel (perfor- } \\
\text { mance bias) } \\
\text { All outcomes }\end{array}$ & High risk & Not possible to blind participants \\
\hline
\end{tabular}

Armour 2007

\begin{tabular}{ll} 
Methods & Design: cluster-RT \\
& Groups: intervention (asthma management); control (usual care) \\
\hline Participants & Pharmacies: invitations to 174 pharmacies, 57 participated (29 intervention and 28 control) \\
& Pharmacy workers: mean number of pharmacists on duty: intervention 2.0 (SD 0.8); control 1.9 (SD 0.7)
\end{tabular}


- mean age: intervention $44 \% \leq 35$ years, $38 \%=36-55$ years, $19 \% \geq 56$ years; control $40 \% \leq 35$ years, $56 \%=36-55$ years, $4 \% \geq 56$ years

- $\%$ female: intervention $44 \%$; control $56 \%$

Pharmacy users: 396 patients with asthma

- mean age: intervention $47.5 \pm 17.1$ years; control $50.4 \pm 16.1$ years

- \% female: intervention $67.5 \%$; control $60.5 \%$

Setting: rural and urban

Country: Australia

Interventions

Pharmacy worker-directed intervention: intervention pharmacists received an asthma education manual and were trained on risk assessment, pathophysiology, medications, the National Asthma Campaign (NAC) 6-step asthma management plan, patient education, goal setting, adherence assessment, spirometry and the Pharmacy Asthma Care Program (PACP) protocol. Renumeration per patient

- Delivered by: respiratory scientists and the research team

- Type: education, communication skills

- Mode of delivery: group

- TDF: knowledge

- Duration: 2-day workshop, with ongoing support visits and meetings

Pharmacy worker control: trained on risk assessment, spirometry and the control protocol during a 1day workshop.

Pharmacy user-directed intervention: patients received education on asthma, assessment, and optimisation of drug therapy by the pharmacist, and referral to a respiratory therapist and/or physician as needed.

- Delivered by: pharmacists, with respiratory therapists and family physicians involved in care as required

- Type: self management, education, disease management

- Mode of delivery: individual face-to-face

- TDF: knowledge, skills, goals

- Duration: 6 sessions

- Length of follow-up: 6 months

Pharmacy user control: usual care

Outcomes

- Uptake of study - $33 \%$

\section{Pharmacy user:}

- Clinical: asthma severity/control (NAC asthma severity assessment table); lung function (FEV1, FEV1/ FVC), spirometry; medication profile (dispensed medication history); daily dose of medications (dispensed medication history)

- Psychological health: not assessed

- Behavioural: inhaler technique (inhaler technique checklist); adherence (brief medication questionnaire)

- Quality of life: asthma-related quality of life (asthma-related quality of life questionnaire); 
- Process: perceived control of asthma (perceived control of asthma questionnaire); action plan ownership (self-reported data); asthma knowledge (consumer asthma knowledge questionnaire)

- Costs: cost effectiveness over 5 years (see Gordois 2007 paper listed under Armour 2007)

Notes Study/intervention name:Pharmacy Asthma Care Program (PACP)

Funding source: Australia Department of Health and Aging. Gordois 2007 paper reported economic outcomes.

Gordois 2007, Saini 2004 (cited under Armour 2007) also report on this study.

\section{Risk of bias}

\begin{tabular}{lll}
\hline Bias & Authors' judgement & Support for judgement \\
\hline $\begin{array}{ll}\text { Random sequence genera- } \\
\text { tion (selection bias) }\end{array}$ & Low risk & $\begin{array}{l}\text { Randomisation was accomplished through an internet randomisation ser- } \\
\text { vice provided by the Epidemiology Coordinating and Research (EPICORE) Cen- } \\
\text { tre, and the Centre for Community Pharmacy Research and Interdisciplinary } \\
\text { Strategies (COMPRIS) at the University of Alberta. Randomisation was strati- } \\
\text { fied by centre. }\end{array}$
\end{tabular}

\begin{tabular}{|c|c|c|}
\hline $\begin{array}{l}\text { Allocation concealment } \\
\text { (selection bias) }\end{array}$ & Low risk & Centralised service, see above \\
\hline $\begin{array}{l}\text { Baseline outcome mea- } \\
\text { sures similar }\end{array}$ & Low risk & Difference in level of control, but accounted for in analysis \\
\hline $\begin{array}{l}\text { Baseline characteristics } \\
\text { similar }\end{array}$ & Low risk & $\begin{array}{l}\text { Although differences in smoking, lung disease, and brief medication question- } \\
\text { naire, these were controlled for in the analyses. }\end{array}$ \\
\hline $\begin{array}{l}\text { Incomplete outcome data } \\
\text { (attrition bias) } \\
\text { All outcomes }\end{array}$ & Low risk & Sensitivity analysis conducted \\
\hline $\begin{array}{l}\text { Blinding of outcome as- } \\
\text { sessment (detection bias) } \\
\text { All outcomes }\end{array}$ & Unclear risk & Not reported \\
\hline $\begin{array}{l}\text { Protection against conta- } \\
\text { mination }\end{array}$ & Low risk & Cluster-RT \\
\hline $\begin{array}{l}\text { Selective reporting (re- } \\
\text { porting bias) }\end{array}$ & Low risk & Not noted \\
\hline Other bias & Low risk & Not noted \\
\hline $\begin{array}{l}\text { Blinding of participants } \\
\text { and personnel (perfor- } \\
\text { mance bias) } \\
\text { All outcomes }\end{array}$ & Low risk & Pharmacists not informed regarding allocation to groups \\
\hline
\end{tabular}

Barbanel 2003

$\begin{array}{ll}\text { Methods } & \text { Design: RT } \\ & \text { Groups: intervention (asthma self-management); control (usual care) }\end{array}$


Barbanel 2003 (Continued)
Participants
Pharmacies: 1
Pharmacy worker: 1 pharmacist

Pharmacy users: 24 patients with asthma

- mean age: intervention 45 years (SD 17); control 47 years (SD 17)

- $\%$ female: intervention $100 \%$; control $71.4 \%$

Setting: urban

Country: UK

Interventions

Pharmacy worker-directed intervention: a single pharmacist acting as the study intervention attended a 3-day multidisciplinary course on asthma care and self-management.

- Delivered by: not mentioned, but possibly researchers

- Type: education

- Mode of delivery: face-to-face

- TDF: knowledge, skills

- Duration: 3 days

Pharmacy worker control: it appears the same pharmacist delivered both control and intervention treatments

Pharmacy user-directed intervention: self-management advice on asthma

- Delivered by: pharmacist.

- Type: self-management, education

- Mode of delivery: individual face-to-face or telephone contact. Took place in pharmacy, or at GP surgeries (although delivered by pharmacist).

- TDF: knowledge, skills, goals, environment context and resources, behavioural regulation

- Duration: 13 sessions; duration: 1 x 45- to 60-minute session +12 phone calls

- Length of follow-up: 3 months from baseline

Pharmacy user control: usual care, no input from pharmacist

\section{Pharmacy user:}

- Clinical: asthma symptom scores (North of England Asthma Symptoms Scale)

- Psychological health: not assessed

- Behavioural: not assessed

- Quality of life: not assessed

- Process: not assessed

- Costs: not assessed 
Barbanel 2003 (Continued)

\begin{tabular}{|c|c|c|}
\hline Bias & Authors' judgement & Support for judgement \\
\hline $\begin{array}{l}\text { Random sequence genera- } \\
\text { tion (selection bias) }\end{array}$ & Low risk & Randomised using sealed envelopes \\
\hline $\begin{array}{l}\text { Allocation concealment } \\
\text { (selection bias) }\end{array}$ & Low risk & As above \\
\hline $\begin{array}{l}\text { Baseline outcome mea- } \\
\text { sures similar }\end{array}$ & Low risk & No differences \\
\hline $\begin{array}{l}\text { Baseline characteristics } \\
\text { similar }\end{array}$ & Low risk & No differences \\
\hline $\begin{array}{l}\text { Incomplete outcome data } \\
\text { (attrition bias) } \\
\text { All outcomes }\end{array}$ & Low risk & Nothing noted \\
\hline $\begin{array}{l}\text { Blinding of outcome as- } \\
\text { sessment (detection bias) } \\
\text { All outcomes }\end{array}$ & Unclear risk & Not reported \\
\hline $\begin{array}{l}\text { Protection against conta- } \\
\text { mination }\end{array}$ & High risk & intervention and control patients from same pharmacy \\
\hline $\begin{array}{l}\text { Selective reporting (re- } \\
\text { porting bias) }\end{array}$ & Low risk & Not noted \\
\hline Other bias & Unclear risk & Possible recruitment bias \\
\hline $\begin{array}{l}\text { Blinding of participants } \\
\text { and personnel (perfor- } \\
\text { mance bias) } \\
\text { All outcomes }\end{array}$ & Unclear risk & No information provided \\
\hline
\end{tabular}

\section{Basheti 2008}

$\begin{array}{ll}\text { Methods } & \text { Design: cluster-RT } \\ & \text { Groups: intervention (asthma inhaler technique); control (usual care) }\end{array}$

\section{Participants}

\section{Pharmacies: not reported}

Pharmacy worker: 31 pharmacists (16 intervention; 15 control) of 120 invited

Pharmacy user: 97 patients with asthma

- mean age: intervention group $40.4 \pm 10.7$ years; control $33.4 \pm 9.3$ years

- $\%$ female: intervention group $56.2 \%$; control $33.3 \%$

Setting: urban

Country: Australia 
Basheti 2008 (Continued)

Interventions
Pharmacy worker-directed intervention: pharmacists received general information about asthma, inhaled medications, and peak flow meter technique. They were also trained to assess and teach correct Turbuhaler and Diskus inhaler techniques, asthma management etc. They were reassessed at the end of the workshop and 2 years after.

- Delivered by: specialists

- Type: education

- Mode of delivery: group

- TDF: knowledge, memory, attention and decision making

- Duration: 1 evening workshop for all pharmacists, lasted 3 hours for intervention group, 2 hours for control

- Follow-up: 2 years

Pharmacy worker control: pharmacists received general information about asthma, inhaled medications, and peak flow meter technique.

Pharmacy user-directed intervention: patients' inhaler technique was assessed and then they were educated using a specialised "Show and Tell" inhaler technique counselling service, going through each step on a checklist to describe and demonstrate correct use; had an inhaler technique label placed on their inhaler, which highlighted incorrect steps

- Delivered by: pharmacists

- Type: behaviour change; self-management

- Mode of delivery: individual face-to-face

- TDF: knowledge, skills, environment, context and resources

- Duration: length of intervention: 3 months + extra visit at 6 months

- Length of follow-up: 6 months (end of intervention), and 2 years; follow-ups at baseline, 3 monthly visits +1 visit 6 months after study began

Pharmacy user control: wait list - inhaler technique assessed and then inhaler technique counselling provided at end of study.

\section{Pharmacy worker:}

- Uptake: percentage

- Behavioural: inhaler technique

\section{Pharmacy user:}

- Clinical: peak flow variability (Min\%Max); categorisation of asthma severity based on the Australian Asthma Management Handbook

- Psychological health: not assessed

- Behavioural: inhaler technique (Mean Inhaler Technique Score)

- Quality of life: Asthma-Related Quality of Life (AQOL)

- Process: Perceived Control of Asthma Questionnaire (PCAQ)

- Costs: not assessed

Funding source: Faculty of Pharmacy, Univeristy of Sydney; placebo inhalers by AstraZeneca and GlaxoSmithKline

Basheti 2007 and Basheti 2009 (both cited under Basheti 2008) also report on this study

\section{Risk of bias}

Community pharmacy interventions for health promotion: effects on professional practice and health outcomes (Review) 
Basheti 2008 (Continued)

\begin{tabular}{|c|c|c|}
\hline Bias & Authors' judgement & Support for judgement \\
\hline $\begin{array}{l}\text { Random sequence genera- } \\
\text { tion (selection bias) }\end{array}$ & Low risk & $\begin{array}{l}\text { Quote: "Pharmacists were allocated randomly by computer-generated list to } \\
\text { Active or Control groups." }\end{array}$ \\
\hline $\begin{array}{l}\text { Allocation concealment } \\
\text { (selection bias) }\end{array}$ & Low risk & By computer \\
\hline $\begin{array}{l}\text { Baseline outcome mea- } \\
\text { sures similar }\end{array}$ & Low risk & Analysis accounted for baseline \\
\hline $\begin{array}{l}\text { Baseline characteristics } \\
\text { similar }\end{array}$ & Unclear risk & Not reported \\
\hline $\begin{array}{l}\text { Incomplete outcome data } \\
\text { (attrition bias) } \\
\text { All outcomes }\end{array}$ & Low risk & Minimal dropouts \\
\hline $\begin{array}{l}\text { Blinding of outcome as- } \\
\text { sessment (detection bias) } \\
\text { All outcomes }\end{array}$ & Low risk & $\begin{array}{l}\text { Quote: "We blinded pharmacists and patients by teaching both groups how to } \\
\text { educate patients in correct peak flow meter technique." }\end{array}$ \\
\hline $\begin{array}{l}\text { Protection against conta- } \\
\text { mination }\end{array}$ & Unclear risk & $\begin{array}{l}\text { Unclear, as intervention and control pharmacists could work in same pharma- } \\
\text { cy }\end{array}$ \\
\hline $\begin{array}{l}\text { Selective reporting (re- } \\
\text { porting bias) }\end{array}$ & Low risk & Not noted \\
\hline Other bias & Unclear risk & $\begin{array}{l}\text { Not noted - possible recruitment bias of patients - every second asthma pa- } \\
\text { tient }\end{array}$ \\
\hline $\begin{array}{l}\text { Blinding of participants } \\
\text { and personnel (perfor- } \\
\text { mance bias) } \\
\text { All outcomes }\end{array}$ & Low risk & Quote: "pharmacists ... blinded to true nature of intervention" \\
\hline
\end{tabular}

\title{
Bereznicki 2013
}

$\begin{array}{ll}\text { Methods } & \text { Design: cluster-RT } \\ \text { Groups: intervention (asthma education delivered either face to face or by mail); control (usual care) }\end{array}$

Participants

\author{
Pharmacies: 71 \\ Pharmacy worker: at least 1 per pharmacy \\ Pharmacy users: 1483 patients with asthma \\ - mean age: no information given \\ - \% female: no information given \\ Setting: unclear \\ Country: Australia (South Australia, Tasmania and Victoria)
}


Bereznicki 2013 (Continued)

Interventions
Pharmacy worker-directed intervention: education sessions for all participating pharmacists overview of asthma management in Australia; outline of project's objectives and methods; demonstration of the data-mining software. For pharmacists unable to attend an education session, a personalised one-to-one visit was arranged. Renumeration for training and AUD 200 per pharmacy

- Delivered by: respiratory physician

- Type: education meetings

- Mode of delivery: group; individual face-to-face

- TDF: knowledge, memory, attention decision making, environment context and resources

Pharmacy worker control: received the same education as above. Randomization at pharmacy user level

Pharmacy user-directed intervention: patients received educational material and a referral to their GP for an asthma management review either by mail or a face-to-face intervention

- Delivered by: pharmacists

- Type: behaviour change

- Mode of delivery: individual face-to-face or mailed information

- TDF: knowledge, environment context and resources

- Duration: the intervention period ran for 6 weeks

- Follow-up: post intervention

Pharmacy user control: usual treatment, no intervention pack

\section{Pharmacy worker:}

- Uptake: not reported

- Process: satisfaction and perception survey

\section{Pharmacy user:}

- Clinical: preventer-to-reliever (P:R) ratio; daily short-acting beta agonist usage; daily inhaled corticosteroid usage.

- Psychological health: not assessed

- Behavioural: not assessed

- Quality of life: not assessed

- Process: not assessed

- Costs: not assessed

Funding source: Australian Government Department of Health and Aging

Bereznicki 2008, 2011 (cited under Bereznicki 2013) also reported on this study

\section{Risk of bias}

\begin{tabular}{lll}
\hline Bias & Authors' judgement & Support for judgement \\
\hline $\begin{array}{ll}\text { Random sequence genera- } \\
\text { tion (selection bias) }\end{array}$ & Unclear risk & $\begin{array}{l}\text { Pharmacies randomly assigned to deliver first type of pharmacist-initiated in- } \\
\text { tervention - mailed or face-to-face, then alternate allocation for remaining } \\
\text { pharmacies. First patients within pharmacies randomly allocated to receive in- } \\
\text { tervention or control then alternately allocation. }\end{array}$ \\
& &
\end{tabular}


Bereznicki 2013 (Continued)

\begin{tabular}{|c|c|c|}
\hline $\begin{array}{l}\text { Allocation concealment } \\
\text { (selection bias) }\end{array}$ & Low risk & Software allocated \\
\hline $\begin{array}{l}\text { Baseline outcome mea- } \\
\text { sures similar }\end{array}$ & Low risk & No significant differences \\
\hline $\begin{array}{l}\text { Baseline characteristics } \\
\text { similar }\end{array}$ & Unclear risk & Not reported \\
\hline $\begin{array}{l}\text { Incomplete outcome data } \\
\text { (attrition bias) } \\
\text { All outcomes }\end{array}$ & Low risk & Numbers mentioned in paper \\
\hline $\begin{array}{l}\text { Blinding of outcome as- } \\
\text { sessment (detection bias) } \\
\text { All outcomes }\end{array}$ & Low risk & $\begin{array}{l}\text { Quote: "The patient receiving the greatest number of relievers was randomly } \\
\text { assigned to the intervention or control group, with subsequent patients being } \\
\text { alternately assigned to the control or intervention group." }\end{array}$ \\
\hline $\begin{array}{l}\text { Protection against conta- } \\
\text { mination }\end{array}$ & Low risk & Each pharmacy only performed one type of intervention \\
\hline $\begin{array}{l}\text { Selective reporting (re- } \\
\text { porting bias) }\end{array}$ & Low risk & Nothing noted \\
\hline Other bias & Low risk & Nothing noted \\
\hline $\begin{array}{l}\text { Blinding of participants } \\
\text { and personnel (perfor- } \\
\text { mance bias) } \\
\text { All outcomes }\end{array}$ & Low risk & $\begin{array}{l}\text { Quote: "Pharmacists were blinded to the control patients' identities until the } \\
\text { end of the } 12 \text {-month post-intervention period, with the intention that control } \\
\text { patients would receive no intervention other than the pharmacists' usual care } \\
\text { until after the post-intervention period." }\end{array}$ \\
\hline
\end{tabular}

Bond 2007

Methods

Design: RT

Groups: intervention (medicines management for cardiovascular disease); control (usual care)

Participants Pharmacies: 9

Pharmacy workers: 62 pharmacists

Pharmacy user: 1493 patients with CHD

- mean age: intervention $68.7 \pm 9.2$ years; control $68.8 \pm 9.1$ years

- \% female: intervention $32.6 \%$; control $29.4 \%$

Setting: mixed

Country: UK

Interventions

Pharmacy worker-directed intervention: pharmacists received training on medicines management, identification of essential information from GP patient records, facilitation of independent studying, communication skills, and action learning.

- Delivered by: Centre for Pharmacy Post-Graduate Education

- Type: medication management, disease management, self management

- Mode of delivery: face-to-face, written material, clinical case studies 
Bond 2007 (Continued)

- TDF: knowledge, skills

- Duration: 2-hour launch event, 2.5-hour CHD event, a full day communication event

Pharmacy worker control: it appears the same pharmacists delivered both control and intervention treatments

Pharmacy user-directed intervention: consultations on medicines management delivered, included assessments of the following: therapy, medication compliance, lifestyle and social support

- Delivered by: pharmacists

- Type: self-management; behaviour change; medication management; disease management; education

- Mode of delivery: individual face-to-face

- TDF: knowledge, social support

- Duration: initial meeting then as needed over 12 months

- Follow-up: 12 months (end of intervention period)

Pharmacy user control: usual treatment from GP and community pharmacist

Outcomes Pharmacy worker: no valid measures

\section{Pharmacy user:}

- Clinical: proportion of patients receiving secondary prevention treatment for $\mathrm{CHD}$ in accordance with the National Service Framework (2000) (composite of 8 behaviours: aspirin-related management; lipid management; BP management; smoking management; physical activity; diet; alcohol consumption; weight); a cumulative score summarising 'appropriate treatment' and advice; 5-year risk of cardiovascular death

- Psychological health: not assessed

- Behavioural: not assessed

- Quality of life: SF-36, EuroQol

- Process: satisfaction (non validated measure)

- Cost: incremental cost per patient; annual costs of intervention (training and delivery); usual costs of NHS treatment (costs of pharmaceuticals, GP and hospital visits) and costs borne by patients

Notes

Study/intervention name: community pharmacy-led medicines management (MEDMAN)

Funding source: Department of Health England and Wales

Jaffray 2007 and Scott 2007 (cited under Bond 2007) also reported on this study

\section{Risk of bias}

\begin{tabular}{lll}
\hline Bias & Authors' judgement & Support for judgement \\
\hline $\begin{array}{l}\text { Random sequence genera- } \\
\text { tion (selection bias) }\end{array}$ & Low risk & $\begin{array}{l}\text { Quote: "Patients were randomized in a ratio of 2:1, intervention to control } \\
\text { group. This was done independently of the research team using a password } \\
\text { protected computer programme in permuted blocks stratified by practice." }\end{array}$ \\
\hline $\begin{array}{l}\text { Allocation concealment } \\
\text { (selection bias) }\end{array}$ & Low risk & $\begin{array}{l}\text { Quote: "Audit clerks performing data extraction were blind to the randomiza- } \\
\text { tion status of participants, as were the researchers conducting the statistical } \\
\text { analyses." }\end{array}$ \\
\hline $\begin{array}{l}\text { Baseline outcome mea- } \\
\text { sures similar }\end{array}$ & Low risk & $\begin{array}{l}\text { Quote: "No substantial differences in the baseline characteristics of the study } \\
\text { groups" }\end{array}$
\end{tabular}


Bond 2007 (Continued)

$\begin{aligned} & \text { Baseline characteristics } \\ & \text { similar }\end{aligned} \quad \begin{aligned} & \text { Quote: "No substantial differences in the baseline characteristics of the study } \\ & \text { groups" }\end{aligned}$

Incomplete outcome data Low risk Quote: "Missing data was tested, and adjusted for"

(attrition bias)

All outcomes

Blinding of outcome as- $\quad$ Low risk Quote: "Data extraction and analysis were blind,"
sessment (detection bias)
All outcomes

\begin{tabular}{lll}
\hline $\begin{array}{l}\text { Protection against conta- } \\
\text { mination }\end{array}$ & Unclear risk & Unclear if possible contamination \\
\hline $\begin{array}{l}\text { Selective reporting (re- } \\
\text { porting bias) }\end{array}$ & Low risk & Nothing noted \\
\hline Other bias & Low risk & Nothing noted \\
\hline $\begin{array}{l}\text { Blinding of participants } \\
\text { and personnel (perfor- } \\
\text { mance bias) } \\
\text { All outcomes }\end{array}$ & Unclear risk & $\begin{array}{l}\text { Quote: "Patients could not be blind to trial intervention because of its nature. } \\
\text { Community pharmacists were not informed which control patients had nomi- } \\
\text { nated their pharmacy." }\end{array}$ \\
\hline
\end{tabular}

\section{Burford 2013}

\begin{tabular}{ll}
\hline Methods & Design: RT \\
Groups: intervention (photo-aging smoking cessation); control group (usual care)
\end{tabular}

Participants
Pharmacies: 8
Pharmacy users: 160 smokers
- mean age: intervention $24.2 \pm 4.1$ years; control $25.1 \pm 4.1$ years
- \% female: intervention $68.7 \%$; control $56.2 \%$
Setting: urban
Country: Perth, Australia

Pharmacy user-directed intervention: standard 2-minute smoking cessation advice from the pharmacist plus participants were digitally photo-aged so they could preview images of themselves as a lifelong smoker and as a nonsmoker, and were invited to view the age-processed images, received smoking cessation advice, and were screened for body dysmorphia.

- Delivered by: unclear whether pharmacist or researcher delivered the intervention

- Type: behaviour change/smoking cessation

- Mode of delivery: individual face-to-face

- TDF: knowledge, beliefs about consequences 
Burford 2013 (Continued)

- Duration: unclear - probably a single session with email of image sent to client. Not clear if there was further support from pharmacist.

- Follow-up: 6 months

Pharmacy user control: standard 2-minute smoking cessation advice from the pharmacist.

\begin{tabular}{ll}
\hline Outcomes & Pharmacy worker: not assessed \\
Pharmacy user: \\
- Clinical: carbon monoxide (CO) breath test \\
- Psychological health: not assessed \\
- Behavioural: Fagerström Smoking Dependence scale \\
- Process: study designed questions concerning: attitudes toward personal appearance, opinions \\
about health risks associated with smoking, and perceived barriers to quitting smoking; willingness \\
to pay (WTP) for the digital aging service. \\
Cost: estimated cost per participant; cost-effectivenes \\
Study/intervention name: none given \\
Funding source: not reported \\
\hline Notes
\end{tabular}

\section{Risk of bias}

\begin{tabular}{|c|c|c|}
\hline Bias & Authors' judgement & Support for judgement \\
\hline $\begin{array}{l}\text { Random sequence genera- } \\
\text { tion (selection bias) }\end{array}$ & High risk & Randomisation by researcher on alternate weeks \\
\hline $\begin{array}{l}\text { Allocation concealment } \\
\text { (selection bias) }\end{array}$ & High risk & $\begin{array}{l}\text { Quote: "Allocation to groups was not performed as eligible participants were } \\
\text { recruited, but according to the treatment being used at the pharmacy during } \\
\text { that week." }\end{array}$ \\
\hline $\begin{array}{l}\text { Baseline outcome mea- } \\
\text { sures similar }\end{array}$ & Low risk & $\begin{array}{l}\text { Quote: "there were no significant differences between the control and inter- } \\
\text { vention group on demographic or smoking dependence at baseline" }\end{array}$ \\
\hline $\begin{array}{l}\text { Baseline characteristics } \\
\text { similar }\end{array}$ & Unclear risk & $\begin{array}{l}\text { There were differences between groups for concern about physical appear- } \\
\text { ance, and the belief that facial wrinkles are associated with smoking. }\end{array}$ \\
\hline $\begin{array}{l}\text { Incomplete outcome data } \\
\text { (attrition bias) } \\
\text { All outcomes }\end{array}$ & Low risk & Few participants lost \\
\hline $\begin{array}{l}\text { Blinding of outcome as- } \\
\text { sessment (detection bias) } \\
\text { All outcomes }\end{array}$ & High risk & $\begin{array}{l}\text { Quote: "Because of the nature of the intervention, the participants and re- } \\
\text { searcher could not be blinded to the study group." }\end{array}$ \\
\hline $\begin{array}{l}\text { Protection against conta- } \\
\text { mination }\end{array}$ & Unclear risk & $\begin{array}{l}\text { Allocation to group dependent on week to avoid contamination, but unclear if } \\
\text { successful }\end{array}$ \\
\hline $\begin{array}{l}\text { Selective reporting (re- } \\
\text { porting bias) }\end{array}$ & Low risk & All outcomes appear to have been reported. \\
\hline Other bias & Unclear risk & $\begin{array}{l}\text { Low numbers of control groups self report quit status was verified with objec- } \\
\text { tive carbon monoxide measurement }\end{array}$ \\
\hline
\end{tabular}


Burford 2013 (Continued)

Blinding of participants and personnel (perfor-

High risk mance bias)

All outcomes
Quote: "Because of the nature of the intervention, the participants and researcher could not be blinded to the study group."

Bynum 2001

Methods Design: RT

Groups: intervention (telepharmacy counselling); control group (usual care)

Participants

Pharmacies: not reported

Pharmacy worker: 2 pharmacists

Pharmacy user: 49 asthma patients

- mean age (43.4\% aged $12-14$ years; $50 \%$ aged $15-17$ years; $6.5 \%$ aged $18-19$ years)

- $\%$ female: $69.4 \%$

Setting: rural

Country: USA

Interventions

Pharmacy worker-directed intervention: not reported

Pharmacy user-directed intervention: pharmacists used interactive compressed video (telepharmacy) to teach metered dose inhaler (MDI) technique to a rural, adolescent asthma population in junior high and high schools.

- Delivered by: pharmacists and other healthcare professionals

- Type: condition management (correct MDI technique).

- Mode of delivery: video/DVD, telemedicine

- TDF: knowledge, skills

- Duration: 3 sessions, 15 minutes, over 3 to 4 weeks

- Follow-up: 2 to 4 weeks

Pharmacy user control: had telepharmacy contact, but not counselling until after study

Outcomes Pharmacy worker: not assessed

\section{Pharmacy user:}

- Clinical: not assessed

- Psychological health: not assessed

- Behavioural: MDI technique checklist; Telepharmacy Metered-Dose Inhaler Technique evaluation

- Quality of life: not assessed

- Process: not assessed

- Costs: not assessed

Notes

Funding source: grant from the Office for the Advancement of Telehealth in the Department of Health Resources and Services Administration 
Bynum 2001 (Continued)

Study/intervention name: none given

\section{Risk of bias}

\begin{tabular}{|c|c|c|}
\hline Bias & Authors' judgement & Support for judgement \\
\hline $\begin{array}{l}\text { Random sequence genera- } \\
\text { tion (selection bias) }\end{array}$ & Low risk & Random number chart \\
\hline $\begin{array}{l}\text { Allocation concealment } \\
\text { (selection bias) }\end{array}$ & Unclear risk & Not specified \\
\hline $\begin{array}{l}\text { Baseline outcome mea- } \\
\text { sures similar }\end{array}$ & Low risk & Reported in text as non significant \\
\hline $\begin{array}{l}\text { Baseline characteristics } \\
\text { similar }\end{array}$ & Low risk & Reported in text as non significant \\
\hline $\begin{array}{l}\text { Incomplete outcome data } \\
\text { (attrition bias) } \\
\text { All outcomes }\end{array}$ & High risk & Some loss to follow-up and no reporting of correction for missing data \\
\hline $\begin{array}{l}\text { Blinding of outcome as- } \\
\text { sessment (detection bias) } \\
\text { All outcomes }\end{array}$ & Unclear risk & Not specified \\
\hline $\begin{array}{l}\text { Protection against conta- } \\
\text { mination }\end{array}$ & Unclear risk & Not clear if control had access to intervention pharmacists \\
\hline $\begin{array}{l}\text { Selective reporting (re- } \\
\text { porting bias) }\end{array}$ & Low risk & Seemed to report all planned outcomes. \\
\hline Other bias & Low risk & Not noted \\
\hline $\begin{array}{l}\text { Blinding of participants } \\
\text { and personnel (perfor- } \\
\text { mance bias) } \\
\text { All outcomes }\end{array}$ & Unclear risk & Unclear whether pharmacist assessors were aware of grouping \\
\hline
\end{tabular}

\section{Charrois 2006}

$\begin{array}{ll}\text { Methods } & \text { Design: RT } \\ \text { Groups: intervention (asthma management); control group (usual care) }\end{array}$

$\begin{array}{ll}\text { Participants } & \text { Pharmacies: } 5 \\ & \text { Pharmacy workers: not reported }\end{array}$

Pharmacy user: 70 patients with asthma

- mean age: intervention $35.7 \pm 10.2$ years; control $38.7 \pm 10.7$ years

- \% female:intervention 52.8\%; control 52.9\%

Setting: rural 
Charrois 2006 (Continued)

$$
\text { Country: Canada }
$$

Interventions

Pharmacy worker-directed intervention: pharmacist trained in an interactive, activity and casebased program which focused on patient assessment, patient interviewing and communication skills

- Delivered by: unclear

- Type: self-management; patient assessment, patient interviewing and communication skills

- Mode of delivery: group

- TDF: knowledge, skills

- Duration: appears to have been a single afternoon with ongoing support visits and meetings as needed.

Pharmacy worker control: the same pharmacists delivered care to both intervention and control groups

Pharmacy user-directed intervention: patients received education on asthma, assessment, and optimisation of drug therapy, with focus on a written asthma plan

- Delivered by: pharmacist and referral to respiratory therapist and/or physician as needed

- Type: self-management; education; medication management; based on clinical practice guidelines

- Mode of delivery: individual face-to-face

- TDF: knowledge, behavioural regulation

- Duration: an initial visit for information/education, referral to physician and pharmacist follow-up: 2 weeks and at 1, 2, 4, and 6 months. Respiratory therapist follow-up: 2 and 6 months

- Follow-up: 6 months (end of intervention)

Pharmacy user control: wait list with asthma education and advice as needed, as well as referral to respiratory therapist

Outcomes

Pharmacy worker: not assessed

\section{Pharmacy user:}

- Clinical: inhaled corticosteroid use; number of courses of oral steroid and FEV1

- Psychological health: not assessed

- Behavioural: change in the Asthma Control Questionnaire (ACQ)

- Quality of life: not assessed

- Process: number of emergency room visits and hospitalisations

- Costs/HCU: emergency room visits, hospitalisations

Notes

Study/intervention name: Better Respiratory Education and Asthma Treatment in Hinton and Edson study (BREATHE)

Funding source: Canadian Institues of Health Research

Charrois 2004 (cited under Charrois 2006) also referred to this study

\section{Risk of bias}

\begin{tabular}{lll}
\hline Bias & Authors' judgement & Support for judgement \\
\hline $\begin{array}{ll}\text { Random sequence genera- } \\
\text { tion (selection bias) }\end{array}$ & Low risk & $\begin{array}{l}\text { Quote: "Randomization was accomplished through an Internet randomization } \\
\text { service provided by the Epidemiology Coordinating and Research (EPICORE) } \\
\end{array}$ \\
& Centre and the Centre for Community Pharmacy Research and Interdiscipli-
\end{tabular}


Charrois 2006 (Continued)

nary Strategies (COMPRIS) at the University of Alberta. Randomization was stratified by centre."

\begin{tabular}{lll}
\hline $\begin{array}{l}\text { Allocation concealment } \\
\text { (selection bias) }\end{array}$ & Low risk & Centralised service, see above \\
\hline $\begin{array}{l}\text { Baseline outcome mea- } \\
\text { sures similar }\end{array}$ & Low risk & No differences for main outcomes \\
\hline $\begin{array}{l}\text { Baseline characteristics } \\
\text { similar }\end{array}$ & Low risk & $\begin{array}{l}\text { Differences for range characteristics - text reported that this was controlled for } \\
\text { in analyses. }\end{array}$
\end{tabular}

Incomplete outcome data Low risk Last value of ACQ carried forward where missing

(attrition bias)

All outcomes

\begin{tabular}{ll}
\hline Blinding of outcome as- & High risk It is possible that assessors were not blinded \\
sessment (detection bias) &
\end{tabular}

All outcomes

Protection against conta- Low risk Cluster randomised
mination

\begin{tabular}{|c|c|c|}
\hline $\begin{array}{l}\text { Selective reporting (re- } \\
\text { porting bias) }\end{array}$ & Unclear risk & Not noted \\
\hline Other bias & High risk & $\begin{array}{l}\text { Quote: "The sites did not apply the intervention uniformly. According to case } \\
\text { report forms received, follow-up was poor, few asthma management recom- } \\
\text { mendations were made, and one-quarter of patients in the intervention group } \\
\text { never received a written action plan, [which was] the focus of the intervention. } \\
\text { The follow-up completed at each site varied, with some sites having less than } \\
30 \% \text { follow-up at the time of the } 6 \text {-month visit. The low rate of follow-up leads } \\
\text { us to believe that the application of the intervention was also minimal at these } \\
\text { sites." }\end{array}$ \\
\hline
\end{tabular}

Blinding of participants High risk Caregivers/pharmacists involved in the study were not blinded.

mance bias)

All outcomes

\section{Cordina 2001}

\begin{tabular}{ll} 
Methods & Design: cluster-RT \\
& Groups: intervention (asthma education and monitoring); control (routine dispensing services) \\
\hline Participants & Pharmacies: 22 (intervention 11; control 11) \\
& Pharmacy worker: not reported \\
& -------------------------------------------------- \\
& Pharmacy user: 152 asthma patients \\
- mean age: intervention $41.3 \pm 18.35$ years; control $45.88 \pm 18.11$ years \\
- \% female:intervention $57 \% ;$ control $39 \%$ \\
Setting: both urban and rural
\end{tabular}


Cordina 2001 (Continued)

$$
\text { Country: Malta }
$$

\section{Interventions $\quad$ Pharmacy worker-directed intervention:}

A manual was prepared in the form of a self-study program with 2 sections: Section 1 dealt with the pathophysiology of asthma and its treatment, including standard intervention instructions; Section 2 provided details of outcome measures and data collection instruments to be used in the study.

- Delivered by: researcher

- Type: education

- Mode of delivery: group

- TDF: knowledge

- Duration: 2 evenings; first evening open only to the intervention group and focused on the intervention, the second evening was open to both groups and focused on study procedures. No other information was provided.

Pharmacy worker control: only attended second evening and received section 2 of manual

Pharmacy user-directed intervention: patients received verbal counselling, an educational video, an information leaflet, and subsequent monitoring with reinforcement.

- Delivered by: pharmacists

- Type: self-management

- Mode of delivery: individual face-to-face; video/DVD; written materials

- TDF: knowledge, skills, behavioural regulation

- Duration: unclear

- Follow up: 12 months (end of intervention)

Pharmacy user control: patients were given their prescribed drugs and informed of the dosage regimen, but received no other assistance.

\section{Pharmacy user:}

- Clinical: PEFR

- Psychological health: not assessed

- Behavioural: inhaler technique

- Quality of life: patient's health-related quality of life Short Form 36 (SF-36); Living With Asthma Questionnaire (LWAQ) for adults; Childhood Asthma Questionnaire (CAQ) for children aged 14 to 17 years

- Process: patients' subjective opinions of the services provided obtained through a structured patient satisfaction questionnaire

- Costs/HCU: hospitalisations, GP visits, days off work

Notes Funding source: not reported

\section{Risk of bias}

\begin{tabular}{lll}
\hline Bias & Authors' judgement & Support for judgement \\
\hline $\begin{array}{l}\text { Random sequence genera- } \\
\text { tion (selection bias) }\end{array}$ & Unclear risk & Method of randomisation not stated. \\
\hline $\begin{array}{l}\text { Allocation concealment } \\
\text { (selection bias) }\end{array}$ & Low risk & Cluster randomised \\
\hline \hline
\end{tabular}


Cordina 2001 (Continued)

Baseline outcome mea- Low risk Some differences, but adjusted for in analysis. sures similar

Baseline characteristics Low risk Some differences, but adjusted for in analysis.
similar

Incomplete outcome data High risk

High dropout and unclear how this was adjusted for.

(attrition bias)

All outcomes

\begin{tabular}{|c|c|c|}
\hline $\begin{array}{l}\text { Blinding of outcome as- } \\
\text { sessment (detection bias) } \\
\text { All outcomes }\end{array}$ & Unclear risk & Not stated \\
\hline $\begin{array}{l}\text { Protection against conta- } \\
\text { mination }\end{array}$ & Unclear risk & Randomisation by pharmacists, but patients came from same asthma clinic. \\
\hline $\begin{array}{l}\text { Selective reporting (re- } \\
\text { porting bias) }\end{array}$ & Low risk & Not noted \\
\hline Other bias & Unclear risk & Differences in groups at baseline and attrition may have had significant effect. \\
\hline $\begin{array}{l}\text { Blinding of participants } \\
\text { and personnel (perfor- } \\
\text { mance bias) } \\
\text { All outcomes }\end{array}$ & Unclear risk & Not stated \\
\hline
\end{tabular}

\section{Crockett 2006}

$\begin{array}{ll}\text { Methods } & \text { Design: cluster-RT } \\ & \text { Groups: intervention (depression management); control (usual care) }\end{array}$

Pharmacies: 32
Pharmacy worker: not reported
Pharmacy user: 106 patients with depression
- mean age: intervention 46 (SD: 12 years); control 46 (SD: 15 years)
- $\%$ female: intervention $76 \%$; control $82 \%$
Setting: rural
Country: Australia

Interventions

Pharmacy worker-directed intervention: intervention pharmacists were given video-conference training on the nature and management of depression and were asked to dispense medication with extra advice and support.

- Delivered by: a psychiatrist, psychologist and GP

- Type: education; disease management

- Mode of delivery: video/DVD (video-conference training)

- TDF: knowledge, skills, environment, context and resources

- Duration: not reported 
Pharmacy user-directed intervention: education on depression management; patient's psychological well-being monitoring, attitudes towards taking antidepressants, adherence and patient satisfaction with service.

- Delivered by: pharmacists.

- Type: education; disease management.

- Mode of delivery: individual face-to-face; video/DVD; written materials

- TDF: knowledge, emotion

- Duration: variable; an initial visit and then, to quote, "checking 'how they were going' at subsequent visits to the pharmacy".

Follow-up: 3 months

Pharmacy user control: usual care

Pharmacy worker: not assessed

\section{Pharmacy user:}

- Clinical: not assessed.

- Psychological health: patients' well-being (K10)

- Behavioural: adherence

- Quality of life: not assessed

- Process: patient satisfaction with service; attitude towards taking antidepressants (using the Drug Attitude Index (DAI)).

- Costs: not assessed.

$\begin{array}{ll}\text { Notes } & \text { Study/intervention name: none given } \\ \text { Funding source: grant from the Rural and Remote Pharmacy Infrastructe Grants scheme }\end{array}$

\section{Risk of bias}

\begin{tabular}{lll}
\hline Bias & Authors' judgement & Support for judgement \\
\hline $\begin{array}{l}\text { Random sequence genera- } \\
\text { tion (selection bias) }\end{array}$ & Unclear risk & Randomised, but no specific method mentioned. \\
\hline $\begin{array}{l}\text { Allocation concealment } \\
\text { (selection bias) }\end{array}$ & Unclear risk & Not mentioned \\
\hline $\begin{array}{l}\text { Baseline outcome mea- } \\
\text { sures similar }\end{array}$ & Unclear risk & Baseline differences unclear \\
\hline $\begin{array}{l}\text { Baseline characteristics } \\
\text { similar }\end{array}$ & Low risk & $\begin{array}{l}\text { No differences in the characteristics reported, but reported adjustment in } \\
\text { analyses for baseline differences }\end{array}$ \\
\hline $\begin{array}{l}\text { Incomplete outcome data } \\
\text { (attrition bias) } \\
\text { All outcomes }\end{array}$ & Low risk & Nothing noted \\
\hline $\begin{array}{l}\text { Blinding of outcome as- } \\
\text { sessment (detection bias) }\end{array}$ & Unclear risk & Not mentioned \\
\hline
\end{tabular}


Crockett 2006 (Continued)

All outcomes

$\begin{array}{lll}\begin{array}{l}\text { Protection against conta- } \\ \text { mination }\end{array} & \text { High risk } & \begin{array}{l}\text { Randomisation at pharmacist level but four of control pharmacies were deliv- } \\ \text { ering similar intervention }\end{array}\end{array}$

\begin{tabular}{lll}
\hline $\begin{array}{l}\text { Selective reporting (re- } \\
\text { porting bias) }\end{array}$ & Low risk & Nothing noted. \\
\hline Other bias & Unclear risk & Assessments may have impacted outcome \\
\hline $\begin{array}{l}\text { Blinding of participants } \\
\begin{array}{l}\text { and personnel (perfor- } \\
\text { mance bias) }\end{array}\end{array}$ & Unclear risk & Not mentioned \\
All outcomes & \\
\hline
\end{tabular}

\section{Dhital 2015}

$\begin{array}{ll}\text { Methods } & \text { Design: RT } \\ \text { Groups: intervention (brief motivational interviewing alcohol intervention); control (leaflet only) }\end{array}$

$\begin{array}{ll}\text { Participants } & \text { Pharmacies: } 16 \\ & \text { Pharmacy worker: not reported }\end{array}$

Pharmacy user: 407 (205 intervention; 202 control)

- mean age: intervention $39.6 \pm 15.9$ years; control $40.5 \pm 17.48$ years

- \% female: intervention $47.8 \%$; control $43.6 \%$

Setting:urban

Country: London, UK

- Delivered by: unclear

- Type: training workshop

- Mode of delivery: possibly face-to-face, but unclear

- TDF: knowledge

- Duration: 3.5 hour training in motivational interviewing approach + 2 hour additional problem solving session 7 weeks after start of the trial

Pharmacy worker control: it appears the same pharmacists saw both intervention and control groups.

Pharmacy user-directed intervention: structured 10-minute discussion about drinking based on motivational interviewing, also gave participants 'Units and You' booklet and unit/calorie calculator wheel and alcohol services leaflet

- Delivered by: pharmacist

- Type: behaviour change

- Mode of delivery: individual, face-to-face; written materials

- TDF:knowledge, beliefs about consequences, environment, context, resources 
Dhital 2015 (Continued)

- Duration: 10 minutes

- Follow-up: 3 months

Pharmacy user control: given a leaflet called "Alcohol: The Basics"

Pharmacy worker: not assessed
Pharmacy user:
- Clinical: not assessed
- Psychological health: not assessed
- Behavioural: Alcohol Use Disorders Identification Test (AUDIT)
- Quality of life: EQ-5D
- Process: not assessed
- Costs: not assessed

Notes Study/intervention name: none given

Funding source: Pharmacy Practice Research Trust, Royal Pharmaceutical Society of Great Britain, and the Harold and Marjorie Moss Charitable Trust

\section{Risk of bias}

\begin{tabular}{|c|c|c|}
\hline Bias & Authors' judgement & Support for judgement \\
\hline $\begin{array}{l}\text { Random sequence genera- } \\
\text { tion (selection bias) }\end{array}$ & Low risk & Sealed numbered envelopes, monitored for tampering \\
\hline $\begin{array}{l}\text { Allocation concealment } \\
\text { (selection bias) }\end{array}$ & Low risk & $\begin{array}{l}\text { Pharmacists not involved in research data collection and allocation after con- } \\
\text { sent }\end{array}$ \\
\hline $\begin{array}{l}\text { Baseline outcome mea- } \\
\text { sures similar }\end{array}$ & Low risk & Did not differ between the two groups \\
\hline $\begin{array}{l}\text { Baseline characteristics } \\
\text { similar }\end{array}$ & Low risk & No significant differences \\
\hline $\begin{array}{l}\text { Incomplete outcome data } \\
\text { (attrition bias) } \\
\text { All outcomes }\end{array}$ & Low risk & Sensitivity analysis and adjustment for attrition \\
\hline $\begin{array}{l}\text { Blinding of outcome as- } \\
\text { sessment (detection bias) } \\
\text { All outcomes }\end{array}$ & Low risk & Researcher blinded to allocation status \\
\hline $\begin{array}{l}\text { Protection against conta- } \\
\text { mination }\end{array}$ & High risk & Both control and intervention participants within one pharmacy \\
\hline $\begin{array}{l}\text { Selective reporting (re- } \\
\text { porting bias) }\end{array}$ & Low risk & All outcomes reported \\
\hline Other bias & Low risk & No other bias obvious \\
\hline $\begin{array}{l}\text { Blinding of participants } \\
\text { and personnel (perfor- } \\
\text { mance bias) }\end{array}$ & High risk & $\begin{array}{l}\text { Relevant personnel were blinded to randomisation status throughout the trial, } \\
\text { but participants not blinded. }\end{array}$ \\
\hline
\end{tabular}


Dhital 2015 (Continued)

All outcomes

Dolovich 2007

\begin{tabular}{ll}
\hline Methods & Design: RT \\
Groups: intervention (Asthma Education Program (AEP); control (usual care-delayed AEP)
\end{tabular}

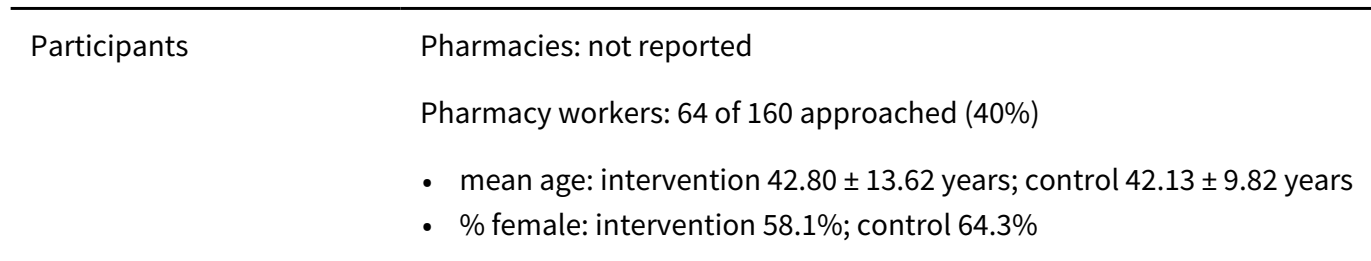

Pharmacy user: not targeted

Setting: urban

Country: Canada

Interventions

Pharmacy worker-directed intervention: volunteer community pharmacists received an asthma education program (AEP)

- Delivered by: not specified

- Type: education: skill building

- Mode of delivery: group; individual face-to-face; written materials

- TDF: knowledge, skills, environment, context, resources

- Duration: one-day workshop; 2 follow-up telephone calls

- Follow-up: 3-5 weeks post workshop

Pharmacy worker control: delayed AEP

Pharmacy user-directed intervention: not targeted

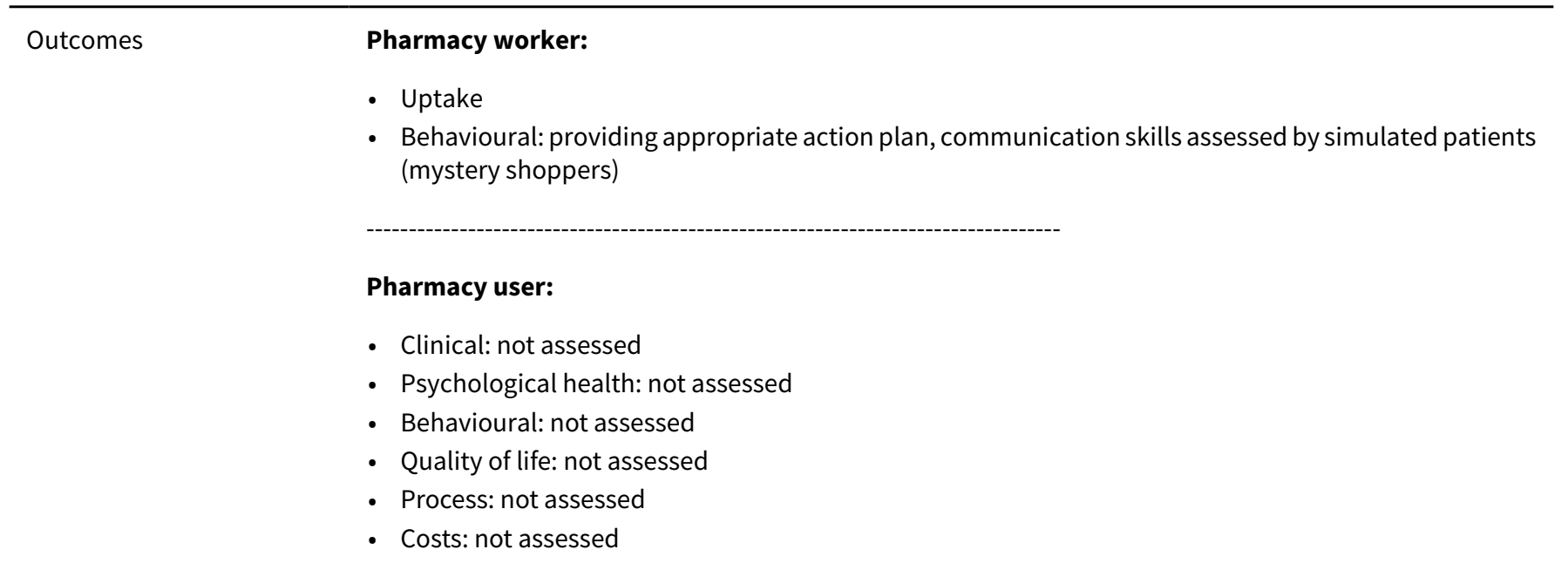


Dolovich 2007 (Continued)

Funding source: Merck Frosst Canada Inc, and in-kind contribution from Agro Health Associates Inc, and the Centre for Evaluation of Medicines

\begin{tabular}{|c|c|c|}
\hline \multicolumn{3}{|l|}{ Risk of bias } \\
\hline Bias & Authors' judgement & Support for judgement \\
\hline $\begin{array}{l}\text { Random sequence genera- } \\
\text { tion (selection bias) }\end{array}$ & Low risk & Random numbers table \\
\hline $\begin{array}{l}\text { Allocation concealment } \\
\text { (selection bias) }\end{array}$ & Low risk & Concealed \\
\hline $\begin{array}{l}\text { Baseline outcome mea- } \\
\text { sures similar }\end{array}$ & Unclear risk & Only assessed post workshop \\
\hline $\begin{array}{l}\text { Baseline characteristics } \\
\text { similar }\end{array}$ & Low risk & No reported differences \\
\hline $\begin{array}{l}\text { Incomplete outcome data } \\
\text { (attrition bias) } \\
\text { All outcomes }\end{array}$ & Low risk & Low dropout, no patterns identified \\
\hline $\begin{array}{l}\text { Blinding of outcome as- } \\
\text { sessment (detection bias) } \\
\text { All outcomes }\end{array}$ & Low risk & $\begin{array}{l}\text { Outcome assessors were blinded to assignment of the pharmacists to inter- } \\
\text { vention or control groups. }\end{array}$ \\
\hline $\begin{array}{l}\text { Protection against conta- } \\
\text { mination }\end{array}$ & Unclear risk & Unclear if there was interaction between sites \\
\hline $\begin{array}{l}\text { Selective reporting (re- } \\
\text { porting bias) }\end{array}$ & Low risk & Not noted \\
\hline Other bias & Unclear risk & Possible selection bias - pharmacists volunteers \\
\hline $\begin{array}{l}\text { Blinding of participants } \\
\text { and personnel (perfor- } \\
\text { mance bias) } \\
\text { All outcomes }\end{array}$ & High risk & Not blinded to group allocation \\
\hline
\end{tabular}

Doucette 2009

\begin{tabular}{ll}
\hline Methods & Design: RT \\
Groups: intervention (extended diabetes care); control (usual care)
\end{tabular}

Participants

Pharmacies: 7

Pharmacy workers: 9 pharmacists

Pharmacy user: 78 people with type 2 diabetes

- Mean age: intervention $58.7 \pm 13.3$ years; control $61.2 \pm 10.9$ years

- $\%$ female: intervention $21 \%$; control $22 \%$

Setting: unclear 
Doucette 2009 (Continued)

$$
\text { Country: USA }
$$

Interventions

Pharmacy worker-directed intervention: participating pharmacists received training in diabetes management and study protocol. Both self-study and live programs included discussion of mock cases. Skills training in monitoring blood pressure, using a blood glucose meter, filling an insulin syringe, and administering an insulin injection

- Delivered by: unclear

- Type: education materials, self-management

- Mode of delivery: self-study and live training

- TDF: knowledge, skills

- Duration: self-study component was 15 hours, but length of live program was not stated.

- Follow-up: not stated

Pharmacy worker control: not applicable as control patients seen by other primary care providers

Pharmacy user-directed intervention: patients had already received 2 diabetes education sessions, then received extended diabetes care, discussed medications, clinical goals, and self-care activities; pharmacists recommended medication changes to physicians when appropriate.

- Delivered by: pharmacists

- Type: self-management; disease management

- Mode of delivery: individual face-to-face

- TDF: knowledge, goals

- Duration: intervention 12 months; number of interventions: up to 4 (quarterly)

- Follow-up: 12 months (end of intervention)

Pharmacy user control: usual diabetes care from their primary care provider

Outcomes Pharmacy worker: not assessed

\section{Pharmacy user:}

- Clinical: HA1c; LDL-C; SBP; DBP; BMI

- Psychological health: not assessed

- Behavioural: The Summary of diabetes self care activities measure (SDSCA)

- Quality of life: not assessed

- Process: not assessed

- Costs: not assessed

Notes Study/intervention name: none given

Funding source: a grant from the Community Pharmacy Federation

\section{Risk of bias}

\begin{tabular}{lll}
\hline Bias & Authors' judgement & Support for judgement \\
\hline $\begin{array}{l}\text { Random sequence genera- } \\
\text { tion (selection bias) }\end{array}$ & Unclear risk & Unclear, no information provided on method of randomisation \\
\hline $\begin{array}{l}\text { Allocation concealment } \\
\text { (selection bias) }\end{array}$ & Unclear risk & Unclear, not stated \\
\hline
\end{tabular}


Doucette 2009 (Continued)

$\begin{aligned} & \text { Baseline outcome mea- Low risk } \\ & \text { sures similar }\end{aligned}$
No differences

$\begin{array}{ll}\text { Baseline characteristics } & \text { Low risk } \\ \text { similar }\end{array}$

similar

Incomplete outcome data Unclear risk

(attrition bias)

All outcomes

\begin{tabular}{|c|c|c|}
\hline $\begin{array}{l}\text { Blinding of outcome as- } \\
\text { sessment (detection bias) } \\
\text { All outcomes }\end{array}$ & Unclear risk & Not stated \\
\hline $\begin{array}{l}\text { Protection against conta- } \\
\text { mination }\end{array}$ & Unclear risk & $\begin{array}{l}\text { Recruitment at patient level, from same centre, unclear if patients attended } \\
\text { different pharmacies }\end{array}$ \\
\hline $\begin{array}{l}\text { Selective reporting (re- } \\
\text { porting bias) }\end{array}$ & Low risk & Paper seemed to report all relevant outcomes. \\
\hline Other bias & Unclear risk & Nothing noted \\
\hline $\begin{array}{l}\text { Blinding of participants } \\
\text { and personnel (perfor- } \\
\text { mance bias) } \\
\text { All outcomes }\end{array}$ & High risk & Not blinded \\
\hline
\end{tabular}

\section{Fuller 2016}

\begin{tabular}{ll}
\hline Methods & Design: cluster-RT \\
& $\begin{array}{l}\text { Groups: intervention (Modified Brief Behavioural Intervention Insomnia (MBBTi)); control (usual care + } \\
\text { information leaflet) }\end{array}$
\end{tabular}

Participants Pharmacies: 12 (7 intervention; 5 control)

Pharmacy workers: not reported

Pharmacy user: 56 insomniacs (22 intervention; 34 control)

- mean age: intervention $53.5 \pm 21.1$ years; control $53.9 \pm 6.1$ years

- \% female: intervention $64.7 \%$; control $78.9 \%$

Setting: unclear

Country: New South Wales, Australia

Interventions

Pharmacy worker-directed intervention: training on sleep and sleep management through interactive lectures, case study discussions, role play plus manual with details of sleep and MBBTi

- Delivered by: sleep clinicians

- Type: education

- Mode of delivery: manual and face-to-face

- TDF: knowledge, skills

- Duration: workshop 7 hours 
Fuller 2016 (Continued)

- Follow-up: 3 months (end of intervention)

Pharmacy worker control: control group manual provided detailed background information on sleep and sleep health, insomnia and its impact, models of insomnia and general insomnia treatment (pharmacological and sleep hygiene methods).

Pharmacy user-directed intervention: standardised education + sleep restriction and/or stimulus control, goal setting, sleep diaries

- Delivered by: pharmacists

- Type: behavioural

- Mode of delivery: face-to-face, workbook

- TDF: knowledge, goals, behavioural regulation

- Duration: 3 visits

- Follow-up: 3 months (end of intervention)

Pharmacy user control: usual care and information sheets on insomnia if needed

\begin{tabular}{|c|c|c|}
\hline Outcomes & $\begin{array}{l}\text { Pharmacy worker: } \\
\text { - Behavioural: interv } \\
\text { Pharmacy user: } \\
\text { - Clinical: Insomnia S } \\
\text { - Psychological healt } \\
\text { - Behavioural: not as } \\
\text { - Quality of life: not a } \\
\text { - Process: participan } \\
\text { - Costs: not assessed }\end{array}$ & $\begin{array}{l}\text { ntions delivered by pharmacists } \\
\text { verity Score (ISI) } \\
\text { : Depression, Anxiety, Stress Scale (DASS-21) } \\
\text { essed } \\
\text { sessed } \\
\text { completed the Dysfunctional Beliefs About Sleep (DBAS-16) questionnaire }\end{array}$ \\
\hline Notes & \multicolumn{2}{|c|}{$\begin{array}{l}\text { Funding source: Scholarship Faculty Pharmacy, University of Sydney and CIRUS (Centre for Integrated } \\
\text { Research into the Understanding of Sleep) }\end{array}$} \\
\hline \multicolumn{3}{|l|}{ Risk of bias } \\
\hline Bias & Authors' judgement & Support for judgement \\
\hline $\begin{array}{l}\text { Random sequence genera- } \\
\text { tion (selection bias) }\end{array}$ & Low risk & Used RAND function in Excel for simple randomisation \\
\hline $\begin{array}{l}\text { Allocation concealment } \\
\text { (selection bias) }\end{array}$ & High risk & Incomplete allocation concealment \\
\hline $\begin{array}{l}\text { Baseline outcome mea- } \\
\text { sures similar }\end{array}$ & Low risk & MBBTi and control patients were similar at baseline \\
\hline $\begin{array}{l}\text { Baseline characteristics } \\
\text { similar }\end{array}$ & Low risk & No significant differences between groups in any of the demographics \\
\hline $\begin{array}{l}\text { Incomplete outcome data } \\
\text { (attrition bias) } \\
\text { All outcomes }\end{array}$ & Low risk & Alternative analysis performed to allow for all available data to be used \\
\hline
\end{tabular}


Fuller 2016 (Continued)

Blinding of outcome as- High risk Pharmacists undertook data collection, but did not score key outcomes at folsessment (detection bias) low-up.

All outcomes

Protection against conta- Low risk Cluster randomised
mination

mination

\begin{tabular}{lll}
\hline $\begin{array}{l}\text { Selective reporting (re- } \\
\text { porting bias) }\end{array}$ & Low risk & Not apparent \\
\hline Other bias & High risk & Cluster effects not taken into account for all key outcomes other than the ISI. \\
\hline $\begin{array}{l}\text { Blinding of participants } \\
\begin{array}{l}\text { and personnel (perfor- } \\
\text { mance bias) }\end{array}\end{array}$ & High risk & Pharmacists were aware of participants' groups. \\
All outcomes & & \\
\hline
\end{tabular}

\section{Garcia 1998}

\begin{tabular}{ll}
\hline Methods & Design: cluster-RT \\
Groups: intervention group (education on sexually transmitted disease (STD) recognition, manage- \\
ment, and prevention counselling); control group (usual care)
\end{tabular}

\section{Participants}

Pharmacies: 168

Pharmacy workers: average 1.7 (range 1 to 7 ) workers per pharmacy

- mean age: 37.9 years

- $\%$ female: $60 \%$

Pharmacy user: not reported

Setting: urban

Country: Peru

Interventions

Pharmacy worker-directed intervention: pharmacists and pharmacist technicians received education on STD recognition, management, and prevention counselling, and were visited by standardised simulated patients.

- Delivered by: intervention team members

- Type: education materials, based on clinical practice guidelines; role playing

- Mode of delivery: group; individual face-to-face; written materials

- TDF: knowledge, skills, environment, context, resources, social support

- Duration: 8-hour training course (23\%), or a 1.5 to 2-hour on site training using a 32-page revised manual offered at each intervention pharmacy.

Pharmacy user-directed intervention: not reported

Pharmacy worker:
- Behavioural: simulated patients STD management
- Costs: cost of treatment


Garcia 1998 (Continued)

Pharmacy user: not assessed

\begin{tabular}{ll}
\hline Notes & Study/intervention name: none given \\
& Funding source: Fogarty International Center grant NIAID Center for AIDS Research Grant NIH grant, \\
& USAID
\end{tabular}

\section{Risk of bias}

\begin{tabular}{|c|c|c|}
\hline Bias & Authors' judgement & Support for judgement \\
\hline $\begin{array}{l}\text { Random sequence genera- } \\
\text { tion (selection bias) }\end{array}$ & Unclear risk & Randomised, but method not mentioned \\
\hline $\begin{array}{l}\text { Allocation concealment } \\
\text { (selection bias) }\end{array}$ & Low risk & By pharmacy \\
\hline $\begin{array}{l}\text { Baseline outcome mea- } \\
\text { sures similar }\end{array}$ & Unclear risk & Overall scores reported, but not comparison between control and intervention \\
\hline $\begin{array}{l}\text { Baseline characteristics } \\
\text { similar }\end{array}$ & Unclear risk & Overall scores reported, but not comparison between control and intervention \\
\hline $\begin{array}{l}\text { Incomplete outcome data } \\
\text { (attrition bias) } \\
\text { All outcomes }\end{array}$ & Unclear risk & Reported loss to follow-up, but unclear how this was adjusted for \\
\hline $\begin{array}{l}\text { Blinding of outcome as- } \\
\text { sessment (detection bias) } \\
\text { All outcomes }\end{array}$ & Low risk & Simulated patients were blinded \\
\hline $\begin{array}{l}\text { Protection against conta- } \\
\text { mination }\end{array}$ & Low risk & Pharmacies cluster randomised \\
\hline $\begin{array}{l}\text { Selective reporting (re- } \\
\text { porting bias) }\end{array}$ & Low risk & All outcomes reported \\
\hline Other bias & Unclear risk & Not noted \\
\hline $\begin{array}{l}\text { Blinding of participants } \\
\text { and personnel (perfor- } \\
\text { mance bias) } \\
\text { All outcomes }\end{array}$ & High risk & Only intervention group were offered training \\
\hline
\end{tabular}

\section{Garcia 2003}

\begin{tabular}{ll}
\hline Methods & Design: cluster-RT \\
& $\begin{array}{l}\text { Groups: intervention group (management and prevention of STDs); control group (1-day seminar on } \\
\text { management of diarrhoea) }\end{array}$
\end{tabular}

Participants

Pharmacies: the 24 districts in Lima that had the lowest socio-economic status were selected and matched in 12 pairs; 7 pairs of districts were chosen randomly to participate in 2 phases reported separately by study: 
- First phase: a pilot phase:

* Intervention: 1 district with 221 pharmacies of which 200 pharmacies received training and 120 pharmacies were randomly selected for evaluation;

* Control: 1 district with 159 pharmacies, all invited to seminar and 120 pharmacies were randomly selected for evaluation.

- Second phase: full study phase:

* Intervention: 6 districts with 897 pharmacies of which 684 received training and 100 pharmacies were randomly selected for evaluation;

* Control: 6 districts with 883 pharmacies, all invited to seminar after which pharmacies were randomly selected for evaluation.

Pharmacy workers: 2223 workers in intervention group participated in at least one seminar, 1872 (84.2\%) attended all seminars.

Pharmacy user: not reported

Setting: rural

Country: Peru

Interventions

Pharmacy worker-directed intervention: pharmacies received education on STD recognition, management, and prevention counselling and were visited by standardised simulated patients.

- Delivered by: pharmacist and midwife team

- Type: education materials, based on clinical practice guidelines; education meetings

- Mode of delivery: group; written materials

- TDF: knowledge, skills, environment, context and resources, social support

- Duration: 3 x 90-minute luncheon training seminars on STD/HIV. Monthly follow-up visits to discuss STD/HIV prevention and provide materials.

- Follow-up: 1, 3 and 6 months after training

Pharmacy worker control: invited to a seminar on diarrhoea management

Pharmacy user-directed intervention: not reported

\begin{tabular}{ll}
\hline Outcomes & Pharmacy worker: \\
& - Uptake of pharmacies: 884 of $1118(79 \%)$ \\
& - Behavioural: simulated patient management of STD \\
& Pharmacy user: not assessed \\
\hline Notes & Study/intervention name: none given \\
& Funding source: Wellcome Trust-Burroughs Wellcome Fund Infectious Disease Initiative \\
& Pilot study for 2012 studies \\
\hline Risk of bias & Authors' judgement Support for judgement \\
\hline Bias & Low risk \\
\hline $\begin{array}{l}\text { Random sequence genera- } \\
\text { tion (selection bias) }\end{array}$ & \\
\hline
\end{tabular}


Garcia 2003 (Continued)

\begin{tabular}{|c|c|c|}
\hline $\begin{array}{l}\text { Allocation concealment } \\
\text { (selection bias) }\end{array}$ & Low risk & Adequately concealed - data extraction form \\
\hline $\begin{array}{l}\text { Baseline outcome mea- } \\
\text { sures similar }\end{array}$ & Unclear risk & Preintervention assessments not conducted \\
\hline $\begin{array}{l}\text { Baseline characteristics } \\
\text { similar }\end{array}$ & Unclear risk & Preinterventions assessments not conducted \\
\hline $\begin{array}{l}\text { Incomplete outcome data } \\
\text { (attrition bias) } \\
\text { All outcomes }\end{array}$ & Low risk & Minimal attrition \\
\hline $\begin{array}{l}\text { Blinding of outcome as- } \\
\text { sessment (detection bias) } \\
\text { All outcomes }\end{array}$ & Low risk & $\begin{array}{l}\text { Standardised simulated patients were blinded to the nature of the training, } \\
\text { the randomisation procedure, and the status of districts or pharmacies as in- } \\
\text { tervention or controls. }\end{array}$ \\
\hline $\begin{array}{l}\text { Protection against conta- } \\
\text { mination }\end{array}$ & Low risk & Cluster randomised \\
\hline $\begin{array}{l}\text { Selective reporting (re- } \\
\text { porting bias) }\end{array}$ & Unclear risk & $\begin{array}{l}\text { Findings were presented for the } 4 \text { outcomes, but only for selection of pharma- } \\
\text { cies }\end{array}$ \\
\hline Other bias & Low risk & Not noted \\
\hline $\begin{array}{l}\text { Blinding of participants } \\
\text { and personnel (perfor- } \\
\text { mance bias) } \\
\text { All outcomes }\end{array}$ & Low risk & Control pharmacies offered training in diarrhoea to maintain blinding \\
\hline
\end{tabular}

\section{Garcia 2012}

Methods Design: cluster-RT (by city; $\mathrm{n}=20$ )

Groups: intervention group (management and prevention of STDs); control group (standard care)

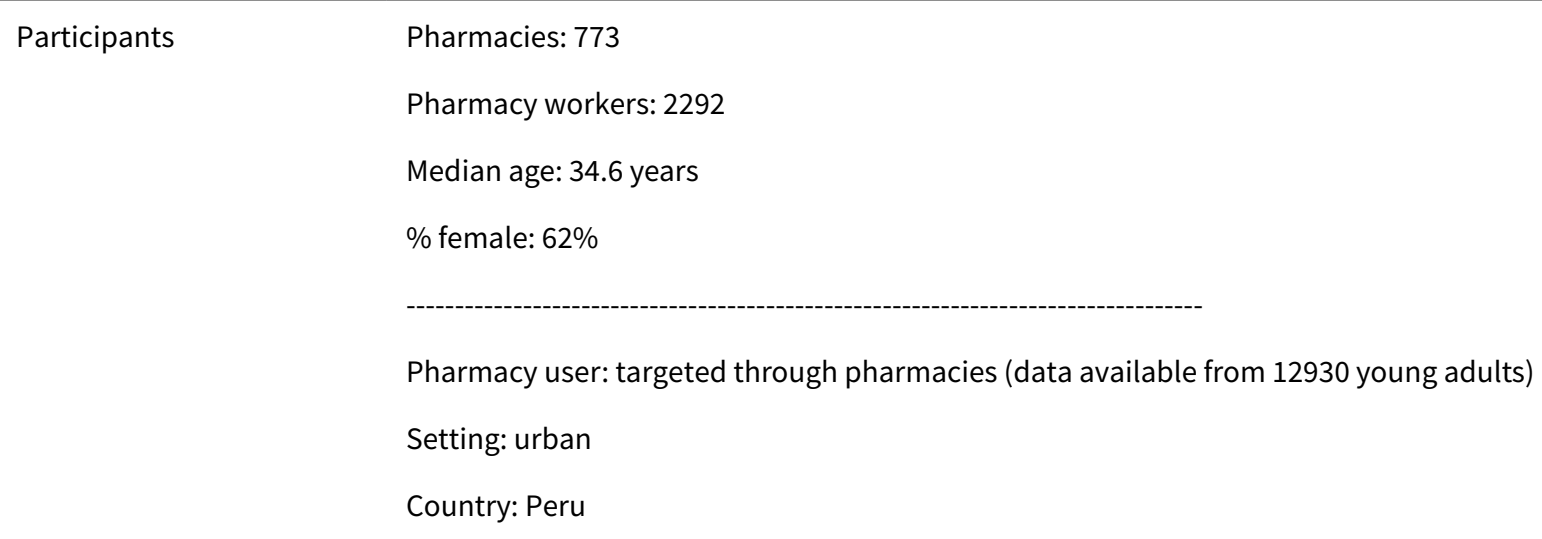

Interventions

Pharmacy worker-directed intervention: the intervention comprised 4 modalities: 
- strengthened STD syndromic management by pharmacy workers and clinicians;

- mobile-team outreach to female sex workers for sexually transmitted infection screening and pathogen-specific treatment;

- periodic presumptive treatment of female sex workers for trichomoniasis; and

- condom promotion for female sex workers and the general population.

- Delivered by: pharmacist and midwife team

- Type: education materials, based on clinical practice guidelines; interactive meeting with role play, case studies

- Mode of delivery: group of 8 to 10 pharmacy workers; written materials

- Duration: 4 x 90-minute luncheon training seminars on STD/HIV. Monthly follow-up visits to discuss STD/HIV prevention and provide materials.

- Follow-up: 1, 3 and 6 months after training

Pharmacy worker control: usual treatment

Pharmacy user-directed intervention: not reported

\begin{tabular}{|c|c|c|}
\hline Outcomes & \multicolumn{2}{|c|}{$\begin{array}{l}\text { Pharmacy user: } \\
\text { - Clinical: infection with STD } \\
\text { - Psychological health: not assessed } \\
\text { - Behavioural: not assessed } \\
\text { - Quality of life: not assessed } \\
\text { - Process: not assessed } \\
\text { - Costs: not assessed }\end{array}$} \\
\hline Notes & \multicolumn{2}{|c|}{$\begin{array}{l}\text { Funding Source: Wellcome Trust and Burroughs Wellcome Fund, National Institues of Health, Centre for } \\
\text { AIDS Research, CIPRA, and USAID-Peru. } \\
\text { Garcia } 2012 \text { (cited under Garcia 2012) also reported on this study. }\end{array}$} \\
\hline \multicolumn{3}{|l|}{ Risk of bias } \\
\hline Bias & Authors' judgement & Support for judgement \\
\hline $\begin{array}{l}\text { Random sequence genera- } \\
\text { tion (selection bias) }\end{array}$ & Low risk & Computer randomisation \\
\hline $\begin{array}{l}\text { Allocation concealment } \\
\text { (selection bias) }\end{array}$ & High risk & $\begin{array}{l}\text { Participants in outcome surveys were recruited after city randomisation, pre- } \\
\text { cluding allocation concealment }\end{array}$ \\
\hline $\begin{array}{l}\text { Baseline outcome mea- } \\
\text { sures similar }\end{array}$ & Low risk & Adjusted for in analysis \\
\hline $\begin{array}{l}\text { Baseline characteristics } \\
\text { similar }\end{array}$ & Low risk & Adjusted for in analysis \\
\hline
\end{tabular}


Garcia 2012 (Continued)

Incomplete outcome data Low risk Missing data replaced with classification of negative composite endpoint
(attrition bias)

All outcomes

US and UK investigators masked until testing complete

Blinding of outcome as- Low risk sessment (detection bias)

All outcomes

Protection against conta- Low risk Cluster randomised
mination

Selective reporting (re- Low risk Primary and secondary outcomes reported
porting bias)

\begin{tabular}{lll}
\hline Other bias & Low risk & Not noted \\
\hline $\begin{array}{l}\text { Blinding of participants } \\
\text { and personnel (perfor- }\end{array}$ & High risk & Fieldworkers and Peruvian study team could not be masked \\
mance bias) & \\
All outcomes & \\
\hline
\end{tabular}

\section{Garcia-Cardenas 2013}

\begin{tabular}{ll}
\hline Methods & Design: cluster-RT \\
& Groups: intervention group (management of asthma); control group (standard care) \\
\hline
\end{tabular}

\section{Participants}

Pharmacies: 51 (29 intervention; 22 control)

Pharmacy workers: 33 pharmacists in intervention group; 32 pharmacists in control group

Pharmacy user: 346 patients with asthma (186 intervention; 160 control)

- mean age: intervention $54.3 \pm 19.1$ years; control $57.8 \pm 19.0$ years

- \% female: intervention $57.9 \%$; control $51.3 \%$

Setting: all pharmacies in Malaga and Madrid (urban and rural)

Country: Spain

Interventions

Pharmacy worker-directed intervention: 33 pharmacists allocated to the intervention group attended a 1-day workshop. They were trained to provide education on asthma control, medication adherence and inhaler technique and received the Spanish Guide for Asthma Management (GEMA 2009).

- Delivered by: respiratory physician and a pharmacist educator/researcher

- Type: education materials, based on clinical practice guidelines; interactive meeting with role play, case studies

- Mode of delivery: group

- TDF: knowledge, skills, social support

- Duration: 1 day with regular visits to assist delivery

Pharmacy worker control: received instructions by phone about study protocol and monitored through 2 visits to the pharmacy 
Pharmacy user-directed intervention: asthma self-management

- Delivered by: pharmacists

- Type: patients were educated using verbal instructions, physical demonstration and written information about turbuhaler use. When appropriate the type of non-adherence (intentional or unintentional) and causes of intentional non-adherence were explored with the Beliefs about Medicines Questionnaire and Health Beliefs Model. Several aspects of asthma control were also covered in each visit. Finally pharmacist and patient jointly agreed goals for the next visit.

- Mode of delivery: individual face-to-face

- TDF: knowledge, skills, beliefs about consequences, goals

- Duration: 3 scheduled visits over 6 months and up to 6 addition visits if needed

Pharmacy user control: usual treatment

Pharmacy worker:
- Uptake: 51 of 65 pharmacies completed study
Pharmacy user:
- Clinical: asthma control via Asthma Control Questionnaire (ACQ)
- Psychological health: not assessed
- Behavioural: inhaler technique (checklist), adherence to medication (Morisky Adherence scale)
- Quality of life: not assessed
- Process: not assessed
- Costs: not assessed

Notes Study/intervention name: The AFasma Study

Funding Source: AstraZeneca Foundation

\section{Risk of bias}

\begin{tabular}{lll}
\hline Bias & Authors' judgement & Support for judgement \\
\hline $\begin{array}{l}\text { Random sequence genera- } \\
\text { tion (selection bias) }\end{array}$ & Low risk & Computer generated \\
\hline $\begin{array}{l}\text { Allocation concealment } \\
\text { (selection bias) }\end{array}$ & Low risk & Computer generated \\
\hline $\begin{array}{l}\text { Baseline outcome mea- } \\
\text { sures similar }\end{array}$ & Low risk & Differences adjusted for in analyses \\
\hline $\begin{array}{l}\text { Baseline characteristics } \\
\text { similar }\end{array}$ & Low risk & Differences adjusted for in analyses \\
\hline $\begin{array}{l}\text { Incomplete outcome data } \\
\text { (attrition bias) } \\
\text { All outcomes }\end{array}$ & Unclear risk & Unclear how missing data were managed \\
\hline $\begin{array}{l}\text { Blinding of outcome as- } \\
\text { sessment (detection bias) } \\
\text { All outcomes }\end{array}$ & Unclear risk & Not clear if assessor blinded \\
\hline
\end{tabular}

Protection against conta- Low risk Cluster randomised
mination


Garcia-Cardenas 2013 (Continued)

Selective reporting (re- Low risk $\quad$ All outcomes reported
porting bias)

\begin{tabular}{lll}
\hline Other bias & Low risk & None noted \\
\hline $\begin{array}{l}\text { Blinding of participants } \\
\text { and personnel (perfor- } \\
\text { mance bias) }\end{array}$ & High risk & $\begin{array}{l}\text { Control group pharmacies were asked not to change care, which suggests that } \\
\text { they had knowledge of groups. }\end{array}$ \\
All outcomes & \\
\hline
\end{tabular}

\section{Jaffray 2014}

\begin{tabular}{ll} 
Methods & $\begin{array}{l}\text { Design: cluster-RT } \\
\text { Groups: intervention group (motivational interviewing to improve methadc } \\
\text { group (standard practice) }\end{array}$ \\
\hline Participants & Pharmacies: 76 of 87 approached were recruited \\
Pharmacy workers: 84 pharmacists of 95 contacted were recruited \\
----------------------------------------------------------------- \\
Pharmacy user: 542 methadone patients (295 intervention; 247 control) \\
- mean age: intervention $32.3 \pm 7.1$ years; control $32.6 \pm 7.3$ years \\
- $\%$ female: intervention $35.9 \%$; control $36.6 \%$ \\
Setting: Tayside, Ayrshire, Fort Valley, Lanarkshire, Grampian, Fife \\
Country: Scotland, UK
\end{tabular}

Interventions

Pharmacy worker-directed intervention: training in motivational interviewing during 4 sessions, the first 2 sessions emphasised techniques and discussion, and subsequent sessions allowed practice of skills. The intervention was also supported by a resource pack.

- Delivered by: Scottish Training on Drugs and Alcohol (STRADA) accredited motivational interview trainers

- Type: education materials; meetings; resource packs

- Mode of delivery: group; individual face-to-face; written materials; videotape

- TDF: knowledge, skills, memory, attention, decision making, environment, context, resources

- Duration: 4 sessions of training

Pharmacy worker control: usual practice

Pharmacy user-directed intervention: motivational interviewing offered at sessions over 6 months

- Delivered by: pharmacists

- Type: motivational interviewing

- Mode of delivery: individual face-to-face

- Duration: 6 month

- Number of sessions: as needed

- TDF: this level of intervention not reported

- Follow-up: 7 months (end of treatment) 
Pharmacy user control: usual treatment

\section{Pharmacy worker:}

- Uptake + attendance at training - $60 \%$ to $80 \%$

- Behaviour: motivational interview techniques using the Behaviour Change Counseling Index (BECCI)

\section{Pharmacy user:}

- Clinical: not assessed

- Psychological health: not assessed

- Behavioural: illicit heroin use

- Quality of life: Maudsley Addition Profile

- Process: interaction with pharmacists

- Costs: not assessed

Notes $\quad$ Funding source: Chief Scientist Office, Edinburgh, Scotland, UK

\section{Risk of bias}

\begin{tabular}{|c|c|c|}
\hline Bias & Authors' judgement & Support for judgement \\
\hline $\begin{array}{l}\text { Random sequence genera- } \\
\text { tion (selection bias) }\end{array}$ & Unclear risk & Randomised but method unclear \\
\hline $\begin{array}{l}\text { Allocation concealment } \\
\text { (selection bias) }\end{array}$ & Unclear risk & Unclear method for randomisation \\
\hline $\begin{array}{l}\text { Baseline outcome mea- } \\
\text { sures similar }\end{array}$ & Low risk & Any differences adjusted for in analyses \\
\hline $\begin{array}{l}\text { Baseline characteristics } \\
\text { similar }\end{array}$ & Low risk & Any differences adjusted for in analyses \\
\hline $\begin{array}{l}\text { Incomplete outcome data } \\
\text { (attrition bias) } \\
\text { All outcomes }\end{array}$ & Unclear risk & $\begin{array}{l}\text { Intention-to-treat with imputation for missing values but only for certain vari- } \\
\text { ables, others excluded }\end{array}$ \\
\hline $\begin{array}{l}\text { Blinding of outcome as- } \\
\text { sessment (detection bias) } \\
\text { All outcomes }\end{array}$ & High risk & Assessor aware of groupings \\
\hline $\begin{array}{l}\text { Protection against conta- } \\
\text { mination }\end{array}$ & High risk & $\begin{array}{l}\text { Although cluster randomised, report considerable movement of patients be- } \\
\text { tween pharmacies. }\end{array}$ \\
\hline $\begin{array}{l}\text { Selective reporting (re- } \\
\text { porting bias) }\end{array}$ & Low risk & Not noted \\
\hline Other bias & Unclear risk & $\begin{array}{l}\text { Only missing estimates were made for treatment satisfaction, physical and } \\
\text { psychological scores. }\end{array}$ \\
\hline $\begin{array}{l}\text { Blinding of participants } \\
\text { and personnel (perfor- } \\
\text { mance bias) } \\
\text { All outcomes }\end{array}$ & Low risk & Patients blinded \\
\hline
\end{tabular}




\section{Methods}

\section{Design: RT}

Groups: intervention group (pharmacist counselling); control group (printed materials)

Participants

Pharmacies: not reported
Pharmacy worker: 22 pharmacists trained

Pharmacy user: 67 patients with type 1 or type 2 diabetes mellitus (with insurance from participating employer)

- mean age: intervention $55.6 \pm 6.8$ years; control $52.6 \pm 9.2$ years

- \% female: intervention $38.89 \%$; control $61.29 \%$

Setting: urban

Country: USA
Pharmacy worker-directed intervention: pharmacists had to demonstrate evidence of prior certification as a diabetes educator or complete 16 hours of online training. All also had to complete 14 hours of didactic and case-based workshops with emphasis on patient education and empowerment, clinical intervention techniques, documentation and billing.

- TDF: knowledge, skills, environment, context and resources, behavioural regulation

Pharmacy worker control: it appears the same pharmacists saw both intervention and control groups.

Pharmacy user-directed intervention: received waiver of patient out-of-pocket expenses (e.g. copayments and/or co-insurance) for specified medications and physician visits, plus multiple scheduled education appointments with a pharmacist over a 12-month period.

- Delivered by: pharmacists

- Type: diabetes empowerment

- Mode of delivery: individual face-to-face

- TDF: knowledge, environment resources and context

- Duration: 12 months (end of intervention

- Length of intervention: 12 months; met monthly for the first 3 months and every 1 to 3 months thereafter (less frequently as patient improved on self-management)

- Session duration: initial visit was 60 minutes, follow-up visits were 30 minutes

Pharmacy user control: printed education materials and the same financial benefits as the intervention group
Pharmacy worker: not reported

\section{Pharmacy user:}

- Clinical: HbAlc; LDL; HDL; triglycerides; total-to-HDL ratio; and fasting blood glucose; SBP and DBP, weight, waist circumference, and BMI; Diabetes Knowledge Test (DKT)

- Psychological health: not assessed

- Behavioural: WHO Health and Work Performance Questionnaire (also known as HPQ); Adherence Starts with Knowledge (ASK-20) 
- Quality of life: Diabetes Empowerment scale (DES); 4 additional questions from the DES 'Long Form'

- Process: not assessed.

- Costs: insurance claims data

Notes Study/intervention name: the EMPOWER study

Funding source: partial funding for this project was received from the Community Pharmacy Foundation, Sanofi-Avetis, and Lane County Pharmacists Association.

\section{Risk of bias}

\begin{tabular}{|c|c|c|}
\hline Bias & Authors' judgement & Support for judgement \\
\hline $\begin{array}{l}\text { Random sequence genera- } \\
\text { tion (selection bias) }\end{array}$ & Unclear risk & Randomised, but methods were not mentioned. \\
\hline $\begin{array}{l}\text { Allocation concealment } \\
\text { (selection bias) }\end{array}$ & Unclear risk & No information provided \\
\hline $\begin{array}{l}\text { Baseline outcome mea- } \\
\text { sures similar }\end{array}$ & Low risk & Any differences accounted for in analyses \\
\hline $\begin{array}{l}\text { Baseline characteristics } \\
\text { similar }\end{array}$ & Low risk & Any differences accounted for in analyses \\
\hline $\begin{array}{l}\text { Incomplete outcome data } \\
\text { (attrition bias) } \\
\text { All outcomes }\end{array}$ & Unclear risk & Not clear how missing data were managed \\
\hline $\begin{array}{l}\text { Blinding of outcome as- } \\
\text { sessment (detection bias) } \\
\text { All outcomes }\end{array}$ & Unclear risk & $\begin{array}{l}\text { It is unclear whether the research team conducting follow-up assessments } \\
\text { were blind to group. }\end{array}$ \\
\hline $\begin{array}{l}\text { Protection against conta- } \\
\text { mination }\end{array}$ & High risk & $\begin{array}{l}\text { Participants were known to discuss the study between themselves, so that } \\
\text { blinding was broken and risk of contamination was possible. }\end{array}$ \\
\hline $\begin{array}{l}\text { Selective reporting (re- } \\
\text { porting bias) }\end{array}$ & Low risk & $\begin{array}{l}\text { No issues noted. Four parameters (cholesterol-to-HDL ratio, weight, waist cir- } \\
\text { cumference, and BMI) were not shown due to lack of changes from baseline } \\
\text { and difference between groups. }\end{array}$ \\
\hline Other bias & Low risk & Not noted \\
\hline $\begin{array}{l}\text { Blinding of participants } \\
\text { and personnel (perfor- } \\
\text { mance bias) } \\
\text { All outcomes }\end{array}$ & High risk & $\begin{array}{l}\text { On self-report } 54 \% \text { of control group indicated they were controls while } 75 \% \text { of } \\
\text { intervention group were unclear on their grouping. At least some participants } \\
\text { discussed the study between themselves, hence blinding was possibly broken. }\end{array}$ \\
\hline
\end{tabular}

Krass 2007

$\begin{array}{ll}\text { Methods } & \text { Design: cluster-RT } \\ \text { Groups: intervention group (education on diabetes, its management, medicines); control group (stan- } \\ \text { dard care) }\end{array}$

Participants Pharmacies: 56

Pharmacy workers: not reported 
Krass 2007 (Continued)

Pharmacy user: 289 patients with type 2 diabetes 289

- mean age $62 \pm 11$ years

- $\%$ female $49 \%$

Setting: both rural and urban

Country: Australia

Interventions

Pharmacy worker-directed intervention: all intervention pharmacists received a diabetes education manual for self-directed learning and also attended a 2-day workshop that consisted of lectures, role playing, training on monitors. Pharmacists received reimbursement for patients who completed all study visits.

- Delivered by: unclear

- Type: based on clinical practice guidelines; medication management; disease management, use of relevant devices; role playing

- Mode of delivery: written materials; face to face workshop

- TDF: knowledge, skills, environment, context and resources

- Duration: 2 days

Pharmacy worker control: training on study procedures and payment for every patient that completed both baseline and follow-up assessments

Pharmacy user-directed intervention: patients were given a blood glucose meter, instructed to use it daily. Measurements discussed at each visit to identify other interventions to support patient care (adherence support, medication review, diabetes self-management, lifestyle information etc.)

- Delivered by: pharmacists

- Type: self-management; behaviour change; based on clinical practice guidelines; medication management

- Mode of delivery: individual face-to-face, written materials

- TDF: knowledge, skills, goals, environment resources and context, behavioural regulation

- Duration: 5 meetings over 6 months (baseline, 2 weeks, 1.5 months, 3.5 months, 6 months)

- Follow-up: 6 months (end of intervention)

Pharmacy user control: usual care

Outcomes

\section{Pharmacy worker:}

- Uptake: not reported

\section{Pharmacy user:}

- Clinical: HbA1c; SBP and DBP, lipid profile and BMI

- Psychological health: not assessed

- Behavioural: not assessed

- Quality of life: EQ-5D

- Process: not assessed

- Costs: not assessed

Notes Study/intervention name: the Pharmacy Diabetes Care Program

NB This appears to be the same research group as Armour 2004, but this is a more complex study with a separate population. 


\section{Risk of bias}

\section{Bias}

Random sequence genera- Low risk tion (selection bias)

\section{Authors' judgement Support for judgement}

The pharmacies identified were located within $300 \mathrm{~km}$ of the participating universities. The percentage of pharmacies in each local government area (LGA) was then calculated. To obtain a random stratified sample of 60 pharmacies, the corresponding percentage per LGA was calculated and the required number within each stratum was randomly chosen using Excel.

\begin{tabular}{|c|c|c|}
\hline $\begin{array}{l}\text { Allocation concealment } \\
\text { (selection bias) }\end{array}$ & Low risk & As above \\
\hline $\begin{array}{l}\text { Baseline outcome mea- } \\
\text { sures similar }\end{array}$ & Low risk & Any differences controlled for in analyses \\
\hline $\begin{array}{l}\text { Baseline characteristics } \\
\text { similar }\end{array}$ & Low risk & Any differences controlled for in analyses \\
\hline $\begin{array}{l}\text { Incomplete outcome data } \\
\text { (attrition bias) } \\
\text { All outcomes }\end{array}$ & Unclear risk & $\begin{array}{l}\text { Comparison was made between completers and non-completers, but unclear } \\
\text { how accounted for in analyses }\end{array}$ \\
\hline $\begin{array}{l}\text { Blinding of outcome as- } \\
\text { sessment (detection bias) } \\
\text { All outcomes }\end{array}$ & Low risk & Objective outcomes \\
\hline $\begin{array}{l}\text { Protection against conta- } \\
\text { mination }\end{array}$ & Low risk & Cluster-RT \\
\hline $\begin{array}{l}\text { Selective reporting (re- } \\
\text { porting bias) }\end{array}$ & Low risk & Not noted \\
\hline Other bias & Low risk & Not noted \\
\hline $\begin{array}{l}\text { Blinding of participants } \\
\text { and personnel (perfor- } \\
\text { mance bias) } \\
\text { All outcomes }\end{array}$ & Unclear risk & Unclear whether intervention group participants were aware of grouping \\
\hline
\end{tabular}

\section{Liambila 2010}

\begin{tabular}{ll}
\hline Methods & Design: cluster-RT \\
& Groups: intervention (training on use of emergency contraceptives); control (standard care)
\end{tabular}

$\begin{array}{ll}\text { Participants } & \text { Pharmacies: } 20 \text { selected from } 98 \\ & \text { Pharmacy worker: } \\ \text { - } & \text { mean age: information not provided } \\ \text { - } \% \text { female: intervention } 67.4 \% \text {; control } 50.0 \%\end{array}$


Liambila 2010 (Continued)

Pharmacy user: not reported

Setting: urban

Country: Nairobi, Kenya

Interventions

Pharmacy worker-directed intervention: updating the private pharmacy providers on appropriate use of emergency contraceptives, how best to dispense it to users, family planning methods, referral for sexually transmitted infection (STI)/HIV testing and counselling. In-pharmacy information for pharmacy workers and users

- Delivered by: research assistants

- Type: education materials; reminders

- Mode of delivery: individual face-to-face; written materials

- TDF: knowledge, skills, environment, context and resources, behavioural regulation

- Duration: weekly sessions over 2 months

- Follow up: 2 months (end of intervention)

Pharmacy worker control: usual practice

Pharmacy user-directed intervention: advice on emergency contraceptives, family planning and STI management.

- Delivered by: pharmacists

- Type: medication management; information provision, behavioural advice

- Mode of delivery: face-to-face

- Duration: delivered over 3 months

Pharmacy user control: usual treatment

Outcomes Pharmacy worker:

- Uptake: 20 of 98 pharmacies selected, all of which participated

- Behavioural: mystery clients assessed pharmacist-given information (on emergency contraceptives, offer of regular family planning services, talk about STIs/HIV and offer of STI services)

Pharmacy user: not assessed

Notes Study/intervention name: none given

Funding source: William and Flora Hewlett Foundation

\section{Risk of bias}

\begin{tabular}{lll}
\hline Bias & Authors' judgement & Support for judgement \\
\hline $\begin{array}{l}\text { Random sequence genera- } \\
\text { tion (selection bias) }\end{array}$ & Unclear risk & Randomised, but method not specified \\
\hline $\begin{array}{l}\text { Allocation concealment } \\
\text { (selection bias) }\end{array}$ & Unclear risk & No information \\
\hline $\begin{array}{l}\text { Baseline outcome mea- } \\
\text { sures similar }\end{array}$ & Low risk & No differences \\
\hline
\end{tabular}


Liambila 2010 (Continued)

Baseline characteristics Unclear risk Little information
similar

\begin{tabular}{l}
\hline Incomplete outcome data Unclear risk No information on missing data \\
(attrition bias) \\
All outcomes
\end{tabular}

\begin{tabular}{|c|c|c|}
\hline $\begin{array}{l}\text { Blinding of outcome as- } \\
\text { sessment (detection bias) } \\
\text { All outcomes }\end{array}$ & Unclear risk & Not clear if mystery clients were aware of groupings \\
\hline $\begin{array}{l}\text { Protection against conta- } \\
\text { mination }\end{array}$ & Low risk & Control and intervention in separate geographical areas \\
\hline $\begin{array}{l}\text { Selective reporting (re- } \\
\text { porting bias) }\end{array}$ & Unclear risk & Nothing noted \\
\hline Other bias & High risk & Not all baseline assessments completed before study commenced \\
\hline $\begin{array}{l}\text { Blinding of participants } \\
\text { and personnel (perfor- } \\
\text { mance bias) } \\
\text { All outcomes }\end{array}$ & High risk & $\begin{array}{l}\text { Intervention participants must have had awareness of grouping due to materi- } \\
\text { als. }\end{array}$ \\
\hline
\end{tabular}

\section{Liekens 2014}

\begin{tabular}{ll}
\hline Methods & Design: cluster-RT \\
Groups: intervention group (pharmacists received communication skills training related to depression); \\
control group (no intervention)
\end{tabular}

\section{Participants}

Pharmacies: 40

Pharmacy worker: 21 in intervention group; 19 in control group

Pharmacy user: not assessed

Setting: urban

Country: Belgium

Interventions

Pharmacy worker-directed intervention: pharmacists received communication skills training related to depression including role playing with a simulated patient and feedback on their counselling skills.

- Delivered by: researcher; lecturer in pharmacotherapy/pharmaceutical care; clinical psychologist; consumer educators

- Type: education meetings; role-playing with simulated patients; feedback on behaviour

- Mode of delivery: group (no more than 10 participants); individual face-to-face

- TDF: knowledge, environment, context and resources, behavoural regulation

- Duration:1 day, 3 parts

- Follow-up: 'a few weeks later'

Pharmacy worker control: not reported 
Pharmacy user-directed intervention: not targeted

\begin{tabular}{ll}
\hline Outcomes & Pharmacy worker: \\
- Uptake: not reported & Behavioural: simulated patients assessed pharmacists' communication skills. Their interactions were \\
& audio-recorded and analysed using Roter Interacation Analysis System (RIAS).
\end{tabular}

Pharmacy user: not assessed

\begin{tabular}{ll}
\hline Notes & Study/intervention name: none given \\
& Funding source: no external funding \\
\hline
\end{tabular}

\section{Risk of bias}

\begin{tabular}{|c|c|c|}
\hline Bias & Authors' judgement & Support for judgement \\
\hline $\begin{array}{l}\text { Random sequence genera- } \\
\text { tion (selection bias) }\end{array}$ & Low risk & Randomly ordered list of pharmacy codes \\
\hline $\begin{array}{l}\text { Allocation concealment } \\
\text { (selection bias) }\end{array}$ & Low risk & Researchers blinded to the identity of pharmacies allocated to study groups \\
\hline $\begin{array}{l}\text { Baseline outcome mea- } \\
\text { sures similar }\end{array}$ & Unclear risk & No baseline assessment \\
\hline $\begin{array}{l}\text { Baseline characteristics } \\
\text { similar }\end{array}$ & Unclear risk & No baseline assessment \\
\hline $\begin{array}{l}\text { Incomplete outcome data } \\
\text { (attrition bias) } \\
\text { All outcomes }\end{array}$ & Low risk & No reported attrition \\
\hline $\begin{array}{l}\text { Blinding of outcome as- } \\
\text { sessment (detection bias) } \\
\text { All outcomes }\end{array}$ & Low risk & $\begin{array}{l}\text { Quote: "The researchers were blind to the identity of the pharmacies allocated } \\
\text { to the study groups." and "The mystery shoppers (MS) were blind to the phar- } \\
\text { macy assignment to training or control groups." }\end{array}$ \\
\hline $\begin{array}{l}\text { Protection against conta- } \\
\text { mination }\end{array}$ & Unclear risk & All pharmacists from same pharmacy chain \\
\hline $\begin{array}{l}\text { Selective reporting (re- } \\
\text { porting bias) }\end{array}$ & Low risk & Not noted \\
\hline Other bias & Unclear risk & $\begin{array}{l}\text { Quote: "limitations of the current study include variable exposure to the inter- } \\
\text { vention as several pharmacists did not complete the role play at the end of the } \\
\text { training day. This may have diminished the impact of the intervention for them } \\
\text { in terms of patient counselling skills." }\end{array}$ \\
\hline $\begin{array}{l}\text { Blinding of participants } \\
\text { and personnel (perfor- } \\
\text { mance bias) } \\
\text { All outcomes }\end{array}$ & Low risk & $\begin{array}{l}\text { Quote: "The researchers were blind to the identity of the pharmacies allocated } \\
\text { to the study groups." and "The mystery shoppers (MS) were blind to the phar- } \\
\text { macy assignment to training or control groups." }\end{array}$ \\
\hline
\end{tabular}


Madurasinghe 2017

\begin{tabular}{ll}
\hline Methods & Design: cluster-RT \\
& Groups: intervention group (pharmacy workers trained in smoking cessation); control (no treatment) \\
\hline Participants & Pharmacies: 12 (7 intervention; 5 control) \\
& Pharmacy worker: pharmacists and counter assistants \\
& Pharmacy user: 621 (302 intervention; 319 control) \\
- mean age: $45.2 \pm 11.0$ years \\
- \% female: intervention $73.7 \%$; control $43.8 \%$ \\
Setting: urban \\
Country: UK
\end{tabular}

- Delivered by: health psychologist and community pharmacist

- Type: behaviour change, interactive practice based

- Mode of delivery: face-to-face

- TDF: knowledge, skills, social/professional role and identity, beliefs about capabilities,

- belief about consequences, memory, social support, environment, context and resources,

- Duration: 2 × 2.5-hour sessions

\section{Pharmacy worker control: no training}

Pharmacy user-directed intervention: optimised smoking cessation programme

- Delivered by: pharmacy worker

- Type: behaviour change (smoking)

- Mode of delivery: face-to-face

- TDF: knowledge, belief about capability, belief about consequences, goals, environment, context and resources

- Duration: 4 sessions of up to 30 minutes

Pharmacy user control: Usual care

- Uptake: 12 of the 54 pharmacies invited participated

- Behaviour: throughput of smokers

\section{Pharmacy user:}

- Clinical: not assessed

- Psychological health: not assessed

- Behavioural: quit rate (cotinine); retention

- Quality of life: not assessed

- Process: not assessed

- Costs: not assessed 
Madurasinghe 2017 (Continued)

Steed 2017 (cited under Madurasinghe 2017) also refers to this study

\section{Risk of bias}

\begin{tabular}{|c|c|c|}
\hline Bias & Authors' judgement & Support for judgement \\
\hline $\begin{array}{l}\text { Random sequence genera- } \\
\text { tion (selection bias) }\end{array}$ & Low risk & Randomisation generated using Stata 12 software. \\
\hline $\begin{array}{l}\text { Allocation concealment } \\
\text { (selection bias) }\end{array}$ & Low risk & Independent statistician generated and administered randomisation list. \\
\hline $\begin{array}{l}\text { Baseline outcome mea- } \\
\text { sures similar }\end{array}$ & Unclear risk & Not reported \\
\hline $\begin{array}{l}\text { Baseline characteristics } \\
\text { similar }\end{array}$ & High risk & Differences in age and \% female \\
\hline $\begin{array}{l}\text { Incomplete outcome data } \\
\text { (attrition bias) } \\
\text { All outcomes }\end{array}$ & Low risk & Low attrition \\
\hline $\begin{array}{l}\text { Blinding of outcome as- } \\
\text { sessment (detection bias) } \\
\text { All outcomes }\end{array}$ & Unclear risk & Not reported \\
\hline $\begin{array}{l}\text { Protection against conta- } \\
\text { mination }\end{array}$ & Low risk & Cluster randomised \\
\hline $\begin{array}{l}\text { Selective reporting (re- } \\
\text { porting bias) }\end{array}$ & Low risk & All outcomes reported \\
\hline Other bias & High risk & $\begin{array}{l}\text { Only } 12 \text { of } 54 \text { pharmacies participated, no comparison with those who were } \\
\text { not recruited }\end{array}$ \\
\hline $\begin{array}{l}\text { Blinding of participants } \\
\text { and personnel (perfor- } \\
\text { mance bias) } \\
\text { All outcomes }\end{array}$ & High risk & Pharmacy workers were aware of intervention arm. \\
\hline
\end{tabular}

\section{Maguire 2001}

$\begin{array}{ll}\text { Methods } & \text { Design: RT } \\ & \text { Groups: intervention group (Pharmacists Action on Smoking (PAS)); control group (usual care) }\end{array}$

\section{Participants}

Pharmacies: 124 (1 pharmacist per site)

Pharmacy workers: 124 pharmacists (100 in Northern Ireland, 24 in London)

Pharmacy user: 484 smokers

- mean age: intervention 42 years; control 38 years

- $\%$ female: intervention $40.37 \%$; control $43.8 \%$

Setting: urban 
Maguire 2001 (Continued)

\section{Country: UK}

Interventions

Pharmacy worker-directed intervention: before study, pharmacists were sent the pharmacy-based smoking cessation (PAS model) documentation and literature review and were asked to study it. Attended workshops on epidemiology, smoking statistics, the use of nicotine replacement therapy, the cycle of change model and the PAS model. Researchers visited the pharmacists to provide support and to address any queries they had in implementing the model.

- Delivered by: researcher

- Type: smoking cessation, education

- Mode of delivery: group; individual face-to-face; written materials

- TDF: knowledge, skills, belief about consequences, environment, context and resources, behavioural regulation

- Duration: 1 x 3-hour workshop

Pharmacy worker control: it appears the same pharmacists saw both intervention and control groups.

Pharmacy user-directed intervention: patients received counselling using PAS approach

- Delivered by: pharmacist

- Type: smoking cessation: behaviour change

- Mode of delivery: individual face-to-face; written materials

- TDF: knowledge, reinforcement, goals, environment, context and resources

- Duration: Length of intervention: weekly sessions for 4 weeks, then monthly for 3 months

- Follow-up: 3, 6 and 12 months (intervention ended at 4 months)

Pharmacy user control: usual care including the provision of nicotine replacement therapy as appropriate

Outcomes

Pharmacy worker:

- Uptake: not reported

- Qualitative experience of delivering study

\section{Pharmacy user:}

- Clinical: not assessed

- Psychological health: not assessed

- Behavioural: smoking abstinence (cotinine confirmed)

- Quality of life: not assessed

- Process: not assessed

- Costs: not assessed

Notes

Study/intervention name: Pharmacist Action on Smoking (PAS)

Funding source: Medical Research Council and Northern Ireland Department of Health and Social Services

Also informed by Maguire 1996 (additional reference under Maguire 2001)

\section{Risk of bias}


Maguire 2001 (Continued)

Random sequence genera- Low risk Randomised using a sealed envelope technique tion (selection bias)

\begin{tabular}{|c|c|c|}
\hline $\begin{array}{l}\text { Allocation concealment } \\
\text { (selection bias) }\end{array}$ & Low risk & Blind to allocation \\
\hline $\begin{array}{l}\text { Baseline outcome mea- } \\
\text { sures similar }\end{array}$ & Low risk & All participants were smokers at baseline. \\
\hline $\begin{array}{l}\text { Baseline characteristics } \\
\text { similar }\end{array}$ & Unclear risk & Differences between groups not reported \\
\hline $\begin{array}{l}\text { Incomplete outcome data } \\
\text { (attrition bias) } \\
\text { All outcomes }\end{array}$ & Low risk & $\begin{array}{l}\text { Where data were missing for participants, the participants were assumed to } \\
\text { still be smoking. }\end{array}$ \\
\hline $\begin{array}{l}\text { Blinding of outcome as- } \\
\text { sessment (detection bias) } \\
\text { All outcomes }\end{array}$ & Low risk & Objective outcome measure \\
\hline $\begin{array}{l}\text { Protection against conta- } \\
\text { mination }\end{array}$ & High risk & Within pharmacy randomisation \\
\hline $\begin{array}{l}\text { Selective reporting (re- } \\
\text { porting bias) }\end{array}$ & Low risk & Not noted \\
\hline Other bias & Low risk & Not noted \\
\hline $\begin{array}{l}\text { Blinding of participants } \\
\text { and personnel (perfor- } \\
\text { mance bias) } \\
\text { All outcomes }\end{array}$ & High risk & Pharmacy workers aware of group \\
\hline
\end{tabular}

Mansell 2016

\begin{tabular}{ll} 
Methods & Design: cluster-RT \\
& Groups: intervention (self-monitoring of blood glucose (SMBG)); control (usual care) \\
\hline Participants & Pharmacies: 9 (7 intervention; 2 control) \\
& Pharmacy worker: 9 (1 pharmacist per pharmacy) \\
----------------------------------------------------------- \\
Pharmacy user: 36 ( 26 intervention; 10 control) \\
- mean age: intervention $61 \pm 11.8$ years; control $65.2 \pm 11.8$ years \\
- \% female: intervention $38 \%$; control $70 \%$ \\
Setting: mainly rural \\
Country: Canada
\end{tabular}

Interventions

Pharmacy worker-directed intervention: provided education on SMBG, the recent Canadian Diabetes Association (now renamed 'Diabetes Canada') recommendations and the study glucose meter

- Delivered by: not reported 
Mansell 2016 (Continued)

- Type: education

- Mode of delivery: not reported

- TDF: knowledge, environment, context, resources

- Duration: 1 day

Pharmacy worker control: no additional information

Pharmacy user-directed intervention: recommendations for SMBG and behaviours to change

- Delivered by: pharmacist

- Type: self-management

- Mode of delivery: face-to-face

- TDF: knowledge, skills, environmental context, resources, behavioural regulation

- Duration: not reported

Pharmacy user control: usual care

\begin{tabular}{ll}
\hline Outcomes & Pharmacy worker: \\
\hline & Pharmacy user: \\
\hline & - Clinical: HbAlc 12 of 382 invitees, only 9 recruita \\
- Psychological health: not assessed \\
- Behavioural: SMBG (study developed) \\
- Process: not assessed \\
- Costs: not assessed
\end{tabular}

Notes Study/intervention name: none given

Funding source: unrestricted research grant from Sanofi, Canada

\section{Risk of bias}

\begin{tabular}{lll}
\hline Bias & Authors' judgement & Support for judgement \\
\hline $\begin{array}{l}\text { Random sequence genera- } \\
\text { tion (selection bias) }\end{array}$ & Low risk & Random number table \\
\hline $\begin{array}{l}\text { Allocation concealment } \\
\text { (selection bias) }\end{array}$ & High risk & Blinding not possible \\
\hline $\begin{array}{l}\text { Baseline outcome mea- } \\
\text { sures similar }\end{array}$ & High risk & Considerable missing data for baseline BP \\
\hline $\begin{array}{l}\text { Baseline characteristics } \\
\text { similar }\end{array}$ & High risk & Difference diabetes in age between groups \\
\hline $\begin{array}{l}\text { Incomplete outcome data } \\
\text { (attrition bias) } \\
\text { All outcomes }\end{array}$ & Low risk & Attrition accounted for \\
\hline
\end{tabular}


Mansell 2016 (Continued)
Blinding of outcome as-
Low risk
Data analyst was blind to treatment allocations sessment (detection bias)

All outcomes

Protection against conta- Low risk Cluster design
mination

\begin{tabular}{lll}
\hline $\begin{array}{l}\text { Selective reporting (re- } \\
\text { porting bias) }\end{array}$ & Low risk & Not apparent \\
\hline Other bias & Low risk & Not apparent \\
\hline $\begin{array}{l}\text { Blinding of participants } \\
\begin{array}{l}\text { and personnel (perfor- } \\
\text { mance bias) }\end{array}\end{array}$ & Unclear risk & Aware of groups \\
All outcomes & \\
\hline
\end{tabular}

\section{Mayer 1998}

\begin{tabular}{ll}
\hline Methods & Design: cluster-RT \\
& Groups: intervention group (pharmacist training in skin cancer prevention); control group (usual care) \\
\hline
\end{tabular}

Participants

Pharmacies 54 (out of 88 sites)

Pharmacy worker: pharmacists 147 (out of 178 invited)

- mean age: intervention 40.52 years; control 41.84 years

- \% female: intervention $45.1 \%$; control $32.3 \%$

Pharmacy user: not targeted

Setting: unclear

Country: USA

Interventions

Pharmacy worker-directed intervention: training was provided to pharmacists about how to reduce ultraviolet radiation exposure and use sun protection of 15 or higher. A videotape and accompanying print materials were used for 3 weeks, then pharmacists received weekly written feedback on skin cancer prevention counselling performance, plus incentives for the "winning" performance for a further 3 weeks. The 23-minute videotape contained didactic information about skin cancer prevention, a model ("Ask, Advise, and Assist") to help pharmacists give brief counselling to their patients,and 6 brief scenes showing pharmacist-patient interactions.

- Delivered by: researcher; other pharmacist

- Type: education materials

- Mode of delivery: video/DVD; written materials; face-to-face feedback

- TDF: knowledge, skills, environment, context and resources

- Duration: length of intervention: approximately 6 weeks;

- Follow-up: 7 weeks after baseline (i.e. end of intervention)

Pharmacy worker control: not reported

Pharmacy user-directed intervention: not directly targeted 
Mayer 1998 (Continued)

Outcomes

\section{Pharmacy worker:}

- Uptake: 54 sites selected out of 54; 128 of 178 pharmacists completed pretest survey

- Behavioural: simulated patient - reported the percentage provided with verbal counselling; distribution of brochure and/or sunscreen sample

Pharmacy user: not assessed

$\begin{array}{ll}\text { Notes } & \text { Study/intervention name: Project SUNWISE } \\ & \text { Funding source - Grant AR } 43025 \text { from the National Institue of Arthritis and Musculskeletal and Skin Dis- } \\ \text { eases (NIAMS), videotape by Glaxo Wellcome } \\ \text { Mayer } 1998 \text { (cited under Mayer 1998) also refers to this study }\end{array}$

\section{Risk of bias}

\begin{tabular}{|c|c|c|}
\hline Bias & Authors' judgement & Support for judgement \\
\hline $\begin{array}{l}\text { Random sequence genera- } \\
\text { tion (selection bias) }\end{array}$ & Unclear risk & Randomisation method not specified \\
\hline $\begin{array}{l}\text { Allocation concealment } \\
\text { (selection bias) }\end{array}$ & Unclear risk & No information in trial report \\
\hline $\begin{array}{l}\text { Baseline outcome mea- } \\
\text { sures similar }\end{array}$ & Low risk & $\begin{array}{l}\text { Although differences at baseline were reported, these were controlled for in } \\
\text { analyses }\end{array}$ \\
\hline $\begin{array}{l}\text { Baseline characteristics } \\
\text { similar }\end{array}$ & Low risk & No significant differences apparent \\
\hline $\begin{array}{l}\text { Incomplete outcome data } \\
\text { (attrition bias) } \\
\text { All outcomes }\end{array}$ & Unclear risk & $\begin{array}{l}\text { Across all observations, } 138 \text { pharmacists were observed. Of these, } 33 \text { were } \\
\text { observed at pretest only, } 25 \text { were observed at post-test only, and } 80 \text { were ob- } \\
\text { served at both times. Intervention site pharmacists } 71 \text {; control site pharma- } \\
\text { cists } 67 \\
\text { Not clear how missing data from pre/post-test were handled }\end{array}$ \\
\hline $\begin{array}{l}\text { Blinding of outcome as- } \\
\text { sessment (detection bias) } \\
\text { All outcomes }\end{array}$ & Low risk & Simulated patients (mystery shoppers) blind to study groups \\
\hline $\begin{array}{l}\text { Protection against conta- } \\
\text { mination }\end{array}$ & Low risk & Cluster randomisation \\
\hline $\begin{array}{l}\text { Selective reporting (re- } \\
\text { porting bias) }\end{array}$ & Unclear risk & Not noted \\
\hline Other bias & High risk & $\begin{array}{l}\text { There appeared to be some discrepancy in figures reported between publica- } \\
\text { tions. }\end{array}$ \\
\hline $\begin{array}{l}\text { Blinding of participants } \\
\text { and personnel (perfor- } \\
\text { mance bias) } \\
\text { All outcomes }\end{array}$ & High risk & $\begin{array}{l}\text { Confederates were blinded to pharmacy study conditions, but pharmacists } \\
\text { were aware of intervention group. }\end{array}$ \\
\hline
\end{tabular}


McDonough 2005

\begin{tabular}{ll}
\hline Methods & Design: cluster-RT \\
& $\begin{array}{l}\text { Groups: intervention group (identification of glucocorticoid-induced osteoporosis risk); control group } \\
\text { (usual care) }\end{array}$
\end{tabular}

Participants

Pharmacies 15 (8 intervention; 7 control)

Pharmacy worker: pharmacists

Pharmacy user: patients believed to be at high risk for-developing osteoporosis 96 (70 intervention; 26 control)

- mean age: not stated

- \% female: intervention $74.3 \%$; control $57.7 \%$

Setting: both urban and rural

Country: USA

Interventions

Pharmacy worker-directed intervention: pharmacists received classroom education/training on the pathophysiology and management of glucocorticoid-induced osteoporosis, and were given a packet of articles for independent study.

- Delivered by: possibly researchers

- Type: education; written materials

- Mode of delivery: classroom education/training (probably face to face and group, though not specified); written materials

- TDF: knowledge, reinforcement, environment, context, resources

- Duration: approximately 4 hours

- Follow-up: 9 months (end of intervention/monitoring period)

Pharmacy worker control: not reported

Pharmacy user-directed intervention: patients received education; an educational pamphlet about the risks - including behavioural risks - of glucocorticoid-induced osteoporosis; and pharmacists monitored the patients' medical therapy, to identify and address medicine-related problems

- Delivered by: pharmacists

- Type: education; risk management

- TDF: knowledge

- Mode of delivery: individual face-to-face; written materials

- Duration: 9 months of follow-up

Pharmacy user control: usual treatment

\section{Pharmacy worker:}

- Behavioural: discussion of osteoporosis risk and bone mineral density testing

\section{Pharmacy user:}

- Clinical: presence of therapies including biophosphonate therapy, estrogen therapy, calcium supplement

- Psychological health: not assessed. 
McDonough 2005 (Continued)

- Behavioural: behaviourally modifiable risk factors

- Quality of life: not assessed

- Process: patient awareness and receipt of bone mineral density test

- Costs: not assessed

Notes Study/intervention name: none given

Funding source: an unrestricted educational grant from Merck and Co, and by the Center for Improving Medication Use in the Community at the University of lowa

\section{Risk of bias}

\begin{tabular}{|c|c|c|}
\hline Bias & Authors' judgement & Support for judgement \\
\hline $\begin{array}{l}\text { Random sequence genera- } \\
\text { tion (selection bias) }\end{array}$ & Unclear risk & Randomisation method not specified. \\
\hline $\begin{array}{l}\text { Allocation concealment } \\
\text { (selection bias) }\end{array}$ & Unclear risk & Not stated \\
\hline $\begin{array}{l}\text { Baseline outcome mea- } \\
\text { sures similar }\end{array}$ & High risk & $\begin{array}{l}\text { Significant difference by group for alcohol and bisphosphonate therapy at } \\
\text { baseline. }\end{array}$ \\
\hline $\begin{array}{l}\text { Baseline characteristics } \\
\text { similar }\end{array}$ & High risk & Significant difference by group for postmenopausal status at baseline. \\
\hline $\begin{array}{l}\text { Incomplete outcome data } \\
\text { (attrition bias) } \\
\text { All outcomes }\end{array}$ & Unclear risk & Dropouts reported, but unclear how missing data were managed. \\
\hline $\begin{array}{l}\text { Blinding of outcome as- } \\
\text { sessment (detection bias) } \\
\text { All outcomes }\end{array}$ & Unclear risk & Outcome assessment done by web-based survey, but completed in pharmacy. \\
\hline $\begin{array}{l}\text { Protection against conta- } \\
\text { mination }\end{array}$ & High risk & $\begin{array}{l}\text { Both groups of pharmacists received education on glucocorticoid induced os- } \\
\text { teoporosis. }\end{array}$ \\
\hline $\begin{array}{l}\text { Selective reporting (re- } \\
\text { porting bias) }\end{array}$ & Low risk & Nothing noted \\
\hline Other bias & High risk & $\begin{array}{l}\text { Insufficient sample size to detect an effect, all pharmacists participated in re- } \\
\text { search and trained in monitoring drug therapies. }\end{array}$ \\
\hline $\begin{array}{l}\text { Blinding of participants } \\
\text { and personnel (perfor- } \\
\text { mance bias) } \\
\text { All outcomes }\end{array}$ & Unclear risk & It is likely that pharmacists were aware of grouping. \\
\hline
\end{tabular}

\section{McLean 2003}

$\begin{array}{ll}\text { Methods } & \text { Design: cluster-RT (paired by geographic similarity) } \\ \text { Groups: intervention group (enhanced pharmaceutical care); control group (usual care) }\end{array}$

Participants

Pharmacies: 27 
Pharmacy users: 405 (191 enhanced care; 214 usual care)

Setting: unclear

Country: British Columbia, Canada

Pharmacy worker-directed intervention: nothing additional to their pre study training in asthma

Pharmacy user-directed intervention: tailored education to patient's readiness to change (intervention only begun once someone in contemplation and strategies applied when in preparation). Taught correct inhaler technique, peak flow monitoring and self-management skills, and enhanced pharmaceutical care

- Delivered by: pharmacist

- Type: asthma self-management, environment, context, resources, behavioural regulation

- Mode of delivery: individual face-to-face

- TDF: knowledge, skills,

- Duration: length of intervention: $6 \times 60$-minute sessions for a minimum of 9 months. (1 meeting every 2 to 3 weeks for at least 3 appointments then at least every 3 months)

- Follow-up: a minimum of 9 to 12 months from baseline (end of intervention period)

Pharmacy user control: taught inhaler technique and provided a minimum of 9 months usual care after which enhanced care was offered

Outcomes Pharmacy worker: not assessed

\section{Pharmacy user:}

- Clinical: PEFR

- Psychological health: not assessed

- Behavioural: refill prescriptions

- Quality of life: Asthma Quality of Life Questionnaire (AQLQ)

- Process: not assessed

- Costs: health care use and overall health costs

Notes Study/intervention name: the BC Community Pharmacy Asthma Study

Funding source: Health Transition Fund, Health Canada, and Glaxo-Smith-Kline for educational materials and diaries

\section{Risk of bias}

\begin{tabular}{lll}
\hline Bias & Authors' judgement & Support for judgement \\
\hline $\begin{array}{l}\text { Random sequence genera- } \\
\text { tion (selection bias) }\end{array}$ & Low risk & By coin toss, central randomisation \\
\hline $\begin{array}{l}\text { Allocation concealment } \\
\text { (selection bias) }\end{array}$ & Low risk & By coin toss, central randomisation \\
\hline $\begin{array}{l}\text { Baseline outcome mea- } \\
\text { sures similar }\end{array}$ & Unclear risk & $\begin{array}{l}\text { No specific test of baseline similarity, although mean change was used in } \\
\text { analysis. }\end{array}$ \\
\hline \hline
\end{tabular}




\section{McLean 2003 (Continued)}

Baseline characteristics similar
Unclear risk No specific test of baseline similarity

Considerable dropout, although numbers reported it was unclear whether this was corrected for. (attrition bias)

All outcomes

\begin{tabular}{lll}
\hline $\begin{array}{l}\text { Blinding of outcome as- } \\
\text { sessment (detection bias) }\end{array}$ & Unclear risk & $\begin{array}{l}\text { Not clear whether it was the pharmacist or an independent individual who } \\
\text { conducted assessment interviews. }\end{array}$
\end{tabular}

All outcomes conducted assessment interviews.

\begin{tabular}{|c|c|c|}
\hline $\begin{array}{l}\text { tion against conta- } \\
\text { on }\end{array}$ & High risk & $\begin{array}{l}\text { Ind-fathered' pharmacists appear to have offered both enhanced and } \\
\text { care. }\end{array}$ \\
\hline
\end{tabular}
mination

Selective reporting (re- Low risk Not noted
porting bias)

\begin{tabular}{|c|c|c|}
\hline Other bias & Unclear risk & $\begin{array}{l}\text { Although central randomisation used, there were different patient allocation } \\
\text { methods which complicated study design. Usual care was also received from } \\
\text { highly trained pharmacists which may not be reflective of all practice. }\end{array}$ \\
\hline
\end{tabular}

Blinding of participants High risk Pharmacists aware of groupings
and personnel (perfor-
mance bias)
All outcomes

\section{McLean 2008}

Mesign: RT
Groups: intervention (pharmaceutical care); control (usual care)

Pharmacies: 14
Pharmacy workers: not reported
Pharmacy user: 227 (115 intervention; 112 control)
• mean age: intervention $66.2 \pm 11.3$ years, control $61 \pm 54.5$ years
- \% female: intervention $25 \%$, control $39 \%$
Setting: unclear
Country: Alberta, Canada

Interventions

Pharmacy worker-directed intervention: pharmacist training using a combination of an online learning program and a case-based learning session - both based on the Canadian Hypertension Education Program (CHEP) guidelines (www.hypertension.ca)

- TDF: knowledge, skills

Pharmacy worker control: it appears that pharmacists treated both intervention and control groups.

Pharmacy user-directed intervention: education about high blood pressure, diabetes and consequences, a focus on potential lifestyle changes, a BP wallet card, fax to GP 
McLean 2008 (Continued)

- Delivered by: pharmacist and nurse

- Type: screening, disease management

- Mode of delivery: individual face-to-face

- TDF: knowledge, belief about capabilities, beliefs about consequences, environment, context, resouces

- Duration: length of intervention: $6 \times 60$-minute sessions for a minimum of 9 months ( 1 meeting every 2 to 3 weeks for at least 3 appointments then at least every 3 months)

- Follow-up: 24 weeks (end of intervention)

Pharmacy user control: a BP wallet card, a pamphlet on diabetes, general diabetes advice, a 12-week follow-up call and usual care

\section{Outcomes}

\section{Pharmacy worker: not assessed}

\section{Pharmacy user:}

- Clinical: DBP,SBP

- Psychological health: not assessed

- Behavioural: not assessed

- Quality of life: not assessed

- Process: not assessed

- Costs: health care use and overall health costs

\section{Notes}

Study/intervention name: Study of Cardiovascular Risk Intervention by Pharmacists-Hypertension (SCRIP-HTN)

Funding source - grants from the Canadian Diabetes Association, Heart and Stroke Foundation of Canada, Canadian Council of Cardiovascular Nurses, Alberta Heritage Foundation for Medical Research, and Merck Frosst Canada Ltd

McLean 2006 and Houle 2012 (cited under McLean 2008) also refer to this study.

\section{Risk of bias}

\begin{tabular}{lll}
\hline Bias & Authors' judgement & Support for judgement \\
\hline $\begin{array}{l}\text { Random sequence genera- } \\
\text { tion (selection bias) }\end{array}$ & Low risk & $\begin{array}{l}\text { Randomisation was performed centrally to preserve allocation concealment } \\
\text { using a computer-generated sequence over a secure internet service at the } \\
\text { Epidemiology Coordinating and Research (EPICORE) Centre. }\end{array}$ \\
\hline $\begin{array}{l}\text { Allocation concealment } \\
\text { (selection bias) }\end{array}$ & Low risk & As above \\
\hline $\begin{array}{l}\text { Baseline outcome mea- } \\
\text { sures similar }\end{array}$ & Low risk & No reported differences \\
\hline $\begin{array}{l}\text { Baseline characteristics } \\
\text { similar }\end{array}$ & Low risk & No reported differences
\end{tabular}

Incomplete outcome data Low risk $\quad$ Follow-up similar in both arms
(attrition bias)

(attrition bias)

All outcomes

Blinding of outcome as-
sessment (detection bias) $\quad$ Low risk Objective measures, although assessors not blinded


McLean 2008 (Continued)

Protection against conta- High risk Randomisation at patient level mination

\begin{tabular}{lll}
\hline $\begin{array}{l}\text { Selective reporting (re- } \\
\text { porting bias) }\end{array}$ & Unclear risk & Not clear \\
\hline Other bias & Low risk & Not noted \\
\hline $\begin{array}{l}\text { Blinding of participants } \\
\begin{array}{l}\text { and personnel (perfor- } \\
\text { mance bias) }\end{array}\end{array}$ & High risk & Patients and pharmacists were not blind to group. \\
\begin{tabular}{l} 
All outcomes \\
\hline
\end{tabular}
\end{tabular}

Mehuys 2008

$\begin{array}{ll}\text { Methods } & \text { Design: RT } \\ \text { Groups: intervention group (asthma self-management); control group (usual care) }\end{array}$

Pharmacies: 66
Pharmacy worker: pharmacists
Pharmacy user: 201 patients with asthma (107 intervention; 94 control)
- mean age: intervention 35.2 (range 19 to 51 ) years; control 36.3 (range 17 to 51 ) years
- \% female: intervention $55 \%$; control $51 \%$
Setting: urban
Country: Belgium

Interventions

Pharmacy worker-directed intervention: a training session about asthma (pathophysiology), its nonpharmacological and pharmacological treatment (Global Initiative for Asthma (GINA) guidelines), and about the use of the study protocol.

- Delivered by: unclear

- Type: education material; education meeting; based on clinical practice guidelines

- Mode of delivery: unclear

- TDF: knowledge

- Duration: unclear

Pharmacy worker control: it appears that pharmacists saw both control and intervention participants.

Pharmacy user-directed intervention: intervention focused on ensuring correct use of drug therapy including inhaler use and good adherence

- Delivered by: pharmacists

- Type: asthma self-management; education; based on clinical practice guidelines; medication management

- Mode of delivery: individual face-to-face; written materials

- TDF: knowledge, skills

- Duration: number of sessions: 3 (initial, 1 and 3 month visits with pharmacist) 
Pharmacy user control: usual treatment

Outcomes Pharmacy worker: not assessed

\section{Pharmacy user:}

- Clinical: level of asthma control (Asthma Control Test (ACT)), peak expiratory flow (Mini-Wright Standard Peak Flow Meter); rescue medication use, severe exacerbations

- Psychological health: not assessed

- Behavioural: night-time awakenings due to asthma; inhalation technique (8-point checklist); adherence to controller medication (using 2 validated measures: prescription refill rates and self-reporting), smoking quit rates

- Quality of life: asthma-specific quality of life (Standardised Asthma Quality of Life Questionnaire (AQLQ(S))

- Process: knowledge about asthma (Knowledge of Asthma and Asthma Medicine questionnaire) and smoking behaviour

- Costs/health care utilisation: not assessed

\begin{tabular}{ll}
\hline Notes & Study/intervention name: none given \\
& Funding source: funded by Ghent Unviersity
\end{tabular}

\section{Risk of bias}

Bias Authors' judgement Support for judgement

Random sequence genera- Low risk tion (selection bias)
Predetermined by the investigators based on a randomisation table. Serially numbered, closed envelopes were made for each participating pharmacy. The envelope with the lowest number was opened by the pharmacist upon inclusion of a new patient.

\begin{tabular}{lll}
\hline $\begin{array}{l}\text { Allocation concealment } \\
\text { (selection bias) }\end{array}$ & Low risk & See above \\
\hline $\begin{array}{l}\text { Baseline outcome mea- } \\
\text { sures similar }\end{array}$ & Low risk & Baseline variables used as covariates in the analyses \\
\hline $\begin{array}{l}\text { Baseline characteristics } \\
\text { similar }\end{array}$ & Low risk & No significant differences \\
\hline $\begin{array}{l}\text { Incomplete outcome data } \\
\text { (attrition bias) } \\
\text { All outcomes }\end{array}$ & Low risk & $\begin{array}{l}\text { Linear mixed model used with maximum-likelihood method to handle missing } \\
\text { data }\end{array}$ \\
\hline
\end{tabular}

Blinding of outcome as- Low risk Blinded assessment at 6 months
sessment (detection bias) All outcomes

\begin{tabular}{l}
$\begin{array}{l}\text { Protection against conta- High risk } \\
\text { mination }\end{array}$ \\
\hline
\end{tabular}

\begin{tabular}{lll}
\hline $\begin{array}{l}\text { Selective reporting (re- } \\
\text { porting bias) }\end{array}$ & Low risk & Nothing noted \\
\hline Other bias & Unclear risk & Potential selection bias, as only regular clients recruited \\
\hline
\end{tabular}


Mehuys 2008 (Continued)

Blinding of participants High risk Pharmacists aware of patients' groups. and personnel (performance bias)

All outcomes

Mehuys 2011

Methods

Design: cluster-RT

Groups: intervention group (self-management of type 2 diabetes); control group (usual care)

Participants

Pharmacies: 66

Pharmacy worker: pharmacists

Pharmacy user: 288 patients with type 2 diabetes (153 intervention; 135 control)

- mean age: intervention 63.0 (range 40 to 84 ) years; control 62.3 (range 45 to 79 ) years

- $\%$ female: intervention $49 \%$; control $46.3 \%$

Setting: urban

Country: Belgium

Interventions

Pharmacy worker-directed intervention: a training session about type 2 diabetes (pathophysiology), its non-pharmacological and pharmacological management (current guidelines), and the study protocol

- Delivered by: unclearType: education material; education meeting; based on clinical practice guidelines

- Mode of delivery: not clear

- TDF: knowledge, skills, behavioural regulation

- Duration: unclear

Pharmacy worker control: only received training on the study protocol

Pharmacy user-directed intervention: patients received protocol-defined intervention at start of the study and at each prescription refill visit (for hypoglycaemic medication) during the course of the study; received education on disease and medication management, lifestyle and annual reviews.

- Delivered by: pharmacists

- Type: self-management; education; based on clinical practice guidelines; medication management; study protocol defined

- Mode of delivery: individual face-to-face (unclear)

- TDF: knowledge

- Duration: the intervention was implemented on each prescription refill visit

- Length of follow-up: 6 months (end of intervention period)

Pharmacy user control: usual treatment

\section{Pharmacy user:}


- Clinical: fasting plasma glucose (FPG); HbA1c

- Psychological health: not assessed

- Behavioural: adherence to treatment (using 2 widely used measures: prescription refill rates and selfreport); self-management via validated Dutch translation of the Summary of Diabetes Self-Care Activities (SDSCA) questionnaire

- Quality of life: not assessed

- Process: knowledge about type 2 diabetes (validated Dutch translation of the Brief Diabetes Knowledge Test of the Michigan Diabetes Research and Training Center)

- Costs: not assessed

\begin{tabular}{ll}
\hline Notes & Study/intervention name: none given \\
& Funding source: Ghent University
\end{tabular}

Funding source: Ghent University

\section{Risk of bias}

\section{Bias}

Random sequence genera- Low risk tion (selection bias)

\section{Authors' judgement Support for judgement}

The sequence of allocation to control or intervention group was predetermined by the investigators based on randomisation table generated using SPSS.

\begin{tabular}{lll}
\hline $\begin{array}{l}\text { Allocation concealment } \\
\text { (selection bias) }\end{array}$ & Low risk & Sequence of allocation predetermined by randomisation table. \\
\hline $\begin{array}{l}\text { Baseline outcome mea- } \\
\text { sures similar }\end{array}$ & Low risk & No differences between groups \\
\hline $\begin{array}{l}\text { Baseline characteristics } \\
\text { similar }\end{array}$ & Low risk & No differences between groups \\
\hline $\begin{array}{l}\text { Incomplete outcome data } \\
\text { (attrition bias) } \\
\text { All outcomes }\end{array}$ & Low risk & Minimal attrition \\
\hline
\end{tabular}

Nishita 2013

Methods Design: RT


Nishita 2013 (Continued)

Groups: intervention group (diabetes life-coaching and pharmacist counselling); control group (usual care)

\section{Participants}

Pharmacies: 5

Pharmacy worker: 5 licensed pharmacists

Pharmacy user: 190 patients with diabetes

- mean age: intervention $47.59 \pm 0.86$ years; control $50.26 \pm 1.22$ years

- \% female: intervention $65.63 \%$; control $56.45 \%$

Setting: urban

Country: USA

Interventions

Pharmacy worker-directed intervention: pharmacists received a structured training which covered the 8 behaviours key to motivational interviewing. Additional training was provided on medication management, diabetes education, and diet and exercise support. Life coaches also had project training and diabetes education.

- Delivered by: a registered dietician and certified diabetes educator (CDE) trainer

- Type - pharmacists: education; motivational interviewing; medication management; lifestyle

- Mode of delivery: unclear

- TDF: knowledge, environment, context and resources

- Duration: pharmacists 17 hours training and life coaches 65 hours of training

- Theory: life-coaching, motivational interviewing, self-determination theory

Pharmacy worker control: no training

Pharmacy user-directed intervention: pharmacists supported patients in setting and achieving lifestyle goals using motivational interviewing techniques. Patients also had access to life coaches where conversations could focus on lifestyle changes, diabetes health-related behaviours or employment. In addition, participants were provided with access to additional intervention components that included nutrition and diabetes counselling, diabetes education materials a fitness club membership, and reimbursement for diabetes-related medical expenses.

- Delivered by: pharmacists and life coaches

- Type: self-management; behaviour change; education; motivational interviewing (from pharmacist); medication management

- Mode of delivery: individual face-to-face; written materials

- TDF: knowledge, skills, beliefs about consequences, goals, memory, attention, decision making, environment, context, resources, behavioural regulation

- Duration: patients approached and arranged appointments with both pharmacists and life coaches as they wished

- Length of intervention: 12 months

- Follow-up: 12 months (end of intervention)

- Theory: life coaching and motivational interviewing

Pharmacy user control: no treatment

\section{Pharmacy user:}


Nishita 2013 (Continued)

- Clinical: glycaemic control (HbA1c), BMI

- Psychological health: not assessed

- Behavioural: not assessed

- Quality of life: quality of life (WHO Quality of Life-Short Form (WHOQOL-BREF)

- Process: diabetes self-efficacy (Diabetes Empowerment Scale-Short Form (DES-SF)

- Costs: not assessed

Notes

Study/intervention name: Hawai'i Demonstration to Maintain Independence and Employment (Hawai'i DMIE)

Funding source: Centers for Medicare and Medicaid Services

\section{Risk of bias}

\begin{tabular}{|c|c|c|}
\hline Bias & Authors' judgement & Support for judgement \\
\hline $\begin{array}{l}\text { Random sequence genera- } \\
\text { tion (selection bias) }\end{array}$ & Low risk & $\begin{array}{l}\text { Randomised blocked design 2:1 allocation intervention:control, sealed en- } \\
\text { velopes }\end{array}$ \\
\hline $\begin{array}{l}\text { Allocation concealment } \\
\text { (selection bias) }\end{array}$ & Low risk & As above \\
\hline $\begin{array}{l}\text { Baseline outcome mea- } \\
\text { sures similar }\end{array}$ & Low risk & No significant differences reported at baseline \\
\hline $\begin{array}{l}\text { Baseline characteristics } \\
\text { similar }\end{array}$ & Low risk & No significant differences reported at baseline \\
\hline $\begin{array}{l}\text { Incomplete outcome data } \\
\text { (attrition bias) } \\
\text { All outcomes }\end{array}$ & Low risk & Multiple imputation to manage missing data \\
\hline $\begin{array}{l}\text { Blinding of outcome as- } \\
\text { sessment (detection bias) } \\
\text { All outcomes }\end{array}$ & Low risk & Objective primary outcome \\
\hline $\begin{array}{l}\text { Protection against conta- } \\
\text { mination }\end{array}$ & High risk & Randomisation at pharmacy user level \\
\hline $\begin{array}{l}\text { Selective reporting (re- } \\
\text { porting bias) }\end{array}$ & Low risk & Nothing noted \\
\hline Other bias & Low risk & Nothing noted \\
\hline $\begin{array}{l}\text { Blinding of participants } \\
\text { and personnel (perfor- } \\
\text { mance bias) } \\
\text { All outcomes }\end{array}$ & High risk & Pharmacy workers must have been aware of group allocation. \\
\hline
\end{tabular}

Nola 2000

\begin{tabular}{ll}
\hline Methods & Design: RT \\
& Groups: intervention group (lipid management program); control group (usual care) \\
\hline Participants & Pharmacies: not targeted
\end{tabular}


Nola 2000 (Continued)

Pharmacy worker: not targeted

Pharmacy user: 51 patients at risk of coronary artery disease (25 intervention; 26 control)

- mean age: intervention $61.1 \pm 9.5$ years; control $58.4 \pm 9.2$ years

- $\%$ female: intervention $64 \%$; control $53.8 \%$

Setting: urban

Country: USA

Interventions

Pharmacy worker-directed intervention: not reported

Pharmacy user-directed intervention: patients received the lipid management program: diet and exercise evaluation and instruction, monitoring of cholesterol levels, monitoring of drug therapy, collaboration with physicians, education.

- Delivered by: pharmacist

- Type: behaviour change; education; self-management; lifestyle

- Mode of delivery: individual face-to-face

- TDF: knowledge, skills, goals, behavioural regulation

- Duration: 6 months. seen every 1-2 months, average number of visits: 5

Pharmacy user control: usual treatment

Outcomes Pharmacy worker: not assessed

\section{Pharmacy user:}

- Clinical: total cholesterol; LDL-C; HDL-C; triglyceride levels; health-risk appraisal (wellness assessment questionnaire)

- Psychological health: not assessed

- Behavioural: not assessed

- Quality of life: not assessed

- Process: Pharmaceutical Care Satisfaction Questionnaire (PCSQ); Hyperlipidemia-Patient Knowledge evaluation

- Costs: not assessed

$\begin{array}{ll}\text { Notes } & \text { Study/intervention name: none given } \\ & \text { Funding source: Pharmacia-Upjohn Corporation and education grant from Novartiz and Bristol-Myers } \\ & \text { Squibb }\end{array}$

\section{Risk of bias}

\begin{tabular}{lll}
\hline Bias & Authors' judgement & Support for judgement \\
\hline $\begin{array}{l}\text { Random sequence genera- } \\
\text { tion (selection bias) }\end{array}$ & Low risk & $\begin{array}{l}\text { Quote: "A randomization schedule was developed using a computer-generat- } \\
\text { ed list of random numbers" }\end{array}$ \\
\hline $\begin{array}{l}\text { Allocation concealment } \\
\text { (selection bias) }\end{array}$ & Low risk & As above \\
\hline
\end{tabular}


Pharmacy user-directed intervention: home blood pressure monitoring, healthy lifestyle advice using motivational interviewing and brochures

- Delivered by: community pharmacist

- Type: motivational interviewing

- Mode of delivery: face-to-face + leaflets

- TDF: knowledge, skills, goals, environment, context, resources, behavioural regulation

- Duration: 3 visits

- Follow-up: 12 weeks from baseline, 4 weeks from end of intervention

Pharmacy user control: provided with home blood pressure monitor and basic explanation of medications

\begin{tabular}{ll}
\hline Outcomes & Pharmacy worker: \\
- Uptake: 73 pharmacies recruited but 17 did not recruit any patients) \\
Pharmacy user: \\
- Clinical: SBP/DBP, BMI \\
- Psychological health: not assessed \\
- Behavioural: medication adherence (Morisky Scale), International Physical Activity questionnaire, salt \\
- intake \\
- Puality of life: EuroQol \\
- Costs:not assessed \\
Study/intervention name: COMmunity Pharmacists ASSist for Blood Pressure (COMPASS-BP) \\
Funding source: KAKENHI Grant in Aid
\end{tabular}

\section{Risk of bias}

\begin{tabular}{lll}
\hline Bias & Authors' judgement & Support for judgement \\
\hline $\begin{array}{l}\text { Random sequence genera- } \\
\text { tion (selection bias) }\end{array}$ & Low risk & Central randomisation \\
\hline $\begin{array}{l}\text { Allocation concealment } \\
\text { (selection bias) }\end{array}$ & Low risk & Central randomisation \\
\hline
\end{tabular}

Baseline outcome mea- High risk Intervention group had lower blood pressure at baseline
sures similar

Baseline characteristics High risk Differences on several measurements at baseline
similar

Incomplete outcome data Low risk $\quad$ Final analysis used carry forward method to address missing data
(attrition bias)

All outcomes

Blinding of outcome as-
sessment (detection bias) $\quad$ Low risk Outcome assessment was blinded


Okada 2018 (Continued)

All outcomes

Protection against conta- Low risk Cluster design
mination

mination

Selective reporting (re- Low risk Not apparent
porting bias)

\begin{tabular}{|c|c|c|}
\hline Other bias & High risk & $\begin{array}{l}\text { Only patients who had adhered sufficiently to a strict } 2 \text {-week run-in monitor- } \\
\text { ing period were recruited so the sample may not be representative of less mo- } \\
\text { tivated individuals. }\end{array}$ \\
\hline
\end{tabular}

Blinding of participants High risk Group not blinded
and personnel (perfor-
mance bias)
All outcomes

\section{Park 1996}

Methods

Design: RT

Groups: intervention group (Pharmaceutical Scare for Hypertension); control group (usual care)

Pharmacies: 2
Pharmacy worker: pharmacy resident
Pharmacy user: 53 hypertensive patients ( 27 intervention; 26 control)
- mean age: intervention 57.3 years; control 63 years
- \% female: intervention $51.8 \%$; control $50 \%$
Setting: urban
Country: USA

Interventions Pharmacy worker-directed intervention: not reported

Pharmacy user-directed intervention: patients received counselling on lifestyle modifications that would help them manage their condition, and especially their medical treatment.

- Delivered by: community pharmacy resident

- Type: self-management; disease management

- Mode of delivery: individual face-to-face; written materials

- TDF: knowledge, goals, environment, context, resources

- Number of sessions: 4; session duration: 14.6 to 30.7 minutes per visit

- Length of follow-up: 4 months (end of intervention)

Pharmacy user control: usual treatment

Outcomes Pharmacy worker: not assessed

\section{Pharmacy user:}


Park 1996 (Continued)

- Clinical: blood pressure, heart rate

- Psychological health: not assessed

- Behavioural: adherence (pill count)

- Quality of life: Health Status Questionnaire 2.0 (HSQ) - identical to SF-36, but with 4 questions added; Hypertension/Lipid Form 5.1 (HTN; reported as a quality of life measurement)

- Process: not assessed

- Costs: not assessed

Notes Study/intervention name: none given

Funding source: not reported

\section{Risk of bias}

\begin{tabular}{|c|c|c|}
\hline Bias & Authors' judgement & Support for judgement \\
\hline $\begin{array}{l}\text { Random sequence genera- } \\
\text { tion (selection bias) }\end{array}$ & Unclear risk & $\begin{array}{l}\text { Randomised, but method not specified. Furthermore, article stated "the ran- } \\
\text { domization was not balanced. Far more control patients }(26.9 \%) \text { than study } \\
\text { patients }(17.4 \%) \text { had controlled blood pressure, and more study patients } \\
(13 \%) \text { had stage III hypertension at baseline randomization." }\end{array}$ \\
\hline $\begin{array}{l}\text { Allocation concealment } \\
\text { (selection bias) }\end{array}$ & High risk & $\begin{array}{l}\text { Patients were not aware, but the pharmacy residents were aware of the alloca- } \\
\text { tion. }\end{array}$ \\
\hline $\begin{array}{l}\text { Baseline outcome mea- } \\
\text { sures similar }\end{array}$ & High risk & $\begin{array}{l}\text { Reported that at baseline there were differences in blood pressure and severi- } \\
\text { ty of hypertension }\end{array}$ \\
\hline $\begin{array}{l}\text { Baseline characteristics } \\
\text { similar }\end{array}$ & High risk & $\begin{array}{l}\text { Reported that at baseline there were differences in blood pressure and severi- } \\
\text { ty of hypertension }\end{array}$ \\
\hline $\begin{array}{l}\text { Incomplete outcome data } \\
\text { (attrition bias) } \\
\text { All outcomes }\end{array}$ & Unclear risk & Dropouts reported, but not clear how managed \\
\hline $\begin{array}{l}\text { Blinding of outcome as- } \\
\text { sessment (detection bias) } \\
\text { All outcomes }\end{array}$ & High risk & No blinding \\
\hline $\begin{array}{l}\text { Protection against conta- } \\
\text { mination }\end{array}$ & High risk & Randomisation at patient level \\
\hline $\begin{array}{l}\text { Selective reporting (re- } \\
\text { porting bias) }\end{array}$ & High risk & Whilst significance for outcomes was reported, this was only shown in graphs. \\
\hline Other bias & Unclear risk & Study sample size may have been underpowered. \\
\hline $\begin{array}{l}\text { Blinding of participants } \\
\text { and personnel (perfor- } \\
\text { mance bias) } \\
\text { All outcomes }\end{array}$ & High risk & $\begin{array}{l}\text { Quote: "A limitation of this study was that it was a Single-blinded study. The } \\
\text { pharmacy residents were aware of patient assignment into two different treat- } \\
\text { ment groups, which could have introduced bias." }\end{array}$ \\
\hline
\end{tabular}

\section{Patwardhan 2012}

Methods Design: cluster-RT




Participants
Pharmacies: 16
- $\%$ female: intervention $57 \%$; control $43 \%$

Pharmacy user: not assessed

Setting: urban

Country: USA

Interventions

Pharmacy worker-directed intervention: Ask-Advise-Refer (AAR) tobacco cessation counselling through 30 minutes on-site training, recommendations for integrating AAR in pharmacy work flow, a cessation poster and a support visit that drew on social cognitive theory. Also given the same materials as the control group.

- Delivered by: researcher

- Type: smoking cessation education

- Mode of delivery: face-to-face; video, groups of 2 to 3 people

- TDF: knowledge,skills, beliefs about capability, environment, context, resources, social support

- Duration: 30 minutes

Pharmacy worker control: received quit line cards (a card with the telephone number to access free behavioural support), an informational presentation about the quit line and its services, and enrolment in a free service called Fax-to-Quit (FTQ). FTQ enabled pharmacies to refer tobacco users proactively to the quit line by faxing a signed consent form that allowed the quit line to call users back directly to initiate cessation treatment.

Pharmacy user-directed intervention: AAR tobacco cessation counselling, given quit line cards which have the telephone number of a quit line which provided free counseling and free medication

- Delivered by: pharmacists

- Type: smoking cessation education

- Mode of delivery: face-to-face; written materials

- Duration: single sessions

- Follow-up: 1 month

Pharmacy user control: received quit line cards and FTQ

Outcomes Pharmacy worker:

- Behavioural: patient referrals to quit line active (quit line records) and passive (quit line cards distributed)

Pharmacy user: not assessed

Notes Study/intervention name: none given

Funding: Clinical and Translational Science Award, NIH and Wisconsin Department of Health Services and Sonderegger Research Centre

Patwardhan 2009 and Patwardhan 2010 (cited under Patwardhan 2012) also refer to the same intervention. 
Patwardhan 2012 (Continued)

\section{Risk of bias}

\begin{tabular}{|c|c|c|}
\hline Bias & Authors' judgement & Support for judgement \\
\hline $\begin{array}{l}\text { Random sequence genera- } \\
\text { tion (selection bias) }\end{array}$ & Low risk & Block randomisation \\
\hline $\begin{array}{l}\text { Allocation concealment } \\
\text { (selection bias) }\end{array}$ & Low risk & Researchers blinded to study goal \\
\hline $\begin{array}{l}\text { Baseline outcome mea- } \\
\text { sures similar }\end{array}$ & Low risk & No differences reported \\
\hline $\begin{array}{l}\text { Baseline characteristics } \\
\text { similar }\end{array}$ & Low risk & No differences reported \\
\hline $\begin{array}{l}\text { Incomplete outcome data } \\
\text { (attrition bias) } \\
\text { All outcomes }\end{array}$ & Low risk & Data were collected from objective records \\
\hline $\begin{array}{l}\text { Blinding of outcome as- } \\
\text { sessment (detection bias) } \\
\text { All outcomes }\end{array}$ & Unclear risk & Unclear who collected data \\
\hline $\begin{array}{l}\text { Protection against conta- } \\
\text { mination }\end{array}$ & Low risk & Cluster design \\
\hline $\begin{array}{l}\text { Selective reporting (re- } \\
\text { porting bias) }\end{array}$ & Low risk & All outcomes reported \\
\hline Other bias & Unclear risk & $\begin{array}{l}\text { Outcome measures, except for quit line records, were self-report by pharma- } \\
\text { cists }\end{array}$ \\
\hline $\begin{array}{l}\text { Blinding of participants } \\
\text { and personnel (perfor- } \\
\text { mance bias) } \\
\text { All outcomes }\end{array}$ & Low risk & Pharmacy staff not informed of the existence of 2 groups and therefore blind \\
\hline
\end{tabular}

\section{Paulos 2005}

\begin{tabular}{ll}
\hline Methods & Design: RT \\
Groups: intervention group (pharmaceutical care for dyslipidaemia); control group ('normal coun- \\
selling')
\end{tabular}

\section{Participants}

\section{Pharmacies: 1}

Pharmacy worker: pharmacists

Pharmacy user: 42 patients with dyslipidaemia (23 intervention; 19 control)

- mean age: men $64 \pm 10$ years; women $66 \pm 11$ years

- $\%$ female: $81 \%$

Setting: unclear 
Paulos 2005 (Continued)

$$
\text { Country: Chile }
$$

\section{Interventions Pharmacy worker-directed intervention: not described}

Pharmacy user-directed intervention: patients received education on the role of cholesterol in illness and health, explaining risk factors associated with cardiovascular disease, and providing education/counselling regarding medication.

- Delivered by: pharmacists

- Type: behaviour change and education; medication management

- Mode of delivery: face-to-face; written materials

- TDF: knowledge, environment, context, resources

- Duration: 16 weeks. 5 interviews in the intervention group; Each interview lasted 20 to 25 minutes.

- Follow-up: 16 weeks (end of intervention)

Pharmacy user control: usual treatment (2 interviews)

Pharmacy worker: not assessed
Outcomes
Pharmacy user:
- Clinical: blood cholesterol; triglyceride levels; BMI; body weight
- Behohological health: not assessed
- Quality of life: Health Short-Form-36 survey
- Process: not assessed
- Costs: not assessed

Notes Study/intervention name: none given

Funding source: not reported although Roche Diagnostics provided Accutrend GCT device and strips.

\begin{tabular}{lll}
\hline Risk of bias & & \\
\hline Bias & Authors' judgement & Support for judgement \\
\hline $\begin{array}{l}\text { Random sequence genera- } \\
\text { tion (selection bias) }\end{array}$ & Unclear risk & Randomised, but specific method not mentioned \\
\hline $\begin{array}{l}\text { Allocation concealment } \\
\text { (selection bias) }\end{array}$ & Unclear risk & Unclear \\
\hline $\begin{array}{l}\text { Baseline outcome mea- } \\
\text { sures similar }\end{array}$ & Unclear risk & Not reported \\
\hline $\begin{array}{l}\text { Baseline characteristics } \\
\text { similar }\end{array}$ & Unclear risk & Not reported \\
\hline $\begin{array}{l}\text { Incomplete outcome data } \\
\text { (attrition bias) } \\
\begin{array}{l}\text { All outcomes } \\
\hline\end{array}\end{array}$ & Unclear risk & Unclear \\
\hline
\end{tabular}

Blinding of outcome as- $\quad$ Low risk $\quad$ No blinding, but objective primary outcome
sessment (detection bias)
All outcomes


Paulos 2005 (Continued)

Protection against conta- High risk Randomisation at client level
mination

\begin{tabular}{lll}
\hline $\begin{array}{l}\text { Selective reporting (re- } \\
\text { porting bias) }\end{array}$ & High risk & No full reporting of all outcomes at all time points \\
\hline Other bias & Unclear risk & Not noted \\
\hline $\begin{array}{l}\text { Blinding of participants } \\
\begin{array}{l}\text { and personnel (perfor- } \\
\text { mance bias) }\end{array}\end{array}$ & High risk & No blinding \\
All outcomes & & \\
\hline
\end{tabular}

Petkova 2008

$\begin{array}{ll}\text { Methods } & \text { Design: RT } \\ \text { Groups: intervention group (asthma self-management); control group (usual care) }\end{array}$

Participants Pharmacies: 10 (those pharmacies with the highest number of asthma patients)

Pharmacy user: 50 (22 intervention; 28 control)

- mean age: intervention 35.14 years; control 40.82 years

- $\%$ female: intervention $41 \%$; control $31 \%$

Setting: urban, Sofia

Country: Bulgaria

Interventions

Pharmacy worker-directed intervention: not reported

Pharmacy user-directed intervention: education program with information on asthma, medication, inhalers, drug reactions, exacerbation and control of asthma attacks and smoking cessation

- Delivered by: researcher or undergraduate students

- Type: education

- Mode of delivery: face-to-face, written materials

- TDF: knowledge, skills, environment, context, resources

- Duration: 4 sessions held monthly

- Length of follow-up: at 4 months (post-intervention)

Pharmacy user control: usual treatment

\section{Pharmacy user:}

- Clinical: PEF

- Psychological health: not assessed

- Behavioural: inhaler technique, asthma self-monitoring

- Quality of life: asthma assessment form 
Petkova 2008 (Continued)

- Process: patient satisfaction (direct interview)

- Costs: health care utilisation - hospitalisation and GP visits

Notes Study/intervention name: none given

Funding source: not reported

\section{Risk of bias}

\begin{tabular}{|c|c|c|}
\hline Bias & Authors' judgement & Support for judgement \\
\hline $\begin{array}{l}\text { Random sequence genera- } \\
\text { tion (selection bias) }\end{array}$ & Unclear risk & Assigned based on principle of random numbers \\
\hline $\begin{array}{l}\text { Allocation concealment } \\
\text { (selection bias) }\end{array}$ & Unclear risk & No detail provided \\
\hline $\begin{array}{l}\text { Baseline outcome mea- } \\
\text { sures similar }\end{array}$ & Low risk & No differences on outcomes \\
\hline $\begin{array}{l}\text { Baseline characteristics } \\
\text { similar }\end{array}$ & High risk & Differences between groups at the start of the study \\
\hline $\begin{array}{l}\text { Incomplete outcome data } \\
\text { (attrition bias) } \\
\text { All outcomes }\end{array}$ & Low risk & No apparent attrition on main outcomes \\
\hline $\begin{array}{l}\text { Blinding of outcome as- } \\
\text { sessment (detection bias) } \\
\text { All outcomes }\end{array}$ & Unclear risk & Unclear if assessor blind to group \\
\hline $\begin{array}{l}\text { Protection against conta- } \\
\text { mination }\end{array}$ & High risk & Pharmacies offer both intervention and control \\
\hline $\begin{array}{l}\text { Selective reporting (re- } \\
\text { porting bias) }\end{array}$ & Low risk & Not noted \\
\hline Other bias & Low risk & Not noted \\
\hline $\begin{array}{l}\text { Blinding of participants } \\
\text { and personnel (perfor- } \\
\text { mance bias) } \\
\text { All outcomes }\end{array}$ & Unclear risk & Unclear if participants aware of grouping \\
\hline
\end{tabular}

Petkova 2009

$\begin{array}{ll}\text { Methods } & \text { Design: RT } \\ \text { Groups: intervention (arthritis management); control (usual care) }\end{array}$

Participants

Pharmacies: not reported

Pharmacy worker: not targeted

Pharmacy user: 90 (45 intervention; 45 control) 
Petkova 2009 (Continued)

- mean age: intervention $45.74 \pm 2.72$ years; control $44.58 \pm 2.61$ years

- \% female: intervention $67.4 \%$; control $58.1 \%$

Setting: urban, Sofia

Country: Bulgaria

Interventions

Pharmacy worker-directed intervention: 3-day intensive training. Review of disease, pain management, risks, exercise, joint protection, role-play

- Delivered by: rheumatologist, pharmacist and a therapist

- Type: education

- Mode of delivery: face-to-face; written materials

- TDF: knowledge

- Duration: 3 days

Pharmacy worker control: it appears the same pharmacist delivered intervention and control treatment.

Pharmacy user-directed intervention: education program with information on arthritis, heat-cold therapy, physical training, pain management, self-study leaflets

- Delivered by: pharmacist

- Type: education

- Mode of delivery: face-to-face; written materials

- TDF: knowledge, environment, context, resources

- Duration: 4 sessions held monthly

- Length of follow-up: at 4 months (post intervention)

Pharmacy user control: usual treatment

Outcomes Pharmacy worker: not assessed

\section{Pharmacy user:}

- Clinical: frequency of pain

- Psychological health: not assessed

- Behavioural: medication compliance

- Quality of life: pain interference (Brief Pain Inventory)

- Process: patient satisfaction (satisfaction with services questionnaire)

- Costs: healthcare utilisation - GP visits

Notes Study/intervention name: none given

Funding source: not reported

\section{Risk of bias}

\begin{tabular}{lll}
\hline Bias & Authors' judgement & Support for judgement \\
\hline $\begin{array}{l}\text { Random sequence genera- } \\
\text { tion (selection bias) }\end{array}$ & Low risk & Used random number generator \\
\hline $\begin{array}{l}\text { Allocation concealment } \\
\text { (selection bias) }\end{array}$ & Unclear risk & Used random number generator \\
\hline
\end{tabular}


Planas 2012 (Continued)

Pharmacy worker control: it appears the same pharmacists delivered treatment to both intervention and control groups.

Pharmacy user-directed intervention: patient education and diabetes management services

- Delivered by: pharmacists

- Type: self management, education based on clinical practice guidelines, medication management, other (disease management)

- Mode of delivery: individual face-to-face

- TDF: knowledge, skills, reinforcement, goals, environment, context, resources, behavioural regulation

- Duration: 9 x 1-hour sessions held monthly

- Clinical outcomes collected at baseline, 3,6, and 9 months

- Length of follow-up: 9 months (end of intervention)

Pharmacy user control: usual treatment
Pharmacy worker: not assessed

\section{Pharmacy user:}

- Clinical: HbA1c, blood pressure, LDL cholesterol

- Psychological health: not assessed

- Behavioural: not assessed

- Quality of life: not assessed

- Process: Healthcare Effectiveness Data and Information Set (HEDIS) performance measures

- Costs: not assessed

Funding source: American Society of Health System Pharcists Research and Education Foundation

\section{Risk of bias}

\begin{tabular}{lll}
\hline Bias & Authors' judgement & Support for judgement \\
\hline $\begin{array}{l}\text { Random sequence genera- } \\
\text { tion (selection bias) }\end{array}$ & Low risk & Randomised by previously generated random number list \\
\hline $\begin{array}{l}\text { Allocation concealment } \\
\text { (selection bias) }\end{array}$ & Unclear risk & Unclear if allocation was concealed \\
\hline $\begin{array}{l}\text { Baseline outcome mea- } \\
\text { sures similar }\end{array}$ & Low risk & No differences reported \\
\hline $\begin{array}{l}\text { Baseline characteristics } \\
\text { similar }\end{array}$ & High risk & Difference in BMI \\
\hline $\begin{array}{l}\text { Incomplete outcome data } \\
\text { (attrition bias) }\end{array}$ & Unclear risk & $\begin{array}{l}\text { Reported that used carry forward of missing data, but some exclusions if the 3 } \\
\text { All outcomes }\end{array}$ \\
\hline $\begin{array}{l}\text { Blinding of outcome as- } \\
\text { sessment (detection bias) } \\
\text { All outcomes }\end{array}$ & Low risk & Variable use of objective primary outcome \\
\hline
\end{tabular}


Planas 2012 (Continued)

Protection against conta- Unclear risk Individuals were allowed to choose what intervention to visit, it is possible mination

that pharmacies offered both intervention and control

Selective reporting (re- Low risk Not noted
porting bias)

\begin{tabular}{ll}
\hline Other bias & Anclear risk \\
& $\begin{array}{l}\text { Ell pharmacies belonged to the same chain, which is a cause of potential bias. } \\
\text { ses. Participant had to attend the initial } 3 \text { month visit to be included in analy- } \\
\text { were excluded from analyses because no effect of intervention on the out- } \\
\text { come measures could be determined. }\end{array}$
\end{tabular}

Blinding of participants Unclear risk Not mentioned - not blinded

and personnel (perfor-

mance bias)

All outcomes

\section{Schmiedel 2015}

\begin{tabular}{ll}
\hline Methods & Design: cluster-RT \\
& Groups: intervention group (diabetes prevention); control group (no treatment) \\
\hline
\end{tabular}

\section{Participants}

Pharmacies: 22 (11 intervention; 11 control)

Pharmacy worker: pharmacists

Pharmacy user: 1092 (565 intervention; 575 control)

- mean age $57.5 \pm 11.3$ years

- $\%$ female: $68.6 \%$

Setting: unclear

Country: Germany (Bavaria)

Interventions

Pharmacy worker-directed intervention: half day training on behaviour change +1 day on how to conduct the trial

- Delivered by: not reported

- Type: not reported

- Mode of delivery: not clear

- TDF: knowledge

- Duration: half day training on behaviour change

Pharmacy worker control: 1 day training on how to conduct the trial

Pharmacy user-directed intervention: 3 individual counselling sessions and 5 group lectures covering diabetes and lifestyle issues and personalised goals. Provided written information on healthy diet and physical activity

- Delivered by: pharmacist

- Type: behaviour change

- Mode of delivery: face-to-face (individual and group) 
Schmiedel 2015 (Continued)

- TDF: knowledge, goals, environment, context, resources, behavioural regulation

- Duration: 3 individual counselling sessions $+5 \times 75$ - to 90-minute lectures

- Follow-up: 12 months (end of intervention)

Pharmacy user control: assessed and informed about their health status but no further counselling.

Pharmacy worker:
- Uptake: not reported, but 2 of 40 dropped out of trial
Pharmacy user:
- Clinical: change in FINDRISC (Finnish Diabetes Risk Score), weight, BP
- Psychological health: not assessed
- Behavioural: physical activity
- Quality of life: SF12
- Process: not assessed
- Costs: not assessed

Funding source: Dr August and Dr Anni Lesmuller-Stiftung Foundation, the Bavarian State Ministry of Public Health and Care Services (through the funding and health promotion initiative Gesund Leben Bayern), the Bavarian State Corporate Health Insurers, and the funding initiative for prevention (Forderinitiative Pravention eV).

\section{Risk of bias}

\begin{tabular}{|c|c|c|}
\hline Bias & Authors' judgement & Support for judgement \\
\hline $\begin{array}{l}\text { Random sequence genera- } \\
\text { tion (selection bias) }\end{array}$ & Unclear risk & No method specified \\
\hline $\begin{array}{l}\text { Allocation concealment } \\
\text { (selection bias) }\end{array}$ & Unclear risk & Not reported \\
\hline $\begin{array}{l}\text { Baseline outcome mea- } \\
\text { sures similar }\end{array}$ & Low risk & No significant differences \\
\hline $\begin{array}{l}\text { Baseline characteristics } \\
\text { similar }\end{array}$ & Low risk & No significant differences \\
\hline $\begin{array}{l}\text { Incomplete outcome data } \\
\text { (attrition bias) } \\
\text { All outcomes }\end{array}$ & Low risk & Missing data imputed \\
\hline $\begin{array}{l}\text { Blinding of outcome as- } \\
\text { sessment (detection bias) } \\
\text { All outcomes }\end{array}$ & Unclear risk & Not reported \\
\hline $\begin{array}{l}\text { Protection against conta- } \\
\text { mination }\end{array}$ & Low risk & Multi-centre cluster-RT \\
\hline $\begin{array}{l}\text { Selective reporting (re- } \\
\text { porting bias) }\end{array}$ & Low risk & None noted \\
\hline
\end{tabular}


Schmiedel 2015 (Continued)

\begin{tabular}{lll} 
Other bias & Low risk & None noted \\
\hline $\begin{array}{l}\text { Blinding of participants } \\
\text { and personnel (perfor- }\end{array}$ & High risk & Not blinded \\
mance bias) & \\
All outcomes & \\
\hline
\end{tabular}

\section{Skowron 2011}

$\begin{array}{ll}\text { Methods } & \text { Design: cluster-RT } \\ \text { Groups: intervention group (pharmaceutical care for hypertension); control group (standard care) }\end{array}$

Participants

Pharmacies: 55 (28 intervention; 27 control)

Pharmacy worker: 95 pharmacists (44 intervention; 51 control)

Pharmacy user: 193 patients with hypertension (70 intervention; 123 control)

- mean age: $42.9 \%$ aged 46 to 60 years, $39.3 \%$ aged 61 to 75 years

Setting: urban, Krakow

Country: Poland

Pharmacy worker-directed intervention: training on detection, classification and monitoring of drug-related problems, pathophysiology of hypertension, risk factors and life-style factors influencing the disease, and rules of pharmacotherapy of hypertension

- Delivered by: researchers (pharmacists) and physicians (specialists in arterial hypertension and cardiology)

- Type: education meetings

- Mode of delivery: group

- TDF: knowledge

- Duration: 3 x 5-hour training sessions

- Length of follow-up: end of project

Pharmacy worker control: wait list; received the same training as the intervention group after final study visit

Pharmacy user-directed intervention: patients received pharmaceutical care and were educated about pathophysiology, risk factors, treatment and style of life with hypertension, as well as blood pressure measurement, and self-measurement of blood pressure.

- Delivered by: pharmacist

- Type: self-management; behaviour change; education; medication management

- Mode of delivery: individual face-to-face

- TDF: knowledge

- Duration: 12 meetings from November 2004 to January 2006

- Length of follow-up: post intervention (12 months)

Pharmacy user control: usual treatment 
- Uptake: not reported, but of original 55 pharmacies and 95 pharmacists randomised only 39 pharmacies and 74 pharmacists were retained in study

- Behavioural: not assessed

\section{Pharmacy user:}

- Clinical: SBP/DBP

- Psychological health: not assessed

- Behavioural: not assessed

- Quality of life: SF-36

- Process: knowledge about hypertension (not validated)

- Costs/HCU: not assessed

Notes Study/intervention name: none given

Funding source: no specific grant

\section{Risk of bias}

\begin{tabular}{|c|c|c|}
\hline Bias & Authors' judgement & Support for judgement \\
\hline $\begin{array}{l}\text { Random sequence genera- } \\
\text { tion (selection bias) }\end{array}$ & Low risk & $\begin{array}{l}\text { Quote: "Randomization of community pharmacies to control and study group } \\
\text { was done by generation of random numbers by computer software." }\end{array}$ \\
\hline $\begin{array}{l}\text { Allocation concealment } \\
\text { (selection bias) }\end{array}$ & Low risk & $\begin{array}{l}\text { Quote: "Randomization of community pharmacies to control and study group } \\
\text { was done by generation of random numbers by computer software." }\end{array}$ \\
\hline $\begin{array}{l}\text { Baseline outcome mea- } \\
\text { sures similar }\end{array}$ & Unclear risk & $\begin{array}{l}\text { Differences in baseline for education, age and place of residence. Unclear if } \\
\text { this was accounted for in the analysis. }\end{array}$ \\
\hline $\begin{array}{l}\text { Baseline characteristics } \\
\text { similar }\end{array}$ & High risk & Differences in education, age and residence \\
\hline $\begin{array}{l}\text { Incomplete outcome data } \\
\text { (attrition bias) } \\
\text { All outcomes }\end{array}$ & High risk & Significant number of dropouts from both groups \\
\hline $\begin{array}{l}\text { Blinding of outcome as- } \\
\text { sessment (detection bias) } \\
\text { All outcomes }\end{array}$ & High risk & No information on blinding \\
\hline $\begin{array}{l}\text { Protection against conta- } \\
\text { mination }\end{array}$ & Low risk & Randomisation by pharmacies \\
\hline $\begin{array}{l}\text { Selective reporting (re- } \\
\text { porting bias) }\end{array}$ & High risk & No numerical reporting of quality of life \\
\hline Other bias & High risk & High number of control pharmacies withdrew \\
\hline $\begin{array}{l}\text { Blinding of participants } \\
\text { and personnel (perfor- } \\
\text { mance bias) } \\
\text { All outcomes }\end{array}$ & High risk & No information about blinding provided \\
\hline
\end{tabular}




\begin{tabular}{ll}
\hline Methods & Design: cluster-RT \\
Groups: \\
- Intervention group 1: pamphlet + education for low back pain (LBP) \\
- Intervention group 2: pamphlet only \\
- Control group (usual care)
\end{tabular}

Participants

Pharmacy worker: 35 pharmacies (11 in group 1; 11 in group 2; 13 in control)

Pharmacy user:

- 317 patients with low back pain (LBP):

* 102 in intervention group 1 (pamphlet + education for LBP)

* 111 in intervention group 2 (pamphlet only)

* 104 in control group

- mean age:

* intervention group 1: $43.3 \pm 13.2$ years

* intervention group 2: $44.2 \pm 12.7$ years

* control group: $44.3 \pm 11.8$ years

- \% female:

* intervention group 1: 55.9\%

* intervention group 2: $64.9 \%$

* control group: $60.6 \%$

Setting: urban

Country: Australia

Interventions

Pharmacy worker-directed intervention: pharmacist staff allocated to the pamphlet + education intervention were provided with specific training: pretrial workshops by the study team, during which pharmacists were instructed about the key pamphlet messages to reinforce and were advised about the necessity of delivering these messages strictly in accordance with the pamphlet content.

- Delivered by: researcher

- Type: education meetings

- Mode of delivery: group

- TDF: knowledge, skills

- Duration: not stated

Pharmacy worker control: not reported

\section{Pharmacy user-directed intervention:}

Intervention group 1 (pamphlet + education): in addition to usual care, participants received verbal reinforcement of the pamphlet's content from a trained pharmacy staff member

Intervention group 2 (pamphlet only): in addition to usual care, participants were provided with the pamphlet, but without further specific reinforcement of pamphlet content.

- Delivered by: pharmacist

- Type: self-management; education

- Mode of delivery: individual face-to-face; written materials

- TDF: knowledge, skills, environment, context, resources, behavioural regulation

- Duration: 1 session 
Slater 2013 (Continued)

- Length of follow-up: 2 weeks and 8 weeks after baseline

Pharmacy user control: no pamphlet at the time of the trial

Pharmacy worker: not assessed
Pharmacy user:
- Clinical: average severity of LBP (unsure whether validated)
- Psychological health: not assessed
- Behavioural: activity impairment (not validated)
- Quality of life: not assessed
Process: beliefs about inevitable consequences of future life with LBP (Back Pain Beliefs Question-
(FABQ)); perceived usefulness of the pamphlet (Global Perceived Impression of Usefulness (GPIU)
Scale)
Costs: not assessed

Notes Study/intervention name: none given

Funding source: grant by Department of Health, Government of Western Australia and Curtin University

\section{Risk of bias}

\begin{tabular}{|c|c|c|}
\hline Bias & Authors' judgement & Support for judgement \\
\hline $\begin{array}{l}\text { Random sequence genera- } \\
\text { tion (selection bias) }\end{array}$ & Low risk & $\begin{array}{l}\text { Quote: "Pharmacies from within each SEIFA block were then randomised (si- } \\
\text { multaneously)" }\end{array}$ \\
\hline $\begin{array}{l}\text { Allocation concealment } \\
\text { (selection bias) }\end{array}$ & Low risk & $\begin{array}{l}\text { Quote: "Allocation of pharmacies was concealed from the PSWA [Pharmaceuti- } \\
\text { cal Society of Western Australia] and the investigator (KW) [Kim Watkins] who } \\
\text { provided access to the clusters." }\end{array}$ \\
\hline $\begin{array}{l}\text { Baseline outcome mea- } \\
\text { sures similar }\end{array}$ & Low risk & Analyses adjusted for baseline scores \\
\hline $\begin{array}{l}\text { Baseline characteristics } \\
\text { similar }\end{array}$ & Low risk & Analyses adjusted for baseline scores \\
\hline $\begin{array}{l}\text { Incomplete outcome data } \\
\text { (attrition bias) } \\
\text { All outcomes }\end{array}$ & Low risk & Used likelihood-based estimation procedure for missing data \\
\hline $\begin{array}{l}\text { Blinding of outcome as- } \\
\text { sessment (detection bias) } \\
\text { All outcomes }\end{array}$ & Low risk & $\begin{array}{l}\text { Quote: "Blinding to group allocation included primary investigators, outcome } \\
\text { assessors and the statistician." }\end{array}$ \\
\hline $\begin{array}{l}\text { Protection against conta- } \\
\text { mination }\end{array}$ & Low risk & Randomisation by pharmacists \\
\hline $\begin{array}{l}\text { Selective reporting (re- } \\
\text { porting bias) }\end{array}$ & Low risk & Nothing noted \\
\hline Other bias & Unclear risk & Possible selection bias \\
\hline
\end{tabular}


Slater 2013 (Continued)
Blinding of participants
High risk
Quote: "Pharmacy staff and consumers were un-blinded." and personnel (performance bias)

All outcomes

\section{Smith 2011}

Methods

Design: cluster-RT

Groups: intervention group (goal setting for allergic rhinitis); control group (standard pharmacy care)

Participants

Pharmacies: 20 (8 intervention; 12 control)

Pharmacy workers: 38 (22 clinicians; 16 non-clinicians)

Pharmacy user: 150 patients with intermittent allergic rhinitis (IAR) (77 intervention; 77 control)

- mean age: intervention 38 (20 to 79 ) years; control 38 (21 to 78 ) years

- $\%$ female: intervention $65 \%$; control $68 \%$

Setting: urban

Country: Australia

Interventions

Pharmacy worker-directed intervention: workshop covering the pathophysiology of allergic rhinitis (AR), the current 'Allergic Rhinitis and its Impact on Asthma' (ARIA) guidelines and pharmacotherapy relating to specific AR symptoms. Also training in self-management theory, goal setting and up-skilling in patient counselling

- Delivered by: not stated

- Type: education meetings; based on clinical practice guidelines; role playing

- Mode of delivery: group

- TDF: knowledge, skills, environment resources and context

- Duration: 3-hour workshop for all, with additional component for intervention pharmacists

Pharmacy worker control: only received the workshop covering the pathophysiology of AR, the current ARIA guidelines and pharmacotherapy relating to specific AR symptoms.

Pharmacy user-directed intervention: patients received an informational brochure and received a goals card titled "My Goals and Treatment Card" where two goals were stated: "Eliminate/minimise hay fever symptoms" and "Avoid/minimise hay fever triggers" to record what they experienced. Individually tailored strategies were developed from these data collaboratively between the participant and the pharmacist or assistant, and entered onto the goals card.

- Delivered by: pharmacist; pharmacist assistant

- Type: self-management; goal setting

- Mode of delivery: individual face-to-face; written materials

- TDF: knowledge, skills, goals, environment, context, resources, behavioural regulation

- Duration: length of intervention: 10 days

- Follow-up: 10 days (end of intervention)

Pharmacy user control: usual treatment and a take-home brochure on AR at follow-up visit 
Smith 2011 (Continued)

\section{Pharmacy user:}

- Clinical: AR symptom severity questionnaire (unsure whether validated)

- Psychological health: not assessed

- Behavioural: Medication Adherence Report Scale (MARS); patient self-report of adherence to medication over the 10-day period (not validated)

- Quality of life: Mini Rhinoconjunctivitis Quality of Life Questionnaire (Mini RQLQ)

- Process: generic self-efficacy for chronic disease management questionnaire adapted for its use in the current study (not validated)

- Costs: not assessed

Notes Study/intervention name: Pharmacy Allergic Rhinitis Intervention Study (PARIS)

Funding source: funded by the Australian Government Department of Health and Ageing as part of the Fourth Community Pharmacy Agreement Research \& Development

Program managed by the Pharmacy Guild of Australia

\section{Risk of bias}

\begin{tabular}{|c|c|c|}
\hline Bias & Authors' judgement & Support for judgement \\
\hline $\begin{array}{l}\text { Random sequence genera- } \\
\text { tion (selection bias) }\end{array}$ & Unclear risk & Randomised, but method not specified \\
\hline $\begin{array}{l}\text { Allocation concealment } \\
\text { (selection bias) }\end{array}$ & Unclear risk & Randomised, but method not specified \\
\hline $\begin{array}{l}\text { Baseline outcome mea- } \\
\text { sures similar }\end{array}$ & Low risk & No significant differences between groups \\
\hline $\begin{array}{l}\text { Baseline characteristics } \\
\text { similar }\end{array}$ & Low risk & No significant differences between groups \\
\hline $\begin{array}{l}\text { Incomplete outcome data } \\
\text { (attrition bias) } \\
\text { All outcomes }\end{array}$ & Unclear risk & No information reported \\
\hline $\begin{array}{l}\text { Blinding of outcome as- } \\
\text { sessment (detection bias) } \\
\text { All outcomes }\end{array}$ & Unclear risk & No information on blinding \\
\hline $\begin{array}{l}\text { Protection against conta- } \\
\text { mination }\end{array}$ & Low risk & Randomisation by pharmacists \\
\hline $\begin{array}{l}\text { Selective reporting (re- } \\
\text { porting bias) }\end{array}$ & Low risk & All outcomes reported \\
\hline Other bias & Unclear risk & Only a small group of pharmacies \\
\hline $\begin{array}{l}\text { Blinding of participants } \\
\text { and personnel (perfor- } \\
\text { mance bias) } \\
\text { All outcomes }\end{array}$ & High risk & Presumably pharmacy workers knew grouping \\
\hline
\end{tabular}


Svarstad 2013

\begin{tabular}{ll}
\hline Methods & Design: cluster-RT \\
Groups: intervention group (hypertension intervention); control group (usual care )
\end{tabular}

Participants

Pharmacies 28 (14 intervention; 14 control)

Pharmacy worker: pharmacist

Pharmacy user: 576 black patients with hypertension

- mean age: intervention $53.2 \pm 11$ years; control $52.8 \pm 11.9$ years

- \% female: intervention 64.9\%; control 67.3\%

Setting: urban

Country: USA

Interventions

Pharmacy worker-directed intervention: 7 hours of continuing education through an interactive workshop that included a lecture, slides, handouts, a demonstration and practice, role play case studies, and break-out discussions. One additional hour of self-study, clinical guidelines summary, clinical tools e.g. BP monitoring equipment. Also BP clinic hours established.

- Delivered by: pharmacy and medical educators

- Type: interactive education, no monetary incentive

- Mode of delivery: unclear

- TDF: skills, environment, context, resources

- Duration: 7 hours

Pharmacy worker control: not reported

Pharmacy user-directed intervention: patients were sent brochures and received an intervention using scheduled visits, Brief Medication Questionnaires (BMQs), and new toolkits including a pill organiser, BP tracker, pedometer, and tips and goals

- Delivered by: pharmacist; pharmacist assistant

- Type: self-management; behaviour change; education; based on clinical practice guidelines

- Mode of delivery: individual face-to-face; telephone contact; written materials

- TDF: knowledge, beliefs about consequences, goals, memory, attention, decision making, environment, context, resources, behavioural regulation

- Duration: 6 monthly sessions

- Length of follow-up: 6 months (end of intervention) and 12 months

- Theory: Svarstad and Bultman's Health Collaboration model, Rogers Diffusion of Innovation model

Pharmacy user control: received patient information only, including a 14-page guide for lowering BP, pamphlet about hypertension in black people, and cards showing their BP at baseline and follow-up interviews, and instructions on when to seek immediate medical care for high BP.

Pharmacy worker: not assessed

\section{Pharmacy user:}

- Clinical: SBP/DBP

- Psychological health: not assessed

- Behavioural: refill adherence (not validated) 
Svarstad 2013 (Continued)

- Quality of life: not assessed

- Process: patient perceptions of pharmacist monitoring (not validated)

- Costs: not effectiveness

Svarstad 2009 and Shireman 2016 also refer to this study (cited under Svarstad 2013).

\section{Risk of bias}

\begin{tabular}{|c|c|c|}
\hline Bias & Authors' judgement & Support for judgement \\
\hline $\begin{array}{l}\text { Random sequence genera- } \\
\text { tion (selection bias) }\end{array}$ & Low risk & Computer software for randomisation \\
\hline $\begin{array}{l}\text { Allocation concealment } \\
\text { (selection bias) }\end{array}$ & Low risk & Computer software for randomisation \\
\hline $\begin{array}{l}\text { Baseline outcome mea- } \\
\text { sures similar }\end{array}$ & Low risk & No differences \\
\hline $\begin{array}{l}\text { Baseline characteristics } \\
\text { similar }\end{array}$ & High risk & Difference between groups for physical activity \\
\hline $\begin{array}{l}\text { Incomplete outcome data } \\
\text { (attrition bias) } \\
\text { All outcomes }\end{array}$ & Unclear risk & Unclear how managed \\
\hline $\begin{array}{l}\text { Blinding of outcome as- } \\
\text { sessment (detection bias) } \\
\text { All outcomes }\end{array}$ & Low risk & Blinded data collectors \\
\hline $\begin{array}{l}\text { Protection against conta- } \\
\text { mination }\end{array}$ & Unclear risk & Randomisation by pharmacy \\
\hline $\begin{array}{l}\text { Selective reporting (re- } \\
\text { porting bias) }\end{array}$ & Low risk & Not noted \\
\hline Other bias & Low risk & Not noted \\
\hline $\begin{array}{l}\text { Blinding of participants } \\
\text { and personnel (perfor- } \\
\text { mance bias) } \\
\text { All outcomes }\end{array}$ & High risk & Clients aware of grouping \\
\hline
\end{tabular}

Tommelein 2014

$\begin{array}{ll}\text { Methods } & \text { Design: RT } \\ \text { Groups: intervention (pharmaceutical care); control (usual care) }\end{array}$

Participants Pharmacies: 22 (11 intervention; 11 control)

Pharmacy workers: 170 
Tommelein 2014 (Continued)

Pharmacy user: 734 chronic obstructive pulmonary disease (COPD) patients (371 intervention; 363 control)

- mean age: intervention $68.4 \pm 9.6$ years; control $68.9 \pm 9.4$ years

- $\%$ female: intervention $36 \%$; control $31 \%$

Setting: unclear

Country: Beligum

Interventions

Pharmacy worker-directed intervention: training session addressing pathophysiology of COPD and its nonpharmacologic and pharmacological treatment

- Delivered by: unclear

- Type: unclear

- Mode of delivery: unclear

- TDF: knowledge

- Duration: unclear

Pharmacy worker control: not clear whether control pharmacists also received the same training session as intervention pharmacists

Pharmacy user-directed intervention: counselling sessions, addressing basic knowledge of COPD, inhalation technique and self-management and lifestyle issues

- Delivered by: pharmacists

- Type: self-management

- Mode of delivery: 1:1, assumed to be face-to-face

- TDF: knowledge, skills, environment, context, resources

- Duration: 2 sessions of 15 to 25 minutes; 1 at start of study and 1 at 1-month follow-up

- Follow-up: 3 months (2 months after end of intervention)

Pharmacy user control: usual treatment

- Uptake: not reported

\section{Pharmacy user:}

- Clinical: dyspnoea (modified Medical Research Council scale (mMRC), COPD Assessment Test (CAT)

- Psychological health: not assessed

- Behavioural: inhalation technique, adherence (medication refill)

- Quality of life: EQ-5D

- Costs: hospitalisations

Funding source: Ghent University, Liège University and GlaxoSmithKline (grant protocol number 114684) 
Tommelein 2014 (Continued)

\begin{tabular}{lll}
$\begin{array}{l}\text { Random sequence genera- } \\
\text { tion (selection bias) }\end{array}$ & Low risk & Web-based system \\
\hline $\begin{array}{l}\text { Allocation concealment } \\
\text { (selection bias) }\end{array}$ & Low risk & Central system \\
\hline $\begin{array}{l}\text { Baseline outcome mea- } \\
\text { sures similar }\end{array}$ & Low risk & Similar \\
\hline $\begin{array}{l}\text { Baseline characteristics } \\
\text { similar }\end{array}$ & Low risk & Similar \\
\hline $\begin{array}{l}\text { Incomplete outcome data } \\
\text { (attrition bias) } \\
\text { All outcomes }\end{array}$ & Low risk & Analysis accounted for missing data \\
\hline
\end{tabular}

\begin{tabular}{|c|c|c|}
\hline $\begin{array}{l}\text { Blinding of outcome as- } \\
\text { sessment (detection bias) } \\
\text { All outcomes }\end{array}$ & High risk & Pharmacists assessed inhalation techniques \\
\hline $\begin{array}{l}\text { Protection against conta- } \\
\text { mination }\end{array}$ & Unclear risk & Possible due to design \\
\hline $\begin{array}{l}\text { Selective reporting (re- } \\
\text { porting bias) }\end{array}$ & Low risk & Not apparent \\
\hline Other bias & Low risk & Not noted \\
\hline $\begin{array}{l}\text { Blinding of participants } \\
\text { and personnel (perfor- } \\
\text { mance bias) } \\
\text { All outcomes }\end{array}$ & High risk & Pharmacists not blinded, but patients were not told of group assignment \\
\hline
\end{tabular}

Tsuyuki 2002

$\begin{array}{ll}\text { Methods } & \text { Design: RT } \\ \text { Groups: intervention group (cholesterol risk management); control group (usual care) }\end{array}$

Participants $\quad$ Pharmacies: 54
Pharmacy workers: pharmacists

Pharmacy user: 675 patients with high risk of vascular events (344 intervention; 331 control)

- mean age: intervention $64.2 \pm 12.2$ years; control $64.6 \pm 11.3$ years

- $\%$ female: intervention $41 \%$; control $38 \%$

Setting: both urban and rural

Country: Alberta and Saskatchewan, Canada

Interventions

Pharmacy worker-directed intervention: training sessions to review the management of heart disease risk factors, especially hyperlipidaemia

- Delivered by: unclear 
Tsuyuki 2002 (Continued)

- Type: education

- Mode of delivery: unclear

- TDF: knowledge

- Duration: unclear

Pharmacy worker control: not reported

Pharmacy user-directed intervention: patients received a brochure; pharmacists completed a physician contact form that listed the patient's risk factors, medications and any recommendations; patients were encouraged to contact physician; and also received education about cardiovascular risk factors to reinforce adherence

- Delivered by: pharmacist

- Type: disease-management

- Mode of delivery: individual face-to-face; written materials

- TDF: knowledge, environment, context, resources

- Duration: participants seen at 2, 4, 8,12, and 16 weeks; 6 sessions

- Length of follow-up: 4 months (post intervention)

Pharmacy user control: patients given a copy of the same brochure and general advice only

Outcomes Pharmacy worker: not assessed

\section{Pharmacy user:}

- Clinical: composite of complete lipid panel

- Psychological health: not assessed

- Behavioural: not assessed

- Quality of life: SF-12

- Process: satisfaction with pharmacy services scale

- Costs: cost effectiveness

Notes Study/intervention name: the Study of Cardiovascular Risk Intervention by Pharmacists (SCRIP)

Funding source: University of Alberta Hospital Foundation, Merck Frossst Canada Inc, SCRIP study

Tsuyuki 1999, Simpson 2001, and Simpson 2004 (cited under Tsuyuki 2002) also refer to this study.

\section{Risk of bias}

\begin{tabular}{lll}
\hline Bias & Authors' judgement & Support for judgement \\
\hline $\begin{array}{l}\text { Random sequence genera- } \\
\text { tion (selection bias) }\end{array}$ & Low risk & Block randomisation stratified by pharmacy, computer-generated sequence \\
\hline $\begin{array}{l}\text { Allocation concealment } \\
\text { (selection bias) }\end{array}$ & Low risk & $\begin{array}{l}\text { Block size for randomisation was not revealed to ensure allocation conceal- } \\
\text { ment }\end{array}$ \\
\hline $\begin{array}{l}\text { Baseline outcome mea- } \\
\text { sures similar }\end{array}$ & Low risk & Baseline scores controlled for in analyses \\
\hline $\begin{array}{l}\text { Baseline characteristics } \\
\text { similar }\end{array}$ & Low risk & Baseline scores controlled for in analyses \\
\hline
\end{tabular}


Tsuyuki 2002 (Continued)

Incomplete outcome data Low risk Low attrition, balanced across groups
(attrition bias)

All outcomes

\begin{tabular}{|c|c|c|}
\hline $\begin{array}{l}\text { Blinding of outcome as- } \\
\text { sessment (detection bias) } \\
\text { All outcomes }\end{array}$ & High risk & Assessed by pharmacist \\
\hline $\begin{array}{l}\text { Protection against conta- } \\
\text { mination }\end{array}$ & High risk & Patient-level of randomisation \\
\hline $\begin{array}{l}\text { Selective reporting (re- } \\
\text { porting bias) }\end{array}$ & Low risk & Not noted \\
\hline Other bias & Unclear risk & Pharmacies were highly selected \\
\hline $\begin{array}{l}\text { Blinding of participants } \\
\text { and personnel (perfor- } \\
\text { mance bias) } \\
\text { All outcomes }\end{array}$ & High risk & Unblinded study \\
\hline
\end{tabular}

\section{Tsuyuki 2016 - RxACT}

\begin{tabular}{ll}
\hline Methods & Design: RT \\
& Groups: intervention (dyslipidaemia care); control (usual care + pamphlet on CV risk) \\
\hline
\end{tabular}

$\begin{array}{ll}\text { Participants } & \text { Pharmacies: } 14 \\ & \text { Pharmacy workers: } 22 \text { (intervention 11; control 11) } \\ & \text { Pharmacy user: uncontrolled dyslipidaemia } 99 \text { (intervention 49; control 50) } \\ \text { - mean age: intervention } 63 \pm 11.91 \text { years; control } 63 \pm 13.34 \text { years } \\ \text { - \% female: intervention } 53 \% \text {; control } 48 \% \\ \text { Setting: unclear } \\ \text { Country: Alberta, Canada }\end{array}$

Pharmacy user-directed intervention: identification, assessment, care plan development, education/counselling on CV risk, medications and health behaviour. Also prescribing/titration of lipid-lowering medications and close follow-up.

- Delivered by: pharmacist

- Type: condition management

- Mode of delivery: face-to-face

- TDF: knowledge, goals

- Duration: sessions every 6 weeks for 6 months

- Length of follow-up: 6 months (end of intervention) 
Pharmacy user control: usual care, lipid results and a pamphlet on CVD

Pharmacy worker: not assessed
Pharmacy user:
- Clinical: proportion achieving dyslipidaemia guidelines, LDL-C levels
- Psychological health: not assessed
- Behavioural: not assessed
- Quality of life: not assessed
- Process: not assessed

Notes Study/intervention name: RXACT (no expansion of this name provided)

Funding source: AstraZeneca grant

\begin{tabular}{|c|c|c|}
\hline \multicolumn{3}{|l|}{ Risk of bias } \\
\hline Bias & Authors' judgement & Support for judgement \\
\hline $\begin{array}{l}\text { Random sequence genera- } \\
\text { tion (selection bias) }\end{array}$ & Low risk & Via a secure website \\
\hline $\begin{array}{l}\text { Allocation concealment } \\
\text { (selection bias) }\end{array}$ & Low risk & Central allocation \\
\hline $\begin{array}{l}\text { Baseline outcome mea- } \\
\text { sures similar }\end{array}$ & Low risk & Similar \\
\hline $\begin{array}{l}\text { Baseline characteristics } \\
\text { similar }\end{array}$ & Low risk & Similar \\
\hline $\begin{array}{l}\text { Incomplete outcome data } \\
\text { (attrition bias) } \\
\text { All outcomes }\end{array}$ & Low risk & Last value carried forward for missing data \\
\hline $\begin{array}{l}\text { Blinding of outcome as- } \\
\text { sessment (detection bias) } \\
\text { All outcomes }\end{array}$ & Low risk & Objective outcome \\
\hline $\begin{array}{l}\text { Protection against conta- } \\
\text { mination }\end{array}$ & High risk & Randomisation at patient level \\
\hline $\begin{array}{l}\text { Selective reporting (re- } \\
\text { porting bias) }\end{array}$ & Low risk & Not apparent \\
\hline Other bias & Low risk & None noted \\
\hline $\begin{array}{l}\text { Blinding of participants } \\
\text { and personnel (perfor- } \\
\text { mance bias) } \\
\text { All outcomes }\end{array}$ & High risk & Blinding not possible \\
\hline
\end{tabular}


Tsuyuki 2016 - RxEACH

\begin{tabular}{ll}
\hline Methods & Design: RT \\
Groups: intervention (CV risk assessment and education); control (usual care)
\end{tabular}

Pharmacies: 56
Pharmacy worker: 723 (370 intervention; 353 control)
Pharmacy user: high risk for CVD 723
- mean age: intervention $61 \pm 12$ years; control $62 \pm 12$ years
- $\%$ female: intervention $43 \%$; control $42 \%$
Setting: unclear
Country: Alberta, Canada

Interventions

Pharmacy worker-directed intervention: online modules on case finding, CVD and risk factors, communicating risk, lifestyle behaviours

- Delivered: online materials as well as access to experts on CVD

- Type: condition management

- Mode of delivery: online training and face to face

- TDF: knowledge, social support

- Duration: unclear

Pharmacy worker control: it appears all pharmacists had training and saw both intervention and control patients.

Pharmacy user-directed intervention: medication therapy management assessment, and education including lifestyle

- Delivered by: pharmacists

- Type: condition management

- Mode of delivery: face-to-face

- TDF: knowledge

- Duration: seen every 3 to 4 weeks for 3 months

- Length of follow-up: 3 months (end of intervention)

Pharmacy user control: usual care with no specific intervention

Outcomes

Pharmacy worker: not assessed

\section{Pharmacy user:}

- Clinical: cardiovascular risk, BP, LDL-C, HbA1c

- Psychological health: not assessed

- Behavioural: smoking cessation

- Quality of life: not assessed

- Process: not assessed

- Costs: not assessed 
Tsuyuki 2016 - RxEACH (Continued)

Funding source: Alberta Health, Merck Canada funds for educational materials

Al Hamarneh 2017 and Al Hamarneh 2018 (cited under Tsuyuki 2016 - RxEACH) also refer to this study.

\section{Risk of bias}

\begin{tabular}{|c|c|c|}
\hline Bias & Authors' judgement & Support for judgement \\
\hline $\begin{array}{l}\text { Random sequence genera- } \\
\text { tion (selection bias) }\end{array}$ & Low risk & Central randomisation \\
\hline $\begin{array}{l}\text { Allocation concealment } \\
\text { (selection bias) }\end{array}$ & Low risk & Central randomisation \\
\hline $\begin{array}{l}\text { Baseline outcome mea- } \\
\text { sures similar }\end{array}$ & Low risk & Similar \\
\hline $\begin{array}{l}\text { Baseline characteristics } \\
\text { similar }\end{array}$ & Low risk & Similar \\
\hline $\begin{array}{l}\text { Incomplete outcome data } \\
\text { (attrition bias) } \\
\text { All outcomes }\end{array}$ & Low risk & Accounted for in analysis \\
\hline $\begin{array}{l}\text { Blinding of outcome as- } \\
\text { sessment (detection bias) } \\
\text { All outcomes }\end{array}$ & Low risk & Objective outcome \\
\hline $\begin{array}{l}\text { Protection against conta- } \\
\text { mination }\end{array}$ & High risk & Pharmacists delivered both intervention and control \\
\hline $\begin{array}{l}\text { Selective reporting (re- } \\
\text { porting bias) }\end{array}$ & Low risk & Not apparent \\
\hline Other bias & Low risk & None detected \\
\hline $\begin{array}{l}\text { Blinding of participants } \\
\text { and personnel (perfor- } \\
\text { mance bias) } \\
\text { All outcomes }\end{array}$ & High risk & Pharmacists not blinded \\
\hline
\end{tabular}

Venkatesan 2012

\begin{tabular}{ll} 
Methods & Design: RT \\
& Groups: intervention group (pharmaceutical care model for diabetes); contro \\
\hline Participants & Pharmacies: 2 \\
& Pharmacy worker: pharmacist \\
& \\
Pharmacy user: 39 patients with type 2 diabetes (19 intervention; 20 control) \\
- mean age: intervention $51.47 \pm 9.99$ years; control $57.0 \pm 12.05$ years \\
- $\%$ female: intervention $57.8 \%$; control $50 \%$
\end{tabular}


Venkatesan 2012 (Continued)

\author{
Setting: rural \\ Country: Tamil Nadu, India
}

Pharmacy worker-directed intervention: not targeted
Interventions
ucational material and instructions on dietary regulation, exercise
- Delivered by: pharmacist
- Type: self-management; education; medication management
- Mode of delivery: individual face-to-face
- TDF: knowledge, goals, behavioural regulation
- Follow-up at 8 months (post intervention)

Pharmacy user control: usual treatment

Pharmacy worker: not targeted
Pharmacy user:
- Clinical: fasting blood glucose; BMI
- Psychological health: not assessed
- Behavioural: not assessed
- Quality of life: Diabetes Care Profile (DCP)
- Costs: not assessed

Notes Study/intervention name: none given

Funding source: Tamil Nadu Pharmaceutical Sciences Welfare Trust, Chennai, India

\title{
Risk of bias
}

\begin{tabular}{lll}
\hline Bias & Authors' judgement & Support for judgement \\
\hline $\begin{array}{l}\text { Random sequence genera- } \\
\text { tion (selection bias) }\end{array}$ & Unclear risk & Randomised, but method not specified \\
\hline $\begin{array}{l}\text { Allocation concealment } \\
\text { (selection bias) }\end{array}$ & Unclear risk & Unclear \\
\hline $\begin{array}{l}\text { Baseline outcome mea- } \\
\text { sures similar }\end{array}$ & Unclear risk & Not clear if any differences were significant \\
\hline $\begin{array}{l}\text { Baseline characteristics } \\
\text { similar }\end{array}$ & Unclear risk & Not clear if any differences were significant \\
\hline $\begin{array}{l}\text { Incomplete outcome data } \\
\text { (attrition bias) } \\
\text { All outcomes }\end{array}$ & Low risk & No attrition reported \\
\hline
\end{tabular}

Blinding of outcome as-
sessment (detection bias) $\quad$ Low risk $\quad$ Unclear if blinded, but objective outcome


Venkatesan 2012 (Continued)

All outcomes

Protection against conta- High risk Randomisation at level of patient

mination

Selective reporting (re- Low risk Objective outcomes presented in text
porting bias)

\begin{tabular}{lll}
\hline Other bias & Unclear risk & Low power \\
\hline $\begin{array}{l}\text { Blinding of participants } \\
\text { and personnel (perfor- }\end{array}$ & Unclear risk & No information about blinding \\
mance bias) & \\
All outcomes & \\
\hline
\end{tabular}

Villeneuve 2010

$\begin{array}{ll}\text { Methods } & \text { Design: cluster-RT } \\ \text { Groups: intervention group (collaborative dyslipidaemia management); control group (usual care) }\end{array}$

\section{Participants}

Pharmacies: 15 (from 148 eligible)

Personnel: 77 physicians; 108 pharmacists

- 51 physicians in 18 clinics; \% female: intervention $56 \%$; control $42 \%$

- 49 pharmacists in 38 pharmacies; $\%$ female: intervention $86 \%$; control $57 \%$

Pharmacy user: 225 patients with dyslipidaemia (108 intervention; 117 control)

- mean age: intervention $59.3 \pm 9.6$ years; control $62.2 \pm 12.0$ years

- $\%$ female: intervention $36 \%$; control $40 \%$

Setting: unclear

Country: Canada

Pharmacy worker-directed intervention: pharmacists in the collaborative care group attended a 1day training workshop. During this workshop, formal lectures, role-playing and interactive exercises were used to present the Canadian treatment recommendations, guidance about the pharmacotherapy, information about the treatment protocol, and communication strategies for optimising adherence + a 2-hour gathering to discuss the intervention after 1 month.

- Delivered by: pharmacists, family physicians and a cardiologist

- Type: education; illness-management

- Mode of delivery: group

- TDF: knowledge, skills, memory, attention and decision making, environment resources and context

- Duration: 1-day workshop

Pharmacy worker control: no additional training

Pharmacy user-directed intervention: patients received counselling and a treatment plan, which included lifestyle changes and pharmacotherapy.

- Delivered by: pharmacists 
Villeneuve 2010 (Continued)

- Type: behaviour change

- Mode of delivery: individual face-to-face; written materials

- TDF: knowledge

- Duration: possibly 12 months; initial session 30 minutes, 15 -minute titration visits at 2-month intervals, adherence visit (30 minutes) if required, follow-up visit (15 minutes) 3 months later

- Length of follow-up: 12 months

Pharmacy user control: usual treatment

Pharmacy worker: not assessed
Pharmacy user:
- Clinical: change in: LDL-C levels; height; weight; waist circumference; SBP; DBP; target lipids; triglyc-
- erides; fasting blood glucose; BMI
- Behohological health: not assessed
- Quality of life: not assessed
- Process: not assessed
- Costs: not assessed

Notes Study/intervention name: Trial to Evaluate an Ambulatory primary care Management program for patients with dyslipidemia (TEAM)

Funding: funded by a grant from the Canadian Institutes of Health Research (grant number 200409MCT-133732-RCT) and unrestricted research grants from AstraZeneca Canada Inc, Merck Frosst Canada Ltd and Pfizer Canada Inc.

Villeneuve 2009 and Villeneuve 2007 (cited under Villeneuve 2010) also refer to the same study.

\section{Risk of bias}

\begin{tabular}{lll}
\hline Bias & Authors' judgement & Support for judgement \\
\hline $\begin{array}{l}\text { Random sequence genera- } \\
\text { tion (selection bias) }\end{array}$ & Low risk & $\begin{array}{l}\text { Quote: "We stratified the randomization by type of medical clinic and number } \\
\text { of physicians per cluster. We also blocked the clusters, with two or four clus- } \\
\text { ters per block and balanced randomization within each block' }\end{array}$ \\
\hline $\begin{array}{l}\text { Allocation concealment } \\
\text { (selection bias) }\end{array}$ & Low risk & $\begin{array}{l}\text { Quote: "We stratified the randomization by type of medical clinic and number } \\
\text { of physicians per cluster. We also blocked the clusters, with two or four clus- } \\
\text { ters per block and balanced randomization within each block' }\end{array}$ \\
\hline $\begin{array}{l}\text { Baseline outcome mea- } \\
\text { sures similar }\end{array}$ & Low risk & Adjustment for baseline in analyses \\
\hline $\begin{array}{l}\text { Baseline characteristics } \\
\text { similar }\end{array}$ & Low risk & Adjustment for baseline in analyses \\
\hline $\begin{array}{l}\text { Incomplete outcome data } \\
\text { (attrition bias) }\end{array}$ & Low risk & Used last value carried forward approach \\
$\begin{array}{l}\text { All outcomes } \\
\begin{array}{l}\text { Blinding of outcome as- } \\
\text { sessment (detection bias) }\end{array}\end{array}$ & Unclear risk & No information provided on blinding \\
\hline \begin{tabular}{l} 
all oumes \\
\hline
\end{tabular} &
\end{tabular}


Villeneuve 2010 (Continued)

Protection against conta- Low risk Randomisation by pharmacy mination

\begin{tabular}{lll}
\hline $\begin{array}{l}\text { Selective reporting (re- } \\
\text { porting bias) }\end{array}$ & Unclear risk & Unclear \\
\hline Other bias & Unclear risk & Only 15 of 148 clusters eligible and agreed to participate \\
\hline $\begin{array}{l}\text { Blinding of participants } \\
\begin{array}{l}\text { and personnel (perfor- } \\
\text { mance bias) }\end{array}\end{array}$ & Unclear risk & No information on blinding \\
All outcomes & \\
\hline
\end{tabular}

Weinberger 2002

\begin{tabular}{ll}
\hline Methods & Design: cluster-RT \\
Groups: \\
- Intervention: pharmaceutical care program (PCP) for asthma or COPD \\
- Control: \\
$*$ peak flow monitoring control group (PFMCG) \\
$*$ usual care control group (UCCG)
\end{tabular}

\section{Participants}

Pharmacies: 36 (12 pharmacies per group)

Pharmacy worker:

Pharmacy user: 1113 patients with asthma or COPD (447 PCP; 363 PFMCG; 303 UCCG)

- mean age: UCCG: $62.2 \pm 11.9$ years; PCP: $62.2 \pm 11.0$ years; PFMCG: $62.9 \pm 10.3$ years

- \% female: UCCG: 67.4\%; PCP: 63.5\%; PFMCG: $66.2 \%$

Setting: urban

Country: Indianapolis, USA

Interventions

Pharmacy worker-directed intervention: included an overview of pharmaceutical care, orientation to study, interpretation and use of data, measuring PEF, resources.

- Delivered by: "Investigators representing various backgrounds'

- Type: education

- Mode of delivery: face-to-face

- Duration: unclear

Pharmacy worker control: pharmacists received 4-hour training, but were excluded from PCP

Pharmacy user-directed intervention: patients received individualised handouts based on problems associated with specific clinical data stored on the computer

- Delivered by: pharmacist

- Type: behaviour change

- Mode of delivery: individual face-to-face; written materials

- TDF: knowledge, environment, context, resources 
Weinberger 2002 (Continued)

- Duration: unclear

- Length of follow-up: 1 year (possibly at end of intervention period)

Pharmacy user control: usual care

Outcomes Pharmacy worker: not assessed

\section{Pharmacy user:}

- Clinical: PEFR

- Psychological health: not assessed

- Behavioural: medication compliance

- Quality of life: disease-specific health-related quality of life (HRQOL)

- Process: patient satisfaction (validated)

- Costs: breathing-related emergency department or hospital visits

Notes Study/intervention name: none given

Funding source: Agency for Healthcare Research and Quality and the Health Services Research and Development Service, Department of Veteran Affairs (grant 5 R01 HS09083)

Weinberger 2001 (cited under Weinberger 2002) also refers to the same study.

\section{Risk of bias}

\begin{tabular}{lll}
\hline Bias & Authors' judgement & Support for judgement \\
\hline $\begin{array}{l}\text { Random sequence genera- } \\
\text { tion (selection bias) }\end{array}$ & Low risk & Used random number chart \\
\hline $\begin{array}{l}\text { Allocation concealment } \\
\text { (selection bias) }\end{array}$ & Low risk & $\begin{array}{l}\text { Quote: "interviewers, blinded to study group assignment, obtained informed } \\
\text { consent and conducted baseline interviews. After completing the interview, } \\
\text { the laptop computer used to administer interviews revealed the patient's } \\
\text { study group assignment." At that time, interviewers distributed peak flow me- } \\
\text { ters as appropriate. }\end{array}$ \\
\hline
\end{tabular}

Baseline outcome mea- Low risk Differences between groups controlled for in analyses
sures similar

Baseline characteristics Low risk Differences between groups controlled for in analyses
similar

Incomplete outcome data High risk $\quad$ Dropouts had worse breathing problems at 12 months
(attrition bias)

All outcomes

\begin{tabular}{lll}
\hline $\begin{array}{l}\text { Blinding of outcome as- } \\
\text { sessment (detection bias) } \\
\text { All outcomes }\end{array}$ & Low risk & \\
\hline $\begin{array}{l}\text { Protection against conta- } \\
\text { mination }\end{array}$ & Low risk & Cluster randomised \\
\hline
\end{tabular}

Selective reporting (re- Low risk Not noted
porting bias) 
Weinberger 2002 (Continued)

\begin{tabular}{|c|c|c|}
\hline Other bias & High risk & $\begin{array}{l}\text { Fidelity may have been low, as pharmacists only implemented protocol ap } \\
\text { proximately } 50 \% \text { of the time }\end{array}$ \\
\hline
\end{tabular}
proximately $50 \%$ of the time

Blinding of participants

High risk

Pharmacists aware of groupings

and personnel (perfor-

mance bias)

All outcomes

Yuksel 2010

$\begin{array}{ll}\text { Methods } & \text { Design: RT } \\ \text { Groups: intervention group (osteoporosis risk management); control group (usual care) }\end{array}$

Participants

Pharmacy worker: not targeted

Pharmacy user: 262 patients with osteoporosis (129 intervention; 133 control)

- mean age: intervention 61 years; control 63 years

- $\%$ female: intervention $62 \%$; control $67 \%$

Setting: unclear

Country: Canada

Interventions

\section{Pharmacy worker-directed intervention: not reported}

Pharmacy user-directed intervention: patients received tailored education program on aspects of osteoporosis; including risk factors, bone mineral density testing, lifestyle measures, calcium and vitamin D intake, and medications and written information, and discussion of heel ultrasound

- Delivered by: pharmacists

- Type: behaviour change

- Mode of delivery: individual face-to-face; written materials

- TDF: knowledge, environment, context, resources

- Duration: 30-minute consultation

Pharmacy user control: usual treatment and information provided by pharmacy

Outcomes Pharmacy worker: not assessed

\section{Pharmacy user:}

- Clinical: bone mineral density

- Psychological health: not assessed

- Behavioural: calcium and Vitamin D intake

- Quality of life: SF-12 and Osteoporosis Targeted Quality of Life questionnaire (OPTQoL)

- Process: not assessed

- Costs: not assessed 
Yuksel 2010 (Continued)

By a grant from the Institute of Health Economics (Edmonton) and Faculty Start Up Grant to Nesé Yuk-

sel from the Faculty of Pharmacy and Pharmaceutical Sciences (University of Alberta)

Yuksel 2006 (cited under Yuksel 2010) also refers to this study.

\begin{tabular}{|c|c|c|}
\hline \multicolumn{3}{|l|}{ Risk of bias } \\
\hline Bias & Authors' judgement & Support for judgement \\
\hline $\begin{array}{l}\text { Random sequence genera- } \\
\text { tion (selection bias) }\end{array}$ & Low risk & Internet randomisation \\
\hline $\begin{array}{l}\text { Allocation concealment } \\
\text { (selection bias) }\end{array}$ & Low risk & Internet randomisation \\
\hline $\begin{array}{l}\text { Baseline outcome mea- } \\
\text { sures similar }\end{array}$ & Low risk & Similar \\
\hline $\begin{array}{l}\text { Baseline characteristics } \\
\text { similar }\end{array}$ & Low risk & $\begin{array}{l}\text { Similar - control group had higher family history of osteoporosis but unlikely } \\
\text { to change result }\end{array}$ \\
\hline $\begin{array}{l}\text { Incomplete outcome data } \\
\text { (attrition bias) } \\
\text { All outcomes }\end{array}$ & Low risk & Used intention-to-treat analysis; similar dropout in both groups \\
\hline $\begin{array}{l}\text { Blinding of outcome as- } \\
\text { sessment (detection bias) } \\
\text { All outcomes }\end{array}$ & Low risk & Blinded \\
\hline $\begin{array}{l}\text { Protection against conta- } \\
\text { mination }\end{array}$ & High risk & Both groups were based in the same pharmacies \\
\hline $\begin{array}{l}\text { Selective reporting (re- } \\
\text { porting bias) }\end{array}$ & Low risk & Not noted \\
\hline Other bias & Low risk & Not noted \\
\hline $\begin{array}{l}\text { Blinding of participants } \\
\text { and personnel (perfor- } \\
\text { mance bias) } \\
\text { All outcomes }\end{array}$ & High risk & Not blinded \\
\hline
\end{tabular}

BMI: body-mass index; BP: blood pressure; cluster-RT: cluster randomised trial; COPD: chronic obstructive pulmonary disease; CV: cardiovascular; CVD: cardiovascular disease; DBP: diastolic blood pressure; EQ-5D: Euroqol Measure of quality of life; FEV1: forced expiratory volume in 1 second; FVC: forced vital capacity; GP: general practitioner (family doctor); HbA1c: glycosylated haemoglobin; HCU: health care utilisation; HDL: high-density lipoprotein; HDL-C: high-density lipoprotein cholesterol; LDL: low-density lipoprotein; LDL-C: low-density lipoprotein cholesterol; NHS: National Health Service; PEF: peak expiratory flow; PEFR: peak expiratory flow rate; RT: randomised trial; SBP: systolic blood pressure; SD: standard deviation; SF-12: short form-12; STD: sexually transmitted disease; TC: total cholesterol; TDF: theoretical domains framework; WHO: World Health Organization

Characteristics of excluded studies [ordered by study ID]

\begin{tabular}{ll}
\hline Study & Reason for exclusion \\
\hline Ahrens 2003 & Compared 2 active intervention groups \\
\hline
\end{tabular}




\begin{tabular}{|c|c|}
\hline Study & Reason for exclusion \\
\hline Aleo 2014 & Inappropriate intervention \\
\hline Ammari 2013 & Compared 2 active intervention groups. Control not randomised or representative \\
\hline Anderson 1995 & Inappropriate design, retrospective controlled study \\
\hline Anderson 2003 & Inappropriate design \\
\hline Armour 2004 & Inappropriate design \\
\hline Armour 2013 & Compared 2 active intervention groups; 3 versus 4 counselling sessions \\
\hline Basheti 2005 & Compared 3 active intervention groups - 3 forms of verbal counselling for turboinhaler device \\
\hline Bauld 2009 & Compared 2 active intervention groups - 1:1 versus group smoking cessation \\
\hline Bernsten 2001 & Inappropriate intervention \\
\hline Bock 2010 & Compared 2 intervention groups; control group not concurrent or randomised \\
\hline Butt 2016 & Not community pharmacy \\
\hline Chabot 2003 & Inappropriate design \\
\hline Chalker 2002 & Unclear intervention - focus primarily on medication, no valid outcomes \\
\hline Cody 1998 & Not community pharmacy \\
\hline Correr 2009 & Inappropriate intervention \\
\hline Crawford 2013 & No validated outcomes, only process-level outcomes (pharmacy support for service) \\
\hline De Vera 2014 & Inappropriate intervention \\
\hline de Vries 2010 & Inappropriate intervention \\
\hline Denig 2003 & Inappropriate intervention \\
\hline DeRemer 2008 & Inappropriate design \\
\hline DiDonato 2013 & Inappropriate design \\
\hline Ditusa 2001 & Not community pharmacy \\
\hline Ekedahl 2008 & Inappropriate intervention \\
\hline Fera 2008 & Inappropriate design \\
\hline Fikri-Benbrahim 2012 & Inappropriate design \\
\hline Fornos 2006 & Inappropriate intervention \\
\hline Fuller 2007 & Inappropriate outcomes \\
\hline Garcao 2002 & Inappropriate intervention \\
\hline
\end{tabular}




\begin{tabular}{|c|c|}
\hline Study & Reason for exclusion \\
\hline Goeree 2013 & Inappropriate intervention \\
\hline Gorgas 2012 & Inappropriate intervention \\
\hline Grainger-Rousseau 1997 & Inppropriate intervention \\
\hline Green 2008 & Not community pharmacy \\
\hline Haga 2017 & Inappropriate intervention \\
\hline Herborg 2001 & Inappropriate design \\
\hline Kaczorowski 2008 & Not community pharmacy \\
\hline Karwalajtys 2009 & Inapproriate intervention \\
\hline Kradjan 1999 & Inappropriate outcome \\
\hline Krass 2011 & Comparison of 2 active interventions ( 6 months versus 12 months) and no control group \\
\hline Kritikos 2007 & Inappropriate design \\
\hline Kumar, 2009 & Not community pharmacy \\
\hline Lalonde 2008 - PRoFIL & Inappropriate intervention \\
\hline Lugo de Ortellado 2007 & Inappropriate intervention \\
\hline Manfrin 2015 & Inappropriate intervention \\
\hline Mangiapane 2005 & Inappropriate design \\
\hline Marra 2012 & $\begin{array}{l}\text { The intervention included both education from a pharmacist, exercise from a physiotherapist and } \\
\text { referral to a self-management programme. It was not possible to identify the contribution of the } \\
\text { pharmacist's intervention. }\end{array}$ \\
\hline Marrero 2006 & Inappropriate intervention \\
\hline Meijer 2005 & No validated outcome \\
\hline Michie 2014 & No validated outcomes \\
\hline Michiels 2017a & Inappropriate intervention \\
\hline Noor 2016 & Inappropriate design \\
\hline O'Dwyer 2016 & Inappropriate intervention \\
\hline Obarcanin 2015 & Not community pharmacy \\
\hline Olivera 2016 & Inappropriate intervention \\
\hline Phimarn 2017 & Inappropriate design - comparison of 2 interventions \\
\hline Podhipak 1993 & Inappropriate intervention \\
\hline
\end{tabular}




\begin{tabular}{|c|c|}
\hline Study & Reason for exclusion \\
\hline Prokhorov 2010 & $\begin{array}{l}2 \text { active interventions (smoking cessation counselling versus skin cancer prevention counselling); } \\
\text { only process outcomes and not validated. }\end{array}$ \\
\hline Ratanajamit 2002 & Inappropriate intervention \\
\hline Rickles 2006 & Inappropriate intervention \\
\hline Rouleau 2007 & Unable to retrieve \\
\hline Rubio-Valera 2009 & Inappropriate intervention \\
\hline Saini 2008 & Inappropriate design \\
\hline Saji 2012 & Inappropriate setting (clinic and pharmacy) \\
\hline Santos 2010 & Unable to retrieve \\
\hline Sarayani 2012 & 3 active interventions ( 3 different intervention formats) and only process outcomes \\
\hline Sarkadi 2004 & Inappropriate outcomes \\
\hline Sinclair 1998 & No objective outcomes, only self-reported smoking status provided \\
\hline Sperandio 2012 & Inappropriate intervention \\
\hline Stergachis 2002 & Not community pharmacy (<50\% community pharmacy) \\
\hline Suppapitiporn 2005 & Not community pharmacy \\
\hline Taskila 2012 & Compared 2 active interventions \\
\hline Thavorn 2008 & Not community pharmacy \\
\hline Tobari 2010 & Not community pharmacy \\
\hline Tsuyuki 2015 & Not clear whether it was community pharmacy \\
\hline Tumwikirize 2004 & Inappropriate intervention \\
\hline Usami 2009 & Unable to retrieve \\
\hline Van de Steeg-van 2011 & Inappropriate intervention \\
\hline Viens 2007 & Inappropriate intervention \\
\hline Wang 2013 & Inappropriate intervention \\
\hline Watson 2002 & Inappropriate design \\
\hline Westrick 2016 & Comparison of 2 interventions, no control group \\
\hline Wilson 2004 & Inappropriate intervention/design \\
\hline Young 2012 & Setting not clearly community pharmacy \\
\hline
\end{tabular}


Characteristics of ongoing studies [ordered by study ID]

Davis 2016

\begin{tabular}{ll}
\hline Trial name or title & Effectiveness of a pharmacist-driven intervention in COPD (EPIC) \\
\hline Methods & Design: cluster-RT \\
& Groups: intervention group (enhanced care for management of COPD); control group (usual care)
\end{tabular}

Participants

Pharmacies: 20 (10 intervention; 10 control)

Pharmacy workers: pharmacists

Pharmacy users: 140 patients with COPD

Setting: unclear

Country: Canada

Interventions

Pharmacy worker-directed intervention: refresher COPD management training, and how to deliver the intervention

Pharmacy worker control: training on study protocols

Pharmacy user-directed intervention: 7 elements:

- an education pamphlet:

- medication review

- patient education

- a written COPD action plan provided in collaboration with the family physician (see next point)

- patient referral to pulmonary rehabilitation in collaboration with the family physician

- provision of, or referral to, smoking cessation counselling (where applicable), and

- referral to a community-based chronic disease self-management program

- Delivered by: pharmacists

- Type: condition management

- Mode of delivery: face-to-face

- Duration: over 1 or 2 visits

Pharmacy user control: usual care and a COPD education pamphlet

Outcomes Pharmacy worker: not targeted

\section{Pharmacy user:}

- Clinical: not assessed

- Psychological health: not assessed

- Behavioural: Adherence Medication Possession Ratio and Morisky scale

- Quality of life: St George's Respiratory questionnaire

- Process: not assessed

- Costs: frequency of physician visits, hospitalisations, emergency department visits 
Davis 2016 (Continued)

Contact information emdavis@mun.ca

Notes Funding: Health Research Foundation: Canada

\section{Ekers 2017}

Trial name or title Community pHarmaciEs Mood Intervention STudy (CHEMIST)

\begin{tabular}{ll}
\hline Methods & Design: pilot RT \\
Groups: intervention group (enhanced support for depression); control group (usual care)
\end{tabular}

\section{Participants}

Pharmacies: 7

Pharmacy users: 130

Pharmacy users: patients with sub-threshold depression

Setting: unclear

Country: UK

Interventions

Pharmacy worker-directed intervention: none specific but pharmacists must have experience of extended role or training to Royal Society of Public Health standard (Understanding Health Improvement Level 2).

Pharmacy user-directed intervention: behavioural activation focused self-help support; proactive follow-up; symptom monitoring; and decision supported signposting

- Delivered by: pharmacists

- Type: condition management

- Mode of delivery: face-to-face

- Duration: 4 to 6 sessions over 4 months

Pharmacy user control: usual care

\section{Outcomes}

Pharmacy worker: not targeted

\section{Pharmacy user:}

- Clinical: not assessed

- Psychological health: depression, anxiety

- Behavioural: participants use of intervention

- Quality of life: SF-12, EQ-5D

- Process: qualitative interviews

- Costs: AD-SUS (Adult Service Use Schedule)

\begin{tabular}{ll}
\hline Starting date & 13 June 2016 \\
\hline Contact information & liz.littlewood@york.ac.uk; david.ekers@york.ac.uk
\end{tabular}


Ekers 2017 (Continued)
Notes
Funding NIHR

Michiels 2017

\begin{tabular}{ll} 
Trial name or title & $\begin{array}{l}\text { Impact of a Community Pharmacy-Based Information Program on Type 2 Diabetic Patients' } \\
\text { ence to Their Oral Treatment: (Iphodia) }\end{array}$ \\
\hline Methods & Design: cluster-RT \\
& Groups: intervention group (diabetes management); control group (usual care) \\
\hline Participants & Pharmacies: 182 \\
& -------------------------------------------------------------- \\
& Pharmacy users: 800 patients with type 2 diabetes (required from sample size calculation) \\
& Setting: unclear \\
Country: France
\end{tabular}

Interventions

Pharmacy worker-directed intervention: not reported

Pharmacy user-directed intervention: thematic information on diabetes, namely diet for diabetics, monitoring drug treatment and the complications of diabetes

- Delivered by: pharmacist

- Type: self-management

- Mode of delivery: face-to-face

- Duration: 3 x 30-minute visits over 6 months

Pharmacy user control: usual care

Outcomes
Pharmacy worker: unclear
- Clinical: HbAlc
- Psychological health: not assessed
- Behavioural: adherence - Medication Possession Ratio
- Quality of life: not assessed
- Process: knowledge, satisfaction
- Costs: not assessed

\begin{tabular}{ll}
\hline Starting date & 1 March 2014 \\
\hline Contact information & Dr Yves Michiels \\
\hline Notes & Funding source: MSG, France \\
\hline
\end{tabular}


Porteous 2013

\begin{tabular}{ll}
\hline Trial name or title & Help for Hayfever \\
\hline Methods & Design: pilot cluster-RT \\
& Groups: intervention group (hay fever management); control group (usual care) \\
\hline
\end{tabular}

Participants

Pharmacies: 12

Pharmacy workers: at least one pharmacist and pharmacy assistant per pharmacy

Pharmacy users: 144 patients with allergic rhinitis

Setting: unclear

Country: Scotland

Interventions

Pharmacy worker-directed intervention: 3-hour training workshop in self-management theory, the use of goal-setting as a behaviour-change technique

Pharmacy user-directed intervention: setting and achieving goals that aim to avoid/minimise triggers for, and eliminate/minimise symptoms of allergic rhinitis, including problem solving

- Delivered by: pharmacy workers

- Type: behaviour change

- Mode of delivery: face-to-face

- Duration: unclear

Pharmacy user control: usual care

Outcomes Pharmacy worker: uptake

\section{Pharmacy user:}

- Clinical: symptom severity

- Psychological health: not assessed

- Behavioural: medication adherence

- Quality of life: mini-rhinoconjunctivitis quality of life questionnaire, EQ-5D

- Costs: pharmacy and health service costs, QALYS

\begin{tabular}{ll}
\hline Starting date & April 2012 \\
\hline Contact information & t.porteous@abdn.ac.uk \\
\hline Notes & Funded by the Chief Scientist Office of the Scottish Government.
\end{tabular}

\section{Spadaro 2010}

Trial name or title

Methods

GIFT (the Genetic Informatics Trial of Warfarin to Prevent Deep Vein Thrombosis trial)

Design: RT

Groups: intervention group (community pharmacy follow-up); control group (usual care) 
Spadaro 2010 (Continued)
Participants
Pharmacy worker: not reported

Pharmacy users: 220 patients with heart failure

Setting: unclear

Country: Italy

Pharmacy worker-directed intervention: informed about epidemiological relevance of heart failure and therapeutic management

- Delivered by: unclear

- Type: unclear

- Mode of delivery: unclear

- Duration: 9 meetings

Pharmacy worker control: no intervention

Pharmacy user-directed intervention: patients and relatives receive education in hospital, then community pharmacy follow-up

- Delivered by: pharmacists

- Type: behaviour change

- Mode of delivery: individual face-to-face; written materials

- Duration: unclear

Pharmacy user control: usual care

\begin{tabular}{ll}
\hline Outcomes & Pharmacy worker: not assessed \\
& Pharmacy user: \\
& - Clinical: not assessed \\
& - Psychological health: not assessed \\
& - Quality of life: SF-12 \\
& - Process: not assessed \\
& Costs: not assessed \\
\hline Starting date & October 2010 \\
\hline Contact information & Francesca Spadaro \\
\hline Notes & Funding source: unclear \\
\hline
\end{tabular}

\section{Abbreviations}

COPD: chronic obstructive pulmonary disease; EQ-5D: EuroQol measure of quality of life; HbA1c: glycosylated haemoglobin; QALY: quality adjusted life year; SF-12: Short Form-12

\section{DATA AND ANALYSES}


Comparison 1. Community pharmacy user health-promotion intervention versus usual treatment

\begin{tabular}{|c|c|c|c|c|}
\hline Outcome or subgroup title & $\begin{array}{l}\text { No. of } \\
\text { studies }\end{array}$ & $\begin{array}{l}\text { No. of } \\
\text { partici- } \\
\text { pants }\end{array}$ & Statistical method & Effect size \\
\hline 1 Health-related behaviour & 10 & 2138 & $\begin{array}{l}\text { Std. Mean Difference (IV, Random, 95\% } \\
\mathrm{Cl} \text { ) }\end{array}$ & $0.43[0.14,0.72]$ \\
\hline 1.1 Medication adherence & 3 & 1245 & $\begin{array}{l}\text { Std. Mean Difference (IV, Random, 95\% } \\
\mathrm{Cl} \text { ) }\end{array}$ & $0.17[-0.23,0.57]$ \\
\hline 1.2 Inhaler technique & 4 & 384 & $\begin{array}{l}\text { Std. Mean Difference (IV, Random, 95\% } \\
\mathrm{Cl} \text { ) }\end{array}$ & $0.92[0.35,1.48]$ \\
\hline $\begin{array}{l}\text { 1.3 Other - alcohol consumption, } \\
\text { diabetes self-care and activity im- } \\
\text { pairment }\end{array}$ & 3 & 509 & $\begin{array}{l}\text { Std. Mean Difference (IV, Random, 95\% } \\
\mathrm{Cl} \text { ) }\end{array}$ & $0.14[-0.41,0.68]$ \\
\hline $\begin{array}{l}2 \text { Intermediate clinical outcomes } \\
\text { (final value scores) }\end{array}$ & 20 & 3971 & $\begin{array}{l}\text { Std. Mean Difference (IV, Random, 95\% } \\
\mathrm{Cl} \text { ) }\end{array}$ & $-0.43[-0.65,-0.21]$ \\
\hline 2.1 Asthma & 8 & 2120 & $\begin{array}{l}\text { Std. Mean Difference (IV, Random, 95\% } \\
\mathrm{Cl} \text { ) }\end{array}$ & $-0.20[-0.40,-0.00]$ \\
\hline 2.2 Diabetes & 6 & 651 & $\begin{array}{l}\text { Std. Mean Difference (IV, Random, 95\% } \\
\mathrm{CI} \text { ) }\end{array}$ & $-0.81[-1.60,-0.02]$ \\
\hline 2.3 Hypertension & 4 & 1050 & $\begin{array}{l}\text { Std. Mean Difference (IV, Random, 95\% } \\
\mathrm{Cl} \text { ) }\end{array}$ & $-0.34[-0.49,-0.18]$ \\
\hline 2.4 CVD/dyslipidaemia & 2 & 150 & $\begin{array}{l}\text { Std. Mean Difference (IV, Random, 95\% } \\
\mathrm{CI} \text { ) }\end{array}$ & $-0.08[-0.40,0.24]$ \\
\hline $\begin{array}{l}3 \text { Intermediate clinical outcome } \\
\text { (mean change scores) }\end{array}$ & 7 & 1413 & $\begin{array}{l}\text { Std. Mean Difference (IV, Random, 95\% } \\
\mathrm{Cl} \text { ) }\end{array}$ & $-0.27[-0.38,-0.17]$ \\
\hline 3.1 Asthma & 2 & 467 & $\begin{array}{l}\text { Std. Mean Difference (IV, Random, 95\% } \\
\mathrm{Cl} \text { ) }\end{array}$ & $-0.14[-0.32,0.04]$ \\
\hline 3.2 Diabetes & 2 & 133 & $\begin{array}{l}\text { Std. Mean Difference (IV, Random, 95\% } \\
\mathrm{CI} \text { ) }\end{array}$ & $-0.30[-0.64,0.05]$ \\
\hline 3.3 Hypertension & 1 & 546 & $\begin{array}{l}\text { Std. Mean Difference (IV, Random, 95\% } \\
\mathrm{CI} \text { ) }\end{array}$ & $-0.36[-0.53,-0.19]$ \\
\hline 3.4 Lipids & 2 & 267 & $\begin{array}{l}\text { Std. Mean Difference (IV, Random, 95\% } \\
\mathrm{Cl} \text { ) }\end{array}$ & $-0.34[-0.67,-0.00]$ \\
\hline 4 Quality of life & 10 & 2733 & $\begin{array}{l}\text { Std. Mean Difference (IV, Random, 95\% } \\
\mathrm{Cl} \text { ) }\end{array}$ & $0.30[0.10,0.50]$ \\
\hline 4.1 Generic quality of life & 5 & 1567 & $\begin{array}{l}\text { Std. Mean Difference (IV, Random, 95\% } \\
\mathrm{Cl} \text { ) }\end{array}$ & $0.21[-0.10,0.52]$ \\
\hline 4.2 Asthma-specific & 5 & 1120 & $\begin{array}{l}\text { Std. Mean Difference (IV, Random, 95\% } \\
\mathrm{Cl} \text { ) }\end{array}$ & $0.38[0.08,0.67]$ \\
\hline
\end{tabular}




\begin{tabular}{lllll}
\hline Outcome or subgroup title & $\begin{array}{l}\text { No. of } \\
\text { studies }\end{array}$ & $\begin{array}{l}\text { No. of } \\
\text { partici- } \\
\text { pants }\end{array}$ & Statistical method & Effect size \\
\hline 4.3 Diabetes-specific & 1 & 46 & $\begin{array}{l}\text { Std. Mean Difference (IV, Random, 95\% } \\
\text { Cl) }\end{array}$ & $0.48[-0.11,1.06]$ \\
\hline
\end{tabular}

Analysis 1.1. Comparison 1 Community pharmacy user health-promotion intervention versus usual treatment, Outcome 1 Health-related behaviour.

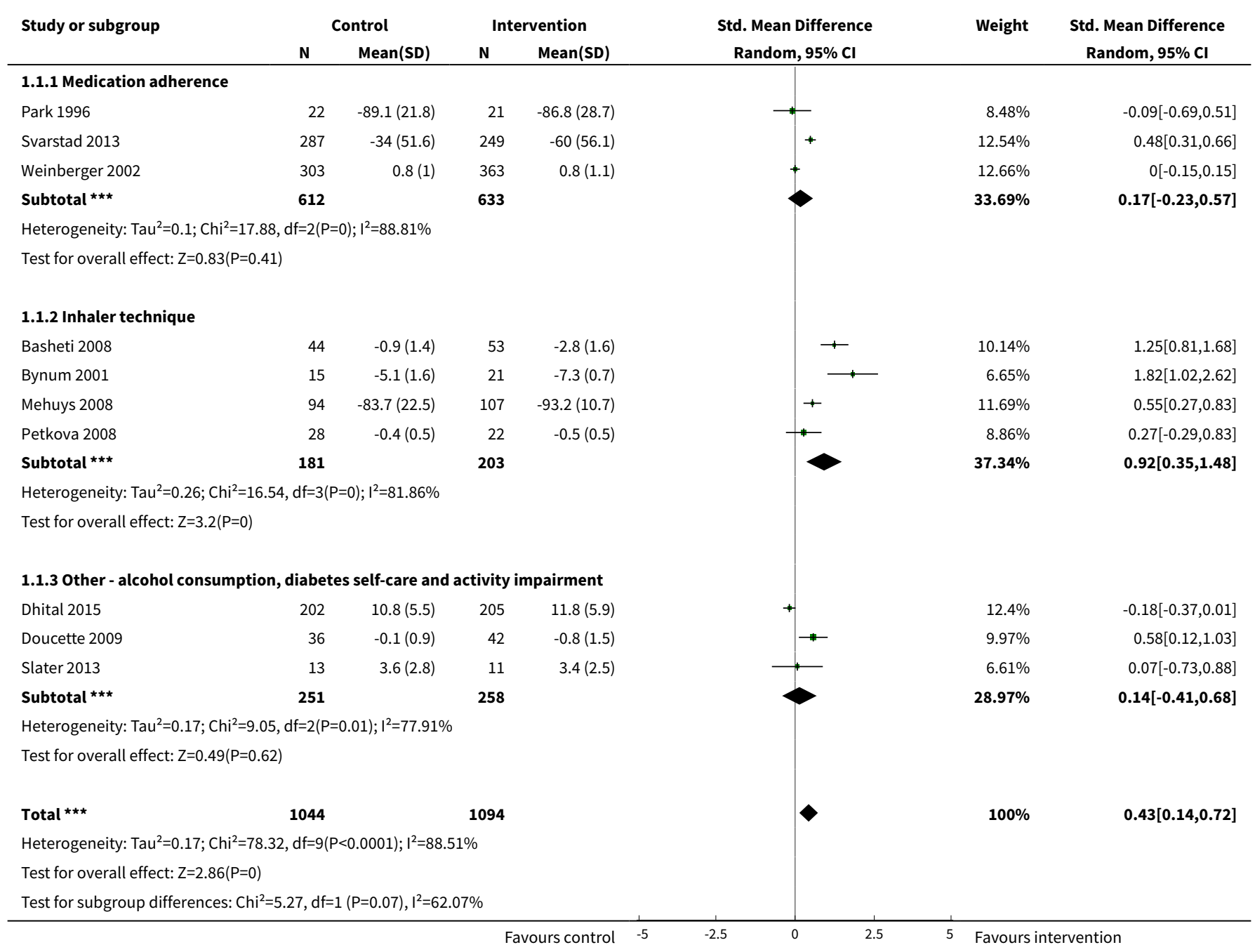

Analysis 1.2. Comparison 1 Community pharmacy user health-promotion intervention versus usual treatment, Outcome 2 Intermediate clinical outcomes (final value scores).

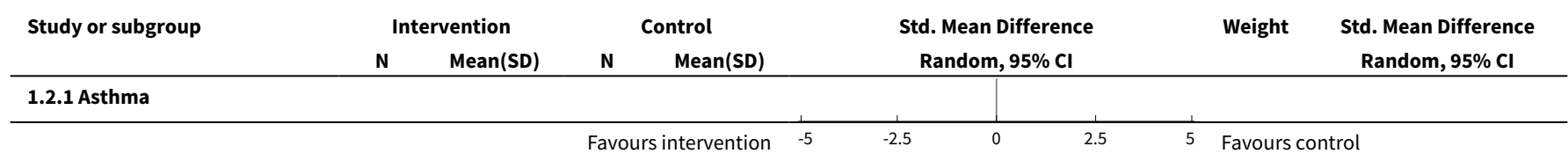




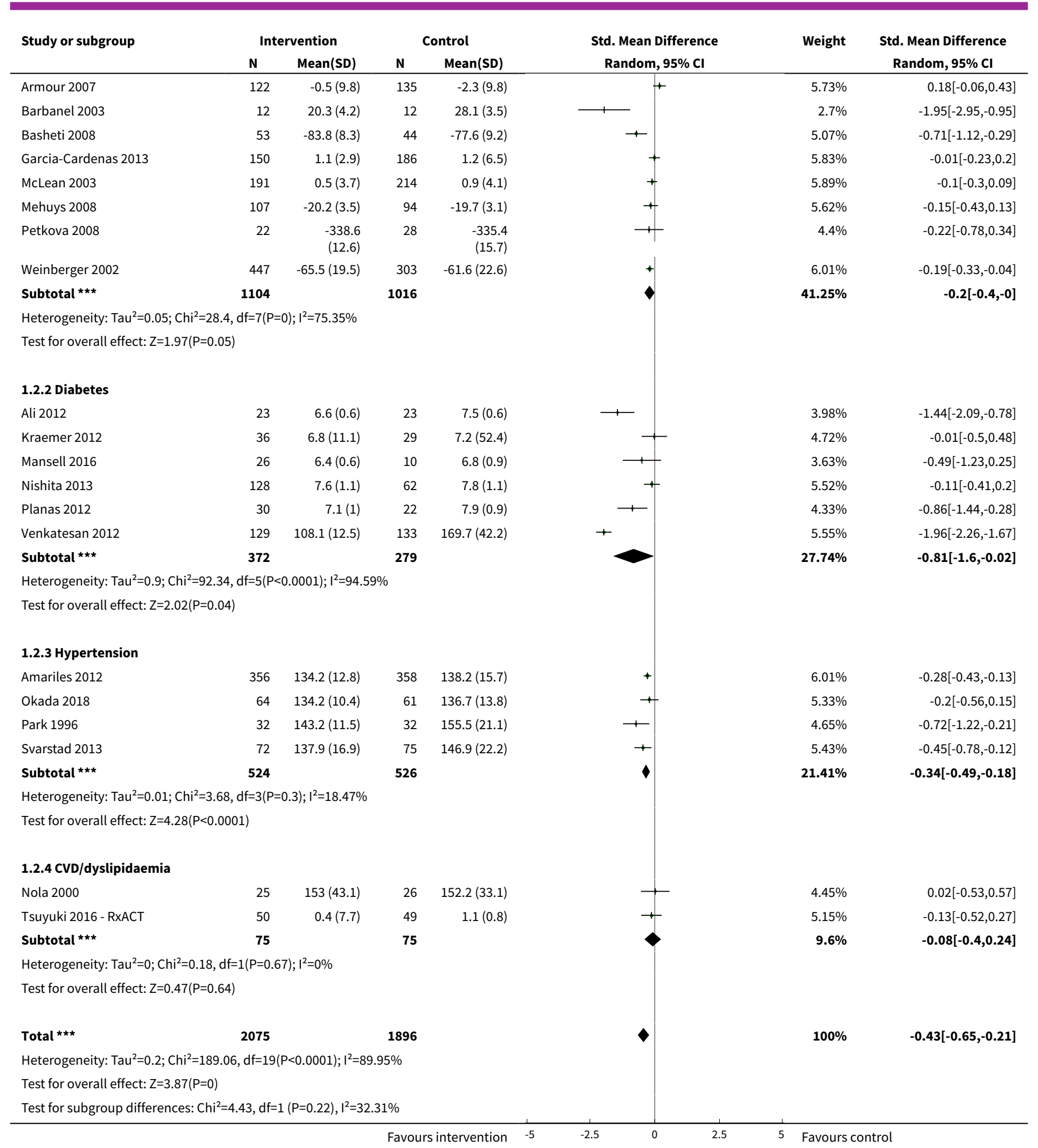


Analysis 1.3. Comparison 1 Community pharmacy user health-promotion intervention versus usual treatment, Outcome 3 Intermediate clinical outcome (mean change scores).

\begin{tabular}{|c|c|c|c|c|c|c|c|}
\hline \multirow[t]{2}{*}{ Study or subgroup } & \multicolumn{2}{|c|}{ Control } & \multicolumn{2}{|c|}{ Intervention } & \multirow{2}{*}{$\begin{array}{c}\text { Std. Mean Difference } \\
\text { Random, } 95 \% \mathrm{Cl}\end{array}$} & \multirow[t]{2}{*}{ Weight } & \multirow{2}{*}{$\begin{array}{c}\text { Std. Mean Difference } \\
\text { Random, } 95 \% \mathrm{Cl}\end{array}$} \\
\hline & $\mathbf{N}$ & Mean(SD) & $\mathbf{N}$ & Mean(SD) & & & \\
\hline \multicolumn{8}{|l|}{ 1.3.1 Asthma } \\
\hline Armour 2007 & 191 & $-0.5(13.5)$ & 205 & $1.3(10.8)$ & \# & $28.29 \%$ & $-0.15[-0.35,0.05]$ \\
\hline Charrois 2006 & 37 & $0.3(1)$ & 34 & $0.4(0.9)$ & + & $5.08 \%$ & $-0.1[-0.57,0.36]$ \\
\hline Subtotal $* \star \star$ & 228 & & 239 & & $\gamma$ & $33.37 \%$ & $-0.14[-0.32,0.04]$ \\
\hline \multicolumn{8}{|c|}{ Heterogeneity: $\mathrm{Tau}^{2}=0 ; \mathrm{Chi}^{2}=0.03, \mathrm{df}=1(\mathrm{P}=0.86) ; \mathrm{I}^{2}=0 \%$} \\
\hline \multicolumn{8}{|l|}{ 1.3.2 Diabetes } \\
\hline Doucette 2009 & 31 & $-0.3(1.1)$ & 35 & $0.1(1.7)$ & $\rightarrow$ & $4.67 \%$ & $-0.26[-0.75,0.22]$ \\
\hline Kraemer 2012 & 36 & $-0.5(0.9)$ & 31 & $-0.2(1.1)$ & + & $4.71 \%$ & $-0.33[-0.82,0.15]$ \\
\hline 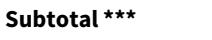 & 67 & & 66 & & 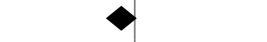 & $9.39 \%$ & $-0.3[-0.64,0.05]$ \\
\hline \multicolumn{8}{|c|}{ Heterogeneity: $\operatorname{Tau}^{2}=0 ; \mathrm{Chi}^{2}=0.04, \mathrm{df}=1(\mathrm{P}=0.84) ; \mathrm{I}^{2}=0 \%$} \\
\hline \multicolumn{8}{|l|}{ 1.3.3 Hypertension } \\
\hline Svarstad 2013 & 259 & $-12.6(21.2)$ & 287 & $-5.3(19.1)$ & $\Psi$ & $38.42 \%$ & $-0.36[-0.53,-0.19]$ \\
\hline 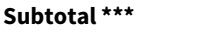 & 259 & & 287 & & $\boldsymbol{\nabla}$ & $38.42 \%$ & $-0.36[-0.53,-0.19]$ \\
\hline \multicolumn{8}{|c|}{ Heterogeneity: Not applicable } \\
\hline \multicolumn{8}{|c|}{ Test for overall effect: $Z=4.21(P<0.0001)$} \\
\hline \multicolumn{8}{|l|}{ 1.3.4 Lipids } \\
\hline Paulos 2005 & 23 & $-27.1(41.1)$ & 19 & $-1.4(37.2)$ & 1 & $2.83 \%$ & $-0.64[-1.26,-0.02]$ \\
\hline Villeneuve 2010 & 108 & $-1.1(1)$ & 117 & $-0.9(0.5)$ & + & $16 \%$ & $-0.24[-0.5,0.02]$ \\
\hline Subtotal *** & 131 & & 136 & & $\gamma$ & $18.82 \%$ & $-0.34[-0.67,-0]$ \\
\hline \multicolumn{8}{|c|}{ Heterogeneity: $\mathrm{Tau}^{2}=0.02 ; \mathrm{Chi}^{2}=1.33, \mathrm{df}=1(\mathrm{P}=0.25) ; \mathrm{I}^{2}=24.92 \%$} \\
\hline \multicolumn{8}{|c|}{ Test for overall effect: $Z=1.98(P=0.05)$} \\
\hline \multicolumn{8}{|c|}{ Heterogeneity: $\mathrm{Tau}^{2}=0 ; \mathrm{Chi}^{2}=4.59, \mathrm{df}=6(\mathrm{P}=0.6) ; \mathrm{I}^{2}=0 \%$} \\
\hline \multicolumn{8}{|c|}{ Test for overall effect: $Z=5.07(P<0.0001)$} \\
\hline \multicolumn{8}{|c|}{ Test for subgroup differences: $\mathrm{Chi}^{2}=3.27, \mathrm{df}=1(\mathrm{P}=0.35), \mathrm{I}^{2}=8.32 \%$} \\
\hline & & & Favo & ervention & -2.5 & Favours & \\
\hline
\end{tabular}

Analysis 1.4. Comparison 1 Community pharmacy user healthpromotion intervention versus usual treatment, Outcome 4 Quality of life.

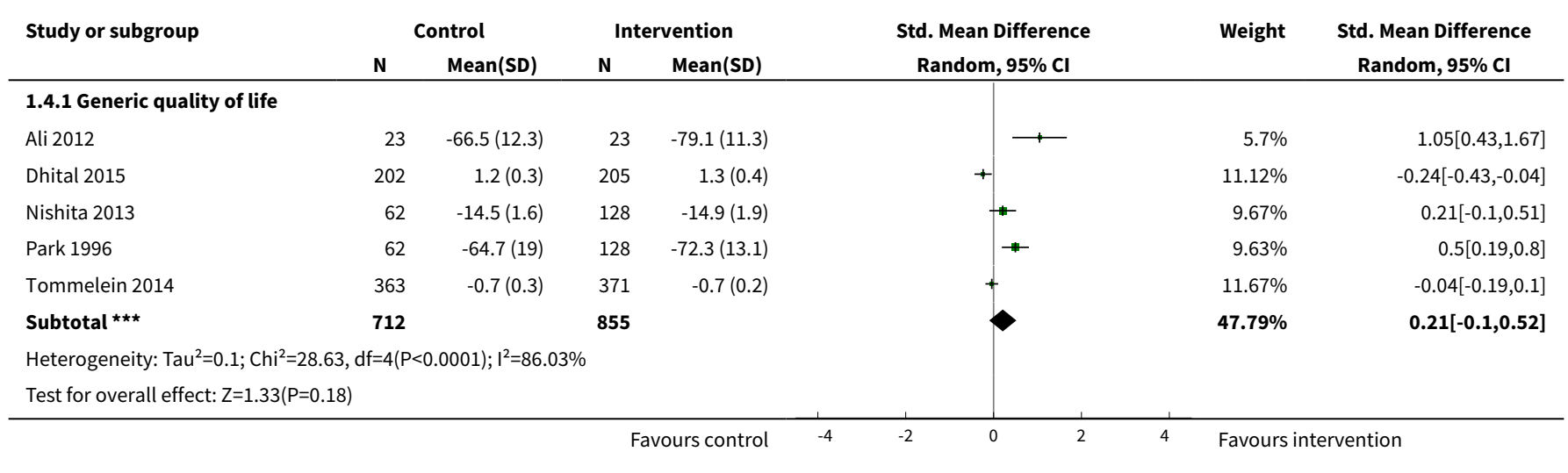




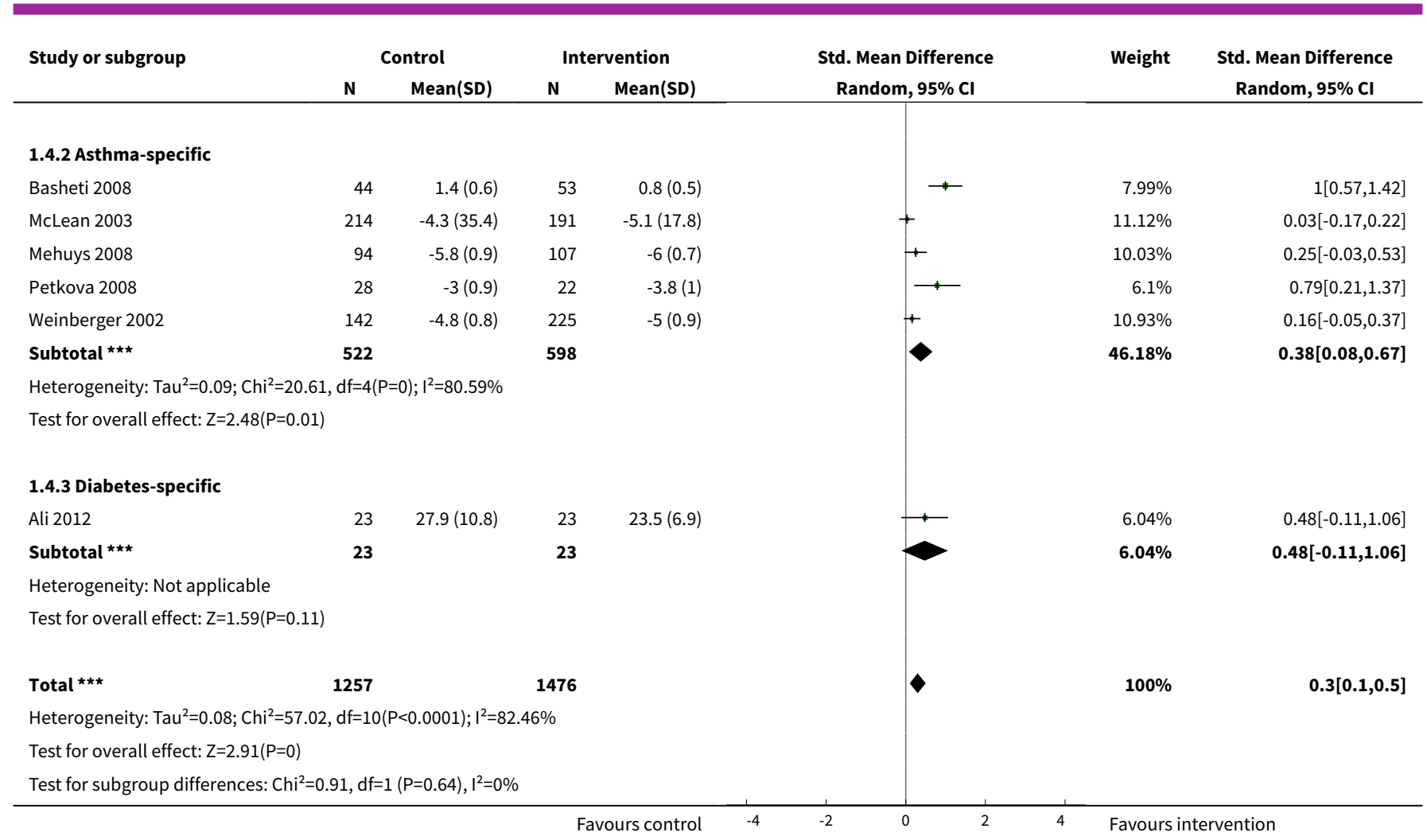

\section{ADDITIONAL TABLES}

Table 1. Studies included and excluded from meta-analysis of behavioural outcome

\begin{tabular}{|c|c|c|c|}
\hline & Adherence & $\begin{array}{l}\text { Inhaler tech- } \\
\text { nique }\end{array}$ & Other behaviours \\
\hline $\begin{array}{l}\text { Studies in- } \\
\text { cluded in the } \\
\text { meta-analy- } \\
\text { sis and out- } \\
\text { come mea- } \\
\text { sure used }\end{array}$ & $\begin{array}{l}\text { - Pharmacy records: Park 1996; } \\
\text { Svarstad 2013; Weinberger } 2002\end{array}$ & $\begin{array}{l}\text { - Technique } \\
\text { checklist: } \\
\text { Basheti 2008; } \\
\text { Bynum 2001; } \\
\text { Mehuys 2008; } \\
\text { Petkova } 2008\end{array}$ & $\begin{array}{l}\text { - Diabetes self-care: Doucette } 2009 \\
\text { - Alcohol consumption: Dhital } 2015 \\
\text { - Activity impairment: Slater } 2013\end{array}$ \\
\hline $\begin{array}{l}\text { Studies ex- } \\
\text { cluded from } \\
\text { the meta- } \\
\text { analysis with } \\
\text { reasons for } \\
\text { exclusion }\end{array}$ & $\begin{array}{l}\text { - Data poorly presented: Mehuys } \\
2008 \\
\text { - Mean change data: Armour 2007; } \\
\text { Okada } 2018 \\
\text { - Median score data: Smith } 2011 \\
\text { - Dichotomous data: Garcia-Carde- } \\
\text { nas 2013; Villeneuve } 2010 \\
\text { - Unvalidated measure: Crockett } \\
\text { 2006; Paulos 2005; Petkova } 2009\end{array}$ & $\begin{array}{l}\text { Dichotomous } \\
\text { data: Cordi- } \\
\text { na 2001; Gar- } \\
\text { cia-Cardenas } \\
\text { 2013; Tom- } \\
\text { melein } 2014\end{array}$ & $\begin{array}{l}\text { - Dichotomous data for: } \\
\text { * quitting smoking: Burford 2013; Maguire 2001; } \\
\text { Madurasinghe } 2017 \\
* \text { heroin use: Jaffray } 2014 \\
\text { - Mean change data for exercise: Okada } 2018 \\
\text { - Unvalidated measures for: } \\
* \text { sleep: Fuller } 2016 \\
* \text { exercise: Schmiedel 2015; Mansell } 2016 \\
* \text { self-monitoring of blood glucose:Mansell } 2016\end{array}$ \\
\hline
\end{tabular}


Table 2. Studies included and excluded from meta-analysis of intermediate clinical outcomes

\begin{tabular}{|c|c|c|c|c|}
\hline & Asthma & Diabetes & CVD/hypertension & $\begin{array}{l}\text { Other condi- } \\
\text { tions }\end{array}$ \\
\hline $\begin{array}{l}\text { Studies includ- } \\
\text { ed in the meta- } \\
\text { analysis with } \\
\text { outcome mea- } \\
\text { sure used }\end{array}$ & $\begin{array}{l}\text { - ACQ/symptoms: Bar- } \\
\text { banel 2003; Gar- } \\
\text { cia-Cardenas 2013; } \\
\text { McLean 2003; } \\
\text { Mehuys } 2008 \\
\text { - FEV: Armour } 2007 \\
\text { - PEF variability: } \\
\text { Basheti 2008; Petko- } \\
\text { va 2008; Weinberger } \\
2002\end{array}$ & $\begin{array}{l}\text { - HbA1c: Ali 2012; Krae- } \\
\text { mer 2012; Mehuys 2011; } \\
\text { Mansell 2016; Nishi- } \\
\text { ta 2013; Planas 2012; } \\
\text { Venkatesan } 2012\end{array}$ & $\begin{array}{l}\text { - } \text { SBP: Amariles 2012; Park 1996; Oka- } \\
\text { da 2018; Svarstad 2013 } \\
\text { - Lipids-LDL: Nola 2000; Tsuyuki } 2016 \\
\text { - RxEACH }\end{array}$ & \\
\hline
\end{tabular}

\section{Abbreviations}

ACQ: Asthma Control Questionnaire; FEV: forced expiratory volume ; HbA1c: glycosylated haemoglobin; LDL: low-density lipoprotein; PEF: peak expiratory flow; SBP: systolic blood pressure

Table 3. Studies included and excluded from meta-analysis of quality of life

\begin{tabular}{|c|c|c|c|c|}
\hline & Generic & Asthma specific & $\begin{array}{l}\text { Diabetes } \\
\text { specific }\end{array}$ & $\begin{array}{l}\text { Other illness } \\
\text { specific }\end{array}$ \\
\hline $\begin{array}{l}\text { Studies included in } \\
\text { the meta-analysis } \\
\text { and outcome mea- } \\
\text { sure used }\end{array}$ & $\begin{array}{l}\text { - SF-36: Ali 2012; Park } 1996 \\
\text { - EQ-5D: Dhital 2015; Tommelein } 2014 \\
\text { - WhoQol: Nishita } 2013\end{array}$ & $\begin{array}{l}\text { - Basheti 2008; McLean } \\
\text { 2003; Mehuys 2008; } \\
\text { Petkova 2008; Wein- } \\
\text { berger } 2002\end{array}$ & & \\
\hline $\begin{array}{l}\text { Studies exclud- } \\
\text { ed from the meta- } \\
\text { analysis and rea- } \\
\text { sons fpr exclusion }\end{array}$ & $\begin{array}{l}\text { - Insufficiently reported: Bond 2007; Cor- } \\
\text { dina 2001; Okada 2018; Paulos 2005; } \\
\text { Krass 2007; Skowron 2011; Schmiedel } \\
\text { 2015; Tsuyuki 2002; Yuksel } 2010\end{array}$ & $\begin{array}{l}\text { - Insufficiently reported: } \\
\text { Armour 2007; Barbanel } \\
\text { 2003; Cordina } 2001\end{array}$ & $\begin{array}{l}\text { Insuffi- } \\
\text { ciently re- } \\
\text { ported: } \\
\text { Adepu } \\
2007 ; \\
\text { Kraemer } \\
2012 ; \\
\text { Venkate- } \\
\text { san } 2012\end{array}$ & $\begin{array}{l}\text { - Insufficiently } \\
\text { reported: } \\
\text { Petkova } 2009 \\
\text { - BPI; Jaffray } \\
\text { 2014 - MAP; } \\
\text { Smith } 2011 \text { - } \\
\text { RQLQ }\end{array}$ \\
\hline
\end{tabular}

\section{Abbreviations}

BPI: Back Pain Index; EQ-5D: Euroqol quality of life measure; MAP: Maudsley Addiction Profile; RQLQ: Rhinitis Quality of Life Questionnaire; SF-36: Short Form-36; 


\section{APPENDICES}

\section{Appendix 1. Search Strategies \\ MEDLINE (OVID)}

Ovid MEDLINE(R) Epub Ahead of Print, In-Process \& Other Non-Indexed Citations, Ovid MEDLINE(R) Daily, Ovid MEDLINE and Versions(R) $<1946$ to January 31, 2018>

\begin{tabular}{|c|c|}
\hline No. & Search terms \\
\hline 1 & community pharmacy services/ \\
\hline 2 & ((pharmacy or pharmacist? or pharmacies) adj2 (community or communities)).ti,ab,kf. \\
\hline 3 & ((pharmacy or pharmacist? or pharmacies) adj2 intervention?).ti,ab,kf. \\
\hline 4 & pharmaceutical care.ti,ab,kf. \\
\hline 5 & (community or communities).ti,ab,kf. \\
\hline 6 & 4 and 5 \\
\hline 7 & or/1-3,6 \\
\hline 8 & exp randomized controlled trial/ \\
\hline 9 & controlled clinical trial.pt. \\
\hline 10 & randomi\#ed.ti,ab. \\
\hline 11 & placebo.ab. \\
\hline 12 & randomly.ti,ab. \\
\hline 13 & Clinical Trials as topic.sh. \\
\hline 14 & trial.ti. \\
\hline 15 & or/8-14 \\
\hline 16 & exp animals/ not humans/ \\
\hline 17 & 15 not 16 \\
\hline 18 & 7 and 17 \\
\hline
\end{tabular}

\section{Embase (OVID)}

Embase $<1974$ to 2018 February 05> 


\begin{tabular}{|c|c|}
\hline 5 & 3 and 4 \\
\hline 6 & or/1-2,5 \\
\hline 7 & random*.ti,ab. \\
\hline 8 & factorial* ${ }^{*}$ ti,ab. \\
\hline 9 & (crossover* or cross over ).ti,ab. \\
\hline 10 & $\left(\left(\right.\right.$ doubl$^{\star}$ or singl $\left.l^{\star}\right)$ adj blind $\left.{ }^{\star}\right) . t i, a b$. \\
\hline 11 & (assign* or allocat* or volunteer* or placebo*).ti,ab. \\
\hline 12 & crossover procedure/ \\
\hline 13 & single blind procedure/ \\
\hline 14 & randomized controlled trial/ \\
\hline 15 & double blind procedure/ \\
\hline 16 & or/7-15 \\
\hline 17 & exp animal/ not human/ \\
\hline 18 & 16 not 17 \\
\hline 19 & 6 and 18 \\
\hline
\end{tabular}

\section{The Cochrane Library}

\begin{tabular}{ll}
\hline No. & Search terms \\
\hline$\# 1$ & {$[$ mh "community pharmacy services"] } \\
\hline$\# 2$ & ((pharmacy or pharmacist? or pharmacies) near/2 (community or communities)):ti,ab \\
\hline$\# 3$ & ((pharmacy or pharmacist? or pharmacies) near/2 intervention?):ti,ab \\
\hline$\# 4$ & (pharmaceutical next care):ti,ab \\
\hline$\# 5$ & (community or communities):ti,ab \\
\hline
\end{tabular}




\begin{tabular}{ll}
$\# 6$ & $\# 4$ and \#5 \\
\hline$\# 7 \quad\{$ or \#1-\#3, \#6\} \\
\hline
\end{tabular}

\section{PsycINFO (OVID)}

PsycINFO <1967 to January Week 5 2018>

\begin{tabular}{|c|c|}
\hline No. & Search terms \\
\hline 1 & ((pharmacy or pharmacist? or pharmacies) adj2 (community or communities)).ti,ab,hw. \\
\hline 2 & ((pharmacy or pharmacist? or pharmacies) adj2 intervention?).ti,ab,hw. \\
\hline 3 & pharmaceutical care.ti,ab,hw. \\
\hline 4 & (community or communities).ti,ab,hw. \\
\hline 5 & 3 and 4 \\
\hline 6 & or/1-2,5 \\
\hline 7 & exp clinical trial/ \\
\hline 8 & random*.ti,ab. \\
\hline 9 & $\left(\left(\right.\right.$ clinical or control $\left.^{\star}\right)$ adj3 trial $\left.{ }^{\star}\right) . \mathrm{ti}, \mathrm{ab}$. \\
\hline 10 & $\left(\left(\right.\right.$ singl ${ }^{\star}$ or doubl ${ }^{\star}$ or trebl* or tripl $\left.^{\star}\right)$ adj5 (blind or mask $\left.\left.^{\star}\right)\right)$. ti,ab. \\
\hline 11 & (volunteer* or control group or controls).ti,ab. \\
\hline 12 & placebo/ or placebo*.ti,ab. \\
\hline 13 & or/7-12 \\
\hline 14 & 6 and 13 \\
\hline
\end{tabular}

\section{CoS Conference Papers Index}

ProQuest Dissertations \& Theses: UK \& Ireland

ProQuest Dissertations \& Theses Global

\begin{tabular}{ll}
\hline No. & Search terms \\
\hline 1 & $\mathrm{TI}, \mathrm{AB}(($ pharmacy or pharmacist? or pharmacies) NEAR/2 (community or communities)) OR \\
& TI,AB((pharmacy or pharmacist? or pharmacies) NEAR/2 intervention?) OR (TI,AB(pharmaceutical \\
& care) AND TI,AB(community OR communities))
\end{tabular}




\section{ClinicalTrials.gov}

community pharmacy OR community pharmacist

\section{WHO International Clinical Trials Registry Platform (ICTRP)}

community pharmacy OR community pharmacist

\section{OpenGrey}

((communit* NEAR/2 pharmac*) OR (intervention* NEAR/2 phramac*))

\section{HIS T O R Y}

Protocol first published: Issue 7, 2014

Review first published: Issue 12, 2019

\begin{tabular}{lll}
\hline Date & Event & Description \\
\hline 18 August 2014 & Amended & Change to author's name \\
\hline
\end{tabular}

\section{CONTRIBUTIONS OFAUTHORS}

Authors LS, RW, and AT have contributed to writing the manuscript.

LS, RS, EE, and CR assisted in data searches and conducted data extraction of studies.

RW assisted in development of the 'Risk of bias' summary tables.

VM provided statistical overview of the analyses.

CR reviewed all quality assessments of studies.

ST and CS provided senior level of guidance and support.

All authors have commented on the manuscript and provided expert advice on the review.

This project was supported by the National Institute for Health Research (NIHR), Department of Health, UK. The views and opinions expressed therein are those of the authors and do not necessarily reflect those of the NIHR, NHS or the Department of Health.

\section{DECLARATIONS OF INTEREST}

LS: is in receipt of grant funding for various projects from the UK National Institutes of Health Research, but has no known conflicts of interest for the current publication

RS: none known

AT: none known

VM: none known

CR: none known

EE: none known

CS: none known

ST: is in receipt of grant funding for various projects from the UK National Institutes of Health Research and (in part) supported by the National Institute for Health Research (NIHR) Collaboration for Leadership in Applied Health Research and Care (CLAHRC) North Thames at Bart's Health NHS Trust but has no known conflicts of interest for the current publication.

RW: is in receipt of grant funding for various projects from the UK National Institutes of Health Research. This review was funded by a programme grant for smoking cessation from the National Institute of Health Research in the UK. RW has received consultancy fees from 
TTS Pharma and holds shares in this company. He has received royalties from a patent on genetic indicators of tobacco consumption. The Cochrane Funding Arbiter has looked closely into whether his patent constitutes a conflict of interest in this instance, and has decided that it does not.

The authors of the current review were also authors of one included study (Madurasinghe 2017). AT, who was not an author of the study therefore screened for inclusion, extracted, and checked all the data for this study.

\section{SOURCES OF SUPPORT}

\section{Internal sources}

- No sources of support supplied

\section{External sources}

- NIHR Programme grant RP-PG-0609-10181, UK.

\section{DIFFERENCES BETWEEN PROTOCOL AND REVIEW}

Due to the large number of studies that we retrieved and a desire to include only data of the highest quality and utmost relevance to investigate the research question, we made a number of amendments to the review compared to what was stated in the protocol. With regard to inclusion criteria, we decided to exclude studies that compared two or more active interventions without the inclusion of a comparable control group, and to include only randomised controlled studies.

Finally, we decided not to collect data on process variables. This was in response to the level of data available, and the finding that there was high heterogeneity between process outcomes and measures, which meant that synthesis of these data would be unlikely to yield any clear findings.

We did not report data on the behaviour-change techniques of the interventions due to limited resources and poor descriptions in the study reports. 